\title{
User's Guide for a Personal Computer Model of Turbulence at a Wind Turbine Rotor
}
J. R. Connell
D. C. Powell
G. L. Gower

August 1989

Prepared for the U.S. Department of Energy under Contract DE-AC06-76RLO 1830

Pacific Northwest Laboratory Operated for the U.S. Department of Energy by Battelle Memorial Institute 


\title{
DISCLAIMER
}

This program was prepared as an account of work sponsored by an agency of the United States Government. Neither the United States Government nor any agency thereof, nor Battelle Memorial Institute, nor any or their employees, makes any warranty, expressed or implied, or assumes any legal liability or responsibility for the accuracy, completeness, or usefulness of any information, apparatus, product, or process disclosed, or represents that its use would not infringe privately owned rights. Reference herein to any specific commercial product, process, or service by trade name, trademark, manufacturer, or otherwise, does not necessarily constitute or imply its endorsement, recommendation, or favoring by the United States Government of any agency thereof, or Battelle Memorial Institute. The views and opinions of authors expressed herein do not necessarily state or reflect those of the United States Government or any agency thereof.

\author{
PACIFIC NORTHWEST LABORATORY \\ operated by \\ BATTELLE MEMORIAL INSTITUTE \\ for the \\ UNITED STATES DEPARTMENT OF ENERGY \\ under Contract DE-AC06-76RLO 1830
}

Printed in the United States of America

Available to DOE and DOE contractors from the

Office of Scientific and Technical Information, P.O. Box 62, Oak Ridge, TN 37831; prices available from (615) 576-8401. FTS 626-8401.

Available to the public from the National Technical Information Service, U.S. Department of Commerce, 5285 Port Royal Rd., Springfield, VA 22161.

NTIS Price Codes, Microfiche A01

\begin{tabular}{|c|c|}
\hline \multicolumn{2}{|c|}{ Printed Copy } \\
\hline Pages & $\begin{array}{l}\text { Price } \\
\text { Codes }\end{array}$ \\
\hline$\overline{001-025}$ & $\mathrm{~A} 02$ \\
\hline $026-050$ & $\mathrm{~A} 03$ \\
\hline $051-075$ & A04 \\
\hline $076-100$ & A05 \\
\hline $101-125$ & A06 \\
\hline $126-150$ & $\mathrm{~A} 07$ \\
\hline $151-175$ & $\mathrm{~A} 08$ \\
\hline $176-200$ & $\mathrm{~A} 09$ \\
\hline $201-225$ & A10 \\
\hline $226-250$ & A11 \\
\hline $251-275$ & A12 \\
\hline $276-300$ & A13 \\
\hline
\end{tabular}


PNL-6959

UC-261

USER'S GUIDE FOR A PERSONAL COMPUTER MODEL

OF TURBULENCE AT A WIND TURBINE ROTOR
J. R. Connel1
D. C. Powell
G. L. Gower

August 1989

Prepared for

the U.S. Department of Energy

under Contract DE-AC06-76RLO 1830

Pacific Northwest Laboratory

Richland, Washington 99352 


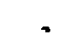

$+$ 


\section{SUMMARY}

The Pacific Northwest Laboratory's (PNL) computational theoretical model of rotationally sampled wind turbulence (RODASIM11), having served its original purpose of verifying concepts and analyses of initial rotational measurements of wind speed, has been extended to include vertical-axis wind turbine configurations and two-dimensional turbulence velocity. It includes a mean wind shear at the user's discretion. The model produces not only spectral results but also time series of the wind experienced by individual points rotating as points on a wind turbine blade would rotate. For convenience, it may be simply modified to repeat the calculations for each radius in any prescribed set of radial positions without the need to resubmit the program code for each radial location chosen.

The turbulence velocities may be computed in either the rectangular coordinate system, or, for the vertical-axis wind turbine, the cylindrical coordinate system. For the horizontal axis of rotation, the through-disk component of wind speed is calculated. The locations of the wind calculated are given only in the cylindrical coordinate system. Thus, to be used with an aerodynamic or structural model that uses the rectangular position coordinates, the position coordinates of the turbulence model must undergo a simple standard position coordinate transformation applied by the user. No turbulence values are calculated for unused locations and times in the plane of rotation. The combination of the features described above makes possible a short computational time.

In its present form, the model includes a zero correlation (or, alternatively, complete correlation) between winds at any two locations on the rotor blades. Other distributions of the value of correlation might be specified; they are in some other models (e.g., by Veers 1988; Connell et al. 1988; and Thresher and Holley 1981, out to only twice the rotation frequency of the blade). However, we have chosen to await the availability of accurate determination of the value of those correlations for rotating blades in the atmospheric boundary layer before considering their inclusion in the model.

The source code and the executable code for the model were assembled to operate on a desktop computer. This document is primarily a user's guide for 
the code and a brief guide to the growing literature on the subject of the rotationally sampled wind. 


\section{CONTENTS}

SUMMARY ................................

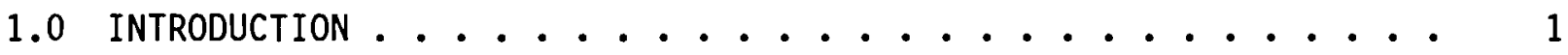

2.0 EXAMPLE OF THE OUTPUT FROM THE MODEL FOR A HORIZONTAL AXIS OF

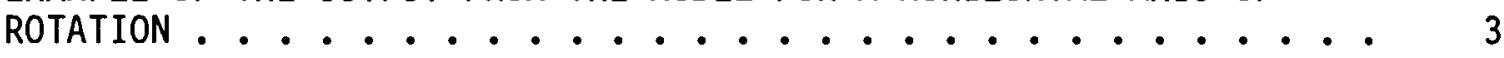

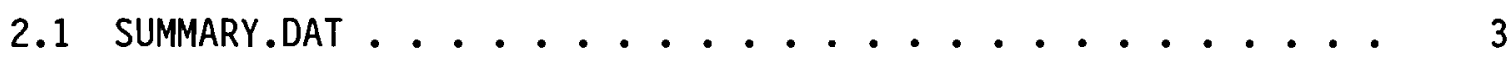

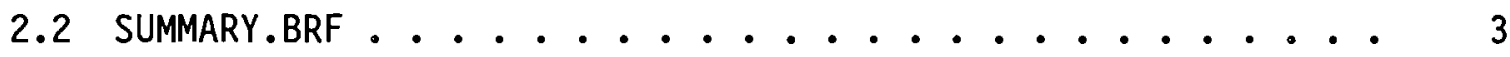

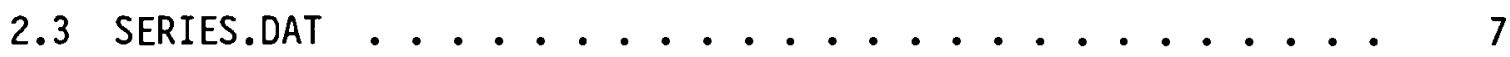

2.4 THE OUTPUT FILES FOR THE FULL RADIUS CONDITION OF THE MOD-OA ....................... 7

3.0 EXAMPLE FOR A VERTICAL AXIS OF ROTATION .......... 9

4.0 THE COMPUTER PROGRAM . . . . . . . . . . . . . . 13

4.1 THE EXECUTABLE FILE: THEORY.EXE ............ 13

4.2 INPUT AND OUTPUT FROM THE PROGRAM ............ 15

5.0 CONCLUDING REMARKS . . . . . . . . . . . . . . 19

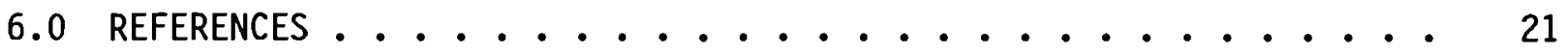

APPENDIX A - THE PNL THEORETICAL TURBULENCE MODEL SOURCE CODE . . . A A.1

APPENDIX B - SELECTED PORTIONS OF REPORT PNL-5857, DEFINING PARAMETERS AND VARIABLES IN THE PNL THEORETICAL TURBULENCE

SIMULATION CODE ..................... B

APPENDIX $C$ - SAMPLE OUTPUT FROM THE FILE SUMMARY.DAT FOR THE HAWT CASE

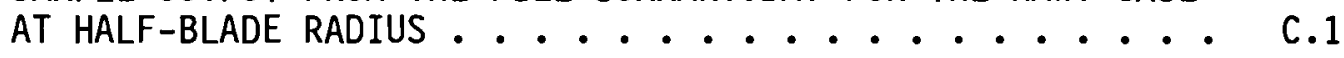

APPENDIX D - SAMPLE OUTPUT FROM THE FILE SERIES.DAT FOR THE HAWT CASE AT HALF-BLADE RADIUS ................ D. 1

APPENDIX E - SAMPLE OUTPUT FROM ALL FILES FOR THE HAWT CASE AT FULL-

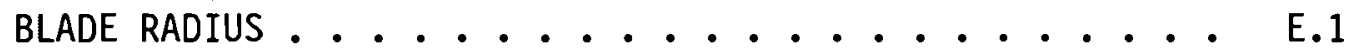

APPENDIX F - SAMPLE OUTPUT FROM ALL FILES FOR THE 34-M VAWT CASE FOR THE TANGENTIAL AND RADIAL WIND COMPONENTS AT THE EQUATORIAL LOCATION OF A BLADE ........... F.1

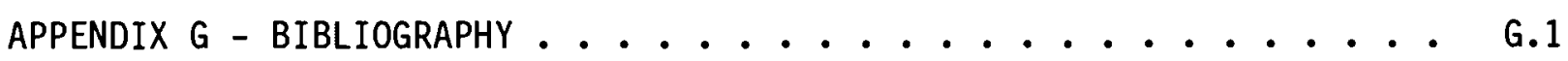




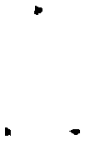




\section{FIGURES}

2.1 The Power Spectral Density Function Calculated From the Model for the Wind at the MOD-OA in Simple Terrain . . . . . . . . 5

2.2 Samples of the Time Series of Cross-disk Wind Speed Generated for the MOD-OA Conditions in Simple Terrain for a Time Increment of $15 \mathrm{~s}$, or 10 Revolutions of a Rotor Blade . . . . . . . 8

3.1 The Spectral Density Functions for the Radial and Tangential Components of the Wind Fluctuation at the Equatorial Point of the Blade of the 34-m Darrieus .............

3.2 Samples of the Time Series for $20 \mathrm{~s}$ or 10 Rotations Corresponding to Figures 3.1a, b, c, and d ...............

\section{TABLES}

2.1 First Page of SUMMARY.DAT File . . . . . . . . . . . 4

2.2 SUMMARY.BRF for the MOD-OA Case . . . . . . . . . . 6

4.1 Files on Disk Including RODASIM. INC . . . . . . . . . . 14

4.2 RODASIM. INC, The Include File Needed for Compiling . . . . . . 14 
.

. 


\subsection{INTRODUCTION}

This document is primarily 1) a user's guide for the personal computer (PC) version of the code for the PNL computational model of the rotationally sampled wind speed (RODASIM11) and 2) a brief guide to the growing literature on the subject of rotationally sampled turbulence, from which the model is derived. The model generates values of turbulence experienced by single points fixed in the rotating frame of reference of an arbitrary wind turbine blade. The character of the turbulence depends on the specification of mean wind speed, the variance of turbulence, the crosswind and along-wind integral scales of turbulence, mean wind shear, and the hub height, radius, and angular speed of rotation of any point at which wind fluctuation is to be calculated.

Having served its original purpose of verifying concepts and analyses of initial rotational measurements of wind speed, RODASIM11 has been extended to include vertical-axis wind turbine configurations and two-dimensional turbulence velocity. The model produces, at the user's discretion, a measure of fluctuation caused by rotation through a mean wind shear. In addition to a computed spectral density function of the wind, time series of the wind, experienced by individual points rotating as points on a wind turbine blade would rotate, are produced. The calculations for each radius and angular position on the rotor in any prescribed set of positions are made in separate submittals of the present version of the program code. The seed selected for generating the time series determines whether there is correlation between different points or not. The present version of RODASIM11 models correlation only as complete or zero correlation.

The turbulence velocity components may be computed in either the rectangular coordinate system or, for vertical-axis wind turbines, the cylindrical coordinate system. For the horizontal axis of rotation, the through-disk component of wind speed is calculated. The locations of the wind calculated are given only in the cylindrical coordinate system. Thus, to be used with an aerodynamic or structural model that uses the rectangular position coordinates, the user must apply a simple standard position coordinate transformation to the position coordinates. No turbulence values are calculated for unused 
locations and times in the plane of rotation. The combination of the features described above makes possible a short computational time.

Since the first publication on rotationally sampled wind characteristics (Connell 1980), an increasing number of variations, extensions, and different approaches to modeling of the rotationally sampled wind have appeared. Each model has contributed to the continuing improvement in understanding and application of the original concept. In addition to the references cited in this document, an extensive bibliography is appended to aid the reader in exploring the literature.

It is important to keep in mind that the present version of the model does not include the effects of the turbine rotor on the character of the inflowing turbulence and mean wind shear. That is, the model is a free-stream one. The distortion induced into the inflow by a rotor affects the character of the rotationally sampled turbulence and the mean wind shear and thus the aerodynamic forces on the blades (Neff, Meroney, and Connell 1987; Strickland 1987). The modification of the mean wind and the turbulence by flow distortion ahead of the rotor do not follow the same pattern. The present version of the model excludes flow distortion effects because they are not satisfactorily known, although the principles have been discussed in the literature (e.g., Moon, Piomelli, and Reynolds 1986; Wyngaard 1981; Britter, Hunt, and Mumford 1979).

An example of the output of the model, computed for a horizontal-axis wind turbine configuration, is given in Section 2. A corresponding example for a vertical-axis wind turbine configuration is given in Section 3 . The user's guide to the computer code of the turbulence model is written as Section 4. A few concluding remarks about use and interpretation of the results are given in Section 5. The full computer code is listed in Appendix $A_{;}$printed output for the examples is given in additional appendices. 


\subsection{EXAMPLE OF THE OUTPUT FROM THE MODEL}

FOR A HORIZONTAL AXIS OF ROTATION

The PC program creates a set of output files from which all input and output data and additional statistics of the output data are accessible. Examples of each of the files are described in this section. Samples of all of the data representative of cross-disk wind fluctuations observed at 0.5 and 1.0 times the radius of the MOD-OA horizontal-axis wind turbine (HAWT) blade for typical wind conditions in simple terrain are included either in this section or in the referenced appendices. The subsections are labeled by the name of the output file discussed therein. More comprehensive descriptions and definitions of the input and output variables for the code are given by Powell and Connell (1986). Selected portions of the cited report are included as Appendix B.

\subsection{SUMMARY.DAT}

The first page of SUMMARY.DAT (reproduced here as Table 2.1) describes the wind conditions and parameters and computational input parameters used to specialize the code for the MOD-OA wind turbine in typical wind conditions in simple terrain for a point at half the radius of the blade. Computed output values of autocorrelation, variance and spectra, etc., from the model are tabulated in the remaining pages of the file. Samples of all pages are included as Appendix $C$.

The power spectral density functions calculated from the model for the wind at the MOD-OA in simple terrain are shown in Figure 2.1. Figures 2.1a and $b$ are for the half-blade radius and Figures $2.1 c$ and $d$ are for the fullblade or tip radius. The PC program does not include plotting routines, but only tabulates the data as shown in the tables.

\subsection{SUMMARY.BRF}

The summary sheet displays selected input parameters to the model and selected computed statistics for the winds computed by the model. An example for the same MOD-OA case is shown in Table 2.2 . 


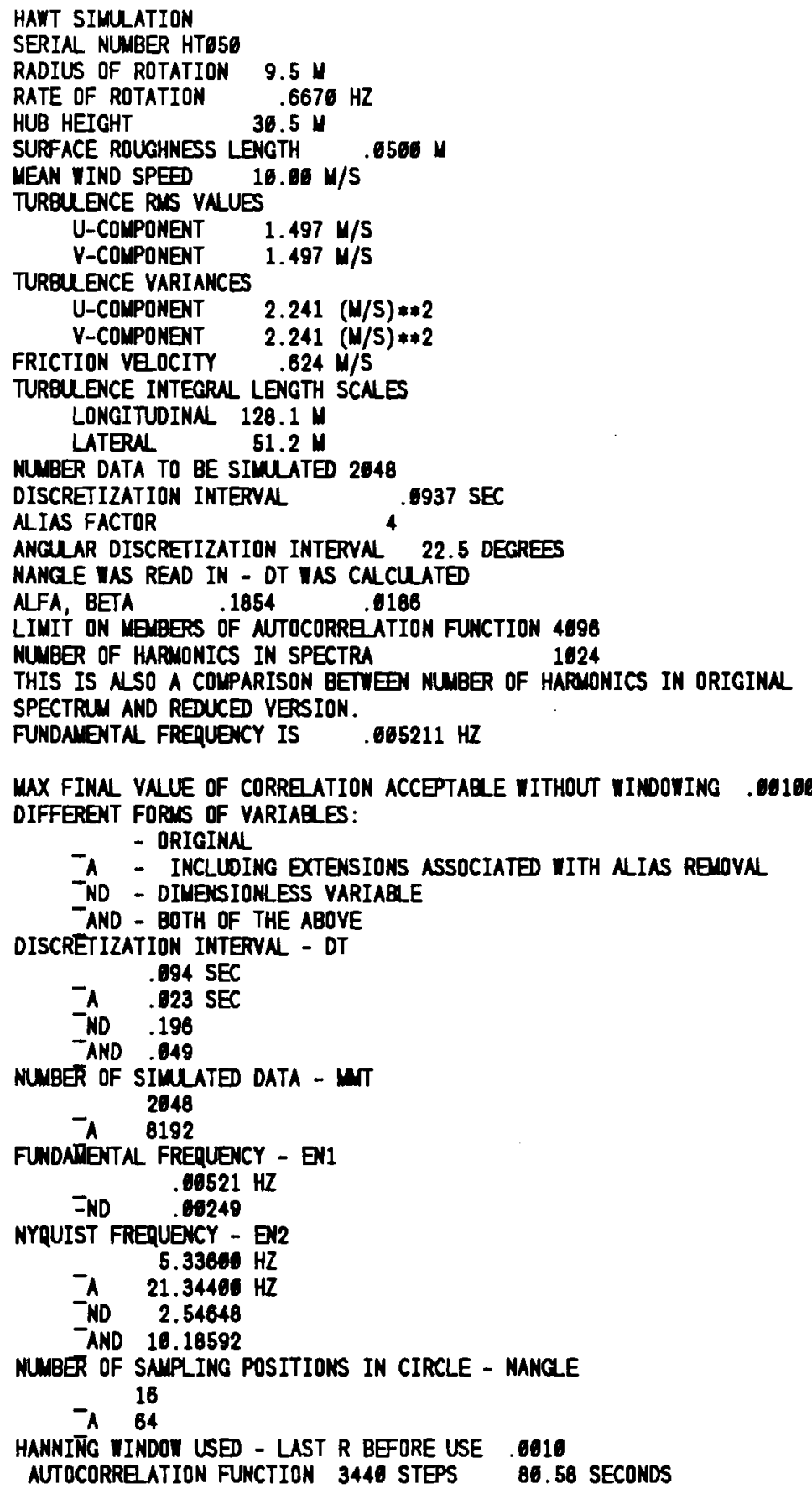


a)

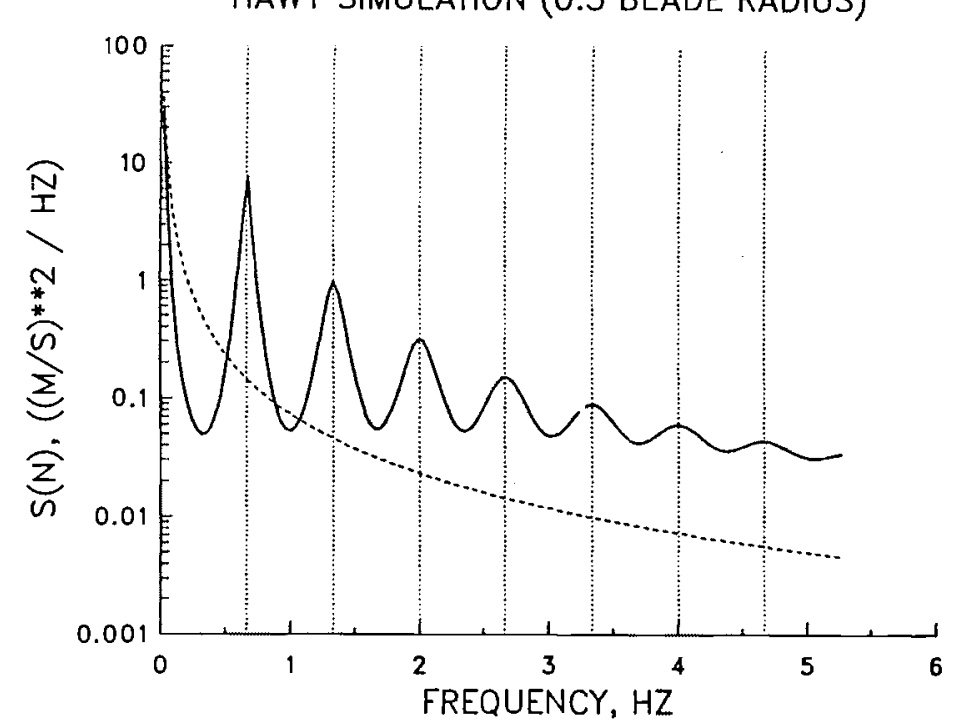

u

c)

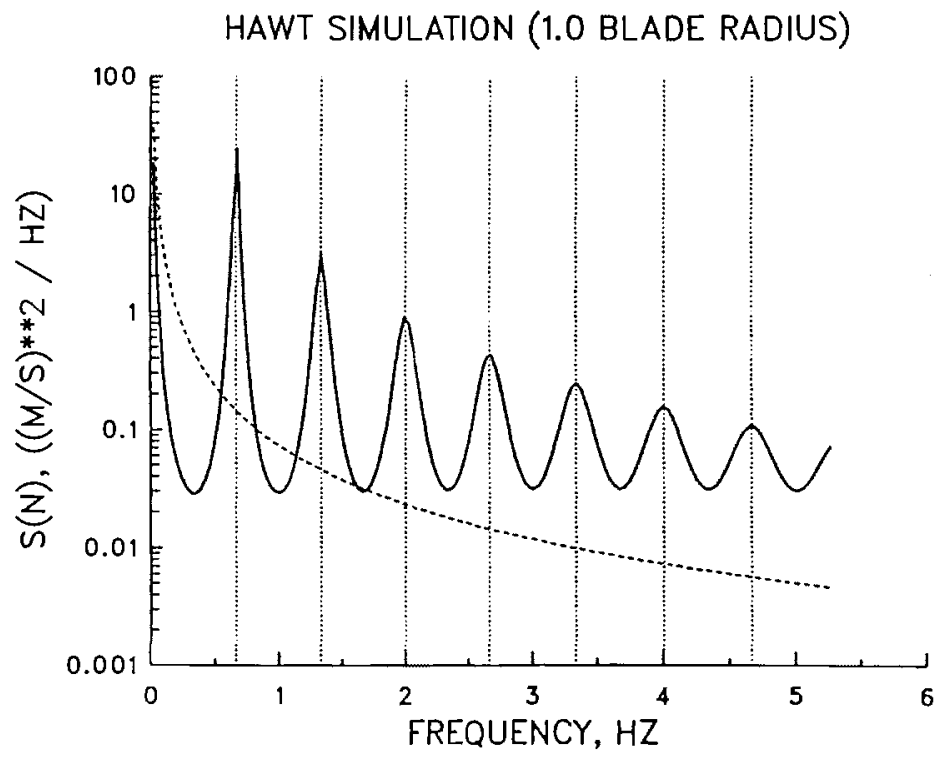

b)

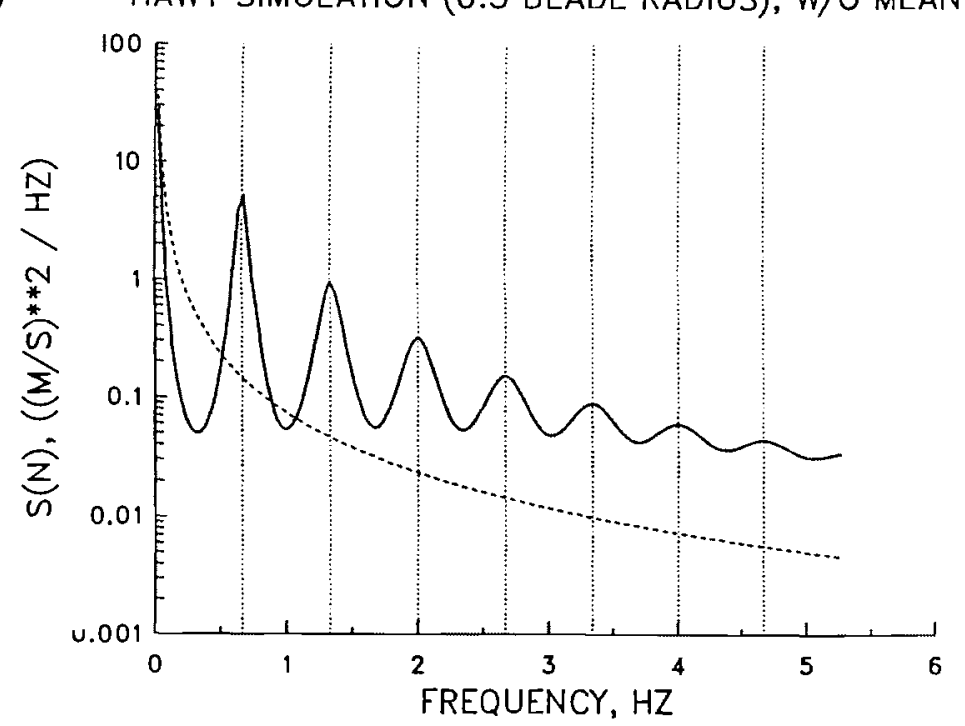

d)

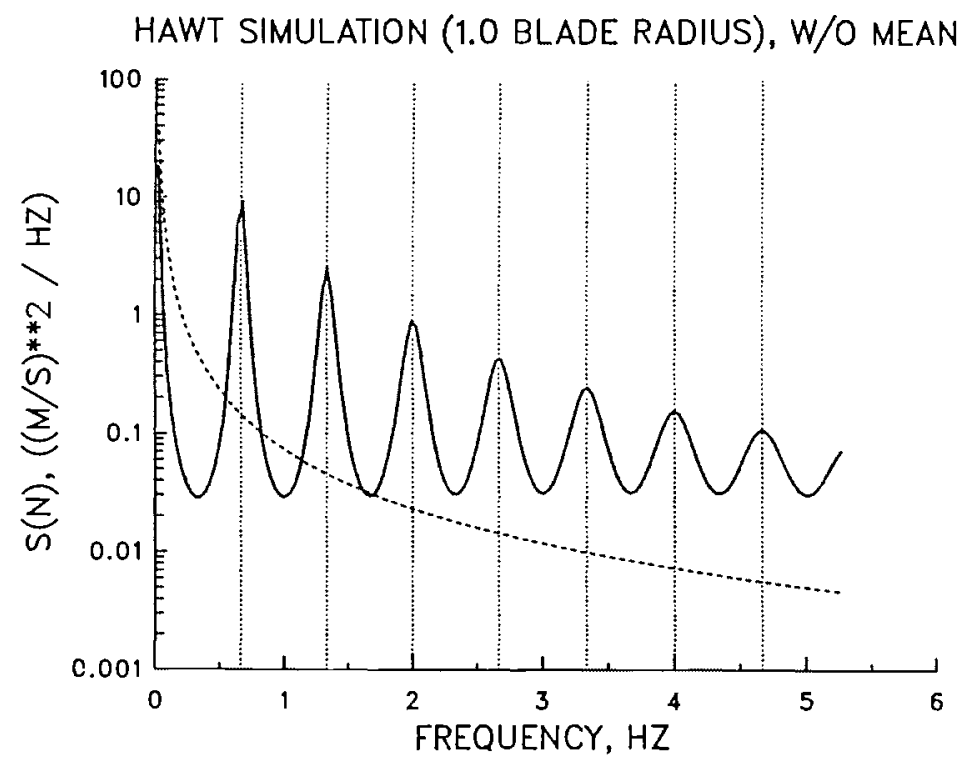

FIGURE 2.1. The Power Spectral Density Function Calculated From the Model for the Wind at the MOD-OA in Simple Terrain. Curves a and $b$ are for the half-blade radius and curves $c$ and $d$ are for the full-blade or tip radius. 
TABLE 2.2. SUMMARY.BRF for the MOD-OA Case

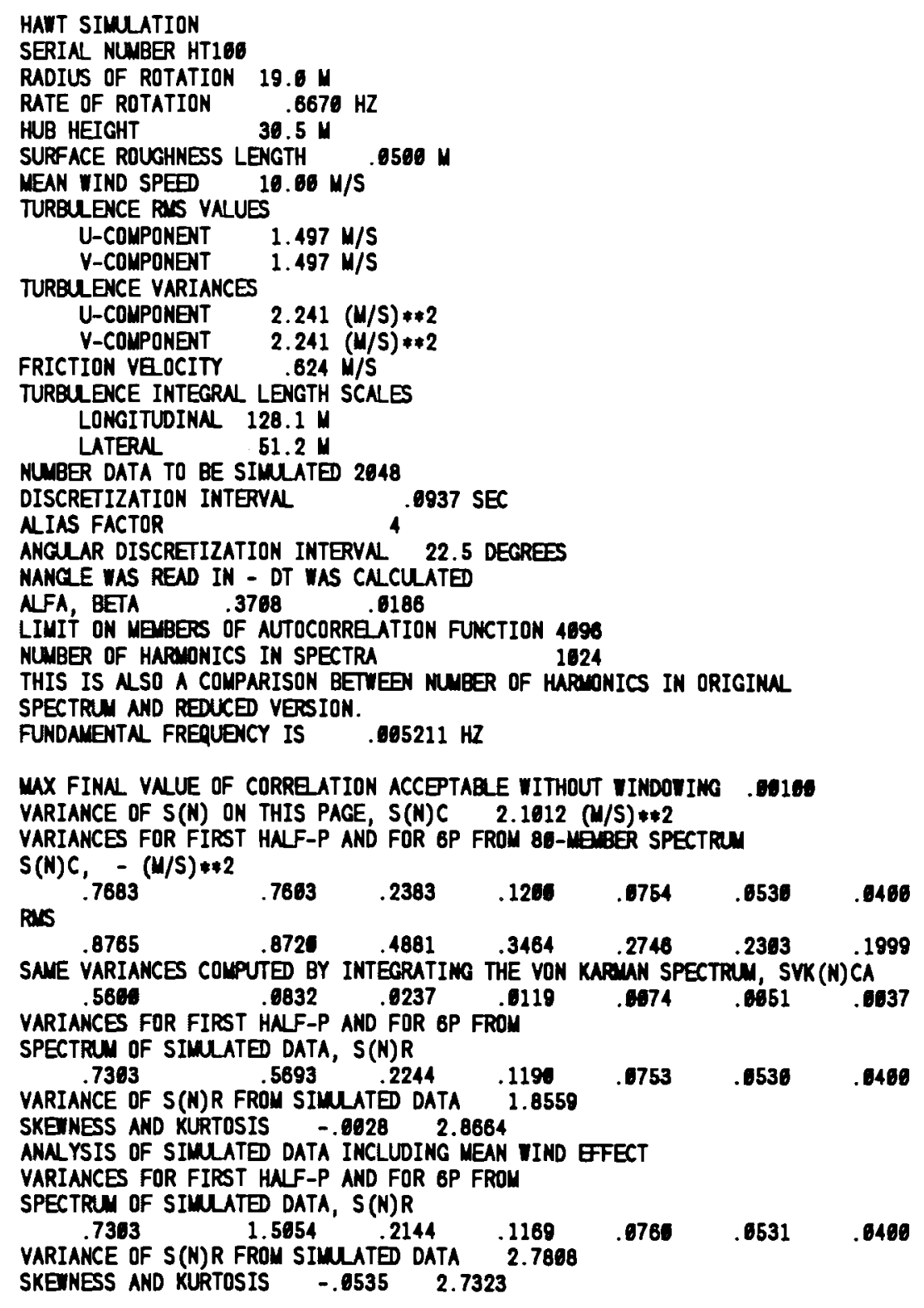




\subsection{SERIES.DAT}

The SERIES.DAT file contains the complete time series of wind speed values computed. A sample of the complete file for the case at half radius, including mean wind shear, and producing a total of 2048 data in the time series, is included as Appendix D. Section D.1 contains a sample of the file for the turbulent part of the wind only. Section D.2 includes the first part of the listing of the fluctuations caused by rotation through the total wind, which is made up of the turbulence and the mean wind. Samples of the time series of through-disk wind speed generated for the MOD-OA conditions in simple terrain are shown in Figure 2.2. Figures $2.2 a$ and $b$ show the fluctuation of wind speed including the effect of the mean wind shear. Figures $2.2 c$ and $d$ show the fluctuation observed with the mean wind shear removed.

\subsection{THE OUTPUT FILES FOR THE FULL RADIUS CONDITION OF THE MOD-OA}

The first portion of each of the files for a radius equal to the tip radius (19 $\mathrm{m}$ ) of the MOD-OA, but otherwise corresponding to the output file conditions discussed in the previous sections, is included in Appendix E. 
a)

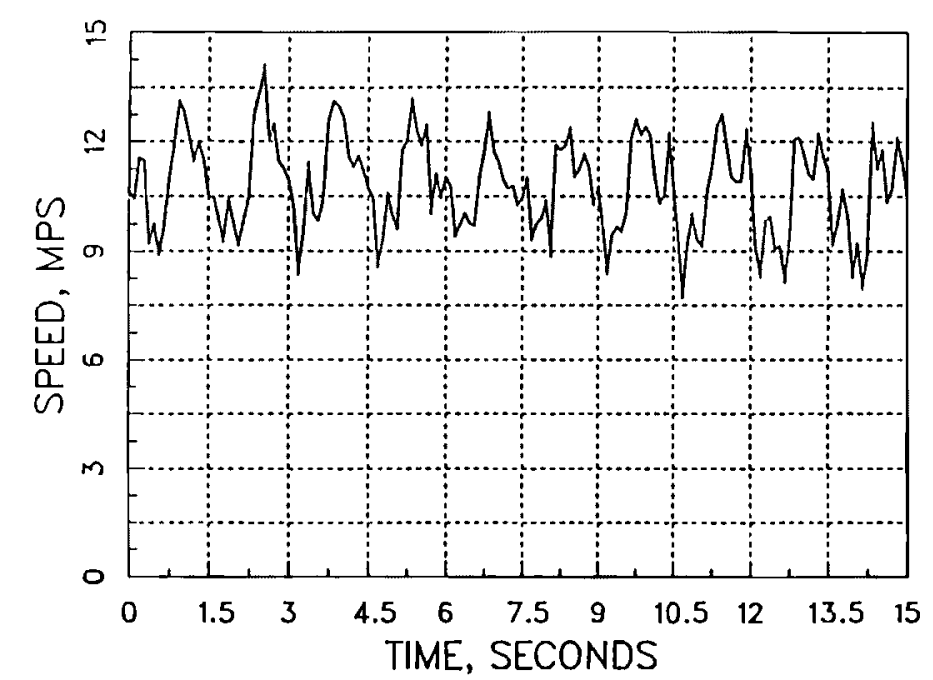

$\infty$

c)

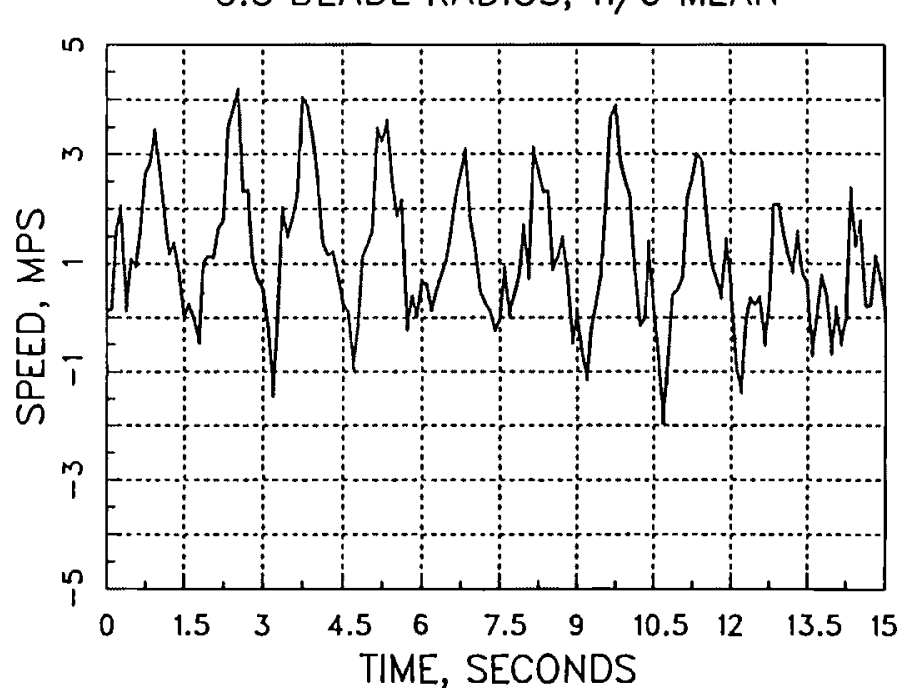

b)

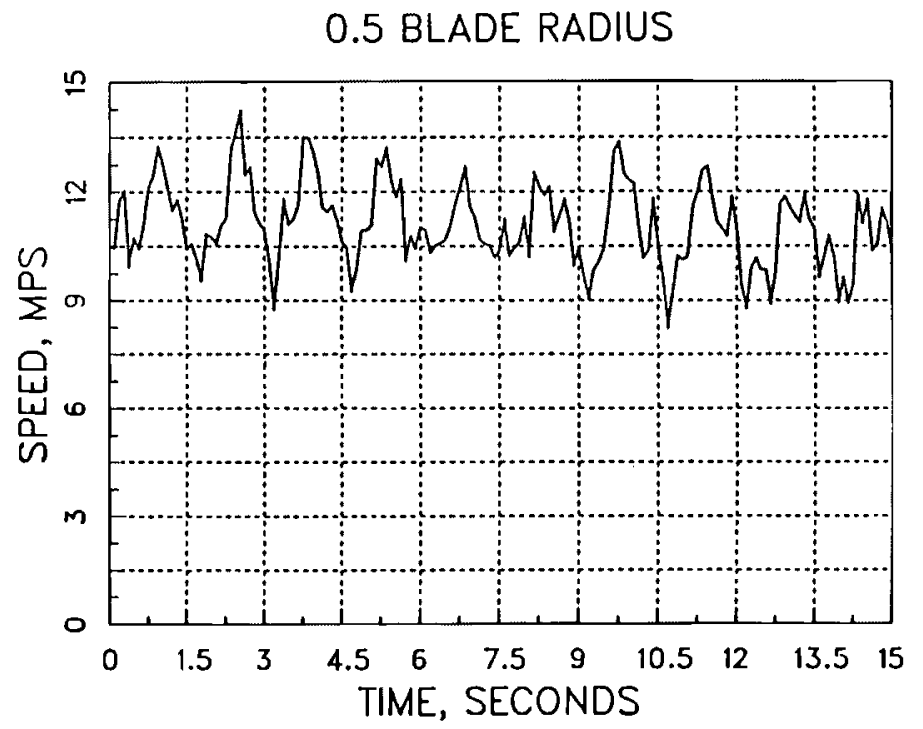

d)

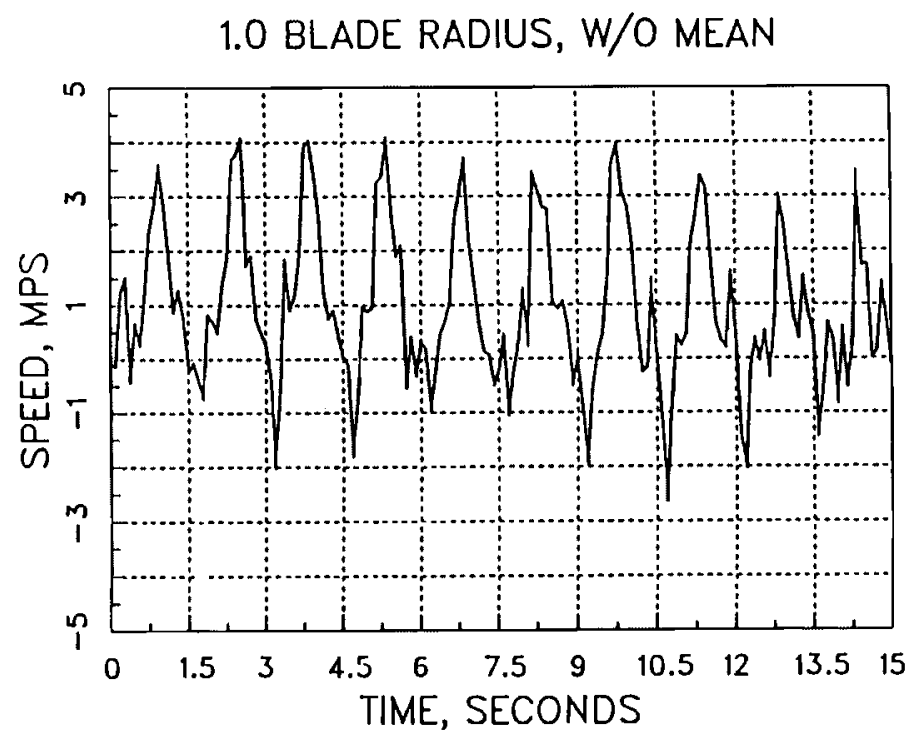

FIGURE 2.2. Samples of the Time Series of Cross-disk Wind Speed Generated for the MOD-OA Conditions in Simple Terrain for a Time Increment of $15 \mathrm{~s}$, or 10 Revolutions of a Rotor Blade. Curves $a$ and $b$ show the fluctuation of wind speed including the effect of the mean wind shear. Curves $c$ and $d$ show the fluctuation observed with the mean wind shear removed. 


\subsection{EXAMPLE FOR A VERTICAL AXIS OF ROTATION}

The output files for the vertical-axis wind turbine (VAWT) case are formatted like the files for the horizontal axis of rotation. The two sets of examples are for the radial (normal to a circumference) and tangential wind components at the equatorial radius rather than for the single component in the HAWT case at two radii presented in Section 2. Samples of all the files are included in Appendix F. They are for a 34-m Darrieus rotating at $0.5 \mathrm{rev} / \mathrm{s}$ in typical wind conditions in simple terrain. The spectral density functions for the radial and tangential components of the wind fluctuation are plotted in Figure 3.1. The radial fluctuations including mean wind are in Figure 3.1a, and without the mean wind in Figure 3.1b. The tangential fluctuations including the mean wind are in Figure 3.1c, and without the mean wind in Figure 3.1d. Samples of the corresponding time series for $20 \mathrm{~s}$, or 10 rotations of the specified 34-m Darrieus, are shown in Figure 3.2. 
a)

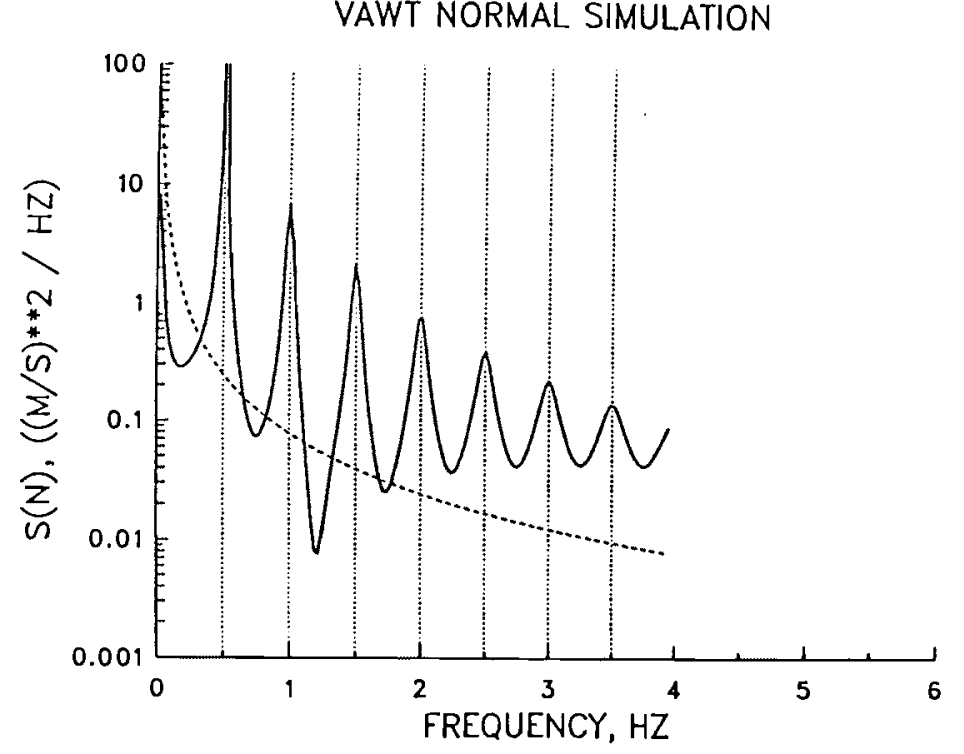

c)

•

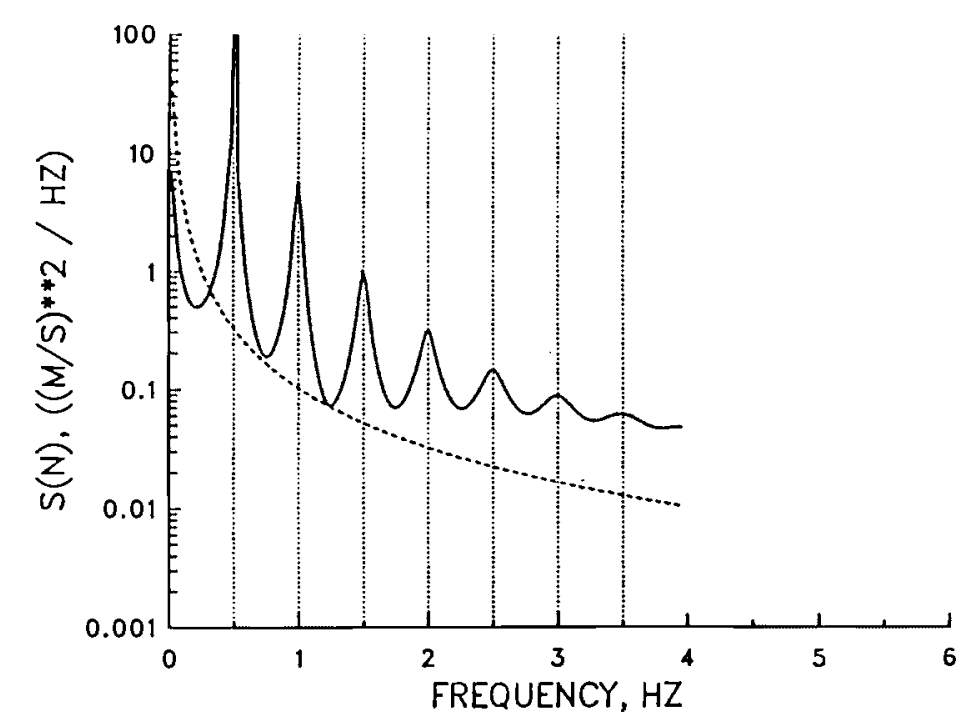

b)

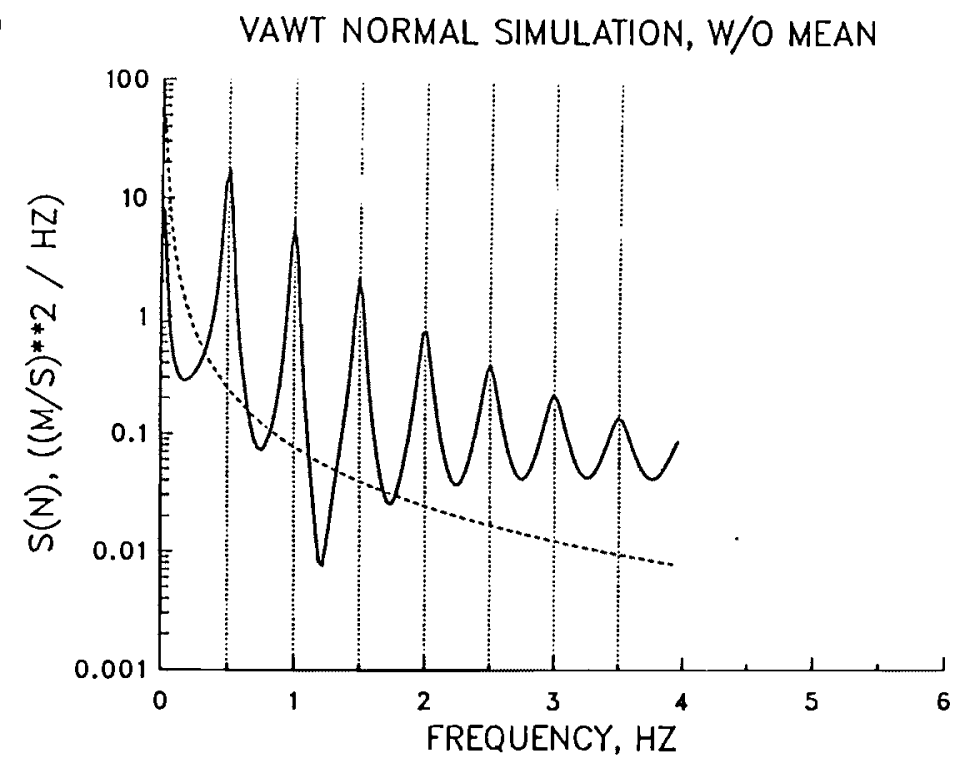

d)

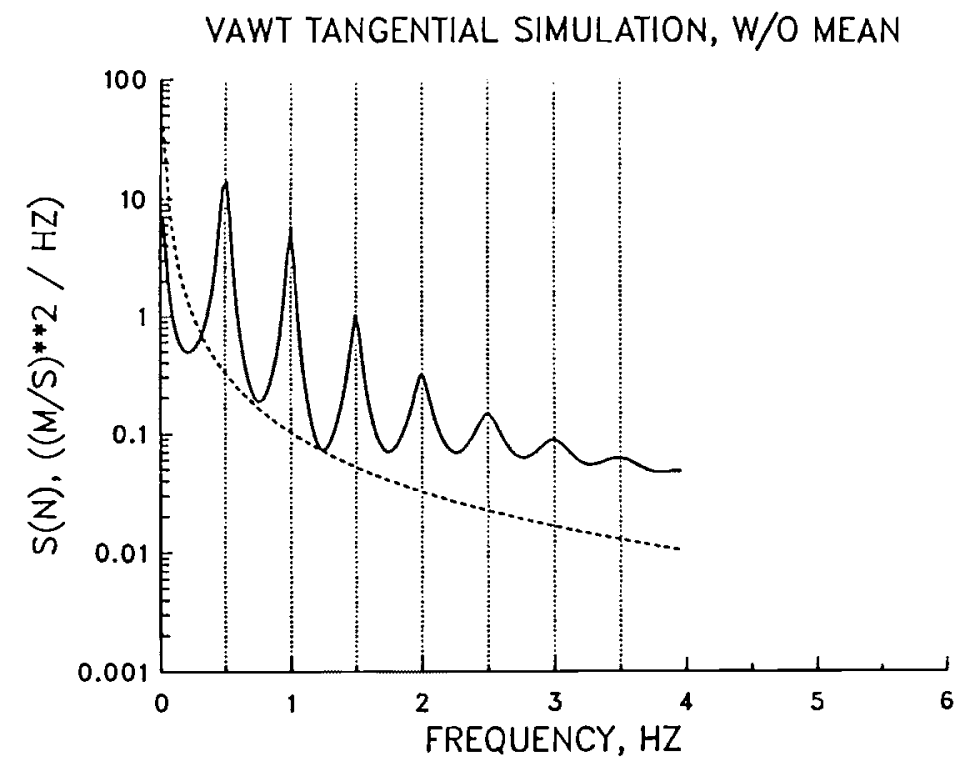

FIGURE 3.1. The Spectral Density Functions for the Radial and Tangential Components of the Wind Fluctuation at the Equatorial Point of the Blade of the 34-m Darrieus. The radial fluctuations including mean wind are shown by curve $a$, and without the mean wind by curve $b$. The tangential fluctuations including the mean wind are shown by curve $c$, and without the mean wind by curve d. 
a)

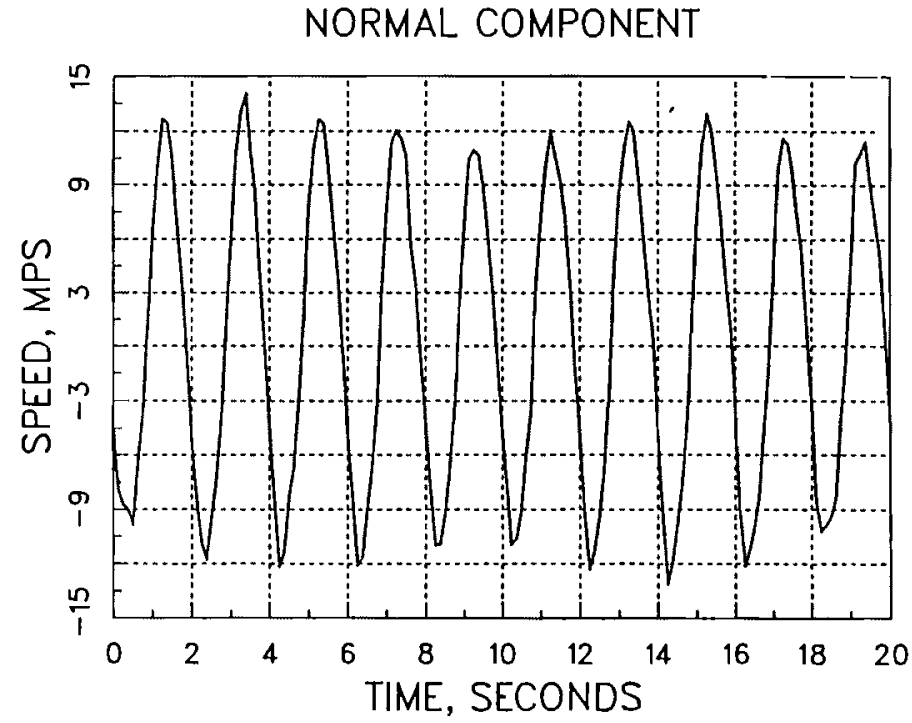

c)

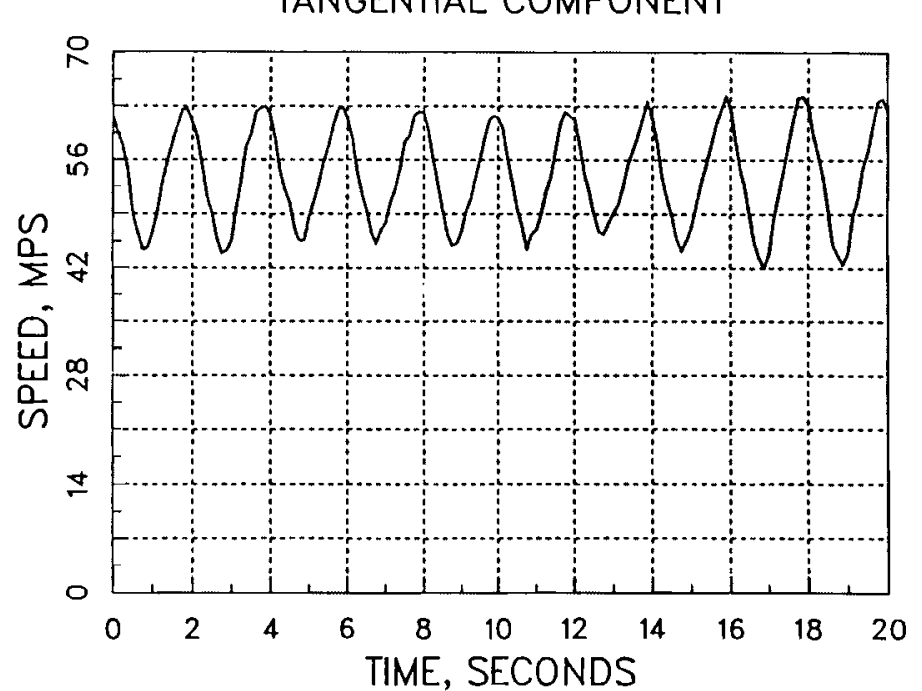

b)

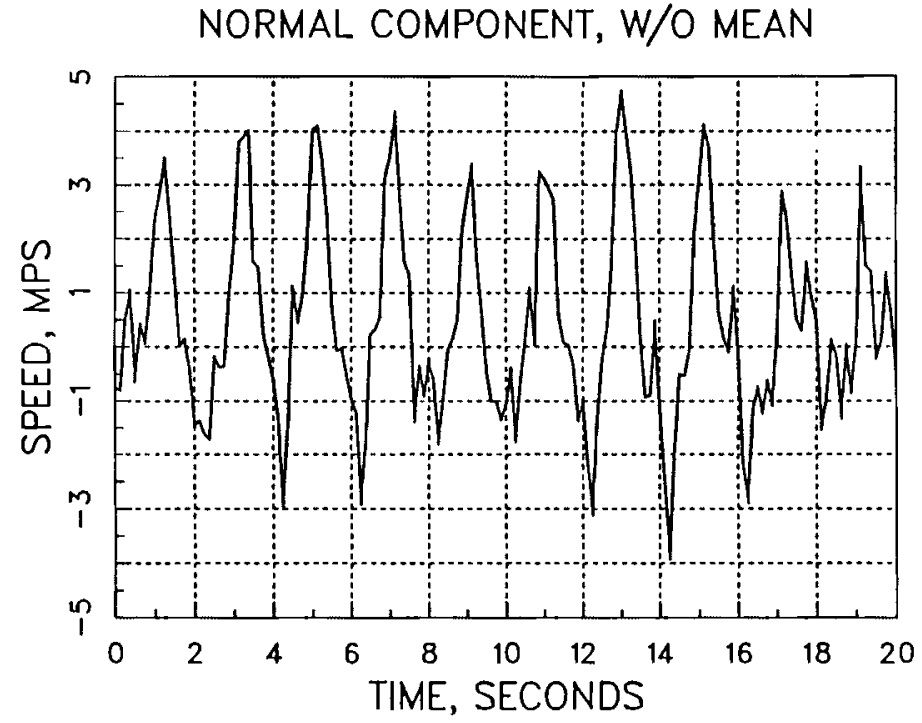

d)

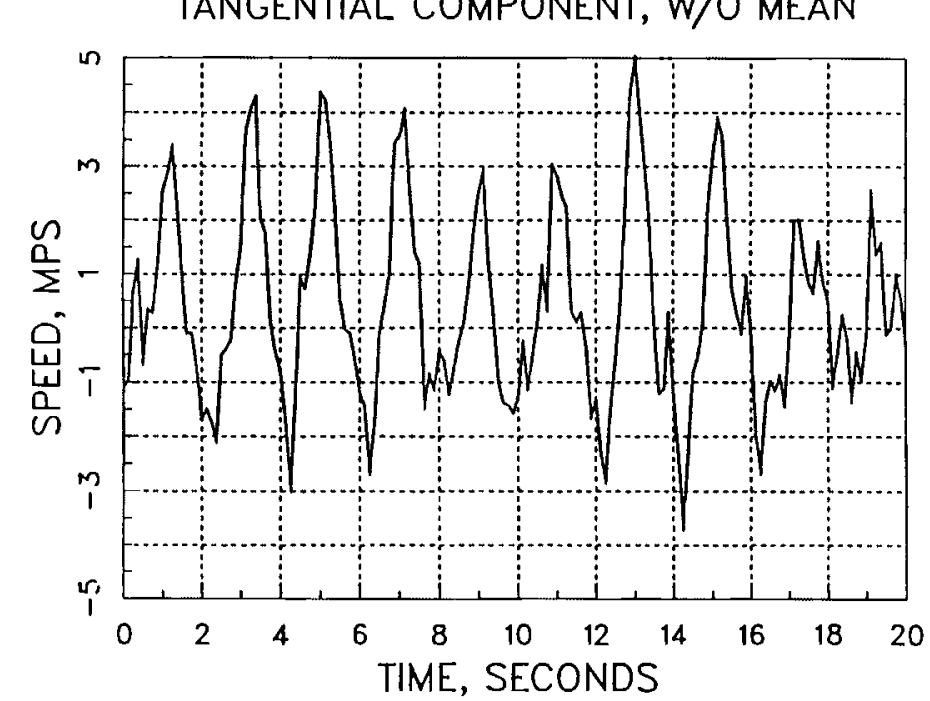

FIGURE 3.2. Samples of the Time Series for $20 \mathrm{~s}$ or 10 Rotations Corresponding to Figures $3.1 \mathrm{a}, \mathrm{b}, \mathrm{c}$, and $\mathrm{d}$ 


\subsection{THE COMPUTER PROGRAM}

The executable file that is supplied with the user's guide should run on any IBM-PC ${ }^{(a)}$ or compatible personal computer. In the event that it does not, or should the user wish to optimize the code for the machine that it will be running on, the FORTRAN77 source code is printed in Appendix A.

\subsection{THE EXECUTABLE FILE: THEORY.EXE}

The executable program was compiled on an IBM-PC ${ }^{(a)}$ with $640 \mathrm{~K}$ of memory using Microsoft's FORTRAN compiler version $4.01^{(b)}$. Command line flags were set to allow for variables with names longer than six characters and to optimize the code. Because of the size of the code, we advise having a two-drive system or one with a hard drive to run the program, although it can be run on a one-drive system.

The maximum size of turbulence time series that can be run without recompiling the program, 2048 data points, is the $360 \mathrm{~K}$ storage limit of the floppy disk on which PNL records the code. This may be too few data points for some purposes, such as wanting to have velocity at 100 points around the ring of rotation or wanting data for more than the 20.48 blade rotations that this condition implies.

In order to increase the number of data points simulated, it is necessary to edit the RODASIM.INC file (see Table 4.1) to increase the magnitude of the exponent, NEXP (see Table 4.2), specifying the size of the time series in powers of two to an integral value greater than 11, e.g., 4096, or 8192 points. The other parameters in RODASIM. INC are automatically calculated as extensions of NEXP. After NEXP is changed, the program will have to be recompiled and available storage will have to be larger in order to run the program. Compiling time using an IBM-PC is about 15 min.

\footnotetext{
(a) IBM-PC is a product of the International Business Machines Corporation, Boca Raton, Florida.

(b) Microsoft Corporation, Bellevue, Washington.
} 
TABLE 4.1. Files on Disk Including RODASIM. INC

$\begin{array}{llrrr}\text { A THRY } & \text { EXE } & 236234 & 9-24-88 & 8: 24 \mathrm{a} \\ \text { A-THRY } & \text { FOR } & 34831 & 9-24-88 & 8: 08 \mathrm{a} \\ \text { BESSEL } & \text { FOR } & 2716 & 9-23-88 & 11: 13 \mathrm{a} \\ \text { COOLEY } & \text { FOR } & 1606 & 9-23-88 & 11: 13 \mathrm{a} \\ \text { FFT } & \text { FOR } & 1052 & 9-23-88 & 11: 14 \mathrm{a} \\ \text { HAWTMN } & \text { FOR } & 395 & 8-08-88 & 12: 41 \mathrm{p} \\ \text { LOGBAND } & \text { FOR } & 3642 & 9-23-88 & 11: 15 \mathrm{a} \\ \text { RANDOM } & \text { FOR } & 1616 & 9-23-88 & 11: 16 \mathrm{a} \\ \text { RODAPRIN } & \text { FOR } & 4222 & 9-23-88 & 11: 17 \mathrm{a} \\ \text { VAWTTN } & \text { FOR } & 3186 & 9-23-88 & 11: 18 \mathrm{a} \\ \text { VAWTTNMN } & \text { FOR } & 638 & 9-23-88 & 11: 18 \mathrm{a} \\ \text { VAWTUV } & \text { FOR } & 2123 & 9-23-88 & 11: 19 \mathrm{a} \\ \text { RODASIM } & \text { INC } & 266 & 11-21-87 & 10: 35 \mathrm{p}\end{array}$

TABLE 4.2. RODASIM. INC, The Include File Needed for Compiling

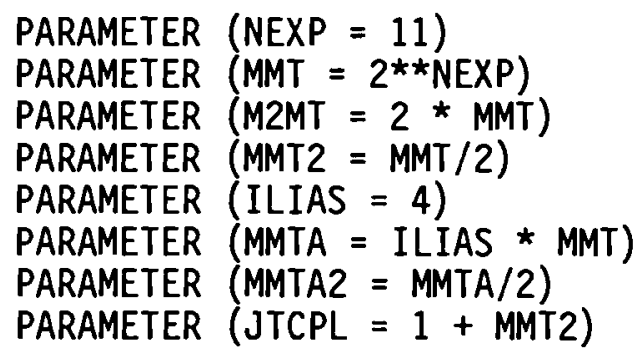

\subsubsection{Executing the Code}

To execute the code on a single disk-drive system:

1) Place the PNL Theory disk in drive $A$.

2) Type A_THRY $\langle$ RET $>$ to execute the program.

3) When the program is finished loading, remove the program disk and replace it with a blank disk; the resulting data files will use approximately $200 \mathrm{~K}$ of disk space during the program run.

4) Answer the prompts that the program supplies.

5) When the program finishes its run, rename the files created so that the program will run correctly when it is next used. 
To execute the code on a dual disk-drive system:

1) Place the PNL Theory disk in drive $B$ and a blank disk in drive $A$.

2) Type from the A>prompt B:A_THRY to execute the program.

3) Answer the prompts that the program supplies.

4) When the program finishes its run, rename the files created so that the program will run correctly when it is next used.

To execute the code on a hard-drive system:

1) Copy the file A_THRY.EXE from the PNL Theory disk to a hard-drive volume.

2) Set the directory to that volume and type the command A_THRY to execute the program.

3) Answer the prompts that the program supplies.

4) When the program finishes its run, rename the files created so that the program will run correctly when it is next used.

\subsection{INPUT AND OUTPUT FROM THE PROGRAM}

The program prints to the screen several prompts for input and generates three text files upon completion. The text files contain the information provided by the user as well as a simulated time series of data and the statistical information needed to create the time series.

\subsubsection{A Sample of the Prompts That the Program Generates}

The following is a sample of the prompts that the program generates for the horizontal axis wind turbine. NOTE: In this section values entered by the user in response to prompts appear underlined and explanatory comments that are not part of the prompts are enclosed in square brackets. 
PNL Mathematical Theory for Rotationally Sampled Wind

Option:

1 - Do HAWT SIMULATION [horizontal wind speed fluctuations are simulated]

2 - Do VAWT U SIMULATION [component in the direction of the mean wind]

3 - Do VAWT V SIMULATION [crosswind horizontal component]

4 - Do VAWT TANGENTIAL SIMULATION

[component in the direction of the rotation of the blade]

5 - DO VAWT NORMAL SIMULATION

[horizontal radial component]

Enter analysis option

$\underline{1}$

Add mean wind to the simulated turbulence? $(0=$ no, $1=y e s)$

[The mean wind is calculated using the logarithmic law from a specification of the roughness length and a wind speed]

$\underline{1}$

Enter offset angle between mean wind effect and 1P harmonic of simulated turbulence (degrees)

[The mean wind speed will result in a fluctuation component almost entirely at the rotation frequency of the blade. The phase between the 1-P component from the mean wind and that from the turbulence may be taken to be $0^{\circ}$ in lieu of other information.]

0.

Enter simulated blade RADIUS (m)

20.

Enter blade rotation rate (cycles/s)

2.

Enter hub height (m)

30.

Enter Hub height wind speed $(\mathrm{m} / \mathrm{s})$

10. 
Enter surface roughness length (m) $\left[z_{0}\right]$

.05

Calculate the sigma- $u, v$ from neutral boundary layer theory?

(0=yes, $1=$ read from keyboard)

$\underline{0}$

Calculate turbulence length (m) at hub height using programmed formula?

( $0=$ yes, $1=$ read from keyboard)

$\underline{0}$

Assign value of rotational step, DT or NANGLE

( $0=$ NANGLE is known, 1=DT is known)

[DT is the time step, NANGLE is the number of equally spaced rotational points of simulation around the circle of rotation.]

$\underline{0}$

Enter number of divisions around the circle for simulation

$\underline{16}$

Calculate autocorrelation and spectrum functions using smoother (Hanning) ( $0=$ No, $1=$ Enter window function factor)

[The spectrum is calculated from an autocorrelation function specified in the rotating frame of reference (see Connell 1982). The smoother option uses the Hanning technique for reducing error in spectral shape that results when a finite length autocorrelation has not converged sufficiently close to zero (see Bendat and Piersol 1971, Sect 9.5.)

$\underline{1}$ Enter the magnitude, in $(m / s)^{2}$, that is to be compared with the calculated raw autocorrelation function in deciding that the calculated function is close enough to zero.

.001

[This truncation saves computational time while preserving the accuracy of the spectral representation to follow.]

[Recommended.] 
Enter the seed for the pseudo-random number generator

[Keep seed value fixed in runs for other radi i if wind speeds at different radii are to be highly correlated with each other.]

32767.D0

Enter the label for the run

'TEST1'

Spectrum computation finished...

Writing Simulated data...

Writing Simulated data...

-.- End of program ---

\subsubsection{A Description of the Output Files Generated}

The sample texts of these files are printed in Appendices because of their size and format.

SERIES.DAT - Text file containing the time-series data simulated by the model (Appendix D).

SUMMARY.DAT - Text file containing all of the pertinent statistical data from which the time-series is calculated, including the input data (Appendix C).

SUMMARY.BRF - A brief summary of the SUMMARY.DAT file (Table 2.2). 


\subsection{CONCLUDING REMARKS}

In its present form, the model includes either complete correlation between winds at any two locations on the rotor blades, or, alternatively, zero correlation, depending on selection of a seed for the random time generator used. Other specifications of the value of correlation might be made, as they are in some other models (e.g., Veers 1984, 1988; Connell et al. 1988; Thresher and Holley 1981). However, we have chosen to await the availability of accurate determination of the value of those correlations for rotating blades in the atmospheric boundary layer before considering their inclusion in a model. A specified correlation might be artificially constructed by the user, but further evaluation of its validity is required.

The model has the unique feature of incorporating separate length scales for the along-wind and crosswind directions. This feature, an empirical extension of the model basis of homogeneous, isotropic turbulence, allows simulation for a wider range of turbulence conditions. The user may determine how to use these two length scales to simulate conditions of interest, and both can be taken to have the same value.

The source code and the executable code for RODASIM11, along with a sample of the output from an execution of the program, were written on floppy disks so that they could be run on desktop rather than mainframe computers. This document is primarily a user's guide for the PC version of the code, and, through its references and bibliography, a guide to the growing literature on the subject of the rotationally sampled wind. 


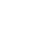




\subsection{REFERENCES}

Bendat, J. S., and A. G. Piersol. 1971. Random Data: Analysis and Measurement Procedures. Wiley-Interscience, New York, Section 9.5, pp. 311-314.

Britter, R. E., J. C. R. Hunt, and J. C. Mumford. 1979. "The Distortion of Turbulence by a Circular Cylinder." Journal of Fluid Mechanics 92:269-301.

Connel1, J. R. 1980. Turbulence Spectrum Observed by a Fast-Rotating Wind Turbine Blade. PNL-3426, Pacific Northwest Laboratory, Richland, Washington.

Connell, J. R. 1982. "The Spectra of Wind Speed Fluctuations Encountered by a Rotating Blade of a Wind Energy Conversion System." Solar Energy $29(5): 363-375$.

Connell, J. R., D. C. Powell, V. R. Morris, and G. L. Gower. 1988. The PNL Single-Tower Measurement Model of Rotationally Sampled Turbulent Wind, with User's Guide for STRS2PC. PNL-6580, Pacific Northwest Laboratory, Richland, Washington.

Moon, J. L., U. Piomelli, and W. C. Reynolds. 1986. "Useful Formulas in the Rapid Distortion Theory of Homogeneous Turbulence." Physics of Fluids $19(10): 341$.

Neff, D. E., R. N. Meroney, and J. R. Connell. 1987. Measurement in a Wind Tunnel of the Modification of Mean Wind and Turbulence Characteristics Due to Induction Effects Near Wind Turbine Rotors. PNL-6248, Pacific Northwest Laboratory, Richland, Washington.

Powell, D. C., and J. R. Connell. 1986. A Model for Simulating Rotational Data for Wind Turbine Applications. PNL-5857, Pacific Northwest Laboratory, Richland, Washington.

Strickland, J. H. 1987. VAWT Stochastic Wind Simulator. SAND87-0501, Sandia National Laboratories, Albuquerque, New Mexico.

Thresher, R. W., and W. E. Holley. 1981. The Response Sensitivity of Wind Turbines to Atmospheric Turbulence. DOE/ET/23144-81/1, Oregon State University, Corvallis, Oregon.

Veers, P. S. 1984. Modeling Stochastic Wind Loads on Vertical-Axis Wind Turbines. SAND83-1909, Sandia National Laboratories, Albuquerque, New Mexico.

Veers, P. S. 1988. Three-Dimensional Wind Simulation. SAND88-0152, Sandia National Laboratories, Albuquerque, New Mexico. 
Wyngaard, J. C. 1981. "The Effects of Probe-Induced Flow Distortion on Atmospheric Turbulence Measurements." Journal of Applied Meteorology 20(7):784794.

NOTE: Appendix G presents a bibliography of other publications on turbulence and rotational sampling. 


\section{APPENDIX A}

THE PNL THEORETICAL TURBULENCE MODEL SOURCE CODE 


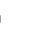


APPENDIX A

THE PNL THEORETICAL TURBULENCE MODEL SOURCE CODE

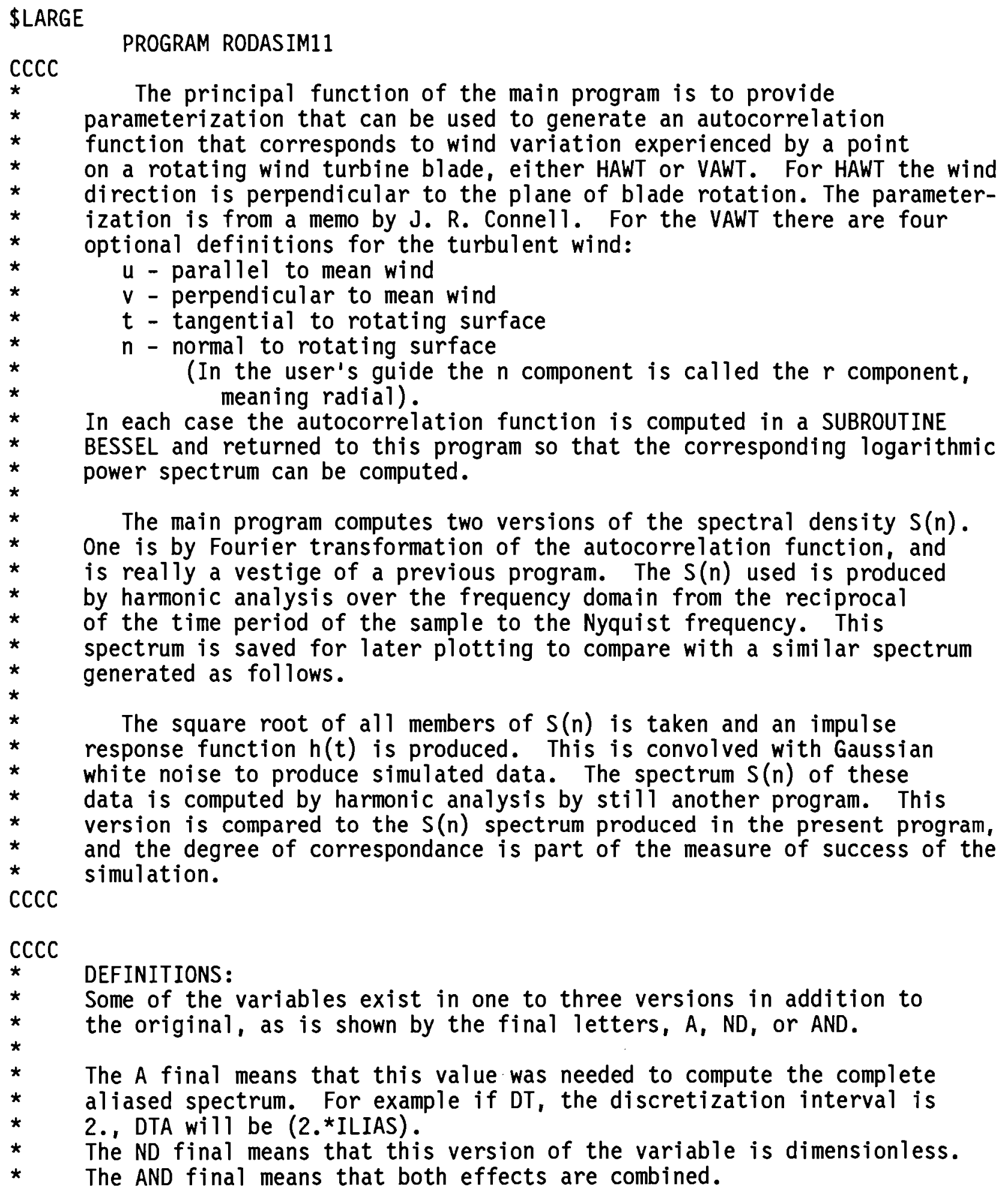


DELAY - offset angle between mean wind effect and $1 P$ harmonic of simulated turbulence (degrees)

ALFA is the ratio of blade radius to turbulence length scale.

ANGLE - Phase angle of $1 P$ harmonic in simulated data. Zero value indicates a cosine wave (degrees).

ANGLEA - The angle the tangent or normal to the circle at the initial position makes with the mean wind direction (degrees). It is now defined in Subroutine VAWTTN.

BETA is the ratio of ALFA to tip speed ratio OMEGA*RADIUS/U.

CHK is the highest final value that will be accepted in an autocorrelation function without windowing (Hanning).

CMMT - number data to be simulated.

CMMTA

DT - the data discretization interval in seconds. DTA, DTND, DTAND

D1() - final simulated data.

D1M() - one cycle of mean wind simulation.

EL1 is the turbulence length scale in beta, (Lu) $x$.

EL2 is the turbulence length scale in alfa, (Lu)y.

ENL() - frequencies $n$ in $\mathrm{Hz}$. These are linearly spaced and limited in number to 80 . ENLND()

ENL1() - Frequencies for 20 divisions of the first band of ENL(). ENL1ND()

ENP() - Cyclic frequency in terms of blade rotation rate (so many $P$ ).

ENO is the blade rotation rate in cycles per second.

EN1 - lowest frequency for which spectral computation is possible reciprocal of data length - fundamental frequency - $\mathrm{Hz}$ EN1ND

EN2 - Nyquist frequency - highest frequency for which spectral computation is possible - $\mathrm{Hz}$. EN2A, EN2ND, EN2AND

G1() - white noise

HT1

IFFSET - Number of positions mean wind wave is to be shifted before adding to simulated turbulence.

ILIAS is the reciprocal of the fraction of the spectrum that is regarded as fit to retain because aliasing can be ignoed. For example: ILIAS = 1 - Retain all of the spectrum.

$=2$ - Retain the lower frequency half.

$=4$ - Retain the lower frequency quarter.

Recommended values are 2 or 4 .

KAWT - option: 1 - Do HAWT u analysis and simulation

2 - DO VAWT u

3 - Do VAWT $v$

4 - Do VAWT $t$

5 - DO VAWT $n$

KMAX is the maximum number of arguements that may be computed for the autocorrelation function.

KSG is an option

0 : Calculate SIGU from neutral boundary layer theory. 
1: Use SIGU as read in.

KWINDOW - additional option to turn off windowing.

$=0$, windowing is bypassed regardless of characterof acf.

K9....K16 are options to write to LU $9 . \ldots .16$

K9 - Write $S(n)$ spectrum to disc

a) FFT of origianal acf

b) $S(n)$ of simulated data

K11 - Write $S(n)$ from cosine integration of acf to file (needed?)

K12 - Write simulated data to file.

K13 - Write $n$ and von Karman $S(n)$ to file.

K14 - Write complex Fourier coefficients of simulated data to file

K15 - Write banded $n S(n)$ spectra of simulated data, preceded by unbanded $\mathrm{nS}(\mathrm{n})$ for lowest frequencies.

MMT is the number of data to be simulted. MMTA

NHAR is the number of unbanded spectral estimates $S(n)$ to be written to output file.

OMEGA is blade rotational rate (radians/sec).

$R()$ - a timelag autocorrelation function generated in SUBROUTINE BESSEL.

RADIUS is blade radius (m).

SIGU is the rms value for u (u-component turbulence), (m/s).

SIGU2 is the corresponding variance $(\mathrm{m} / \mathrm{s}) \star \star 2$.

SIGV, SIGV2 - same for v-component turbulence $(\mathrm{m} / \mathrm{s})$.

SPECL ()$-S(n)$ for linearly spaced frequencies - $\left(m^{\star \star} 2 / \mathrm{sec}\right)$ SPECLND()

SPECL1() - S(n) for 20 divisions of the first band of SPEC(). SPECLIND()

$T$ - running dimensionless time - summation of increments of DTAND.

TMAX is dimensional max time for autocorrelation function.

$U$ is wind speed $(\mathrm{m} / \mathrm{s})$ at height $Z$.

USTAR2 is the square of the corresponding friction velocity $(\mathrm{m} / \mathrm{s}) \star \star 2$.

$\operatorname{VKSPEC}()$ - $S(n)$ according to Von Karman - same frequencies as SPECL () .

XIF1(N) is the power spectral density $S(n)\left(m^{\star \star} 2 / s^{\star \star} 3\right)$

$Z$ is hub height (m).

$\mathrm{ZO}$ is surface roughness length $(\mathrm{m})$.

\$INCLUDE: 'RODASIM. INC'

real ${ }^{\star} 8$ DSEED

CHARACTER KSERIAL $\star 5$

CHARACTER KAWTER $(5) \star 30$

COMPLEX XTEND, AN1, HALF

DIMENSION D1 (MMT), XIF1(JTCPL), XVK(JTCPL), XVKA(JTCPL)

DIMENSION R(MMTA2), XTEND(MMTA), G1 (JTCPL)

DIMENSION ENL(80), ENP(80), SPECL(80), ENL1(20), SPECL1(20)

DIMENSION ENLND(80), SPECLND(80), ENLIND(20), SPECLIND(20)

DIMENSION HT1(2000), SMOM(4)

DIMENSION DCOS $(90), \operatorname{DSIN}(90), \operatorname{D1M}(90), \operatorname{PVAR2}(7), \operatorname{VKSPEC}(80)$

COMMON DT, DTA, DTND, DTAND, EN1, EN1ND, EN2,

*EN2A， EN2ND， EN2AND, NANGLE, NANGLEA, RADIUS, ENO, Z, U, 
*Z0, KSG, SIGU, SIGV, EL1, EL2, KNDOPT,

*KWINDOW, CHK, KMAX, NHAR, USTAR, ALFA, BETA, SIGU2,

*SIGV2, PVAR(7), PRMS(7), PVARVK(7)

EQUIVALENCE ( $R, D 1)$

VKU is the Von Karman u-spectrum. VKUD is the denominator of VKU. $\operatorname{VKUD}($ ENVK $)=(1.0+70.78 *$ ENVK $* \star 2) * \star 0.833333$

$\operatorname{VKU}($ ENVK) $=4.0 *$ ENVK / VKUD(ENVK)

VKUA is the altered Von Karman u-spectrum.

VKUDA (ENVK) $=(1.0+39.48 *$ ENVK**2)**0.833333

$\operatorname{VKUA}($ ENVK) $=4.0 *$ ENVK $/(1.339 * \operatorname{VKUDA}($ ENVK) $)$

Following are the corresponding $v$-spectra.

$\operatorname{VKVN}($ ENVK) $=1.0+188.75 *$ ENVK**2

$\operatorname{VKVD}($ ENVK $)=(1.0+70.78 *$ ENVK $* \star 2) \star \star 1.83333$

$\operatorname{VKV}($ ENVK) $=2.0 *$ ENVK *VKVN (ENVK) / VKVD (ENVK)

altered $v$

VKVNA (ENVK) $=1.0+105.28 *$ ENVK $* * 2$

VKVDA (ENVK) $=(1.0+39.48 *$ ENVK**2)**1.833333

$\operatorname{VKVA}(E)=2.0 * E * \operatorname{VKVNA}(E) /(1.339 * \operatorname{VKVDA}(E))$

DATA KAWTER/'HAWT SIMULATION', 'VAWT U SIMULATION',

*'VAWT V SIMULATION', 'VAWT TANGENTIAL SIMULATION',

* 'VAWT NORMAL SIMULATION'/

PI $=3.141592654$

TWOPI $=2.0 * P I$

$\mathrm{HALF}=(0.5,0.0)$

MWINDFLAG $=0$

C

$c * * *$ Read in the input parameters that the user has control of

$c$

write $(*, *)$ char $(12)$

write $\left(*^{*}\right)$ 'PNL Mathematical Theory for Rotationally Sampled Wind'

1 continue

write $(*, *)$ 'Option:'

write $\left(*^{*}\right)$ ' 1 - Do ',kawter (1)

write $(*, *)$ ' 2 - Do ',kawter (2)

write $\left(*^{*}\right)$ ' 3 - Do ', kawter (3)

write $(*, *)$ ' 4 - Do ', kawter (4)

write $\left(*^{*}\right)$ ' 5 - Do ', kawter (5)

write $(*, *)$ 'Enter analysis option'

$\operatorname{READ}(*, *$, err $=1)$ kawt

2 continue

write $(*, *)$ 'Add mean wind to the simulated'

write $\left(*^{*}\right)$ ' turbulence? ( $0=$ no, $1=$ yes) '

$\operatorname{READ}(*, *, e r r=2)$ mwind

if (mwind.eq.0.) then

delay $=0$.

go to 4

end if 
3 continue

write $\left(*^{*}\right)$ 'Enter offset angle between mean wind effect and $1 P^{\prime}$ write $(*, *)$ ' harmonic of simulated turbulence (degrees)'

$\operatorname{READ}(*, *, e r r=3)$ delay

write $(*, *)$

4 continue

write $(*, *)$ 'Enter simulated blade RADIUS (m)'

$\operatorname{READ}(*, *, e r r=4)$ radius

5 continue

write $(*, *)$ 'Enter blade rotation rate (cycles/sec)'

$\operatorname{READ}(*, *, e r r=5)$ eno

6 continue

write $(*, *)$ 'Enter hub height (m)'

$\operatorname{READ}(*, *, \operatorname{err}=6) \mathrm{z}$

7 continue

write $(*, *)$ 'Enter Hub height wind speed (m/sec)'

$\operatorname{READ}(*, *, \operatorname{err}=7) \mathrm{u}$

8 continue

write $(*, *)$ 'Enter surface roughness length'

$\operatorname{READ}(*, *, \operatorname{err}=8)$ z0

9 continue

write $(*, *)$ 'Calculate the sigma-u,v from neutral boundary'

write $(*, *)$ ' layer theory? ( $0=$ yes, $1=$ read from keyboard) '

$\operatorname{READ}(*, *$, err $=9) \mathrm{ksg}$

if (ksg.eq.1) then

write $(*, *)$ 'Enter sigma-u, sigma-v for turbulence'

$\operatorname{READ}(*, *, e r r=9)$ sigu, sigv

else

SIGU $=0.96 * U / A L O G(Z / Z 0)$

SIGV $=$ SIGU

end if

10

continue

write $(*, *)$ 'Calculate turbulence length $w /$ respect to'

write $(*, *)$ ' hub height? ( $0=$ yes, $1=$ read from keyboard) '

$\operatorname{READ}(*, *$, err $=10)$ kel

if (kel.eq.1) then

write $(*, *)$ 'Enter turbulence length scale for beta, alpha' $\operatorname{READ}(*, *, e r r=10)$ el 1, el2

else

$E L 1=4.2 * Z$

$E L 2=0.4 * E L 1$

END IF

11 continue

A. 5 


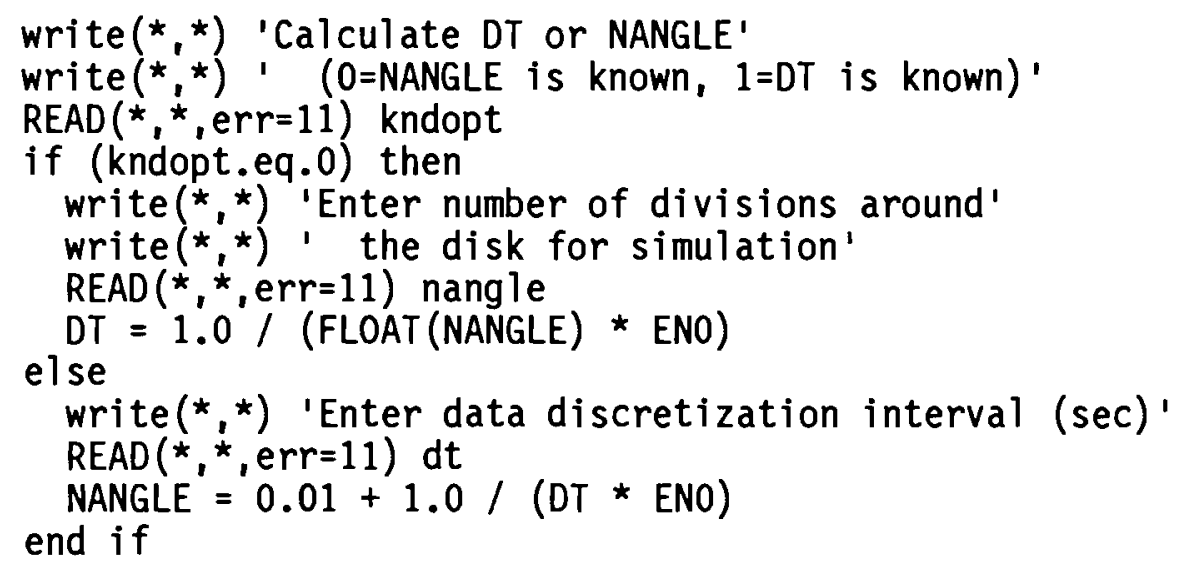

12 continue

write $\left(*^{*}\right)$ 'Calculate using windowing (Hanning)'

write $\left(\star^{*}\right)$ ' $(0=$ No, $1=$ Enter windowing factor $)$ '

$\operatorname{READ}(*, *$, err $=12)$ kwindow

if (kwindow.ne.0) then

write $\left(*^{*}\right)$ 'Enter highest final value acceptable in'

write $\left(*^{*}\right)$ ' the autocorrelation function without '

write $\left(\star^{*}\right)$ ' windowing (Hanning)'

$\operatorname{READ}(*, *, \operatorname{err}=12) \mathrm{CHK}$ end if

13 continue

write $\left(*^{*}\right)$ 'Enter the seed for the pseudo-random' write $\left(*^{*}\right)$ ' number generator'

$\operatorname{READ}(*, *, e r r=13)$ dseed

$\mathrm{k} 9=1$

$k 12=1$

$k 13=1$

$k 14=1$

$k 15=1$

$k 16=1$

15 continue

write $(*, *)$ 'Enter the label for the run'

$\operatorname{READ}(*, *$, err $=15)$ kserial

$c * * *$ hardwire the options for Von Karmen and Spectral output. kxifpr $=1$

kvkpr $=1$

C

$c * \star *$ Open the logical units that are to be used in the program

C

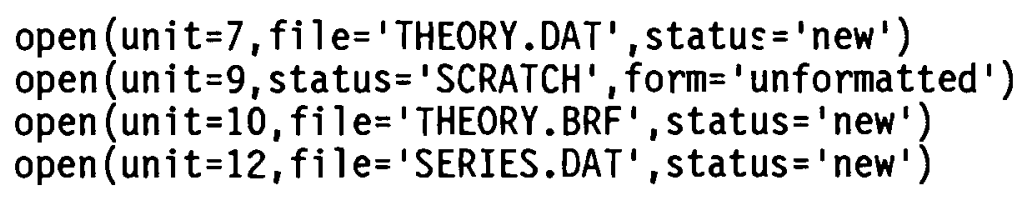




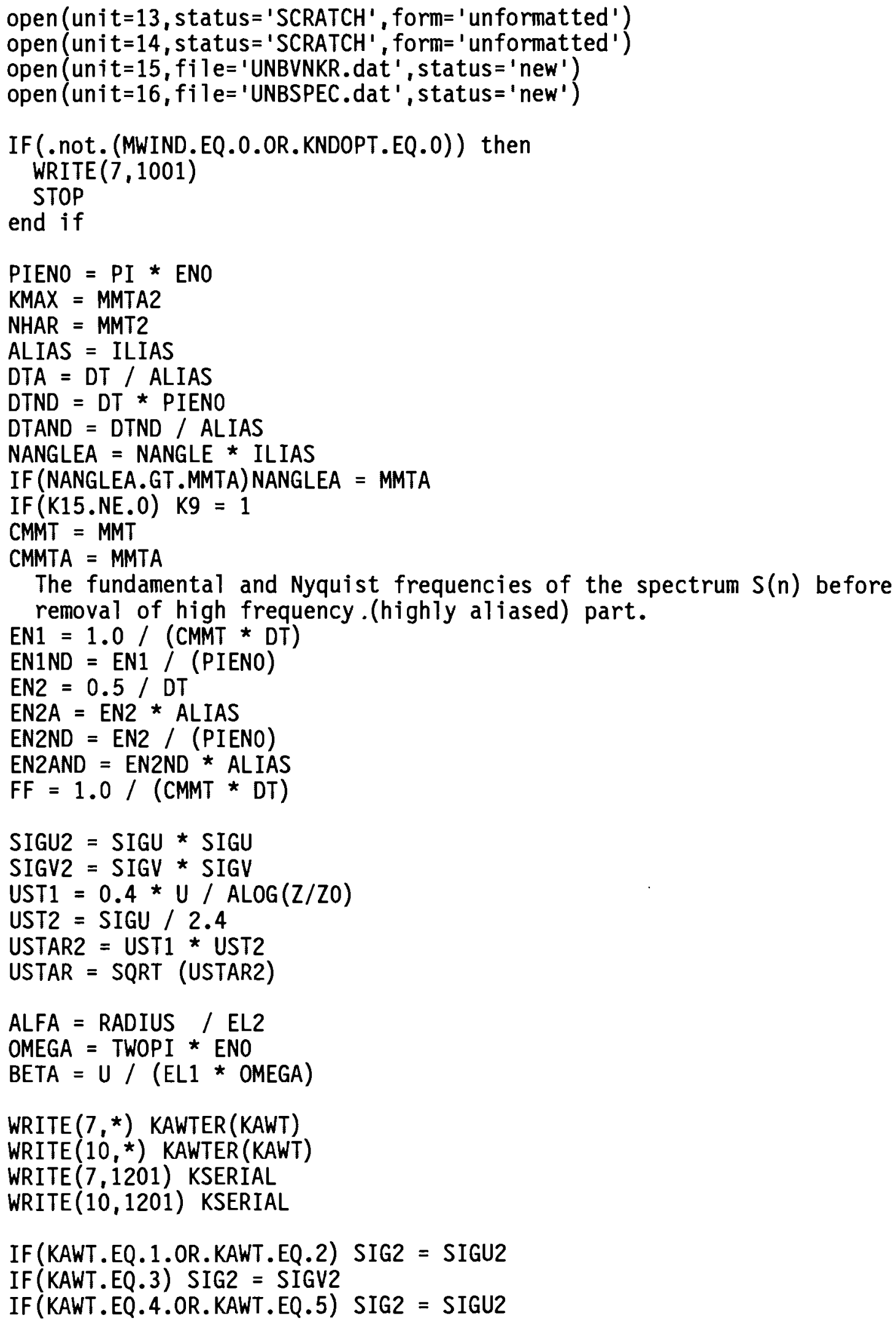


CALL RODAPRINT $(7,1)$

CALL RODAPRINT $(10,1)$

$$
\text { CHKSM }=3.0 * \mathrm{CHK}
$$

* Set linearly spaced dimensionless frequencies.

D0 $21 \mathrm{I}=1,80$ $\operatorname{ENP}(\mathrm{I})=0.1 * \operatorname{FLOAT}(\mathrm{I})$ $\operatorname{ENLND}(\mathrm{I})=\operatorname{ENP}(\mathrm{I}) / \mathrm{PI}$ $\operatorname{ENL}(\mathrm{I})=\operatorname{ENLND}(\mathrm{I}) *$ PIENO CONTINUE
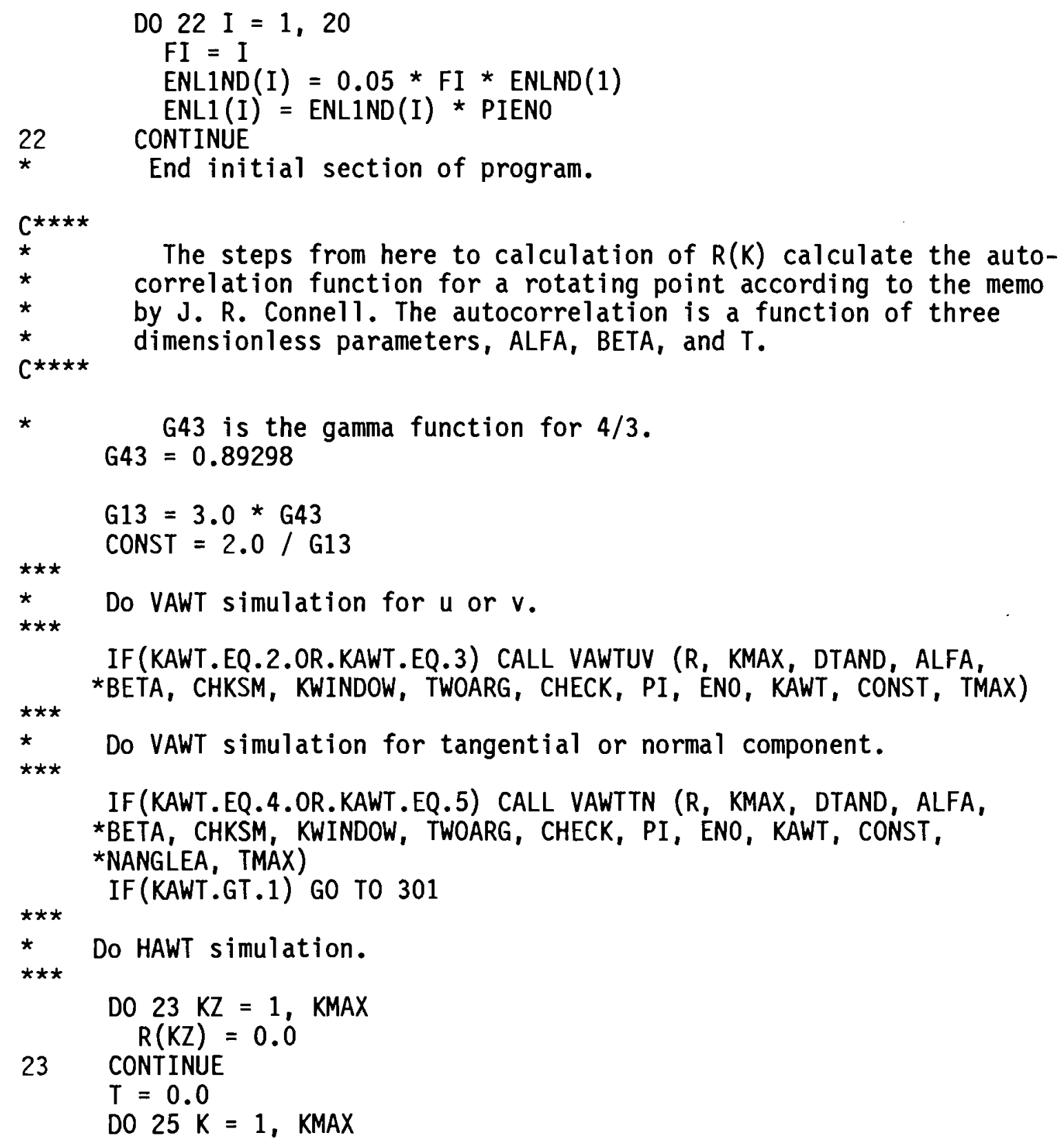
$T$ is the dimensionless time arguement for the autocorrelation function. $T=T+$ DTAND

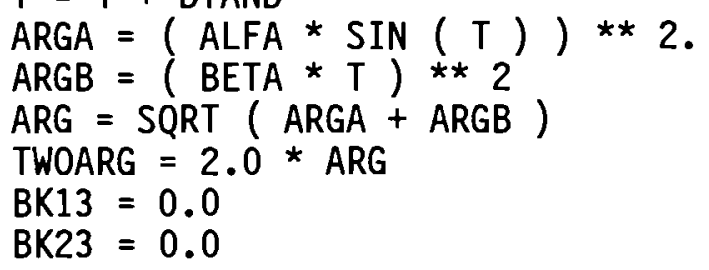

SUBROUTINE BESSEL will calculate a modified Bessel function of the second kind of orders $1 / 3$ and $2 / 3$ provided that the argument is not greater than 8 . If the argument is greater than 8 , the summation used to calculate the Bessel function will not converge, and calculaof the autocorrelation function must be terminated. An autocorrelation function terminated before it intrinsically converges may transform into a spectrum with some values negative. The printed autocorrelation function should be examined to assess whether it converged or not.

IF (TWOARG.LE.8.0) THEN

CALL BESSEL ( TWOARG, BK13, BK23, T )

\section{END IF}

DIFF $=$ BK13 $-(B K 23 * A R G A) / A R G$

$A R G 3=A R G \star \star .33333333333$

$R(K)=$ CONST * ARG3 * DIFF

if $(k .1 t .3)$ go to 25

* Terminate the autocorrelation function if it has converged.

CHECK $=A B S(R(K))+A B S(R(K-1))+A B S(R(K-2))$

25 continue IF (CHECK.LT.CHKSM) GO TO 26

Used only if the above loop runs KMAX times. Printed value of KMAX should be noted.

$\begin{array}{lll}\text { GO TO } & 27\end{array}$

$26 \quad \mathrm{KMAX}=\mathrm{K}$

27 IF(.NOT. (KWINDOW.EQ.0)) THEN

Use Hanning window if convergence has not occurred, and if allowed by option.

RK $=R(K-1)$
FMAX $=$ KMAX

DO $29 K=1, K M A X$

$F K=K$

$R(K)=R(K) *(0.50+0.50 * \cos (P I * F K / F M A X))$

29 CONTINUE

$$
\text { WRITE }(7,2901) \text { RK }
$$

END IF

TMAX = FLOAT $(K M A X) *$ DTA

301 WRITE $(7,3011) \operatorname{KMAX}$, TMAX 


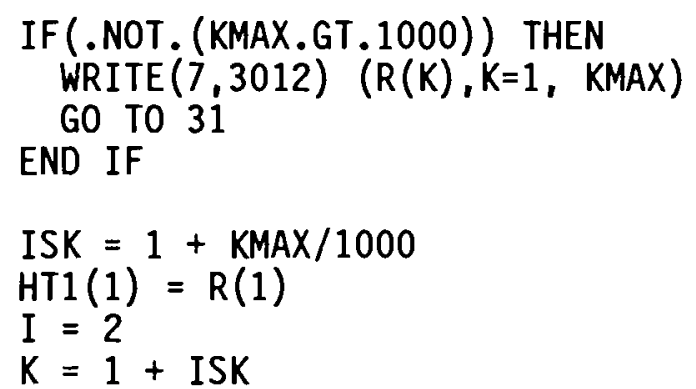

306 CONTINUE

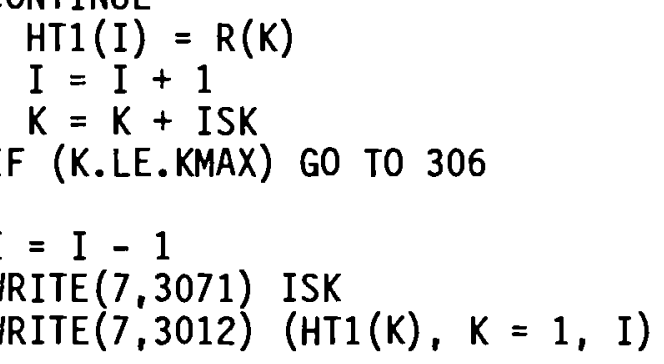

* Determine which warning should be printed out becuse of manner of

* termination of acf.

31 CONTINUE

IF (.NOT. (KWINDOW.NE.0)) THEN

$$
\text { IFLAG }=0
$$

IF(TWOARG.GT.8.0) IFLAG $=1$

IF (CHECK.GT.CHKSM) IFLAG = IFLAG +2

IF(IFLAG.EQ.0) GO TO 315

GO TO $(311,312,313)$ IFLAG

311 CONTINUE

$$
\text { WRITE }(7,3111)
$$

GO TO 315

312 CONTINUE

WRITE $(7,3121)$ CHECK

313 CONTINUE

$$
\text { GO TO } 315
$$

$$
\text { WRITE }(7,3111)
$$

WRITE $(7,3121)$ CHECK

* End correlation calculating section of program

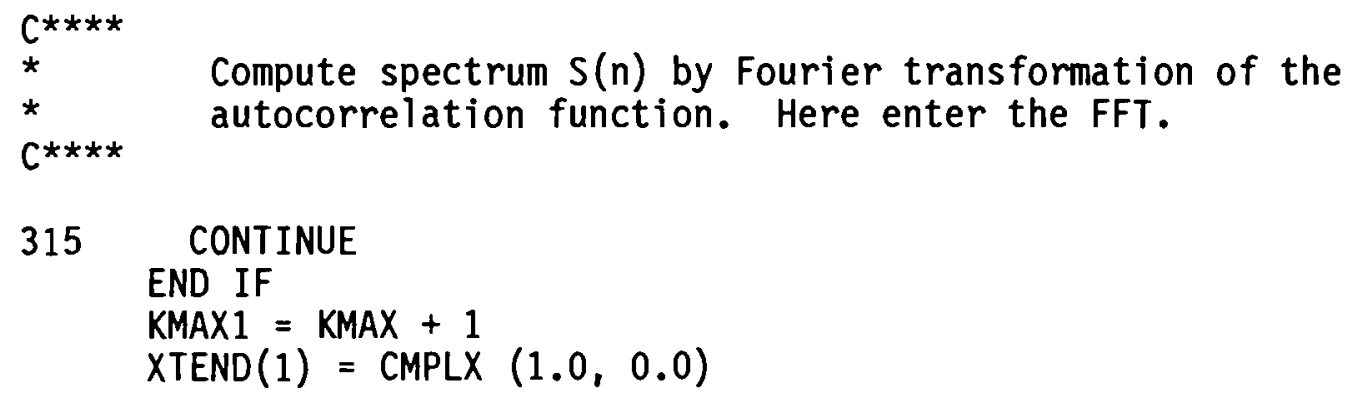

CONTINUE

END IF

KMAX1 = $\mathrm{KMAX}+1$

$X \operatorname{TEND}(1)=\operatorname{CMPLX}(1.0,0.0)$ 


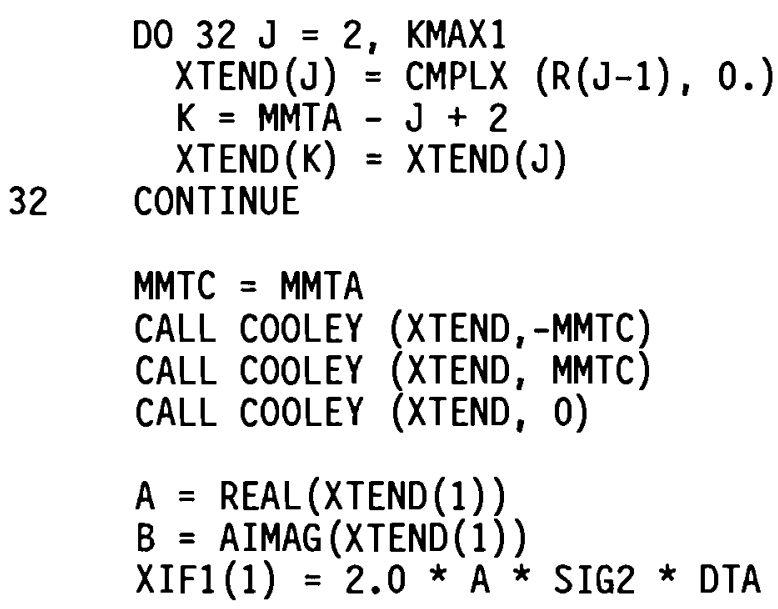

$\operatorname{cccC}$ *

$\operatorname{cccC}$

This section defines parameter values to removed aliased spectra.

NHAR1 $=$ NHAR +1

* End parameter definitions.

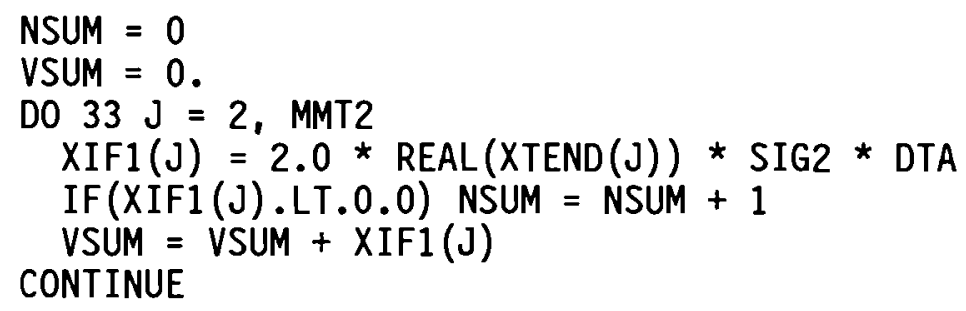

VSUM $=$ VSUM $* F F$

WRITE $(7,3301)$ VSUM

IF (.NOT. (NSUM.EQ.0)) THEN

WRITE $(7,3351)$ NSUM

WRITE $(*, 3351)$ NSUM

END IF

* Write $S(n)$ from FFT of $R(t)$ to disc.

IF(K9.NE.0) WRITE(9) FF, NHAR, (XIF1(I), I = 1, NHAR)

* Compute $S(n)$ version of Von Karman spectrum.

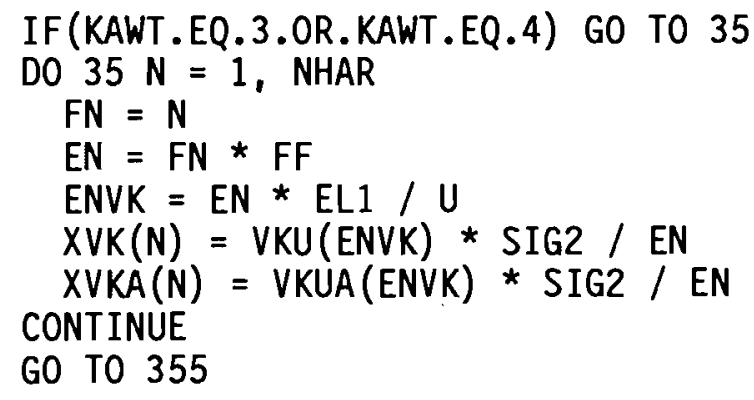




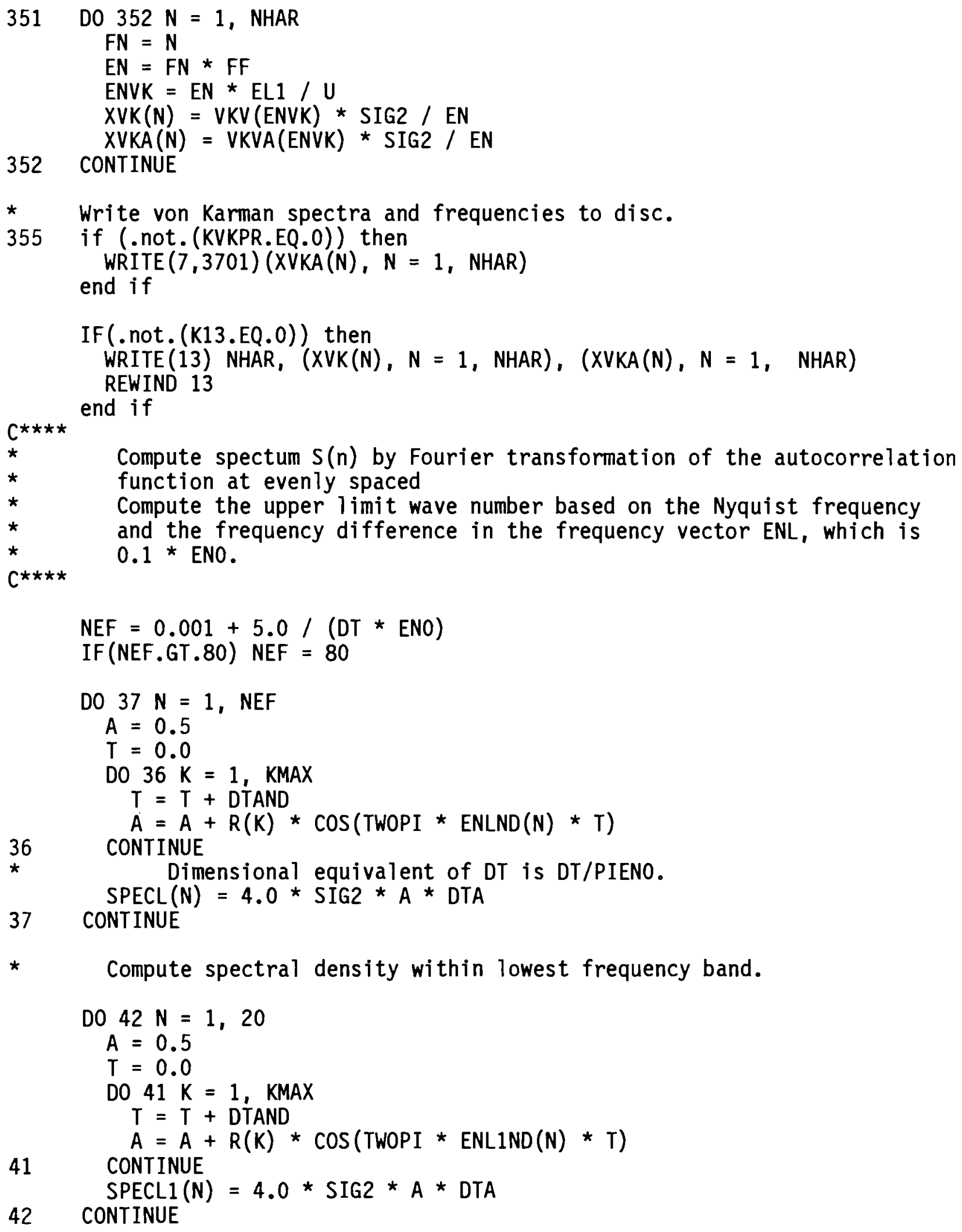


* Calculate length scale by integrating acf.

$$
\begin{aligned}
& A=0.5 \\
& D O 43 K=1, \text { KMAX } \\
& A=A+R^{\prime}(K) \\
& \text { CONTINUE } \\
& \text { SCALEL = A * DTA * U }
\end{aligned}
$$

43 CONTINUE

*

Calculate $S(n)$ version of von Karman spectrum at NEF evenly spaced frequencies.

DO $48 \mathrm{~N}=1$, NEF

$E N V K=E N L(N) * E L 1 / U$

IF (.NOT. (KAWT.EQ.3.OR.KAWT.EQ.4)) THEN $\operatorname{VKSPEC}(\mathrm{N})=$ SIG2 * $\operatorname{VKUA}($ ENVK $) / \operatorname{ENL}(\mathrm{N})$ GO TO 48

END IF

48 CONTINUE

$$
\operatorname{VKSPEC}(\mathrm{N})=\mathrm{SIG2} \text { * } \operatorname{VKVA}(\mathrm{ENVK}) / \operatorname{ENL}(\mathrm{N})
$$

Print out $S(n)$ analysis from FFT. IF (.NOT. (KXIFPR.EQ.0)) THEN $\operatorname{WRITE}(7,7101) \quad(\mathrm{XIF1}(\mathrm{I}), \mathrm{I}=1, \operatorname{NHAR})$

\section{END IF}

* Print out $S(n)$ analysis.

WRITE $(7,8001)$ NEF

$\operatorname{WRITE}(7,8101)$

DO $85 \mathrm{I}=1,40$

$I P=I+40$

$\operatorname{WRITE}(7,8501) \operatorname{ENL}(I), \operatorname{ENP}(I), \operatorname{SPECL}(I), \operatorname{VKSPEC}(I), \operatorname{ENL}(I P)$,

85

* $\operatorname{ENP}($ IP), SPECL(IP), VKSPEC(IP)

85 CONTINUE

$$
\begin{aligned}
& \text { WRITE }(7,8601) \\
& \text { WRITE }(7,8611)(\operatorname{ENL1}(\mathrm{I}), \mathrm{I}=1,20) \\
& \text { WRITE }(7,8621)(\operatorname{SPECL} 1(\mathrm{I}), \mathrm{I}=1,20) \\
& \text { WRITE }(7,8631)(\operatorname{SPC})
\end{aligned}
$$

* Compute and print out sums needed to compute variance from $S(n)$.

$$
A=0 \text {. }
$$

87 CONTINUE

$$
\begin{array}{rl}
\mathrm{DO} 87 & \mathrm{I}=2, \mathrm{NEF} \\
\mathrm{A}=\mathrm{A} & +\operatorname{SPECL}(\mathrm{I})
\end{array}
$$

$$
B=0 \text {. }
$$

$$
\begin{aligned}
& \text { DO } 88 \mathrm{I}=1,20 \\
& \mathrm{~B}=\mathrm{B}+\mathrm{SPECL} 1(\mathrm{I}) \\
& \text { CONTINUE }
\end{aligned}
$$

88

$\operatorname{WRITE}(7,8801) A, B$

$\operatorname{VAR}=\operatorname{ENL}(1) *(A+0.05 * B)$

WRITE $(7,8811)$ VAR 
WRITE $(10,8811)$ VAR

WRITE $(7,8812)$ SCALEL

* End spectrum computing section of program. write $(*, \star)$ 'Spectrum computation finished...'

* Compute variance (energy) in the $1 P, 2 P, \ldots \ldots 6$ bands, where for example, * the variance in the 1P band is found by integrating from the 6 th through

* the 15th evenly spaced $S(n)$ harmonics. This is done for both the

* rotational spectrum SPECL(N) and the von Karman spectrum VKSPEC(N). The

* first lop ending on Lable 882 performs this integration at frequencies

* below the 1P band.

$K=1$

SUM $=0.05 * B$

SUMVK $=$ VKSPEC (1)

D0 $882 \mathrm{I}=2,5$

$K=K+1$

SUM $=$ SUM $+\operatorname{SPECL}(K)$

SUMVK $=$ SUMVK + VKSPEC $(K)$

882 CONTINUE

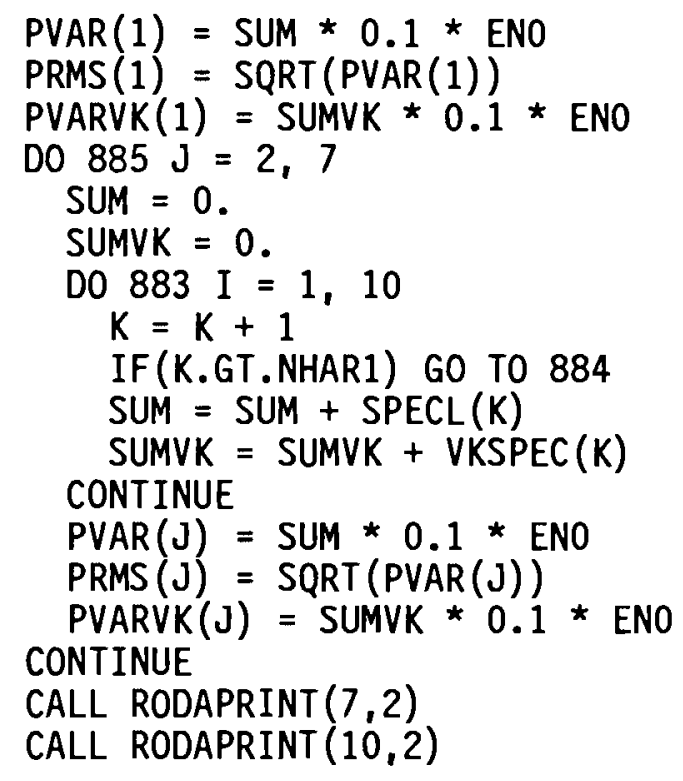

SUMVK = SUMVK $+\operatorname{VKSPEC}(K)$

if (k16.ne.0) then
WRITE $(16,8851)$ ENO
WRITE $(16,8851)$ PVAR
WRITE $(16,8851)$ PVARVK

end if

* Calculate simulated data using harmonic analysis.

$90 \quad$ IGGUWOPT $=1$
$\star$$\quad$ Generate $r v$ between 0 and 1 with uniform probability density. JTCPLZ $=$ JTCPL 
CALL GGUW (DSEED, JTCPLZ, IGGUWOPT, G1)

DO $91 \mathrm{I}=1$, JTCPL

$\mathrm{Gl}(\mathrm{I})=\mathrm{TWOPI} * \mathrm{Gl}(\mathrm{I})$

91 CONTINUE

$\operatorname{XTEND}(1)=(0 ., 0$.

DO $92 \mathrm{I}=2$, JTCPL

$A=S Q R T(0.5 * X I F 1(I) * F F)$

THETA $=$ GI (I)

$C R=A * \cos ($ THETA)

$C I=A * \operatorname{SIN}($ THETA)

$X \operatorname{TEND}(\mathrm{I})=\operatorname{CMPLX}(\mathrm{CR}, \mathrm{CI})$

$K=M M T-I+2$
$X T E N D(K)=$ CONJG

92 CONTINUE

CONTINUE

CALL COOLEY (XTEND, - MMT)

CALL COOLEY (XTEND, MMT)

CALL COOLEY (XTEND,

0)

* These are the simulated data.

DO $93 \mathrm{~J}=1$, MMT

$\mathrm{D} 1(\mathrm{~J})=\operatorname{REAL}(\mathrm{XTEND}(\mathrm{J}))$

93 CONTINUE

96 CONTINUE

* Calculate first four moment of simulated data.

SUM $=0$.

D0 $961 \mathrm{I}=1$, MMT

SUM $=$ SUM + D1 (I)

961 CONTINUE

SUM = SUM $/$ CMMT

DO $962 \mathrm{I}=1$, MMT

$D 1(I)=D 1(I)-S U M$

962 CONTINUE

DO $963 I=1,4$

$\operatorname{SMOM}(I)=0$.

963 CONTINUE

DO $964 \mathrm{I}=1$, MMT

$$
A=1.0
$$

DO $964 \mathrm{~J}=1,4$

$A=A * D 1(I)$

$\operatorname{SMOM}(\mathrm{J})=\operatorname{SMOM}(\mathrm{J})+A$

CONTINUE

964 CONTINUE

DO $965 \mathrm{~J}=1,4$

$\operatorname{SMOM}(\mathrm{J})=\operatorname{SMOM}(\mathrm{J}) / \mathrm{CMMT}$

965 CONTINUE

$\operatorname{SMOM}(3)=\operatorname{SMOM}(3) / \operatorname{SMOM}(2) * \star 1.5$ 


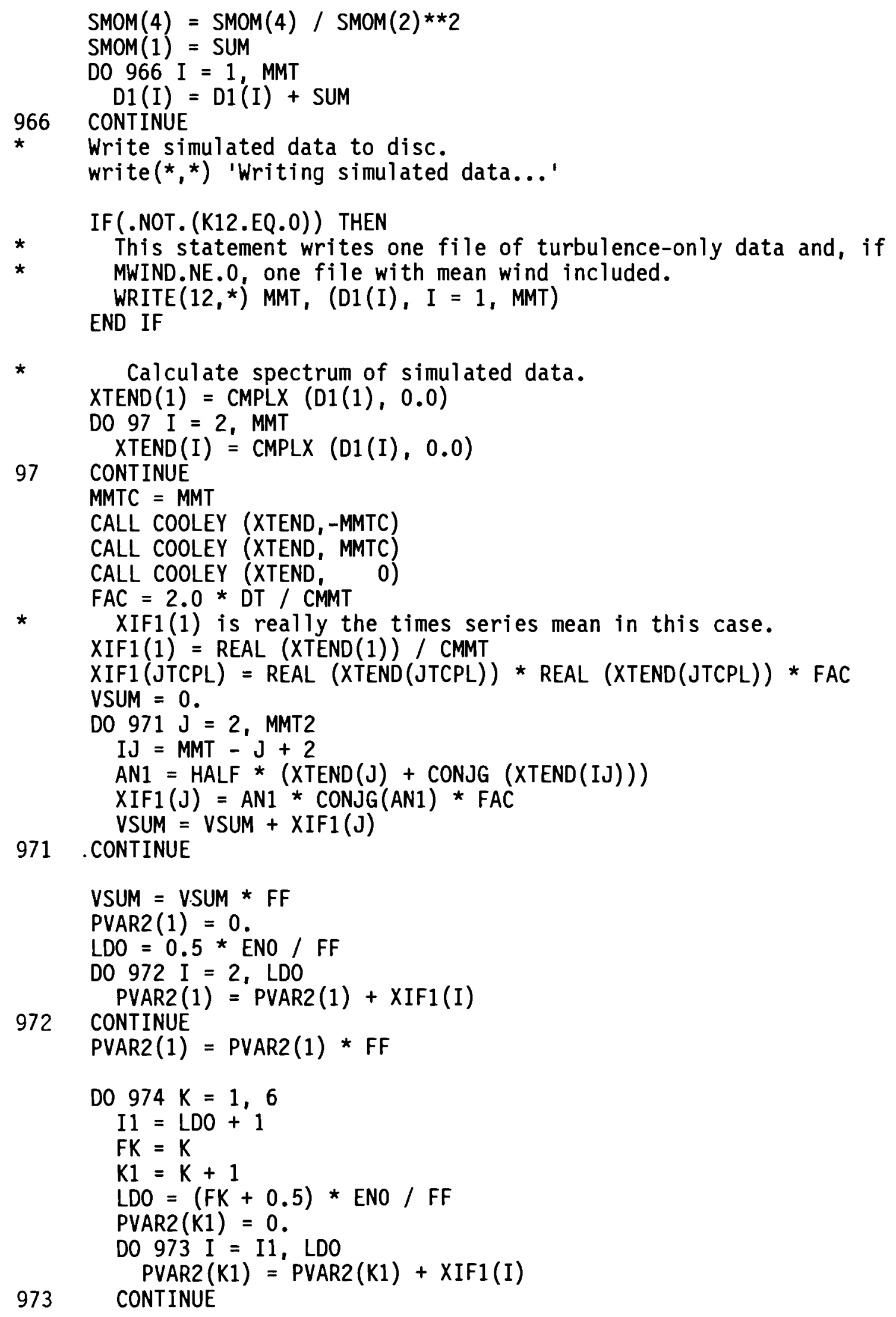


974 CONTINUE

$\underset{\operatorname{PVAR} 2(K 1)}{\operatorname{PVAR} 2(K 1) * F F}$

WRITE $(7,9751)$ PVAR2

WRITE $(10,9751)$ PVAR2

LPRXIF1 $=5.0+2.0$ * ENO / FF

IF(LPRXIF1.GT.JTCPL) LPRXIF1 = JTCPL

WRITE $(7,9801)(\operatorname{XIF1}(\mathrm{I}), \mathrm{I}=1, \operatorname{LPRXIF1})$

WRITE $(7,9811)$ VSUM

WRITE $(10,9811)$ VSUM

WRITE $(7,9812) \operatorname{SMOM}(1), \operatorname{SMOM}(2)$

WRITE $(7,9821)$ SMOM (3), SMOM(4)

WRITE $(10,9821) \operatorname{SMOM}(3), \operatorname{SMOM}(4)$

WRITE $(7,9841)$

$\operatorname{cccc}$

Write $S(n)$ from simulated data to disc, this is a second file.

* IF(MWIND.NE.0) a third file is also written. This one has the series

* mean value in XIF1(1).

CCCC

IF(K9.NE.0) WRITE(9) (XIF1(I), I = 1, NHAR)

REWIND 9

* Write $n S(n)$ from simulated data to disc.

IF(K15.NE.0) CALL LOGBAND (10., K13, MWINDFLAG)

IF (.NOT. (K14.EQ.0)) THEN

DO $985 \mathrm{I}=1$, MMT

985

$$
\text { XTEND(I) }=\text { XTEND(I) / CMMT }
$$

$$
\text { CONTINUE }
$$

* Write complex Fourier coefficients from harmonic analysis of

* simulated data to file.

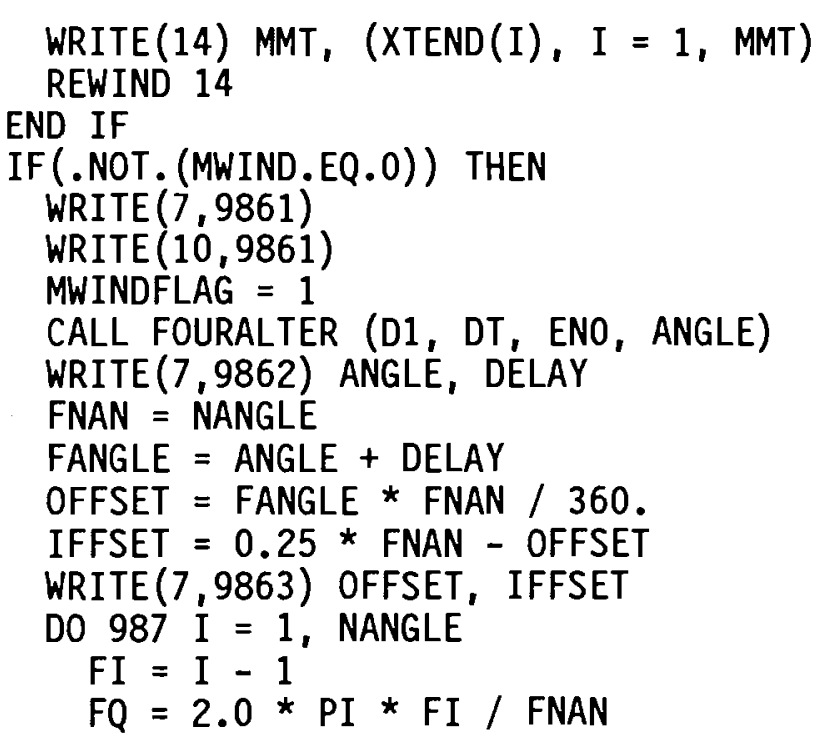




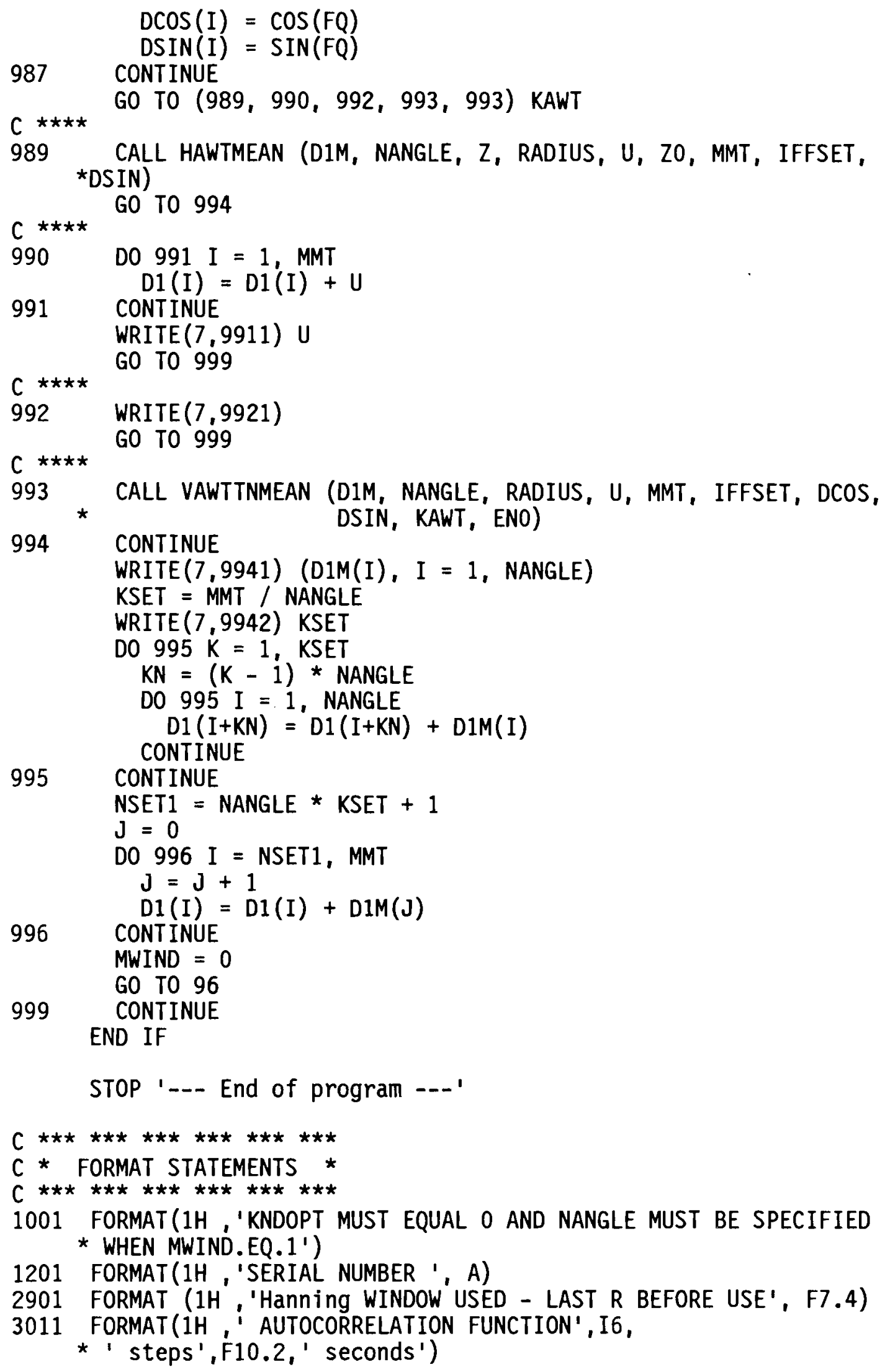




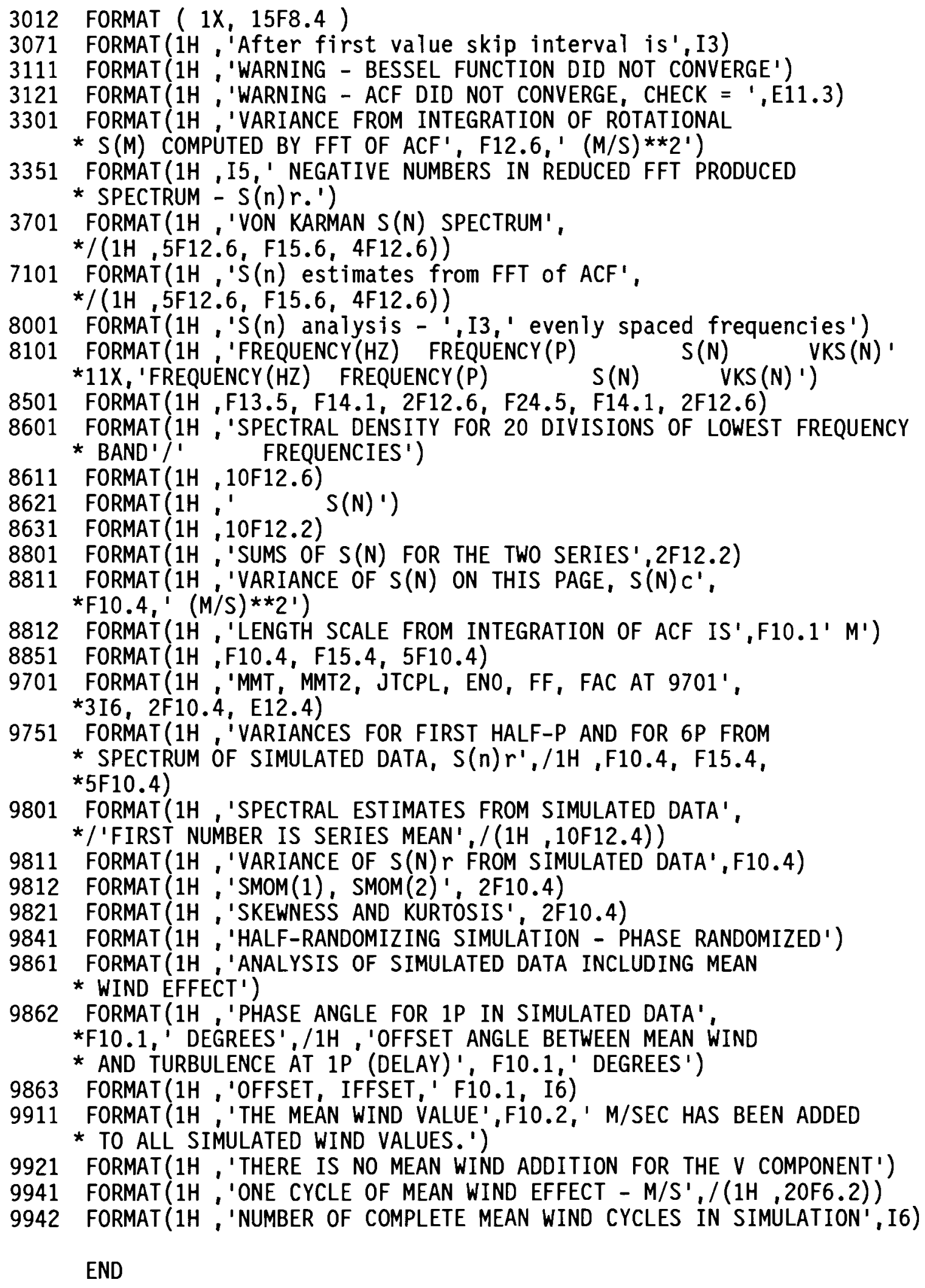


\$LARGE

SUBROUTINE BESSEL ( $X, B K 13, B K 23, T Z)$

C

C This subroutine calculates the summation for the modified

C Bessel function of the second kind with orders $1 / 3$ and $2 / 3$.

C The standard designation of $K(1 / 3)(x)$ or $K(2 / 3)(x)$, as may be

C seen, for example, on page 358 of C.R. Wylie: "Advanced Engineering

C Mathematics" - 3rd edition. When on the UNIVAC or VAX this summation

C converges to an acceptable value only if the arguement $x$ is 8 or less.

C This is presumably due to roundoff or truncation errors.

C

$R E A L \star 8 F 43, F 53, G 43, G 53, G 73, G 83$

* TW043, TW053, TW073, TW083

REAL *8 X43, X53，XSQ，X73，X83，SUM13，SUM23

* , A13, A23

REAL*8 TP13, TM13，TP23，TM23，F13，F23，F73，F83

$\mathrm{TOL}=0.00001$

$\mathrm{PI}=4 * \operatorname{ATAN}(1$.

$\mathrm{C} 13=0.5 * \mathrm{PI} / \mathrm{SIN}(\mathrm{PI} / 3$.

$\mathrm{C} 23=0.5 * \mathrm{PI} / \mathrm{SIN}(2.0 * \mathrm{PI} / 3$.

$\mathrm{F} 13=1 . / 3$.

$F 23=2 . / 3$.

$F 43=4 . / 3$.

$F 53=5 . / 3$.

$\mathrm{F} 73=7 . / 3$.

$\mathrm{F} 83=8 . / 3$.

C

$C \star \star *$ Gamma function of $4 / 3$

$\mathrm{G} 43=.8929797410964966$

$\mathrm{GS43}=\mathrm{G} 43$

C

C $\star * *$ Gamma function of $5 / 3$

$G 53=.9027454853057861$

$\mathrm{GS53}=\mathrm{G} 53$

$G 73=F 43 * G 43$

$\mathrm{G} 83=\mathrm{F} 53 * \mathrm{G} 53$

TW043 $=2.0 * * F 43$

TW053 $=2.0 * * F 53$

TW073 $=2.0 * * \mathrm{~F} 73$

TW083 $=2.0 * * F 83$

$X 43=X^{\star *} F 43$

$X 53=X \star \star F 53$

$X S Q=X * X$

$X 73=X^{* * F 73}$

$X 83=X^{\star *} F 83$

SUM1 $3=0$.

SUM23 $=0$. 


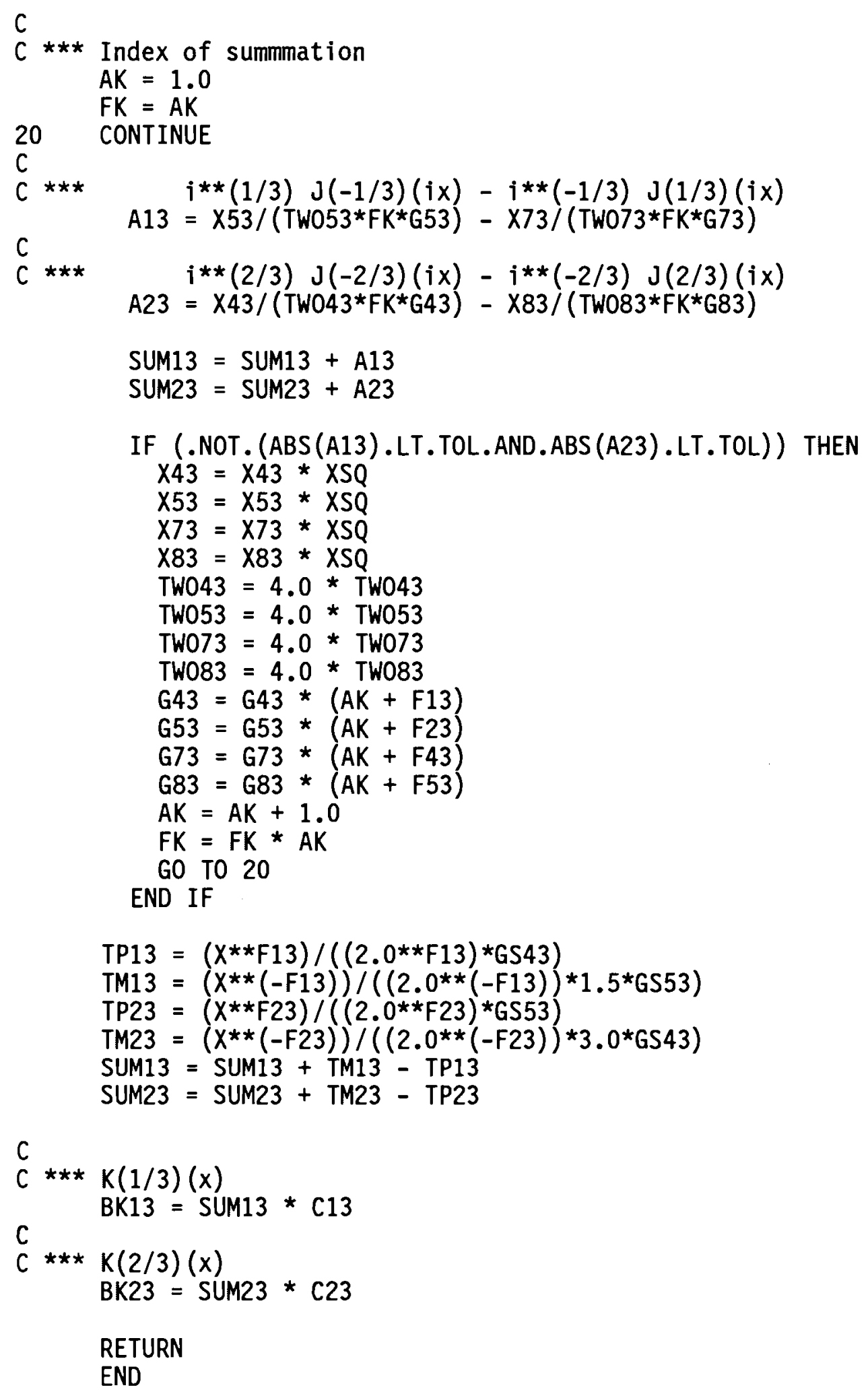




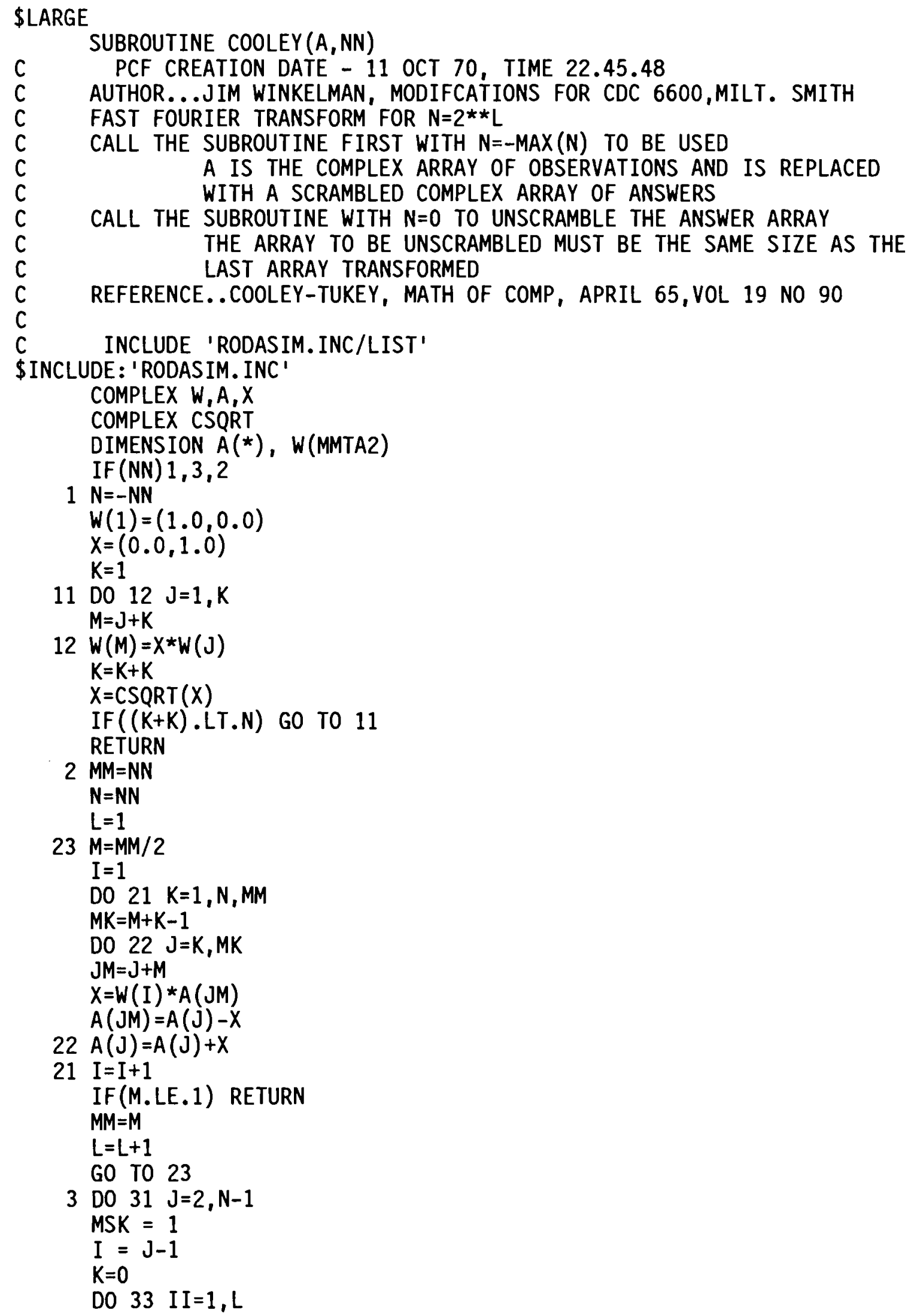




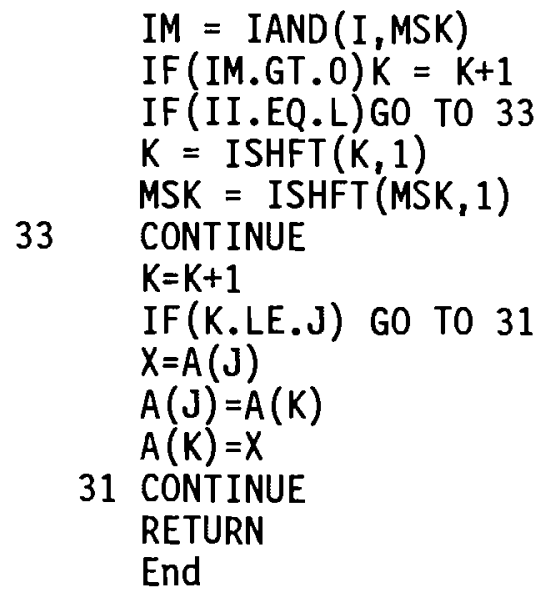




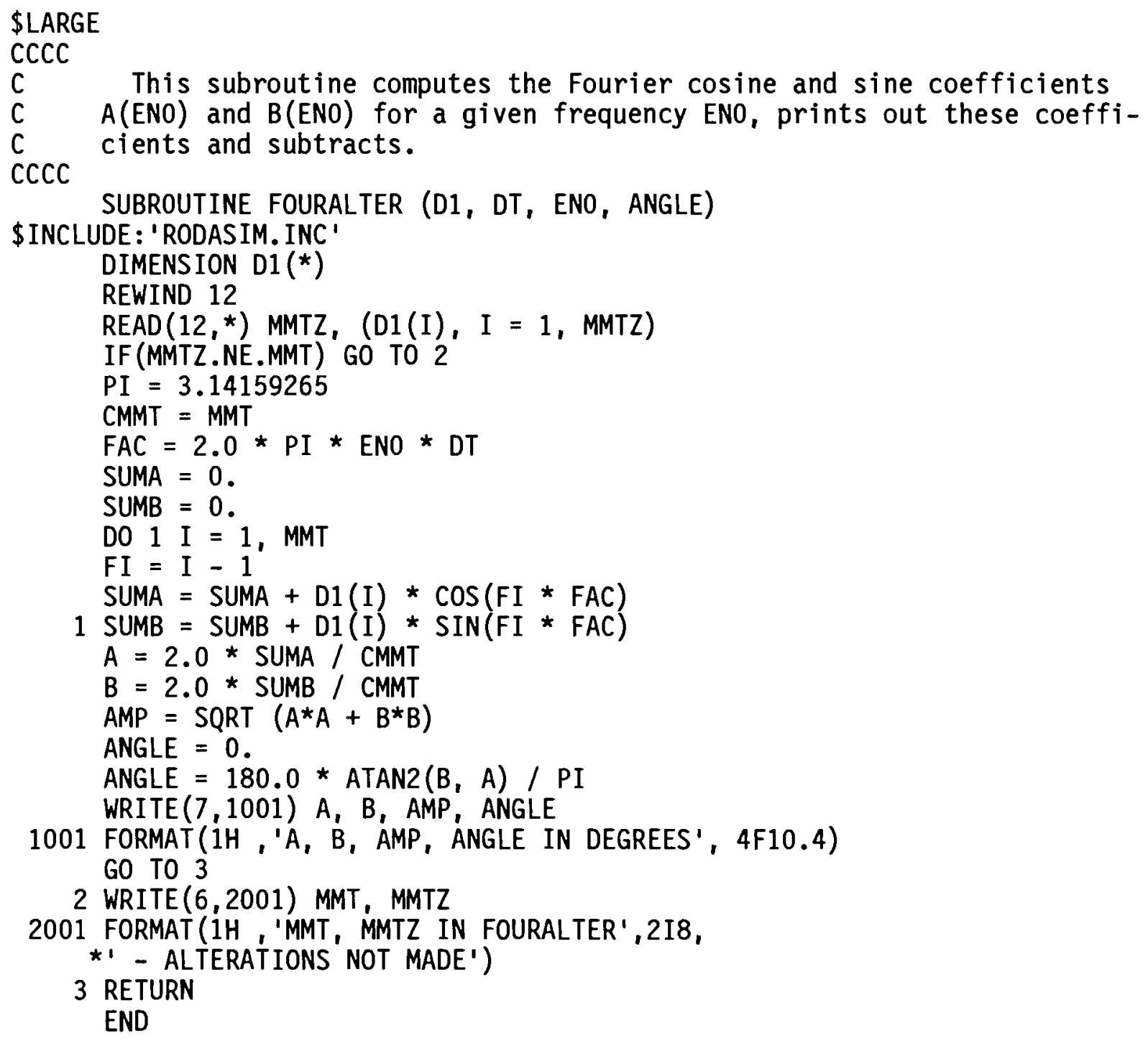




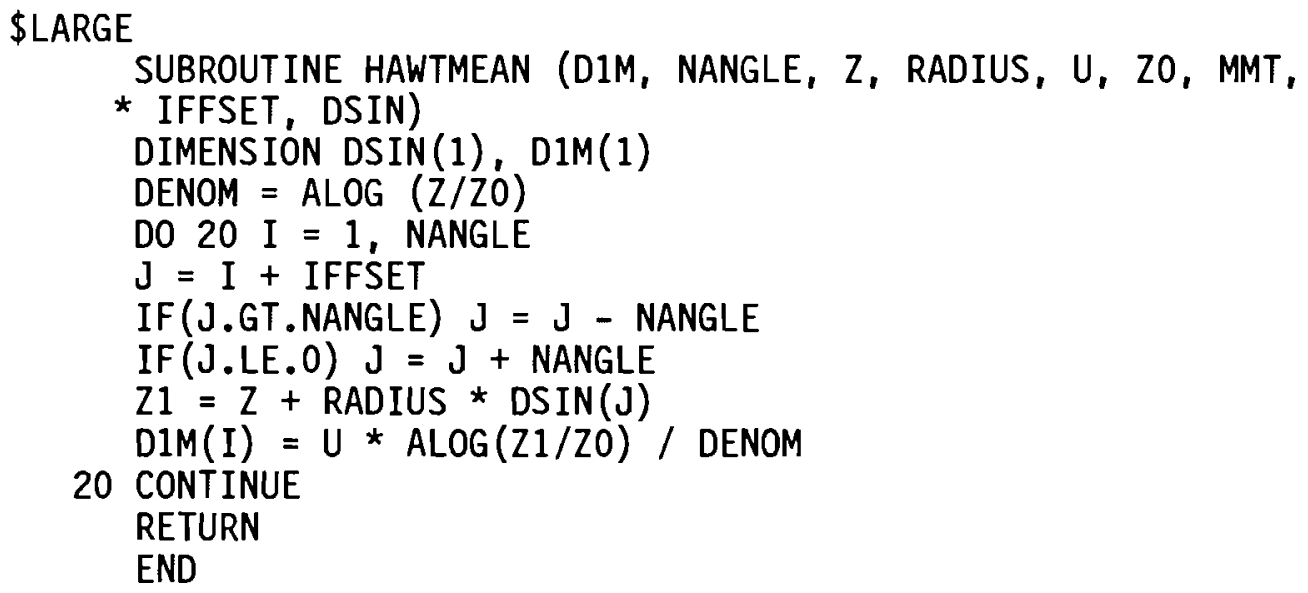




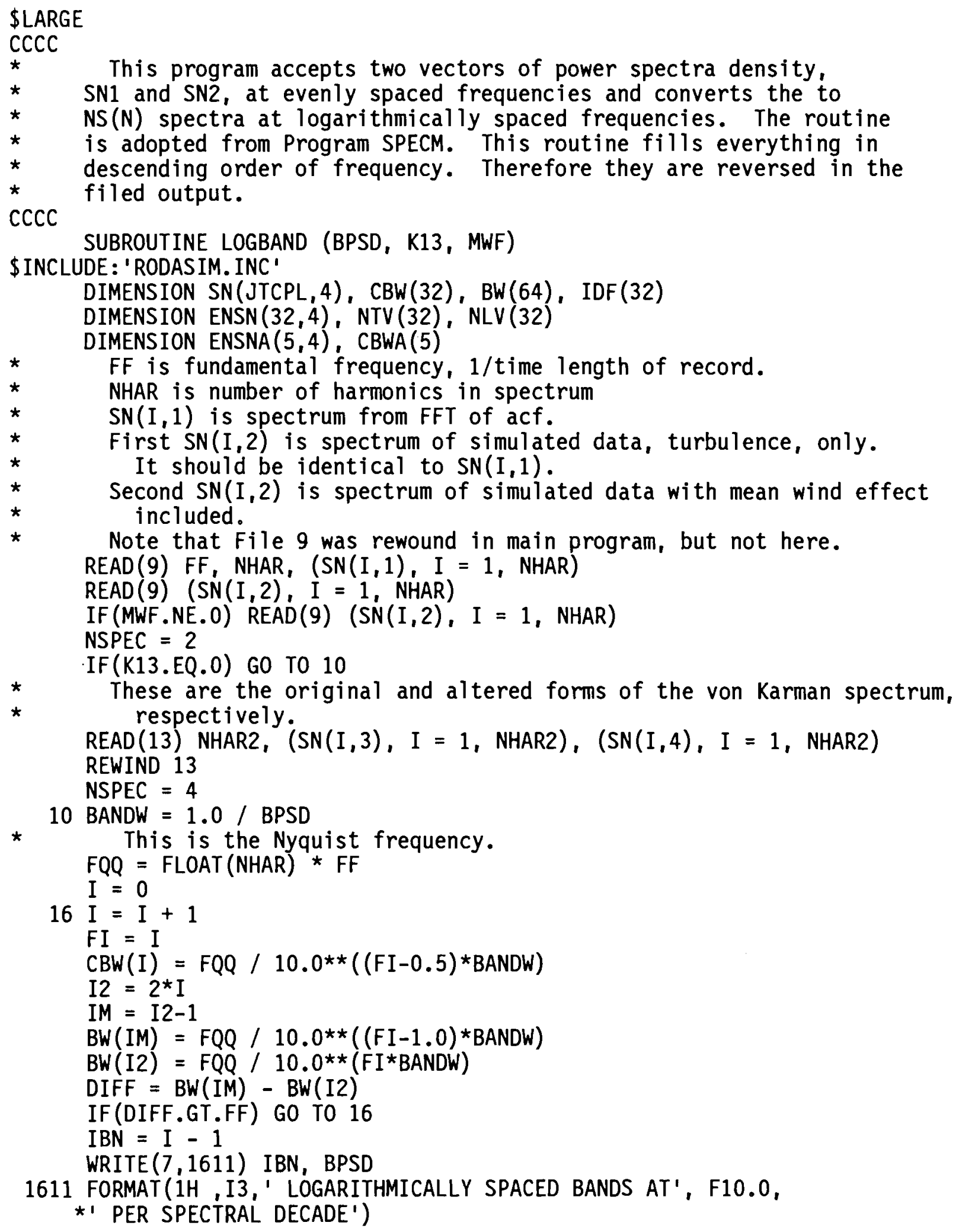




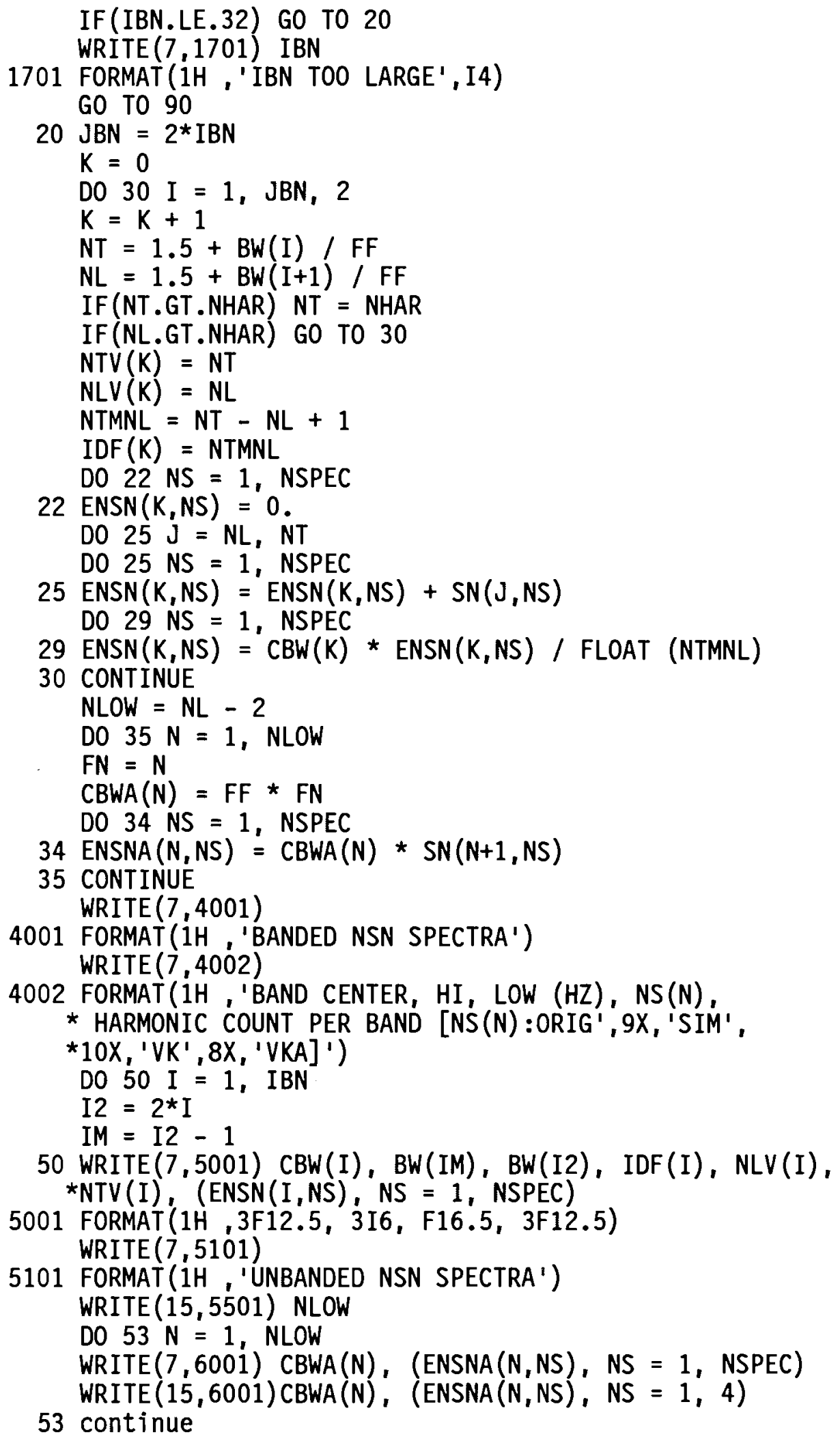


WRITE $(15,5501)$ IBN

5501 FORMAT $(1 \mathrm{H}, \mathrm{I10})$

DO 60 I = IBN, $1,-1$

$60 \operatorname{WRITE}(15,6001) \operatorname{CBW}(\mathrm{I}),(\operatorname{ENSN}(I, N S), N S=1,4)$

6001 FORMAT $(1 \mathrm{H}, 5 \mathrm{~F} 12.6)$

90 RETURN

END 


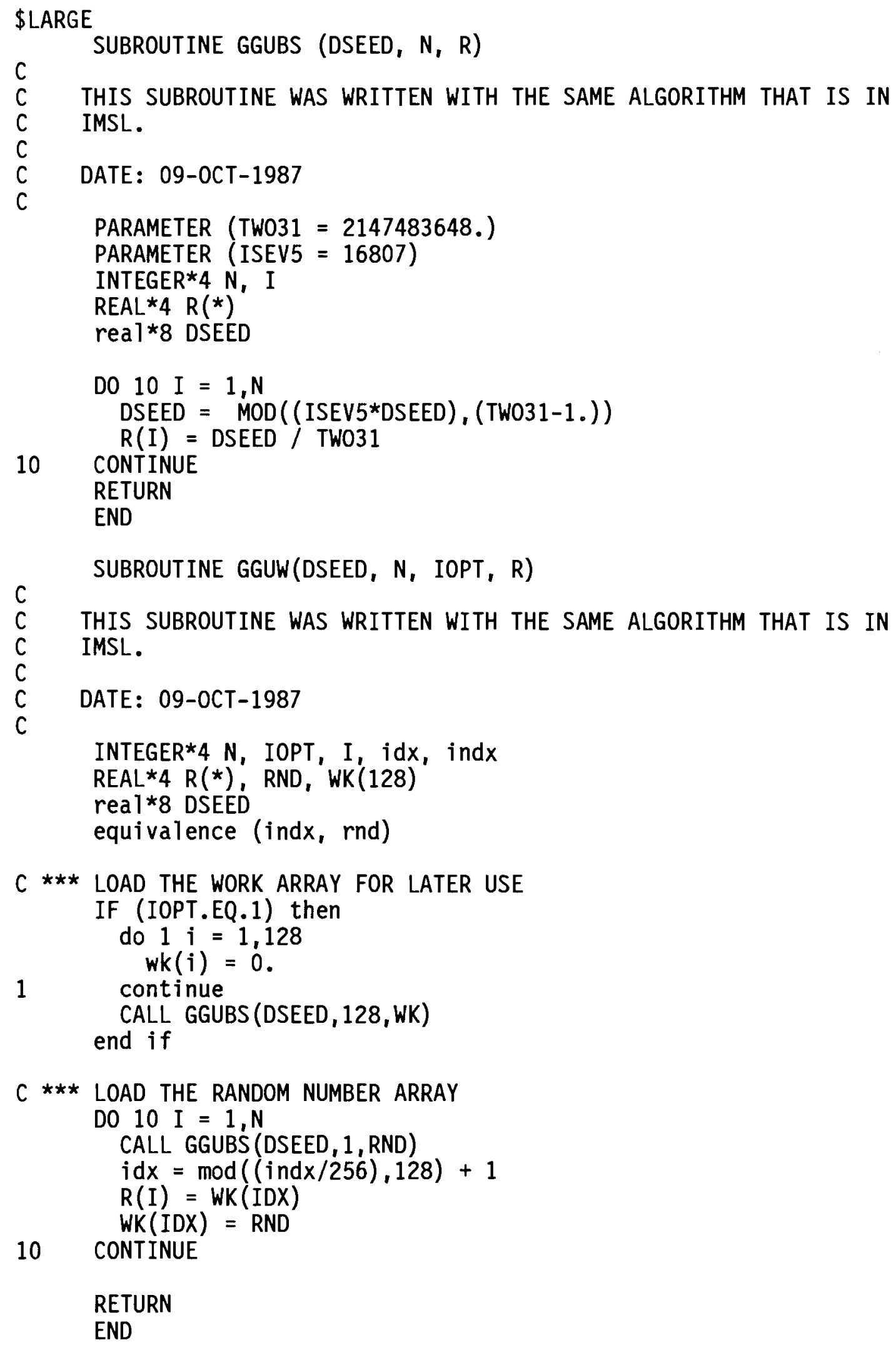


\$LARGE

SUBROUTINE RODAPRINT (LU, KP)

\$INCLUDE: 'RODASIM. INC'

COMMON DT, DTA, DTND, DTAND, EN1, EN1ND, EN2,

*EN2A, EN2ND, EN2AND, NANGLE, NANGLEA, RADIUS, ENO, $Z, U$,

*Z0, KSG, SIGU, SIGV, EL1, EL2, KNDOPT,

*KWINDOW, CHK, KMAX, NHAR, USTAR, ALFA, BETA, SIGU2,

* SIGV2, PVAR(7), PRMS(7), PVARVK(7)

IF(KP.NE.1) GO TO 40

WRITE (LU, 1001) RADIUS

1001 FORMAT(1H, 'RADIUS OF ROTATION',F6.1,

*' $\left.M^{\prime}\right)$

WRITE(LU, 1051) ENO

1051 FORMAT (1H, 'RATE OF ROTATION', F11.4,' HZ')

WRITE(LU, 1101) Z, Z0

1101 FORMAT(1H,'HUB HEIGHT',F14.1,' $\mathrm{M}^{\prime}, / 1 \mathrm{H}$, 'SURFACE

*ROUGHNESS LENGTH',F10.4,' $\mathrm{M}^{\prime}$ )

WRITE(LU, 1151) U

1151 FORMAT (1H , 'MEAN WIND SPEED',F10.2,' M/S')

WRITE(LU, 1201) SIGU, SIGV

1201 FORMAT( $1 \mathrm{H}$, 'TURBULENCE RMS VALUES',/1H, 5X, 'U-COMPONENT',

$\star F 10.3, ' \mathrm{M} / \mathrm{S}^{\prime}, / 1 \mathrm{H}, 5 \mathrm{X}, \mathrm{I}^{\prime} \mathrm{V}$-COMPONENT ', F10.3,' $\mathrm{M} / \mathrm{S}^{\prime}$ ) WRITE(LU, 1301) SIGU2, SIGV2

1301 FORMAT ( $1 \mathrm{H}$, 'TURBULENCE VARIANCES', $/ 1 \mathrm{H}, 5 \mathrm{X}$, 'U-COMPONENT', ${ }^{\star} F 10.3, '(M / S) * \star 2 ', / 1 H, 5 X, ' V$-COMPONENT',$F 10.3$, $\left.\star 1(M / S) * \star 2^{\prime}\right)$

WRITE(LU, 1401) USTAR

1401 FORMAT (1H ,'FRICTION VELOCITY',F9.3,' M/S') WRITE(LU, 1501) EL1, EL2

1501 FORMAT(1H,'TURBULENCE INTEGRAL LENGTH SCALES',

*/1H ,5X, 'LONGITUDINAL', F7.1,' $M$ ',

$\star / 1 H, 5 X,{ }^{\prime}$ LATERAL ',F7.1,' $\left.\mathrm{M}^{\prime}\right)$

WRITE (LU, 1601) MMT

1601 FORMAT (1H, 'NUMBER DATA TO BE SIMULATED', I5) WRITE(LU, 1701) DT

1701 FORMAT (1H, 'DISCRETIZATION INTERVAL ',F13.4,' SEC')

WRITE (LU, 1801) ILIAS

1801 FORMAT(1H,'ALIAS FACTOR 1, I5)

$D E G=360 . / F L O A T$ (NANGLE)

WRITE (LU, 1901) DEG

1901 FORMAT(1H, 'ANGULAR DISCRETIZATION INTERVAL', F7.1, *' DEGREES ')

IF(KNDOPT.EQ.0) WRITE(LU, 2001)

2001 FORMAT (1H , 'NANGLE WAS READ IN - DT WAS CALCULATED') IF (KNDOPT.NE.0) WRITE (LU,2101)

2101 FORMAT(1H ,'DT WAS READ IN - NANGLE WAS CALCULATED') WRITE(LU, 2201) ALFA, BETA

2201 FORMAT(1H ,'ALFA, BETA', 2F12.4)

WRITE(LU, 2301) KMAX, NHAR

2301 FORMAT (1H, 'LIMIT ON MEMBERS OF AUTOCORRELATION FUNCTION', $\star$ I $5, / 1 \mathrm{H}$, 'NUMBER OF HARMONICS IN SPECTRA', I19,/1H, 'This is

* also a comparison between number of harmonics in original 
* spectrum and reduced version.' ) WRITE (LU, 2401) EN1

2401 FORMAT (1H ,'FUNDAMENTAL FREQUENCY IS',F12.6,' HZ') WRITE $(L U, 2501)$ CHK

2501 FORMAT(/1H , 'MAX FINAL VALUE OF CORRELATION ACCEPTABLE WITHOUT

* WINDOWING', F8.5)

IF(LU.NE.7) GO TO 50

WRITE(LU, 3001)

3001 FORMAT (1H , 'DIFFERENT FORMS OF VARIABLES:',

$* / 1 \mathrm{H}, 5 \mathrm{X},{ }^{\prime}-$ original',

$* / 1 \mathrm{H}, 5 \mathrm{X},{ }^{-} \mathrm{A}-$ including extensions associated with alias

* removal ', /1H ,5X,' ND - dimensionless variable',

*/1h, 5X, 'AND - both of the above') WRITE $(L U, \overline{3} 101)$ DT, DTA, DTND, DTAND

3101 FORMAT (1H,'DISCRETIZATION INTERVAL - DT',

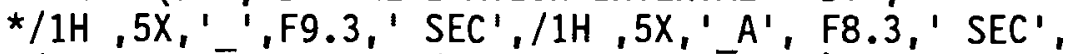

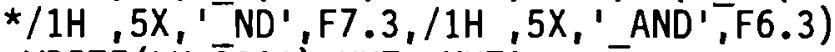
WRITE (LU, $\overline{3} 201)$ MMT, MMTA

3201 FORMAT (1H ,'NUMBER OF SIMULATED DATA - MMT',

$\left.* / 1 H, 5 X,{ }^{\prime}, 19, / 1 H, 5 X, A^{\prime}{ }^{\prime}, 18\right)$

WRITE (LU, $\overline{3} 301)$ EN1, EN1ND̄

3301 FORMAT (1H , 'FUNDAMENTAL FREQUENCY - EN1'/1H, 5X,

* ' ',F13.5,' HZ',/1H, 5X, '-ND',F11.5)

WRITE(LU, 3401)EN2, EN2A, EN2ND, EN2AND

3401 FORMAT (1H, 'NYQUIST FREQUENCY - EN2',

*/1H ,5X,' ',F13.5,' HZ',/1H, 5X, ' A',F12.5,' $\mathrm{HZ}^{\prime}$,

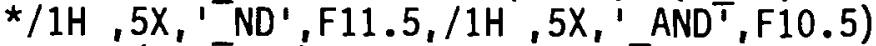

WRITE $(L U, \overline{3} 501)$ NANGLE, NANGLEA

3501 FORMAT (1H , 'NUMBER OF SAMPLING POSITIONS IN CIRCLE - NANGLE',

*/1H, 5X, ' ', I6, /1H, 5X,' $A^{\prime}$, I5)

IF (KP.EQ.1. $)$ GO TO 50

40 CONT INUE

IF (LU.EQ.7) WRITE $(7,4101)$

4101 FORMAT (1H , 'VARIANCES FOR FIRST HALF-P AND FOR 6P

* FROM 80-MEMBER SPECTRUM' $/ 1 \mathrm{H}, ' S(n) \mathrm{C},-(M / S) \star \star 2 ')$ $\operatorname{IF}(\operatorname{LU} . E Q .10)$ WRITE $(10,4111)$

4111 FORMAT (1H , 'VARIANCES FOR FIRST HALF-P AND FOR 6P

* FROM 80-MEMBER SPECTRUM' $/ 1 \mathrm{H}, ' S(n) c,-(M / S) \star \star 2 ')$ WRITE (LU, 4201) PVAR

4201 FORMAT (1H ,F10.4, F15.4, 5F10.4) WRITE $(L U, 4301)$ PRMS

4301 FORMAT (1H ,'RMS'/1H ,F10.4, F15.4, 5F10.4)

WRITE (LU, 4311)

4311 FORMAT( $1 \mathrm{H}$, 'SAME VARIANCES COMPUTED BY INTEGRATING THE

* VON KARMAN SPECTRUM, Svk $\left.(n) c a^{\prime}\right)$

WRITE $(L U, 4201)$ PVARVK

50 RETURN

END 


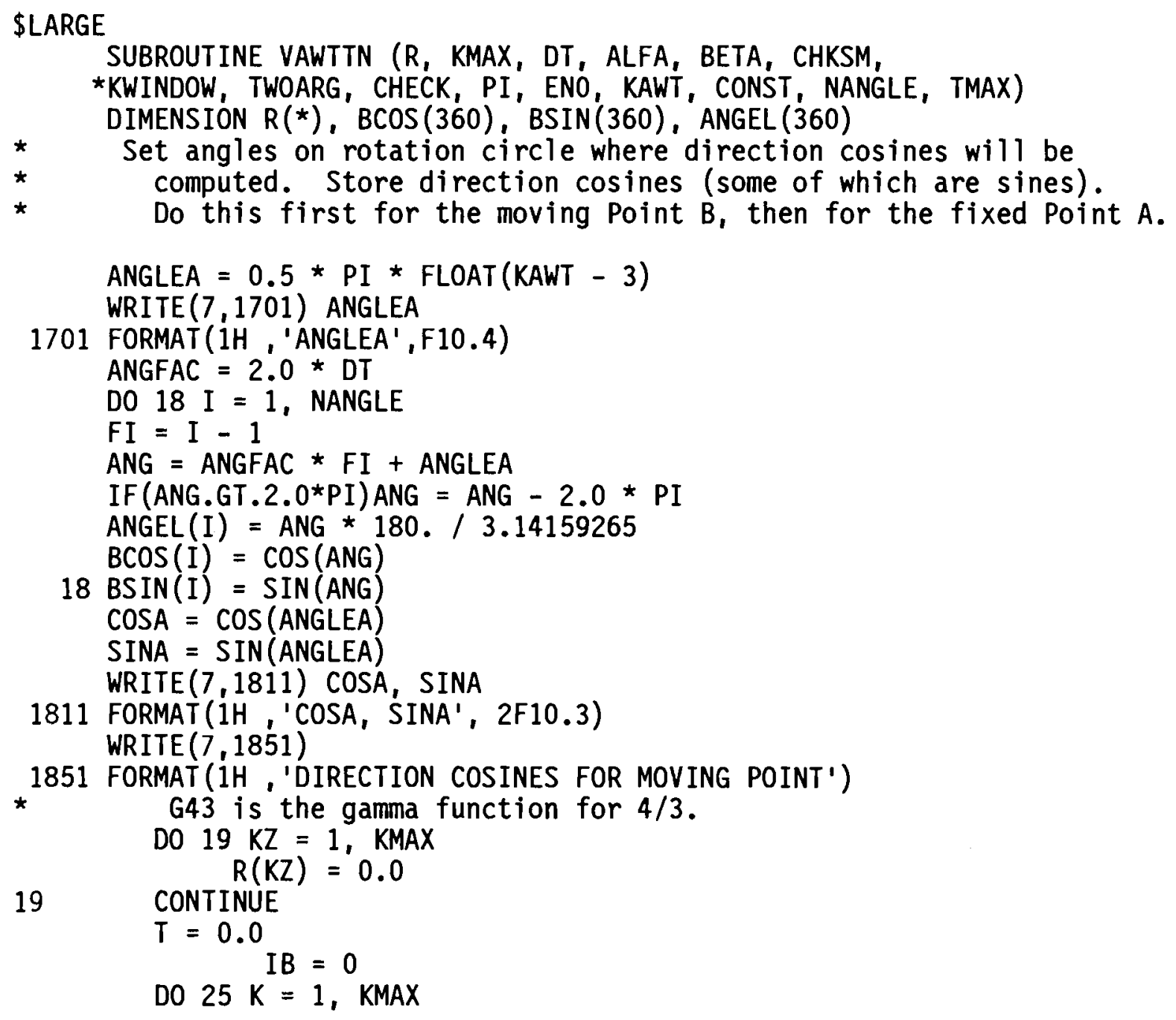

$T$ is the dimensionless time arguement for the autocorrelation function.

* The following is derived on pages 30 and 31 of the notebook lableled

* "Rotational Spectrum Problem" and written by David Powell.

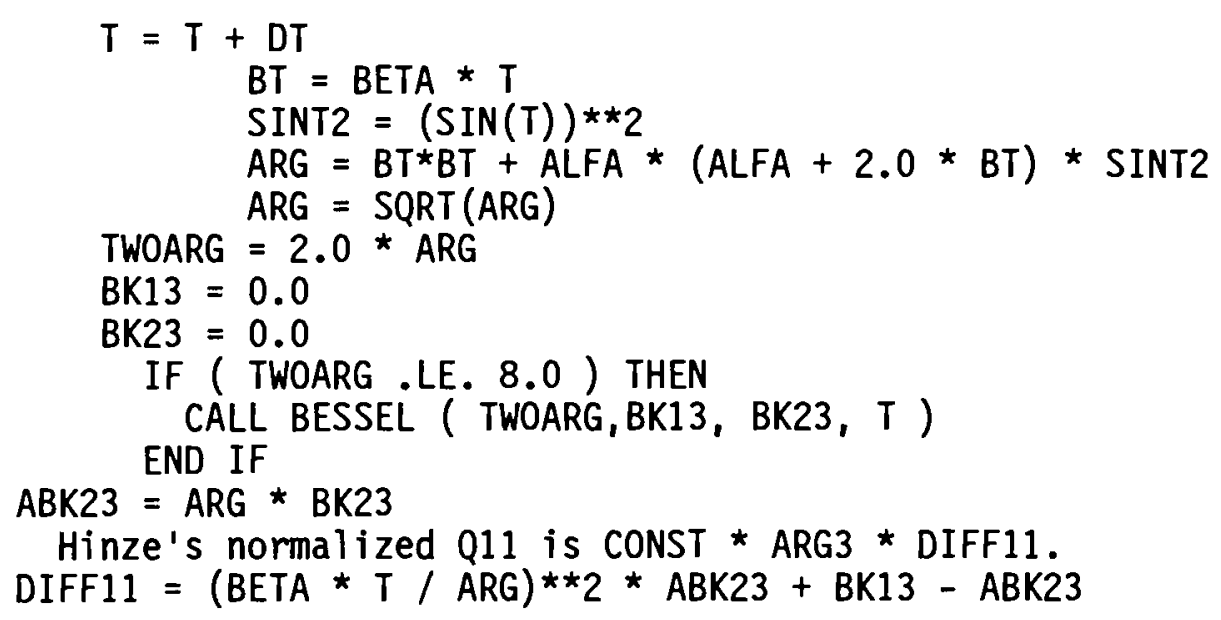




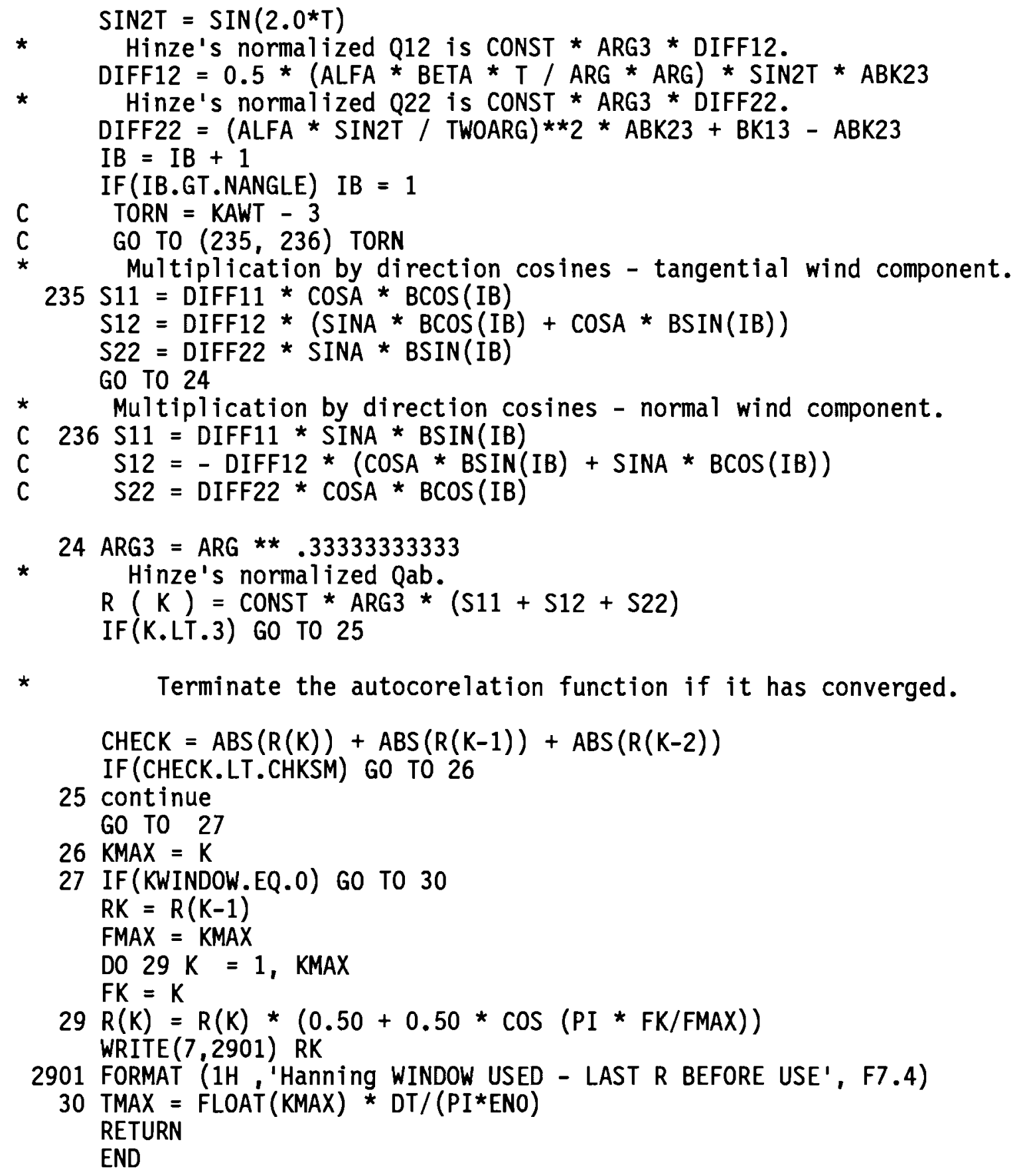


\$LARGE

SUBROUTINE VAWTTNMEAN (D1M, NANGLE, RADIUS, U, MMT, IFFSET, ${ }^{\star D C O S}$, DSIN, KAWT, ENO)

DIMENSION DIM $(*), \operatorname{DCOS}(*), \operatorname{DSIN}(*)$

$P I=3.141592654$

$K 3=K A W T-3$

GO TO $(10,30) \mathrm{K} 3$

10 SPEED $=2.0$ * $\mathrm{PI}$ * ENO * RADIUS

DO $20 \mathrm{I}=1$, NANGLE

$\mathrm{J}=\mathrm{I}+$ IFFSET

IF (J.GT.NANGLE) $\mathrm{J}=\mathrm{J}-$ NANGLE

IF (J.LE.0) $\mathrm{J}=\mathrm{J}+$ NANGLE

$\operatorname{DIM}(\mathrm{I})=U * \operatorname{DSIN}(\mathrm{J})+$ SPEED

20 CONTINUE

GO TO 50

30 DO $40 \mathrm{I}=1$, NANGLE

$\mathrm{J}=\mathrm{I}+$ IFFSET

IF(J.GT.NANGLE) $\mathrm{J}=\mathrm{J}-$ NANGLE

IF (J.LE.0) $\mathrm{J}=\mathrm{J}+$ NANGLE

$\operatorname{DIM}(\mathrm{I})=\mathrm{U} * \mathrm{DCOS}(\mathrm{J})$

40 CONTINUE

50 RETURN

END 


\section{\$LARGE}

SUBROUTINE VAWTUV ( $R$, KMAX, DT, ALFA, BETA, CHKSM, KWINDOW,

*TWOARG, CHECK, PI, ENO, KAWT, CONST, TMAX)

INTEGER UORV

DIMENSION $R(*)$

UORV $=$ KAWT -1

DO $10 \mathrm{KZ}=1$, $\mathrm{KMAX}$

$R(K Z)=0.0$

10 CONTINUE

$T=0.0$

DO $25 \mathrm{~K}=1$, KMAX

* $\quad T$ is the dimensionless time arguement for the autocorrelation function.

* The following is derived on pages 30 and 31 of the notebook lableled

* "Rotational Spectrum Problem" and written by David Powell.

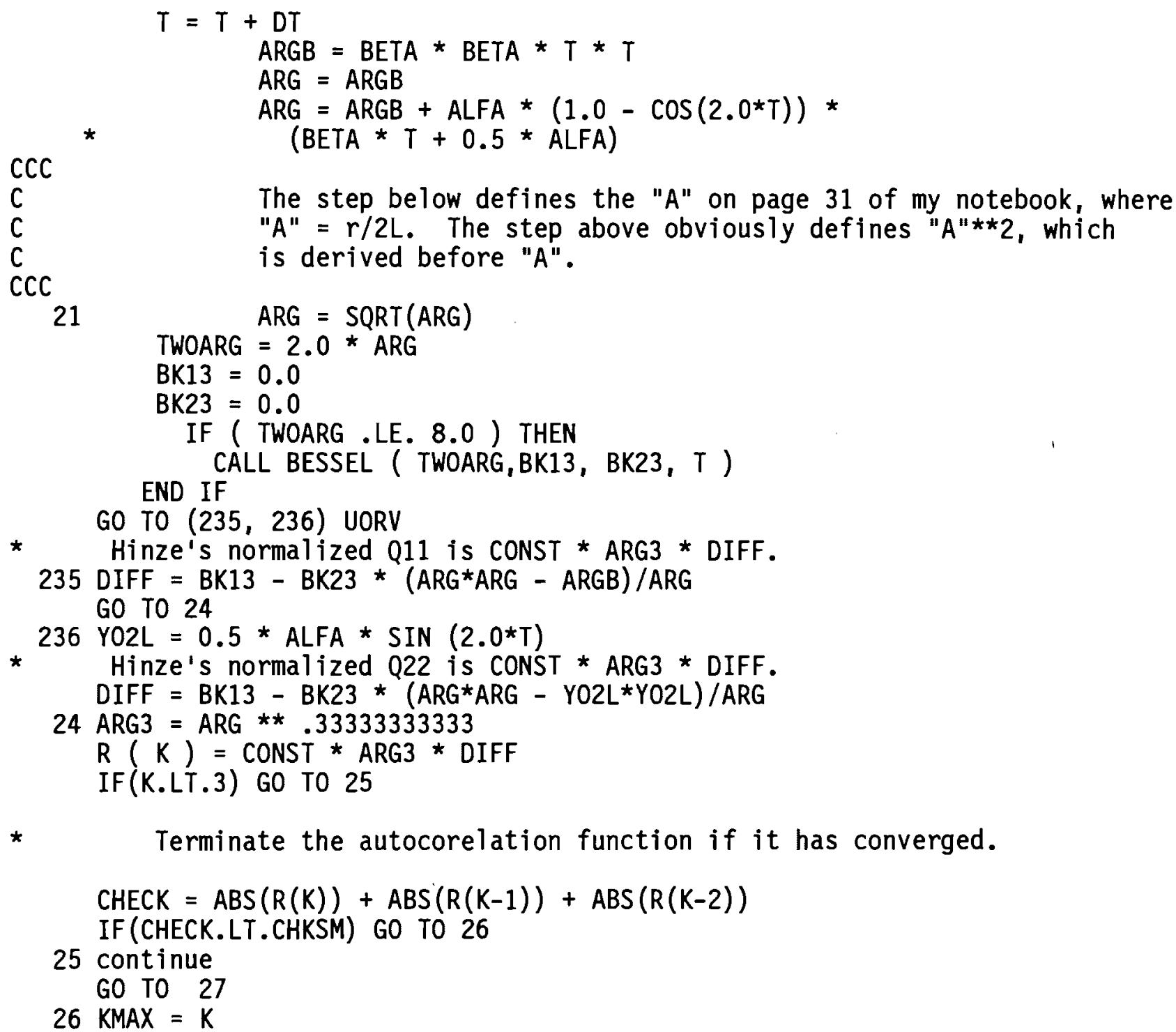




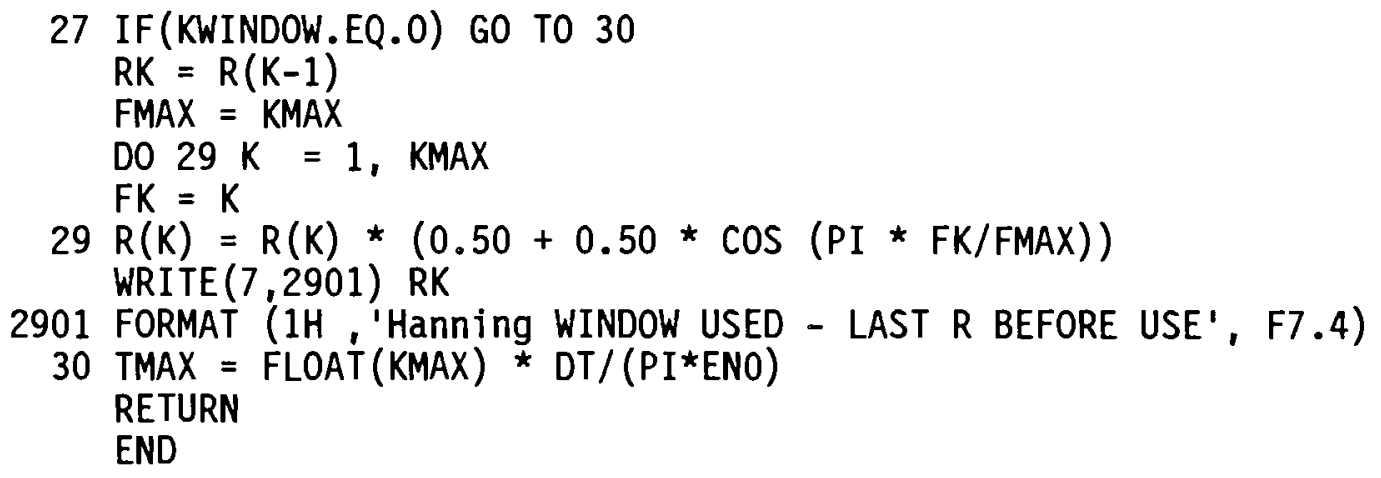


PARAMETER (NEXP $=11$ )

PARAMETER (MMT $=2 * *$ NEXP)

PARAMETER (M2MT $=2 *$ MMT)

PARAMETER (MMT2 $=$ MMT $/ 2$ )

PARAMETER (ILIAS $=4$ )

PARAMETER (MMTA $=$ ILIAS * MMT)

PARAMETER (MMTA2 $=$ MMTA $/ 2)$

PARAMETER (JTCPL $=1+$ MMT2) 



\section{APPENDIX B}

SELECTED PORTIONS OF REPORT PNL-5857, DEFINING PARAMETERS AND VARIABLES IN THE PNL THEORETICAL TURBULENCE SIMULATION CODE 


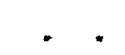


APPENDIX B

SELECTED PORTIONS OF REPORT PNL-5857, DEFINING PARAMETERS AND VARIABLES IN THE PNL THEORETICAL TURBULENCE SIMULATION CODE

Here we reproduce Chapter 3 , the glossary given in Appendix $A$, and Appendix D from a report by David Powell and James Conne11, A Model for Simulating Rotational Data for Wind Turbine Applications (PNL-5857, published at the Pacific Northwest Laboratory, Richland, Washington, in April 1986). The report documents the model RODASIM1. The table of contents from the document is included here to illustrate the other material discussed in the report. 
PNL -5857

UC -60

\section{A MODEL FOR SIMULATING \\ ROTATIONAL DATA FOR WIND \\ TURBINE APPLICATIONS}

D. C. Powell

J. R. Connell

Apri 11986

Prepared for the U.S. Department of Energy under Contract DE-AC06-76RLO 1830

Pacific Northwest Laboratory Richland, Washington 99352

B. 2 
CONTENTS

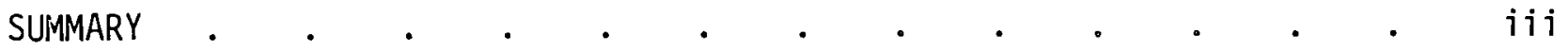

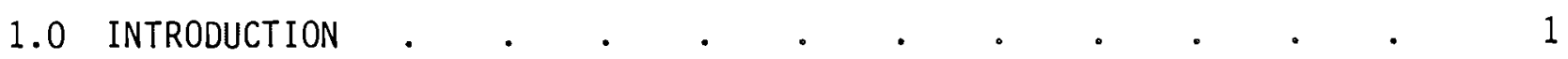

2.0 THE BASIC SPECTRAL THEORY..$\quad$. . . . . . . . . . . . 3

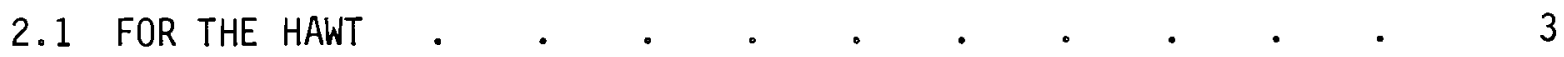

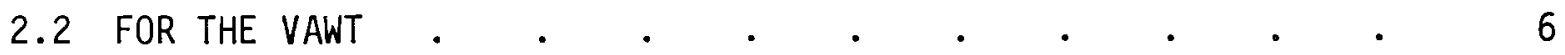

2.3 TURBULENCE SIMULATION

2.3.1 Simulation of Mean Wind Effects and Adding to
Turbulence . . . . . . . . . . . 13

3.0 DESCRIPTION OF PROGRAM AiVD USER'S GUIDE . . . . . . . . . 17

3.1 PARAMETERS TO BE READ IN . . . . . . . . . . . 17

3.1 .1 First Record . . . . . . . . . . . 17

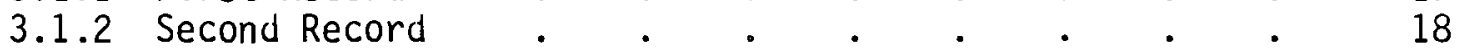

3.1 .3 Third Record. $. \quad . \quad . \quad . \quad . \quad . \quad . \quad . \quad . \quad . \quad . \quad 21$

3.1 .4 Fourth Record . . . . . . . . . . . 24

3.1 .5 Fifth Record . . . . . . . . . . . . . 25

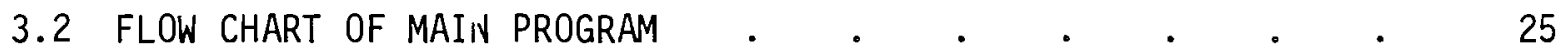

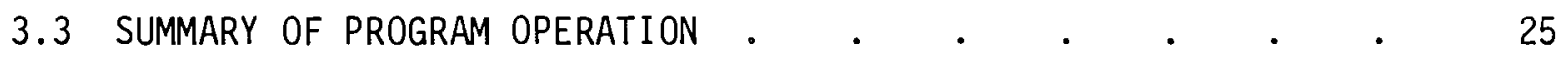

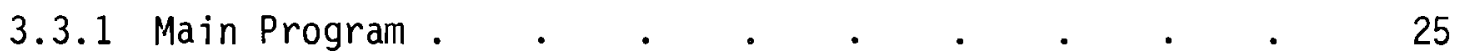

3.3.2 Specific Subroutine Operations $\quad . \quad$. $\quad . \quad$. $\quad . \quad$. 32

3.4 ON BRACKETING THE ANSWERS BY ENVELOPING INPUT PARAMETERS • 35

4.0 MODELING OF SPECTRAL ANALYSIS OBTAINED BY ANALYSIS OF FIELD

TEST DATA .

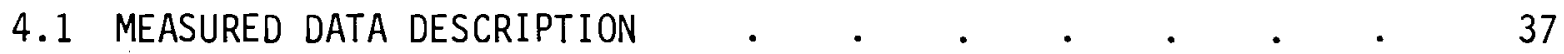

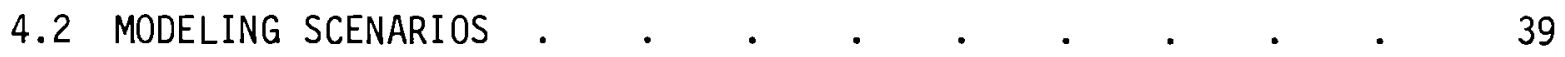

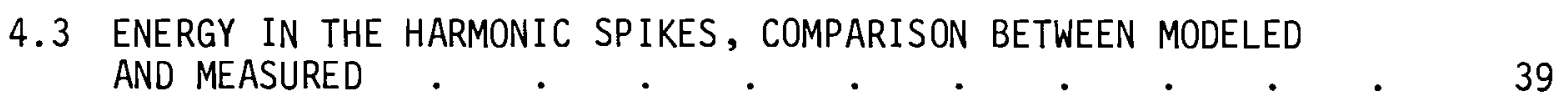

4.3.1 First Harmonic . . . . . . . . . . . . 40

4.3.2 Second Harmonic . . . . . . . . . . . . . 40

4.3.3 Higher Harmonics . . . . . . . . . . . . 41

4.4 SPECTRAL PLOTS, MODELED VS. MEASURED $\quad$ • . . . . . . 43

5.0 CONCLUSIONS AND RECOMMENDATIONS . . . . . . . . . . . $\quad . \quad 45$

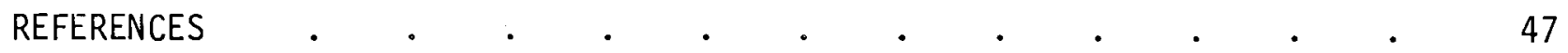

APPENDIX A - LISTINGS OF THE PROGRAM CODE, A GLOSSARY, AND A TEST CASE. A-1

APPENDIX B - COMPARISOIN OF VON KARMAN SPECTRA WITH CORRESPONDING ROTATIONAL SPECTRA WHEN ROTATIONAL RATE AND ROTATION RADIUS OF THE LATTER APPROACH ZERO . . . . . . . B-1

APPENDIX C - SOME BASIC TURBULENCE DEFINITIONS AND LENGTH SCALE CONSIDERATIONS $. \quad . \quad . \quad . \quad . \quad . \quad . \quad . \quad . \quad . \quad C-1$

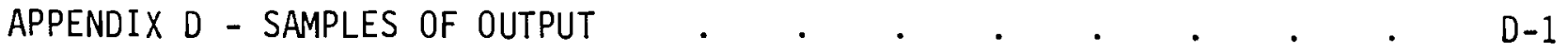




\subsection{DESCRIPTION OF PROGRAM AND USER'S GUIDE}

The computer program is executed by submitting a prepared command file. This command file specifies numerous variables and options set by the user. The variables include both wind turbine and meteorological parameters. The read-in parameters are defined and discussed in the first section. The following section summarizes the operation of the program. The main program is treated first, and then the subroutines. Appendix A lists the code and provides a more complete glossary of program variables.

\subsection{PARAMETERS TO BE READ IN}

The parameters to be read in are organized in five groups, referred to as records. Each parameter has several optional values, described below. Units of the input physical parameters are mks.

\subsubsection{First Record}

KAWT: The option KAWT directs which of the following simulations will be performed:

$$
\begin{aligned}
\text { KAWT }= & \text { 1: } \text { HAWT } u \\
& \text { 2: VAWT } u \\
& \text { 3: VAWT } v \\
& \text { 4: } \text { VAWT tangential (VAWT } t \text { ) } \\
& \text { 5: VAWT radial (VAWT } r \text { ). }
\end{aligned}
$$

MWIivD: The program has the option of simulating either the total wind component, including the mean wind effect, or turbulence only, as determined by the value of MWIND.

$$
\begin{aligned}
\text { MWIND }= & 0: \text { simulate turbulence only } \\
& 1: \text { simulate turbulence and mean wind effect. }
\end{aligned}
$$

DELAY: This is the phase delay, in degrees, imposed on the mean wind effect (mwe), modeled at the rotational frequency $1 P$. If DELAY is zero, the program is written so that the $1 P$ harmonics of mwe and turbulence will be in phase. For any other value of DELAY, the mwe is delayed by that angle. Thus, the mwe DELAY would be incorporated as follows 


$$
U(t, \text { mwe })=\phi(\omega \times t-\pi \times \text { DELAY/180.) }
$$

where $\phi$ is either a sine or a cosine function.

One possible treatment for DELAY is to treat it as a random variable of even distribution. In this case, several runs could be made so that the statistical nature of the interrelation of mean flow and turbulence could be sampled. Another plausible scenario would be to read DELAY in as zero. This is a worst-case scenario for the HAWT $u$-component and the VAWT tangential component simulations, making the mwe and turbulence $1 \mathrm{P}$ effects occur in phase. A lesser variance is produced for the radial simulations when DELAY equals zero, since the radial turbulence is 90 degrees out of phase with the tangential turbulence, and therefore 90 degrees out of phase with the mean wind effect.

\subsubsection{Second Record}

The second record consists of physical parameters and related options.

RADIUS: This specifies the radius of rotation to be simulated.

ENO: This is the rate of rotation, in $\mathrm{Hz}$, to be simulated.

Z: This is hub height.

$U:$ This is the mean wind speed at height $Z$. $U(Z)$ will necessarily take on a value between the machine's cut-in and cut-out wind speeds.

Z0: 20 is a length parameter invented exclusively for meteorological reasons. This is the surface roughness length. Surface roughness consists physically of such things as grasses, bushes, trees, buildings, and terrain features. The rougher the surface, the larger the value of $z 0$. It corresponds to no single factor that can be measured in nature. Since it cannot be measured, a value must be selected from a table of surface roughness values, such as those given by Chan et a1. (1983) and by Panofsky and Dutton (1984). (The first is an engineering report, the second a meteorological book.) For a typical rural setting, gently rolling land with crops and a few trees, setting a $Z 0$ value of $0.1 \mathrm{~m}$ is appropriate. The value of 20 affects only the turbulence variance, not the shape of the spectrum. 
KSG: This option determines whether the computer or the user provides values for SIGU and SIGV, the turbulence rms of the $u$ - and v-components, respectively.

KSG $=0$ : The program calculates SIGU and SIGV.

1: The program accepts values of SIGU and SIGV as the next numbers read in.

There are uncertainties and inconsistencies to be recognized whether SIGU and SIGV are calculated or read in. The uncertainties arise from the fact that not all the physics necessary to model the low frequency part of the $u$ and $v$ turbulence spectra are known. Therefore, when these parameters are estimated using existing models, measured and modeled values may differ significantly. Since the rms is the square root of the frequency integral of the spectrum, these uncertainties are part of the calculated rms. In addition and for the same reason, a measured value may not be typical for the site at which it was measured.

The inconsistency comes from the fact that the von Karman theory on which this model is based assumes that SIGU equals SIGV. Actually, the von Karman theory is based on the theory of isotropic turbulence, which assumes that all variances of turbulence-directional components are equal. In the atmosphere, this is not true. It is more reasonable to assume that SIGV is about 0.8 SIGU. But if such values are used in the program, the high frequency portions of the spectra, which are well-known, will be out of the proper relationship to each other. This higher frequency range of the spectrum is where the harmonic spikes occur.

If the program is allowed to calculate SIGU and SIGV, it takes a conservative approach by setting them equal to each other. Thus, SIGV is set at the higher value appropriate for SIGU.

If measured values are supplied by the user, the values should be based on Eulerian data samples at least 10 minutes long and sampled at a discretization rate of no less than 5 samples per second. Otherwise the calculated variance will be too low. It can be corrected, but the correction depends on the current height and mean wind speed and requires good understanding of meteorological dimensionless turbulence spectra. 
KEL: This option can have the following values:

$$
\begin{aligned}
K E L & =0: \\
& =1: \text { Program calculates EL1 and EL2. } \\
& \text { read in. }
\end{aligned}
$$

The parameters EL1 and EL2 are the integral scales of u-component turbulence in the longitudinal and lateral directions, $L_{x}$ and $L_{y}$, respectively. Numerically, they are of more uncertain evaluation than the rms values. These integral scales are more fully defined and described in Appendix $C$.

The character of the rotational spectra may be adjusted by manipulating values of EL1 and EL2 (Powell et al. 1985). In general, increasing $L_{y}$ decreases the portion of the energy transferred to the spikes and decreases the peakedness. Increasing $L_{x}$ increases the peakedness without significantly affecting the amount of energy transferred to the peaks. Therefore, increasing both length scales proportionally lowers the amount of energy transferred into the spikes without significantly changing the peakedness.

This completes the information on the second record. A simple procedure for determining values for this record is as follows:

Set RADIUS, ENO, and $Z$ according to the machine specifications.

Set $U$ at the assumed mean wind speed.

Set 20 at 0.1 if terrain and building feature are of "average rural roughness." Make comparisons by setting 20 at 0.3 and at 1.0 if greater roughness is estimated; make comparisons by setting 20 at 0.03 and 0.01 if less roughness is estimated. Obtaining a table of surface roughness values will help in estimating 20 . Because individual runs with this model are very cheap, it is economical to try several alternatives to achieve the greatest accuracy.

For HAWT analysis, set KSG and KEL at zero.

For VAWT analysis, set KSG at zero and KEL at 1 . Then set EL1 and EL2 at about $3.3 \mathrm{Z}$.

Remember that all units are mks. 


\subsubsection{Third Record}

The parameters of the third read-in record are more manipulable. Before choosing values, the user must decide how many data he wants to simulate and at what discretization interval. The discretization interval is most easily specified indirectly, by specifying the number of samples per revolution. The following suggestions are made:

KNDOPT: This is an option that allows the user to specify the discretization interval either in angular units or in seconds.

$$
\begin{aligned}
& \text { KNDOPT = 0: This is the easiest option, because the program rather } \\
& \text { than the user makes the calculations. }
\end{aligned}
$$

KNDOPT must be set at zero if MWIND does not equal zero. That is, if the nwe is to be simulated, the model requires an integral number of samples about the rotational circle, specified by the integer NANGLE.

$$
\begin{aligned}
& \text { KNDOPT }=1: \text { Discretization interval (DT) is read in directly. If } \\
& \text { this option is used, DT should be no greater than } \\
& \\
& 1.0 /(12 . \star \text { ENO }) .
\end{aligned}
$$

NANGLE: This is the number of sectors the sampling (discretization) divides the rotational circle into. Note that NANGLE is an integer. The minimum allowable value of NANGLE is twice the number of harmonics the analyst wishes to model, which would be at least four or five. Therefore, NANGLE must be at least eight or ten. Actually, a value of twelve or greater is recommended. If the value is twelve, sampling positions 30 degrees apart are simulated. The discretization interval in seconds (DT) is calculated from NANGLE and ENO. That is, DT equals $1 /$ (NANGLE $\times$ ENO). NANGLE is used directly in the calculation of the autocorrelation function only if KAWT is four or five, i.e., if the simulation is of either the VAWT tangential component or the VAWT radial component. NAivGLE is used only if KNDOPT equals zero.

DT: DT is the discretization, or sampling, interval in seconds. A read-in value of DT is used only if KNDOPT equals one. If KNDOPT equals zero, NANGLE is used. 
MMT: This is the number of simulated data. It must be $2^{N}$, where $N$ is an integer. This is because the FFT method cannot handle any number of data other than $2^{N}$. A problem arises because the number of rotational cycles simulated is more likely to be fractional than integral. Thus, when the spectrum of these data is computed, the energy that physically belongs to certain frequencies is diffused upward and downward among all frequencies. However, if enough rotational cycles are simulated, the fraction of energy diffused out of the $1 P$ rotational band by this mathematical artifice will be small. Twenty cycles seem to be sufficient for this purpose. Therefore, we recommend that the product (MMT $\times$ DT $\times$ ENO), or, equivalently, the quotient MMT/NANGLE, should at least equal 20. Thus, MMT must be greater than 20/(DT $\times$ ENO) or greater than $20 \times$ NANGLE. The program requires the user to perform these calculations.

There are other considerations in setting MMT. Usually the spectrum $S(n)$ should be calculated to a minimum frequency on the order of $0.01 \mathrm{~Hz}$ to adequately model the low frequency part of the spectrum. To do so requires that MMT be no less than the order of (100/DT).

A minimum value of 1024 is recommended for MMT (these considerations may indicate the need for a higher minimum). The speed of the model means that the greater economy resulting from selecting smaller values is not important. In addition, the product MMT x ILIAS, the next parameter, must not exceed 16384 .

ILIAS: This parameter removes the high-frequency part of the spectrum calculated by Fourier transform of the autocorrelation function (acf). The low frequency portion of the spectrum remaining equals 1/ILIAS. Thus:

ILIAS = 1: none of the spectrum is removed. The high-frequency end will be severely aliased.

$=2:$ the upper half of the spectrum is removed, leaving the lower frequency half.

$=4:$ three-fourths of the spectrum is removed.

A value of 4 is recommended for ILIAS. The program will accordingly use a discretization interval DTA one-fourth of the original and will allow calculation of an acf four times as long as the maximum allowance specification. After the 
spectral transform of this acf has been calculated, three-fourths of it will be discarded and the relatively unaliased remainder will be used for data simulation.

KWINDOW: This is an option allowing the use of the Hamming window (Blackman and Tukey 1958) to taper the end of the autocorrelation function. The tapered autocorrelation function is given by:

$$
\begin{aligned}
R(t) \text { tapered } & =0.5 R(t)+0.5 R(t) \cos (\pi t / T), t \leq T, \\
& =0, t>T .
\end{aligned}
$$

$T$ is the time length of the function at the point where it converges according to the convergence criterion $\mathrm{CHK}$, the next parameter read in. If this criterion is not met, $T$ is the maximum time allowed for the acf. The limit on the number of members of $R(t)$ is (MMT $\times$ ILIAS/2). Therefore, the limit on $T$ is $(D T \times$ MMT $\times$ ILIAS/2). The algorithm uses the value of CHK such that the acf is deemed convergent when the the sum of the absolute values of the last three computed values of the function does not exceed $3 \times$ CHK. KWINDOW values are as follows:

$$
\begin{aligned}
\text { KWINDOW }=0: \text { Hanning window is not used. } \\
=1: \text { Hanning window is used whether acf was terminated by } \\
\text { the convergence criterion or not. Otherwise the } \\
\text { spectral transform may have a "beard" (a rapid fre- } \\
\text { quency oscillation in the spectrum). }
\end{aligned}
$$

CHK: This is the convergence criterion discussed above. A reasonable value range for $\mathrm{CHK}$ is 0.001 to 0.01 .

NP: This is the number of degrees of freedom used in the impulse response function when the simulated data are calculated by the convolution of Gaussian white noise with an impulse response function. NP may not exceed MMT/2. It may very well be about one-tenth that amount. As will be explained in Section 3.1.5, the method of calculation using Gaussian white noise is one of two options for calculating the final simulated data. Since the other option, based on harmonic analysis, is the preferred one, we have had little experience setting NP. When the other option is used, NP is ignored. 
This completes the information on the third record. A reasonable set of values would be:

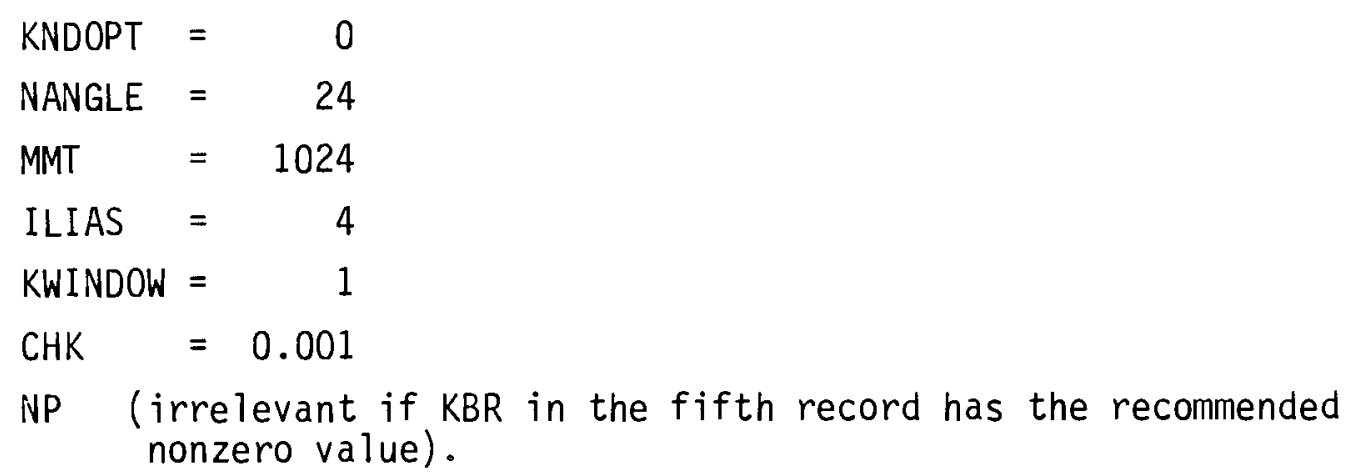

Such a simulation requires about 20 to 45 seconds on the VAX 11/780, if an executable image of the code already exists.

\subsubsection{Fourth Record}

All of the options on this record govern writing to output files that are suitable for plotting by some other program. When they are set at any value other than zero, the specified task is done. Normally K8 and K14 are not used.

K8: Write the entire calculated impulse response function to disk.

K9: Write the following $S(n)$ spectra to disk:

* the FFT transform of the autocorrelation function

* the spectrum calculated from the simulated data.

K11: Write the $S(n)$ from cosine integration of the autocorrelation function to disk.

K12: Write the simulated data to disk.

K13: Write both the original and the altered von Karman $S(n)$ spectra to disk. (These alternatives will be explained below.)

K14: Write the complex Fourier coefficients of the transform of simulated data to disk.

K15: Calculate the logarithmically banded $n S(n)$ spectrum of simulated data and write it to disk, preceded by the unbanded $n S(n)$ values for the lowest three frequenies. (Banding is a smoothing procedure.) 


\subsubsection{Fifth Record}

The last read-in record consists of further options.

KSERIAL: This is a five-character alphameric array used for naming a run.

KBR: This option governs the analytical method by which the simulated data are computed.

$$
\begin{aligned}
\mathrm{KBR} & =0: \begin{array}{l}
\text { Use convolution integral of Gaussian white noise and } \\
\text { impulse response function. }
\end{array} \\
& =1: \begin{array}{l}
\text { Use spectrum for Fourier amplitudes and use random number } \\
\text { generator to compute phases. This method is recommended. }
\end{array}
\end{aligned}
$$

KXIFPR, KVKPR: These are printing options for the unbanded estimates of the spectrum, as calculated by transformation of the autocorrelation function and for the von Karman spectrum, respectively. These spectra are not those of 80 frequencies from $0.1 \mathrm{P}$ to $8 \mathrm{P}$. Rather, these are the $2^{\mathrm{N}}$ harmonic estimates, where $N$ may be 10 or 11 . Therefore, the printouts can be quite large. Usually there is no need of them, as is explained below. Any nonzero value for these options results in printing.

\subsection{FLOW CHART OF MAIN PROGRAM}

Figure 6 is a flow chart of the main program. Subroutines are identified by names written in capital letters, in boxes having probes extending to other boxes. The abbreviation WDO stands for "written to disk by option." The option is usually one of the $K^{*}$ variables, such as K9. If the variable does not equal zero, the writing occurs.

\subsection{SUMMARY OF PROGRAM OPERATION}

Operation of the main program is summarized first, followed by the operations of specific routines.

\subsubsection{Main Program}

The user initiates the program by entering the parameters and variables as described in Section 3.1. The program then calculates autocorrelation functions, spectra and harmonic spike variances, and produces simulated data.

$$
\text { B. } 12
$$




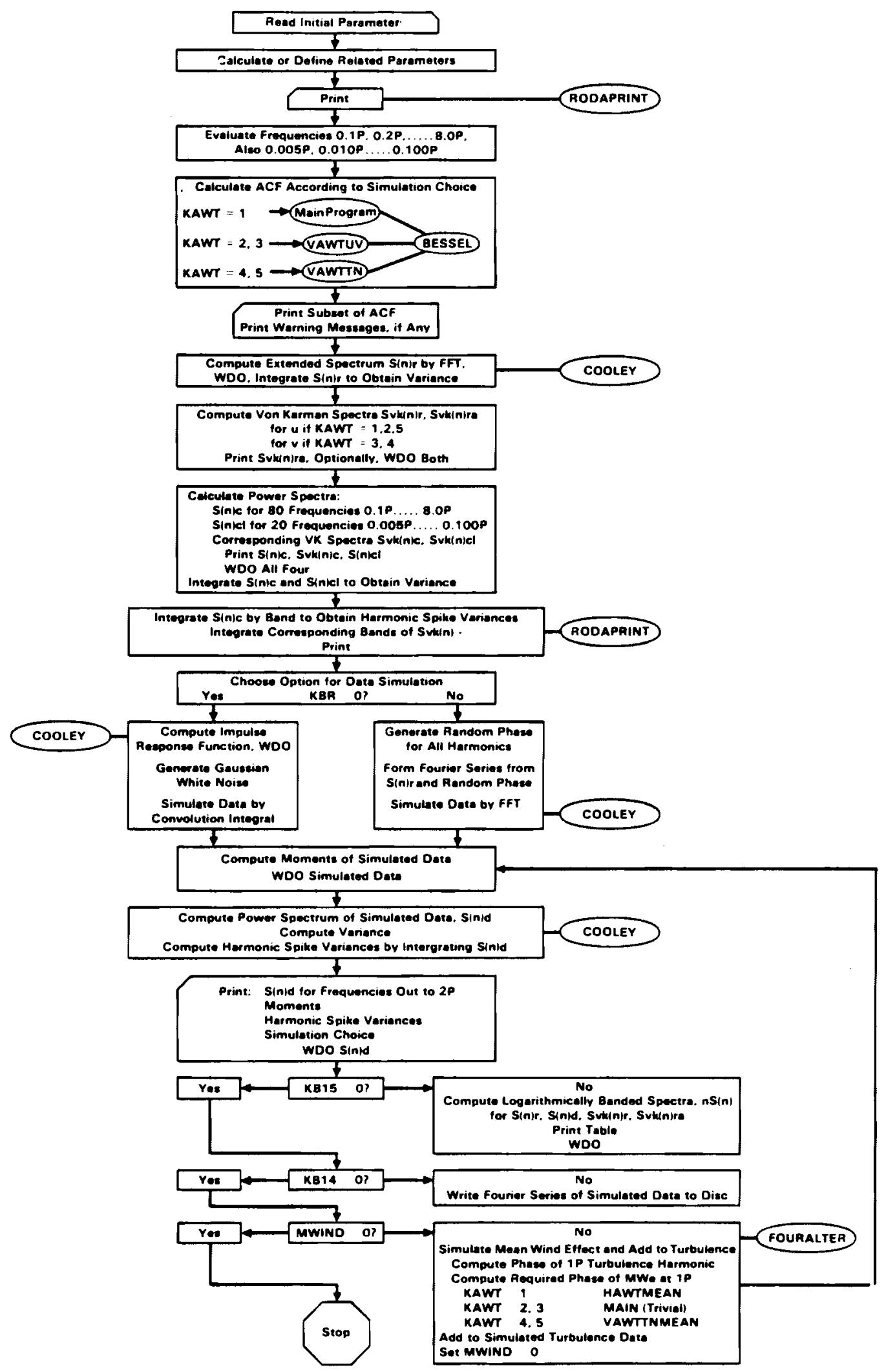

FIGURE 6. Flow Chart Illustrating Operation of the Main Program. $S(n)$ refers to the spectrum of the simulated data, it is numerically equivalent to $S(n) r$.

B. 13 


\subsubsection{Entering Parameters and Variables}

First, the necessary parameter values are read in or determined internally. Then the two limit frequencies for certain of the calculated spectra are determined. The lowest frequency, EN1, is the inverse of the total time period of the simulated data. The highest frequency, EN2, is one-half the reciprocal of the sampling interval, DT.

At this point, other variables are identified by adding the letters A, ND, or AND to variable names already defined. The meanings are best illustrated by examples. Consider the variable DT, the discretization interval. The most direct way to create a spectrum reasonably free of aliasing is to create one with an extended high frequency range that is not needed and which is later disregarded. This is done by using a reduced discretization interval to compute the autocorrelation function of the rotational data. This reduced discretization interval is called DTA. It is computed by dividing DT by the alias reduction factor, ALIAS (the floating point version of ILIAS). Because the autocorrelation function is first computed in terms of dimensionless variables, we also need dimensionless equivalents of DT and DTA. These are DTND and DTAND, obtained by multiplying the corresponding dimensional variable by (PI $\times$ ENO). Other modified variables exist in some or all of these forms for MMT, EN1, EN2, and NANGLE. Some of these additional values are defined for printing only. Others have an analytical role.

Once the initial variables are defined, Subroutine RODAPRINT is called to print out the initial variables.

\subsubsection{Calculation of Autocorrelation Functions and of Several}

The next section of the program calculates the autocorrelation function of the simulated data according to the specifications just read in and those just calculated. It calls on Subroutine BESSEL to calculate the modified Bessel functions of the second kind, $K(1 / 3)$ and $K(2 / 3)$. Then the logic in the main program uses the Bessel function values to determine the particular acf that corresponds to the value of KAWT read in, that is, HAWT $u$, VAWT $u$, etc. The discretization interval of the acf is DTAND. 
If KAWT equals one (HAWT u-simulation), all of the acf calculation is done in the main program except the part done by Subroutine BESSEL. If KAWT is greater than 1 , setting up one of the VAWT simulations, the entire acf calculation is performed in subroutines. Specifically,

if KAWT equals two or three (VAWT $u$ or $v$ simulation), Subroutine VAWTUV is used;

if KAWT equals four or five (VAWT tangential or radial simulation), Subroutine VAWTTN is used.

Subroutines VAWTUV and VAWTTiN call Subroutine BESSEL at the appropriate point. The Hanning window adjustment is done in each of the VAWT subroutines as well as in the main program.

The next section of the program calculates several spectral functions. They may be easily confused with each other unless they are defined at the outset. These spectra are defined and described as follows:

$$
S(n)_{f} \text {, in }(m / s)^{2} / H z
$$

This is the full spectrum calculated by submitting the acf to the fast Fourier transforms, FFT. These are performed by the Cooley-Tukey subroutine, called Subroutine COOLEY. The lowest value of $n$ is EN1. The highest value is EN2A, or EN $2 \times$ ALIAS. The number of frequencies is MMT $\times$ ILIAS $/ 2$.

$$
s(n)_{r}, \text { in }(m / s)^{2} / H z
$$

This is the reduced, relatively unaliased spectrum. It can be defined as

$$
\begin{aligned}
S(n)_{r} & =S(n)_{f} \text {, if } n \text { is not greater than the original EN2. } \\
& =0 \text {, if } n \text { is greater than the original EN2. }
\end{aligned}
$$

The lowest frequency is EN1; the highest frequency is EN2. The number of frequencies is MMT/2. $S(n)_{f}$ is never used after $S(n)_{r}$ is determined. $S(n)_{r}$ is the spectrum used as the basis for later data simulation.

$$
S(n)_{c} \text {, in }(m / s)^{2} / H z
$$


This spectrum is computed by direct cosine integration of the acf for frequencies $0.1 \mathrm{P}, 0.2 \mathrm{P}, \ldots .8 .0 \mathrm{P}$ or EN2, whichever is lower. The maximum number of frequencies is 80 .

$$
S(n)_{c l}, \text { in }(m / s)^{2} / H z
$$

A detailed low frequency description analogous to $S(n)_{C}$, at 20 frequencies, is $0.005 \mathrm{P}, 0.010 \mathrm{P} . . . ., 0.100 \mathrm{P}$.

The following corresponding von Karman spectra are computed.

$\operatorname{Svk}(n)_{r}$, in $(m / s)^{2} / H z$ - original von Karman spectrum analog of $S(n)_{r}$, $\operatorname{Svk}(n)_{r a}$, in $(m / s)^{2} / H z$ - altered von Karman spectrum analog of $S(n)_{r}$, $\operatorname{Svk}(n)_{c a}$, in $(m / s)^{2} / H z$ - altered von Karman spectrum analog of $S(n)_{c}$.

The term "ra" stands for the altered u- or v-spectra that were found to be the limit spectra of the rotational spectra, as rotational rate and radius (or rate alone) approach zero. This finding was not expected. More details and the analytical forms of the original and altered spectra are given in Appendix $B$. Both original and altered versions of the spectra are computed at this point and can be written to disk.

The von Karman spectra are computed according to which component simulation is being performed. The u-spectra are computed if the simulation is of HAWT $u$, VAWT $u$ or VAWT $t$. The $v$-spectra are computed if the simulation is VAWT $v$ or VAWT $r$. Most of these spectral functions can also be written to disk.

The spectra $S(n)_{c}$ and von Karman $S_{v k}(n)_{c a}$ are printed out, along with the variance computed by integrating $S(n)_{C}$. At the bottom of the page, just above the variance, is a print-out of $S(n)_{c 1}$ that was calculated for 20 divisions of the lowest frequency band, that is, from $0.005 \mathrm{P}$ to $0.100 \mathrm{P}$. The reason for computing $S(n)_{C}$ is that both its numerical print-out and its plot make for very easy visual assessment of the rotational effect. $S(n)_{c}$ is a handy spectrum in this respect. The von Karman analogs, $\operatorname{Svk}(n)_{c}$ and $\operatorname{Svk}(n)_{c a}$, are printed and plotted for comparison of the rotational and corresponding Eulerian spectra. 


\subsubsection{Calculation of Harmonic Spike Variances}

The next section of the program computes variances for the first six harmonic spikes of the rotational spectrum. This is the amount of energy per unit mass in each spike. The amount of energy in the von Karman spectrum in each of these frequency bands is also computed for comparison. These results are printed out. The spectra used in these computations are $S(n)_{c}, S(n)_{r}$, and $\operatorname{svk}(n){ }_{c a}$.

The reader should note at this point that since the $S(n)_{r}$ spectrum is used for data simulation, the $S(n)_{c}$ and its von Karman analogs $\operatorname{Svk}(n)_{c}$ and $\operatorname{Svk}(n)_{c a}$ are no longer necessary for the central purpose of the program. However, the $S(n)_{c}$ and $\operatorname{Svk}(n)_{C a}$ spectra were the basis of earlier reported material (Powell et al. 1985) before the simulation capability was added to the code. For this reason, and because these spectra could conceivably be used to generate simulated data by the Gaussian white noise method, they have been retained.

\subsubsection{Data Simulation}

The remainder of the program performs the wind-speed time-series simulation by one of two alternative methods, according to the value given for the option KBR. The first method, used when KBR equals zero, calculates the simulated data by a convolution integration of Gaussian white noise with an impulse response function. The impulse response function is calculated from the spectrum $S(n)_{r}$ and can be written to disk. The result depends on an additional arbitrary input by the user, namely the number of degrees of freedom (members or NP), to be used in the calculated impulse response function. Increasing the number of members gets more of the spectral characteristics into the simulated data, at a cost of greater running expense. Experience is needed to determine what is an optimal number of members to use.

The computations we made by this method used about 50 members in the impulse response function. The spectrum of the simulated data differed somewhat from the original spectrum, and more than $20 \%$ of the original variance was lost. In contrast, when the second simulation alternative is used, the spectrum of the simulated data is identical with the original rotational spectrum, $s(n)_{r}$. Therefore, the two variances are also identical. There is no choice 
to be made corresponding to what number of members of an impulse response function to use. For these reasons, we recommend the second alternative.

The second alternative, chosen when KBR equals one, uses the spectral estimates to calculate the amplitudes of the Fourier harmonics of the simulated data and to add the phase as an uncorrelated random variable from harmonic to harmonic. The random phase is provided by calling a routine that generates an evenly distributed random variable over the range 0 to 1 and scaling this over the range 0 to $2 \pi$.

Following either kind of simulation, several statistical calculations are made based on the simulated data. The variance, skewness and kurtosis of the simulated data are computed. Then the simulated data may be written to disk. Next, the power spectrum of the simulated data is computed. This is identical to the original power spectrum if the second simulation alternative was used or if the mwe has not yet been added in (see Figure 6 ). The computation of variance in the first half-P and in the harmonic spikes is repeated, this time using the spectrum of the simulated data. The spectrum and the Fourier coefficents it was computed from may be written to disk. The last computation, also optional, is a conversion of the $S(n)$ spectrum of the simulated data at evenly spaced frequencies to an $n S(n)$ spectrum at logarithmically spaced frequencies. There are ten bands per frequency decade. The $n S(n)$ estimates for the lowest frequencies are left unbanded. This is because banding has no advantages when the ratio between successive frequencies of the unbanded spectrum is greater than the frequency ratio within the specified band width. The $n S(n)$ version of the von Karman spectrum is also computed if the original version was written to disk.

The program terminates here if MWIND is zero, i.e., if no mwe simulation is to be made. Otherwise, the following operations are performed:

First, Subroutine FOURALTER is called to find the phase angle of the IP harmonic in the simulated data D1. The ANGLE is identified by 
ANGLE $=\operatorname{Arctan}(B, A)$, in degrees, where the equation of the mwe is

$$
U[m w e](t)=A \cos (\omega \times t)+B \sin (\omega \times t)
$$

or

$$
U[\pi w e](t)=C \cos (\omega \times t-\pi \times \text { ANGLE/180. }),
$$

where

$$
C=\sqrt{A^{2}+B^{2}}
$$

and $\omega$ is the rotational rate in radians per second.

The calculated variables OFFSET and IFFSET are a combination designed to bring $U[m w e](t)$ into phase with the $1 P$ turbulence harmonic when DELAY is zero, and when the mwe equations are written as they are in Subroutines HAWTMEAN and VAWTTMMEAN. The program calls up the appropriate subroutine to calculate one cycle of mwe for the particular HAWT or VAWT component simulation being calculated. This does not occur for either the VAWT u- or VAWT v-component simulations.

The one cycle of mwe is returned to the main program. It is extended through as many cycles as are needed to cover the turbulence. It is then added to the turbulence.

With this done, the program goes back to the moment-calculating routine and recalculates all the statistics of the simulated data. These include the moments, spectrum and harmonic spike integrations of the spectrum of the simulated data including mwe.

\subsubsection{Specific Subroutine Operations}

A selection of the following subroutines is called by each run. Figure 6 illustrates where the subroutines fit in the operation of the whole program.

\subsubsection{Subroutine BESSEL}

Subroutine BESSEL computes a summation for each of the Bessel functions until both addends are reduced below a certain tolerance. At this point, the B. 19 
computed sums become the two Bessel function values, and control returns to the main program. The argument going into the summation begins near zero. When the argument exceeds eight, the sums diverge. Therefore, if the argument reaches eight, control is returned to the main program, and a warning message is printed out. Fortunately, this potential problem does not seem to exist in actual computations.

of the four arguments in the call list, three are essential. The fourth applies only in the so-called D-line output used for checking the subroutine. The three essential arguments are the single input argument for the two Bessel functions and the two output values.

\subsubsection{Subroutines VAWTUV and VAWTTN}

These subroutines are alternate routes for the main program, depending on the value of KAWT, that is, on what kind of simulation is being executed. If the simulation is any of the VAWT simulations, the part of the main program that computes the acf for the HAWT simulation is bypassed and one of these subroutines is called. Subroutine VAWTUV is used for a VAWT u- or v-component simulation and Subroutine VAWTTN is used for a VAWT tangential or radial component simulation. Both of these subroutines have the same call to Subroutine BESSEL and the same windowing option as the main program has for the HAWT simulation. The call lists are somewhat long. Most of the variables therein are defined in the glossary in Appendix A. Ordinarily, the user need not be concerned with them.

\subsubsection{Subroutine COOLEY}

This FFT subroutine was authored by Winkelman and Smith before 1970. It accepts two real data series as the real and imaginary parts of a complex series and performs the FFT of the complex series. Certain additional logic is necessary to sort out the values for the two power spectra and the cross spectra when two sets of original data are entered, filling both the real and the imaginary parts of the complex series seen by the subroutine. In the present operations, we filled only the real slots. 
The subroutine is called three times to effect the transform. There are two input variables. The first is the complex data series. The second is an indicator that differs on each of the three submissions:

1. the negative of the number of members in the complex data vector

2. the positive of the same number

3. zero.

The output Fourier transform values occupy the same slots the original data occupied.

\subsubsection{Subroutine LOGBAND}

This subroutine reads in a number of evenly banded $S(n)$ spectra over the same frequency range and converts them to $\mathrm{nS}(\mathrm{n})$ spectra logarithmically banded. This operation is performed on $S(n)_{r}$, and on the von Karman spectra $S v k(n)_{r}$ and $\operatorname{Svk}(n)_{r a}$, if they have been calculated and written to disk. The call list for the subroutine consists of

BPSD number of logarithmically-spaced frequency bands per spectral decade. The recommended value of BPSD is 10 .

K13 the option governing whether the von Karman spectra are written to disk.

MWF a flag telling the subroutine whether or not to read a third record of $S(n)$ values. This third spectrum is of simulated data including mwe.

After the subroutine reads the $S(n)$ input spectra, it constructs the bounds of the logarithmically spaced bands. The highest frequency band has the Nyquist frequency (0.5/DT) for its upper bound. Upper bounds of the successively lower frequency bands are all related by the same ratio, which is

$$
\text { RATIO }=10.0^{(1.0 / B P S D)} \text {. }
$$

That is, if the upper bound of the highest band is FQQ, the Nyquist frequency, the lower bound of this band is FQQ/RATIO, and the central frequency is the geometric mean of those two. The second highest band has FQQ/RATIO for its upper frequency bound and FQQ/RATIO ${ }^{2}$ for $i$ ts lower bound. This formation of frequency bands continues until the frequency band width becomes less than the 
fundamental frequency, thus leaving some of the lowest frequency values of $S(n)$ unbanded. Once the band limits are established, the $n S(n)$ values are computed by straightforward arithmetic. The subroutine prints out a table of the banded estimates and, below these, the unbanded $n S(n)$ values are also printed out.

This feature was used to generate the spectra shown in Appendix B. Genuine rotational spectra would be distorted by this type of banding. Therefore, operation of Subroutine LOGBAND is not essential.

\subsubsection{Subroutine FOURALTER}

Given a frequency ENO, Subroutine FOURALTER computes the $A$ and the $B$ of the $1 P$ wave:

$$
S(1 P) \text { turbulence }=A \cos (2 \pi \times E N O \times t)+B \sin (2 \pi \times E N O \times t) .
$$

These are printed out, and the phase angle

$$
\operatorname{ANGLE}=\operatorname{Arctan}(B, A)
$$

is computed and returned to the main program so that the mean wind effect, which is a wave with frequency $1 P$, can be adjusted to the proper phase relation with the $1 P$ wave of the turbulence.

\subsubsection{Subroutines HAWTMEAN and VAWTTNMEAN}

These subroutines calculate one cycle of simulated mean wind effect. Then this cycle is transferred to the main program and added repeatedly to the turbulence until enough cycles, including partial cycles, have been added to cover the turbulence record. Subroutine HAWTMEAN simulates the mwe for HAWT rotation; Subroutine VAWTTNMEAN simulates the mwe for either the tangential or the radial component of VAWT rotation.

\subsection{ON BRACKETING THE ANSWERS BY ENVELOPING INPUT PARAMETERS}

As indicated above, turbulence rms and length scales are uncertain. The turbulence rms during unstable conditions may well be 50 percent greater than 
the program-calculated value, which applies for neutral conditions. Similarly, the effective surface roughness length may well be anywhere from $2 / 3$ to $3 / 2$ that reasonably assumed. Surface roughness length affects model calculations only through the rms. The results described in the next section suggest that both length scales specified by the model may be about 3.5 times the height. However, turbulence length scales do not scale exactly with height. Therefore, a wider range should be considered. The user may wish to submit a series of runs, varying parameter values within these ranges and plotting all results in order to get an envelope.

A reasonable envelope for rms would be 0.8 to 1.5 times the programcalculated values for SIGU. This allows for uncertainty about both atmospheric stability and surface roughness. However, if the stable atmosphere is to be modeled, the rms may well be half the program-calculated values. An envelope of values for rms can be used without running the model again because all simulated wind values are directly proportional to rms and all spectral values are directly proportional to the square of the rms. Other reasonable envelopes would be:

$$
\begin{aligned}
& \mathrm{L}_{x}: 3 z \text { to } 6 \mathrm{Z} . \\
& \mathrm{L}_{y}: 0.4 \mathrm{~L}_{x} \text { to } 1.0 \mathrm{~L}_{\mathrm{x}} \text {. }
\end{aligned}
$$

For HAWT simulations, a smaller choice of $L_{y}(u)$ is appropriate. For VAWT simulations, $L_{y}$ should approximate $L_{x}$ more closely. Calculating an envelope of values for $L_{x}$ and $L_{y}$ requires running the model for each individual pair of specified values. 


\section{A.2 GLOSSARY}

The following listing describes the commonly used variables in the program. Variables not listed are in one of three categories: 1) working or temporary variables defined and used within a small segment of the program, 2) generalized loop indices, or 3) modifications of basic variables, indicated by names ending with $A$, ND, or AND (see Section 3.3.1.1).

One helpful aspect of the glossary is that it gives the units of all variables. Of course, this depends on the units of such input variables as height and mean wind speed. The program assumes that lengths are in meters and times in seconds. Dimensionless variables are labeled 'dmls.'

\section{SCALARS}

\begin{tabular}{|c|c|c|c|}
\hline Symbol & Description & Unit & $\begin{array}{l}\text { Sub- } \\
\text { routine }\end{array}$ \\
\hline ALFA & $\begin{array}{l}\text { Blade radius/turbulence length scale } \\
L_{y^{*}}\end{array}$ & dmls. & \\
\hline ALIAS & $\begin{array}{l}\text { Floating point ILIAS, alias reduction } \\
\text { factor. }\end{array}$ & dmls. & \\
\hline ANGLE & $\begin{array}{l}\text { Phase angle of } 1 P \text { harmonic in simulated } \\
\text { data. Zero value indicates a cosine wave. }\end{array}$ & $\operatorname{deg}$ & \\
\hline BETA & $\begin{array}{l}\text { Blade rotation rate/(mean wind speed } x \\
\left.\text { turbulence length scale } L_{x}\right) \text {. }\end{array}$ & dmis. & \\
\hline BK13 & $\begin{array}{l}\text { Value of modified Bessel function of } 2 \text { nd } \\
\text { kind, } k(1 / 3) \text {. }\end{array}$ & dmls. & BESSEL \\
\hline BK23 & Same as above, but for $K(2 / 3)$. & dmls. & BESSEL \\
\hline CHECK & Criterion for declaring acf convergent. & dmls. & \\
\hline CHK & $\begin{array}{l}\text { Read-in tolerance level defining conver- } \\
\text { gence of acf. }\end{array}$ & dmls. & \\
\hline CMMT & Floating point MMT. & dmls. & \\
\hline
\end{tabular}


Parameter used in IMSL routine for gener-

Unit

ating uncorrelated random values evenly

spaced from zero to one.

$\mathrm{dml}$ s.

DT

Discretization interval for simulated data.

sec

EL1 Longitudinal integral length scale for

$u$-component turbulence, $L_{x}$.

m

EL2 Lateral integral length scale for

$u$-component turbulence, $L_{y}$.

m

EN Dimensional frequency argument for

von Karman spectrum.

$\mathrm{Hz}$

ENO

Blade rotation rate.

$\mathrm{Hz}$

EN1 Fundamental frequency of data: reciprocal of total time span.

EN2

Nyquist frequency of spectrum $S(n)_{r}$, and

the spectrum of simulated data.

ENVK Dimensionless frequency for von Karman

spectrum.

dmls.

FAC Time factor converting Fourier squared

amplitudes to the one-sided spectral

density $S(n)$.

sec

FF

Fundamental frequency of spectral densities $S(n)_{f}, S(n)_{r}, \operatorname{Svk}(n)_{r}$.

$\mathrm{Hz}$

ILIAS

Alias reduction factor. [If ILIAS $=4$,

$1 / 4$ of the power spectrum $S(n)_{f}$, calcu-

lated from FFT of acf, is retained as

$\left.S(n)_{r} \cdot\right]$

dmls.

JTCPL

1. Index of the last member of acf as it is entered into the FFT process. 


\section{Symbol}

JTCPL

(cont'd.)
Description

2. Index of last member of $S(n)_{r}$ as it is entered into FFT process to compute impulse response function. Smaller value than above if ILIAS is greater than 1.

3. Index of last value of $S(n)$ for simulated data. (Same value as in 2.)

4. Index of last value of random phase used to calculate simulated data. (Same value as in 2.) dm7s.

Option to write impulse response function to disk.

Option to write $S(n)_{r}$ and spectrum of simulated data to disk. These spectra have half as many degrees of freedom as the simulated data have.

K11

K12

Option to write 80 -member spectrum $S(n)_{C}$, $(0.1 \mathrm{P}, 0.2 \mathrm{P} \ldots \mathrm{PP})$ and corresponding altered von Karman spectrum to disk.

K13 Option to write simulated data to file. Option to write von Karman spectra, original and altered, to file. These spectra have half as many degrees of freedom as the simulated data have.

K14 Option to write complex Fourier coefficients of transform of simulated data to file. Option to calculate banded $n S(n)$ spectra for for simulated data; also does so for the von Karman spectra stored if $\mathrm{K} 13$ does not equal zero. 
KAWT

Simulation choice option:

1) HAWT u-component

2) VAWT u-component

3) VAWT $v$-component

4) VAWT tangential component

5) VAWT radial component.

KBR

Option for calculation method for simulated data:

0) Convolution integral of impulse response function with Gaussian white noise.

1) Fourier transform of amplitudes from spectral harmonics and random phase.

KEL

Option for length scales EL1 and EL2:

0) Let program calculate them.

1) Read them in.

KMAX Maximum number of members allowed in acf.

KNDOPT Option governing specification of discretization interval:

0) Specify angular value in degrees.

1) Specify time value in seconds.

KSERIAL Alphameric serial number for run, five characters.

KSG

Option for SIGU and SIGV.

o) Let program calculate them, isotropically.

1) Read them in.

KWINDOW Option to multiply acf by Hamming window values.

0) Do not use window.

1) Use window. 


\begin{tabular}{|c|c|c|}
\hline Symbol & Description & Unit \\
\hline MMT & $\begin{array}{l}\text { Number of simulated data. MMT must be } 2^{N} \text {, } \\
\text { where } N \text { is an integer. }\end{array}$ & \\
\hline NANGLE & $\begin{array}{l}\text { Discretization interval in terms of number } \\
\text { of angular divisions of rotational circle. }\end{array}$ & dmls. \\
\hline NDG & $\begin{array}{l}\text { Number of degrees of freedom in Gaussian } \\
\text { white noise. }\end{array}$ & dm 1s. \\
\hline NEF & $\begin{array}{l}\text { Number of frequencies used in spectra } \\
S(n)_{c} \text { and corresponding von Karman spectra } \\
\text { where frequency spacing interval is } 0.1 P \text {. }\end{array}$ & dmls. \\
\hline NHAR & $\begin{array}{l}\text { Number of harmonics (degrees of freedom) } \\
\text { in spectrum } S(n)_{r} \text { and corresponding } \\
\text { von Karman spectra. (NHAR }=\text { MMT/2.) }\end{array}$ & dmls. \\
\hline NP & $\begin{array}{l}\text { Arbitrary number of points to be used on } \\
\text { one side of the two-sided impulse response } \\
\text { function, not counting central value at } \\
\text { zero argument. }\end{array}$ & dmls. \\
\hline OMEGA & Blade rotation rate. & radians/sec \\
\hline PI & 3.141592654 & $\mathrm{dmls}$. \\
\hline RADIUS & Radius of rotation, blade radius. & $\mathrm{m}$ \\
\hline SIG2 & $\begin{array}{l}\text { SIGU2 or SIGV2, as is appropriate. If SIGU } \\
\text { and SIGV are calculated internally, they } \\
\text { are equal. }\end{array}$ & $(\mathrm{m} / \mathrm{s})^{2}$ \\
\hline SIGU & Rms of u-component turbulence. & $\mathrm{m} / \mathrm{s}$ \\
\hline SIGU2 & Variance of u-component turbulence. & $(\mathrm{m} / \mathrm{s})^{2}$ \\
\hline SIGV & Rms of $v$-component turbulence. & $\mathrm{m} / \mathrm{s}$ \\
\hline SIGV2 & Variance of $v$-component turbulence. & $(\mathrm{m} / \mathrm{s})^{2}$ \\
\hline $\mathrm{T}$ & $\begin{array}{l}\text { Dimensionless running time used in calcu- } \\
\text { lation of acf and in the cosine integration } \\
\text { of the acf to obtain } S(n) C_{c^{\circ}}\end{array}$ & $\mathrm{dmls}$. \\
\hline
\end{tabular}




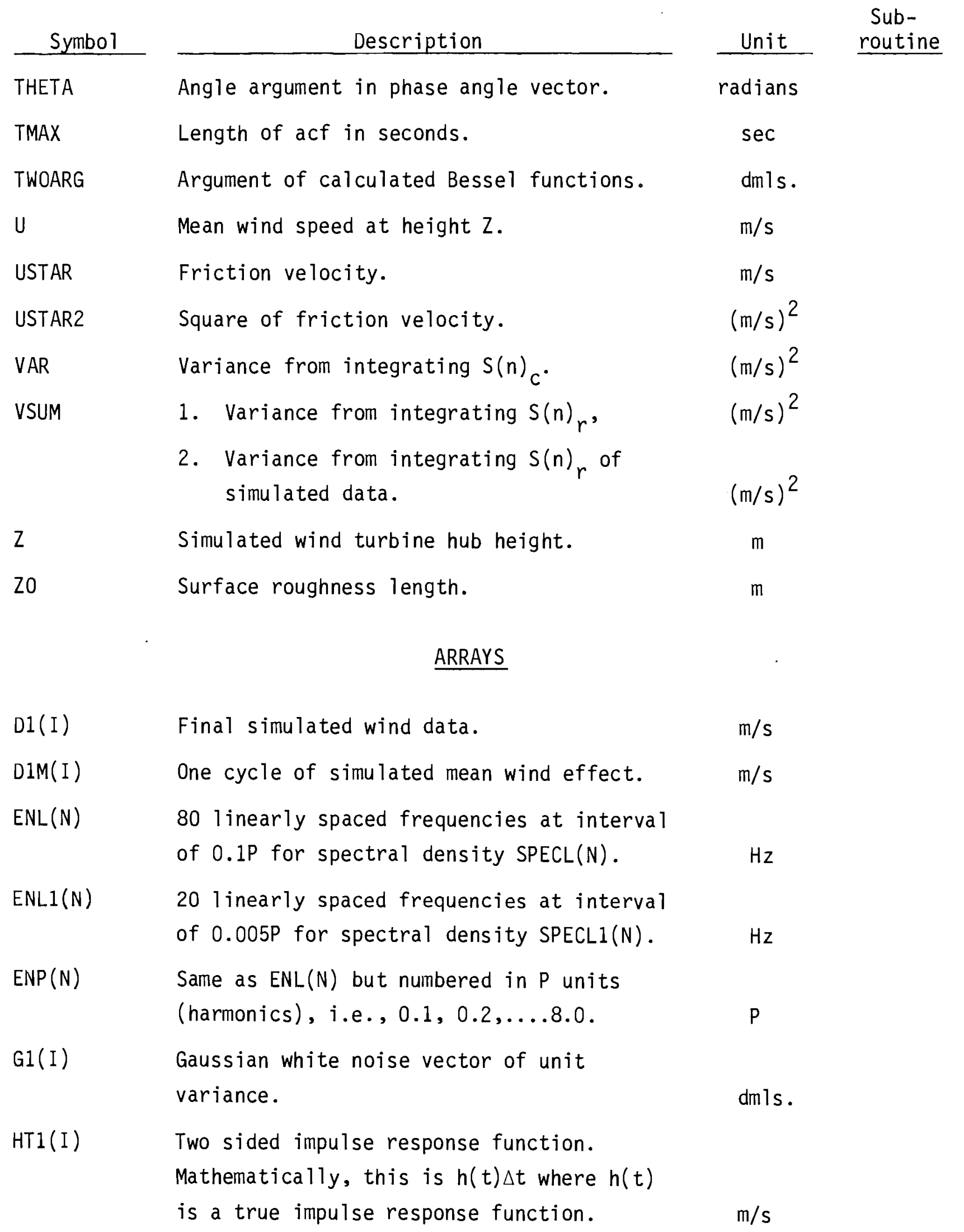


$\operatorname{KAWTER}(C) * 30$ Alphameric array indicating type of simulation.

$\operatorname{PRMS}(M) \quad$ Square root of $\operatorname{PVAR}(M)$.

$\mathrm{m} / \mathrm{s}$

$\operatorname{PVAR}(M) \quad$ Variance in each of the harmonic spikes of the rotational spectrum. PVAR(1) is variance of first 0.5P; PVAR(2) is variance of first spike, etc. This version is calculated by integrating $\operatorname{SPECL}(N)$.

PVARVK(M) Variances found by integrating over corresponding frequency ranges of von Karman spectrum.

PVAR2(M) Same as PVAR(M) but calculated by integrating $X \operatorname{IF} 1(N)$.

$R(T) \quad$ Autocorrelation function incorporating rotational feature. dmis.

$R P(T S) \quad$ Evenly spaced subset of values from $R(T)$ selected for printing convenience. RP is not used analytically.

dmls .

SMOM(4) Mean, variance, skewness, kurtosis of simulated data.

SPECL(N) Spectral density at 80 frequencies, 0.1P, $0.2 P \ldots 8.0$, of simulated data. SPECL is calculated by direct cosine integration of $R(T)$.

$\operatorname{SPECL1}(N)$ Same as SPECL(N) but for the 20 frequencies $(0.005,0.01 \ldots .0 .1) P$.

$\operatorname{VKSPEC}(N) \quad$ Von Karman spectrum for same frequencies as $\operatorname{SPECL}(N)$.

XIF1(N) Spectral density $S(n)$ calculated by FFT of $R(T)$, where fundamental frequency is reciprocal of time length of data set. 
XTEND(K) Input complex vector for FFT.

$\operatorname{XVK}(N)$

Von Karman spectrum corresponding to XIFI.

$\left(\mathrm{m}^{2} / \mathrm{s}\right)$

$\operatorname{XVKA}(\mathrm{N})$

Altered von Karman spectrum corresponding to XIF1. 
APPENDIX D

\section{SAMPLES OF OUTPUT}

The types of output we illustrate here are rotational spectra and simulated time series data. These results were generated using the following set of input parameters. The machine parameters are known to be appropriate for the VAWT but not for the HAWT. However the same input data were used for both, for the purpose of comparing model output. The parameters are:

$\begin{array}{lc}\text { Radius of Rotation } & 8.3 \mathrm{~m} \\ \text { Rate of Rotation } & 1.0000 \mathrm{~Hz} \\ \text { Hub Height } & 16.7 \mathrm{~m} \\ \text { Mean Wind Speed } & 10.00 \mathrm{~m} / \mathrm{s} \\ \text { Turbulence RMS Values } & \\ \quad \text { u-Component } & 1.652 \mathrm{~m} / \mathrm{s} \\ \quad \text { v-Component } & 1.652 \mathrm{~m} / \mathrm{s} \\ \text { Turbulence Variances } & \\ \quad \text { u-Component } & 2.729(\mathrm{~m} / \mathrm{s})^{2} \\ \quad \text { v-Component } & 2.729(\mathrm{~m} / \mathrm{s})^{2} \\ \text { Friction Velocity } & 0.688 \mathrm{~m} / \mathrm{s} \\ \text { Turbulence Integral Length Scales } & \\ \quad \text { Longitudinal } & 70.1 \mathrm{~m} \\ \quad \text { Lateral } & 28.1 \mathrm{~m} \\ \text { Number of Data to be Simulated } & 1024 \\ \text { Discretization Interval } & 0.0417 \mathrm{~s} \\ \text { Alias Factor } & 4 \\ \text { Angular Discretization Interval } & 15.0 \mathrm{degrees}\end{array}$

Figure D.1 compares the turbulence spectra of the simulated HAWT $u$-component and the simulated VAWT u-component. Both spectral density $S(n)$ and the logarithmic spectrum $n S(n)$ are shown. It should be emphasized that the mean wind effect has been omitted in each case. If it had been included, the $1 P$ spike would have been higher in both spectra, considerably higher for the 
a

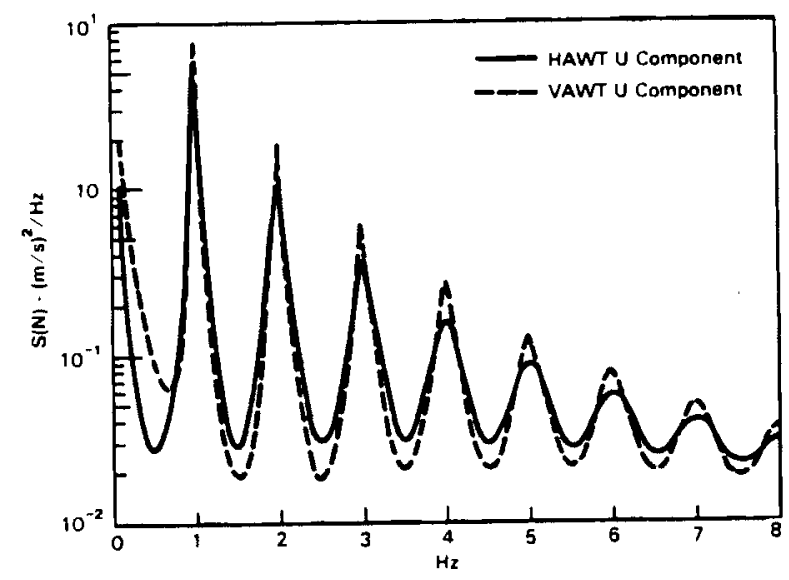

b

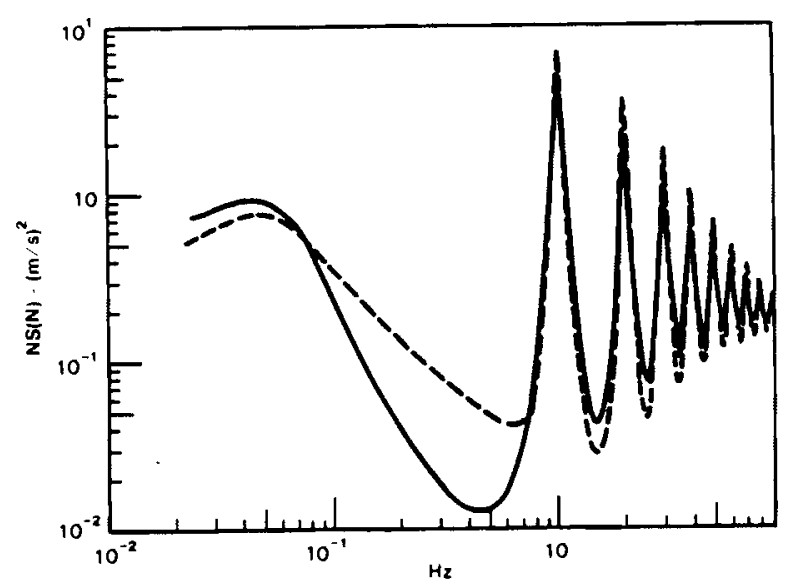

FIGURE D.1. Rotational HAWT $u$ - and VAWT $u$-Spectra. a. $S(n) ; b \cdot n S(n)$

VAWT u-spectrum. Clearly, however, the effect of turbulence alone in the u-component on the rotationally sampled spectrum of wind is more severe for the VAWT than for the HAWT, i.e., more severe on the horizontal circle than on the vertical circle.

Similar plots for the four VAWT simulations ( $u, v$, tangential and radial) are shown in Figure D.2. Interesting features of this figure are:

1. At low $P$, the VAWT radial simulation has the strongest peaks.

2. At higher $P$, only the two $u$ simulations maintain a distinct harmonic spike structure (see Figure D.1). 
a

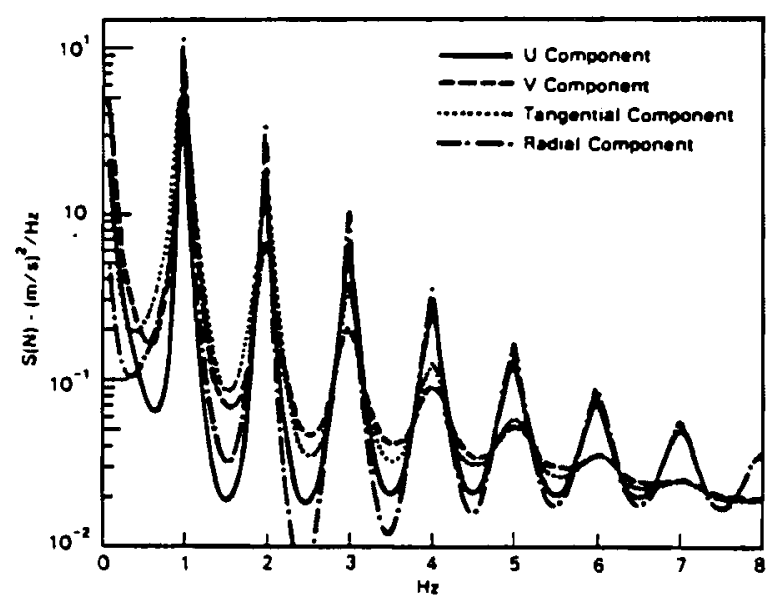

b

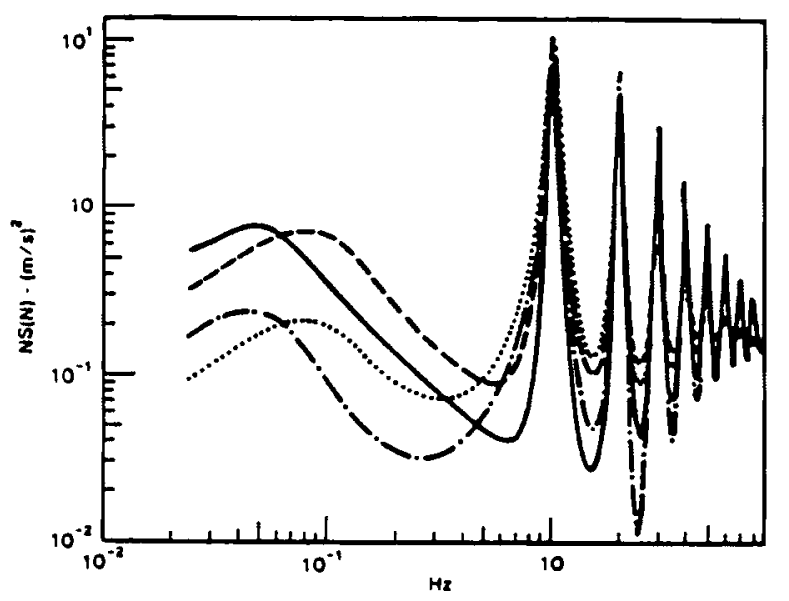

FIGURE D.2. Rotational Spectra $S(n)$ and $n S(n)$ for the Four VAWT Simulations a. $S(n) ; b . n S(n)$

In both Figure $D .1$ and Figure 0.2 , the $S(n)$ spectra are the 80 -frequency spectra $S(n)_{c}$. The $n S(n)$ spectra are made by banding the $S(n)_{r}$ spectral estimates in eight evenly spaced bands.

The turbulence variances for the five runs are given in Table D.1. The spectra $S(n)_{r}$ and $S(n)_{c}$ are defined in Section 3.3.1.2.

The theoretical Eulerian turbulence variance for all cases is 2.73 $(\mathrm{m} / \mathrm{s})^{2}$. The variances above are less because the total length of the simulated time series is only 43 seconds, rather than the 10 or 15 minutes that is required to attain the theoretical variance from field data. 
TABLE D.1. Variances of the Five Simulations, in $(\mathrm{m} / \mathrm{s})^{2}$

$\frac{\text { Integration of }}{S(n)_{r}} \quad \frac{S(n)_{c}+S(n)_{c 1}}{2}$

$\begin{array}{lll}\text { HAWT } \mathrm{u} & 2.17 & 2.41 \\ \text { VAWT } \mathrm{u} & 2.26 & 2.54 \\ \text { VAWT } \mathrm{v} & 2.41 & 2.35 \\ \text { VAWT } \mathrm{t} & 2.53 & 2.48 \\ \text { VAWT } \mathrm{r} & 2.45 & 2.72\end{array}$

Simulated data for VAWT U-component and VAWT radial component turbulence are shown in figure D.3. The simulated wind speed time series are derived from these spectra. The graphs illustrate turbulence only. The changing mean wind effect is not included because it would mask the turbulence. The difference in the character of these stationary data over a short period is evident.

The variances in the first five harmonics for each type of simulation are shown in Figure D.4. One graph, D.4.a, compares the spike variances for the HAWT $u$ and VAWT $u$ simulations; the other, D.4.b, compares the spike variances for all four VAWT simulations. The energy in the first spike of the VAWT $u$ simulation is greater than that in the first spike of the HAWT u simulation. However, the greatest differences are between the VAWT tangential and radial simulations on one hand, and the three other simulations on the other. 

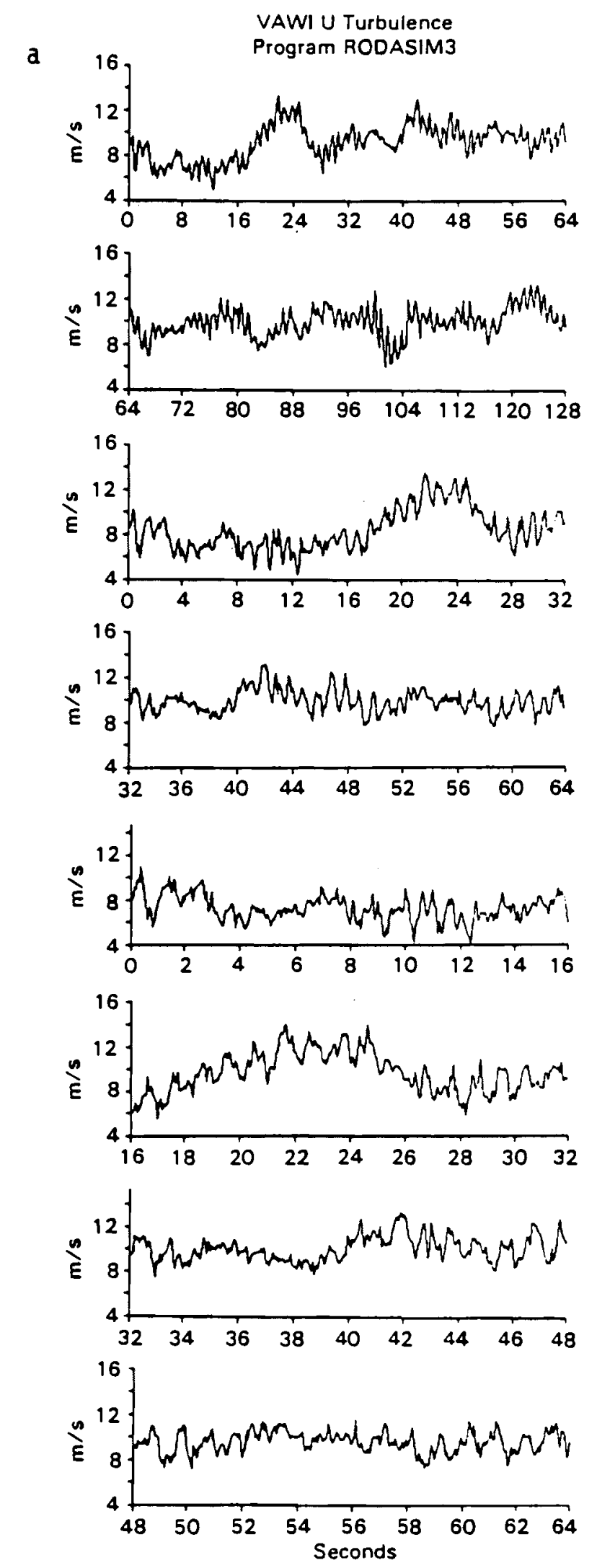

VAWI Radial Turbulence
Program RODASIM3
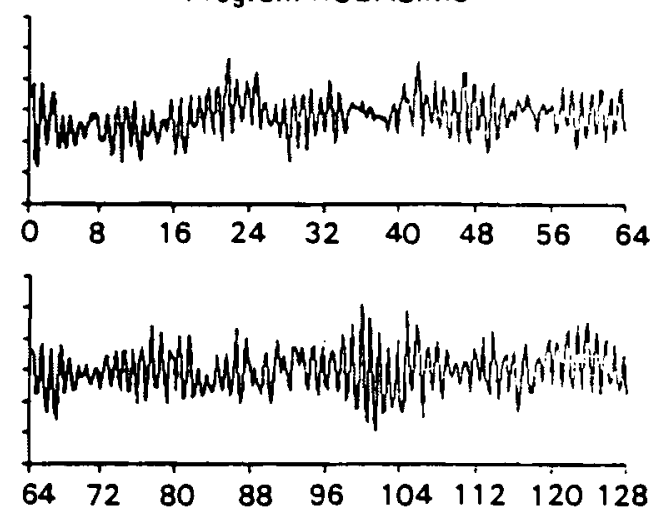

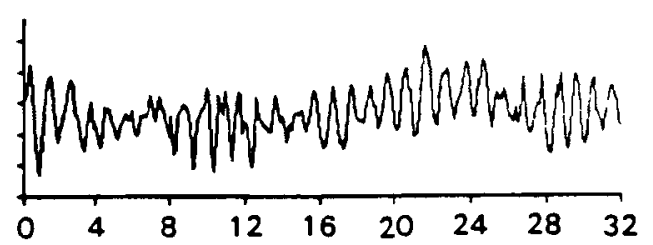
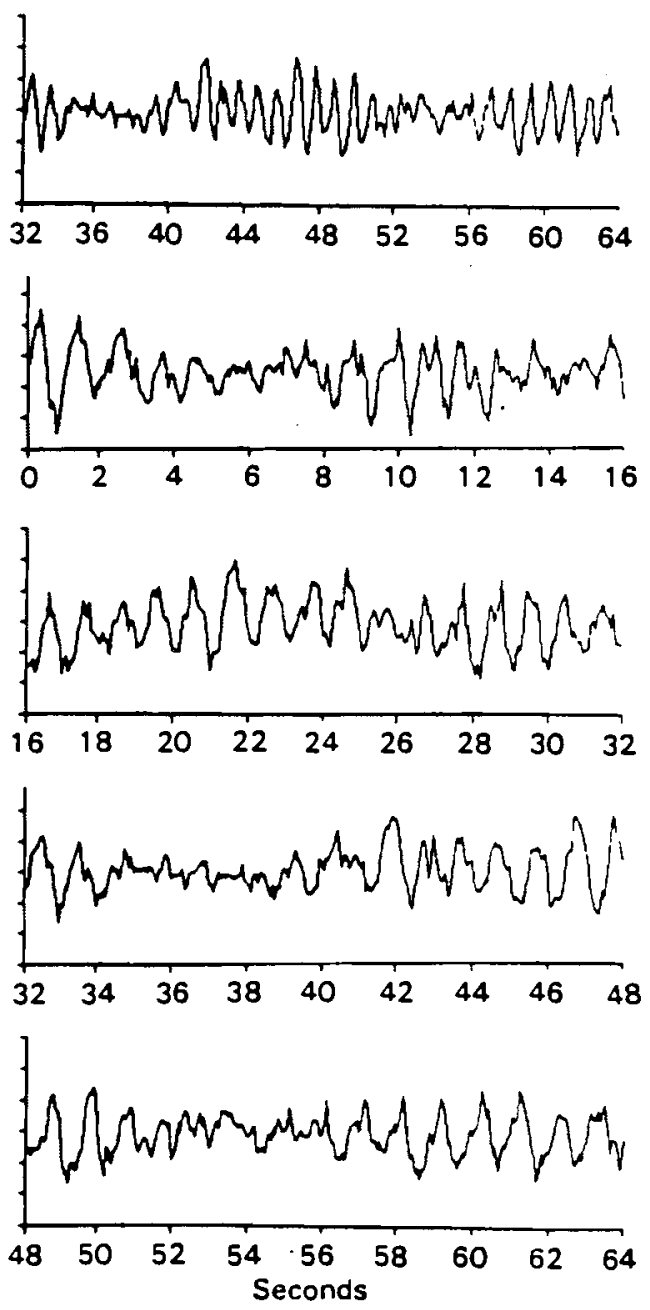

FIGURE D.3. Simulated Turbulence Data. b. VAWT radial component

a. VAWT u-Components; 
APPENDIX C

SAMPLE OUTPUT FROM THE FILE SUMMARY.DAT FOR THE HAWT CASE AT HALF-BLADE RADIUS 


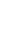

$+$

- 


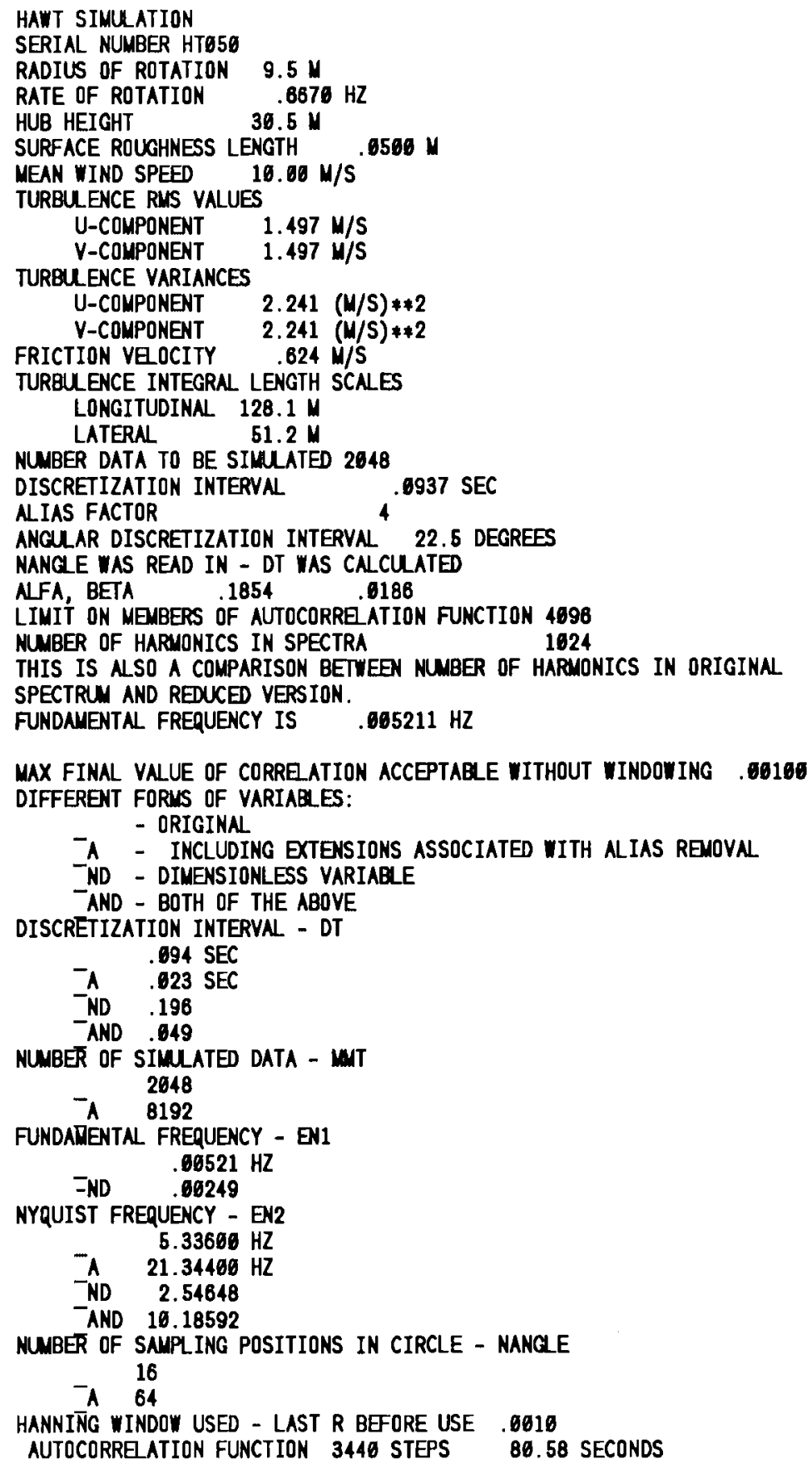$$
\text { - ORIGINAL }
$$

- A - INCLUDING EXTENSIONS ASSOCIATED WITH ALIAS REMOVAL

ND - DIMENSIONLESS VARIABLE

-AND - BOTH OF THE ABOVE

DISCRETIZATION INTERVAL - DT

- .094 SEC

$A \quad .623 \mathrm{SEC}$

-ND $\quad .196$

NUMBER OF SIMLATED DATA - WMT

- 2048

FUNDADENTAL FREQUENCY - EN1

$.00521 \mathrm{HZ}$

FND $\quad .06249$

NYQUIST FREQUENCY - EN2

$\begin{array}{rr}5.33606 \mathrm{HZ} \\ -\mathrm{A} & 21.34460 \mathrm{HZ}\end{array}$

ND 2.54648

AND 10.18592

NUMBER OF SAMPLING POSITIONS IN CIRCLE - NANGLE

- 64

NNING WINDOW USED - LAST R BEFORE USE

AUTOCORREATION FUNCTION 3446 STEPS 80.58 SECONDS 
AFTER FIRST VALUE SKIP INTERVAL IS 4

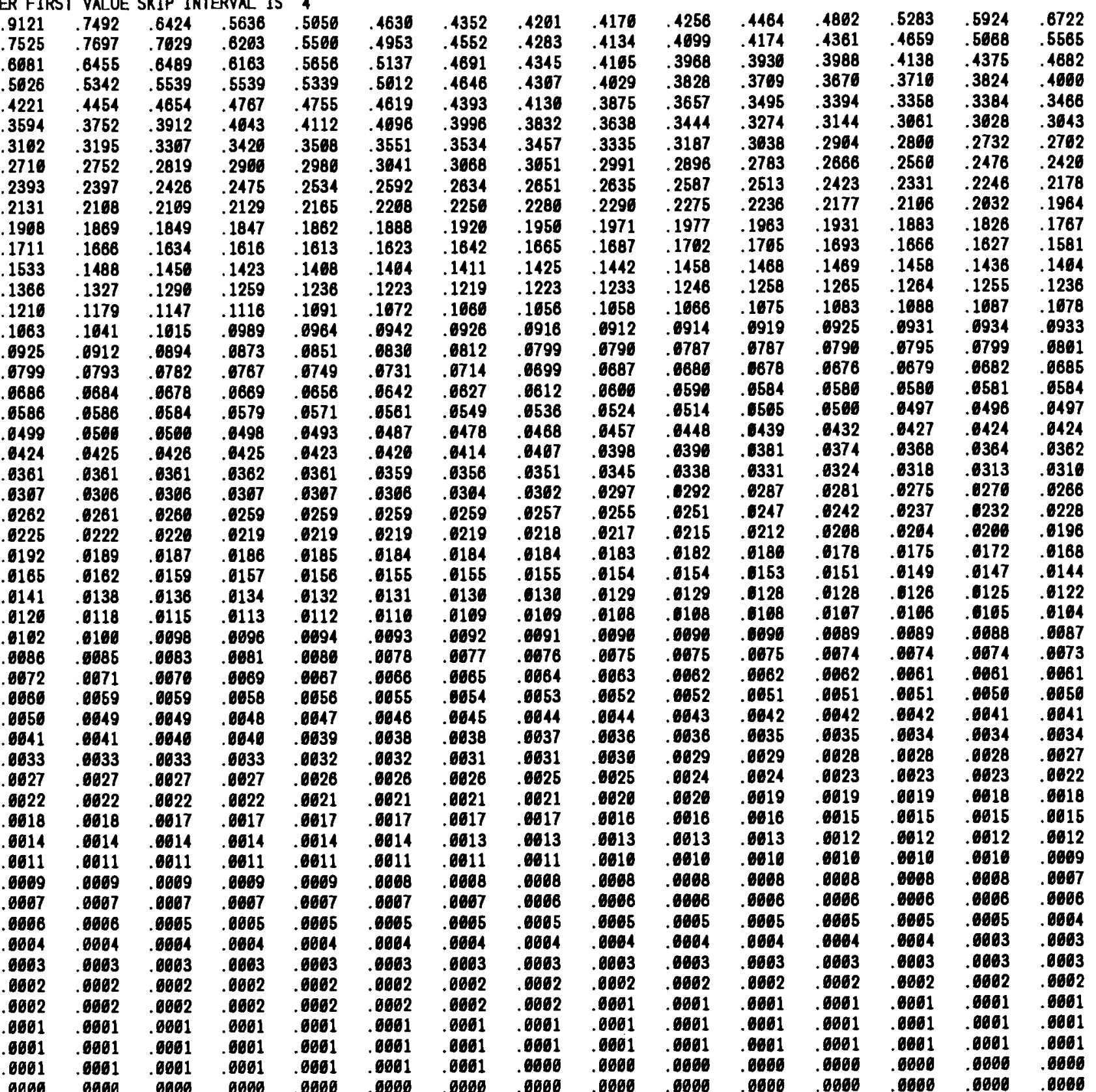




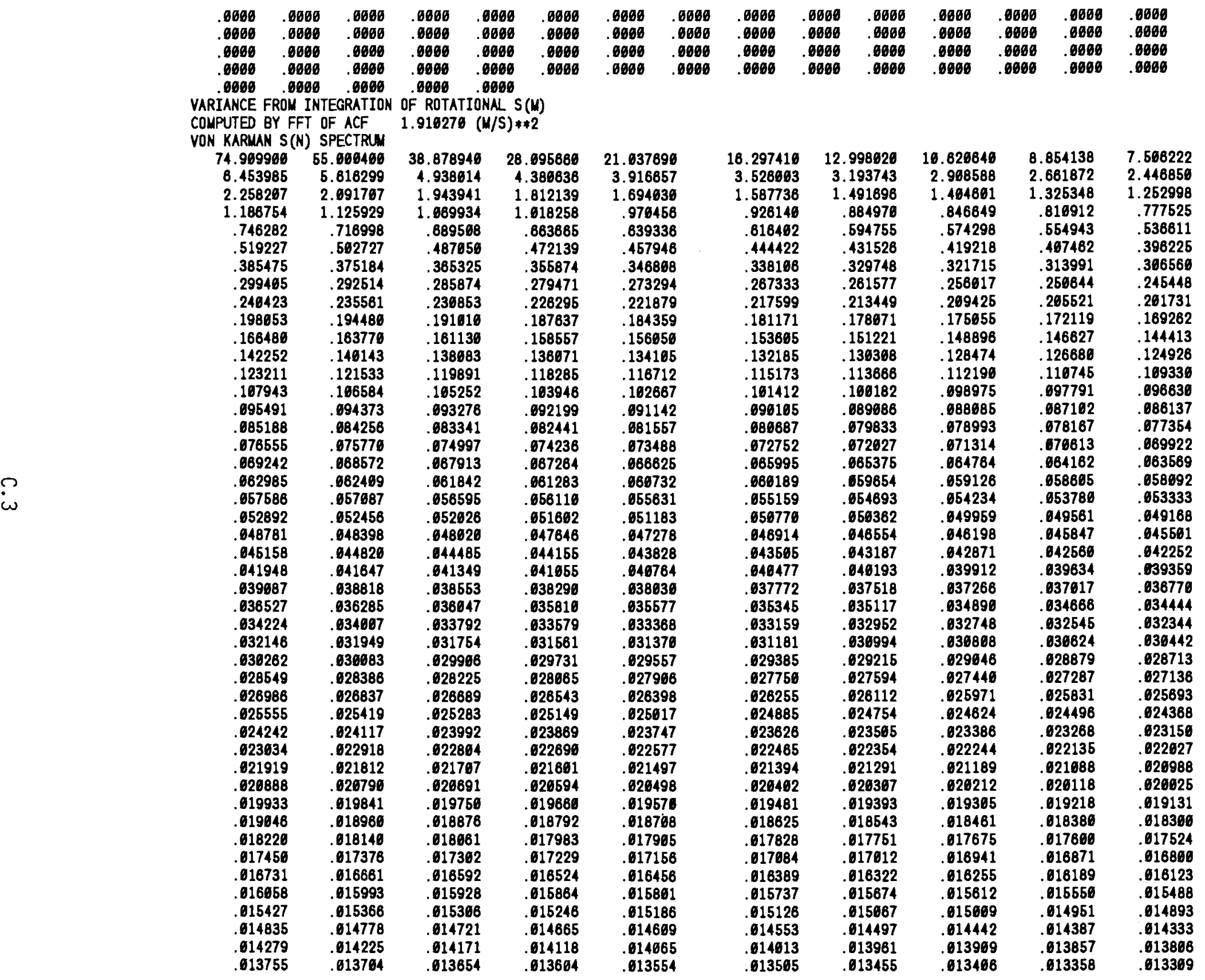




\begin{tabular}{|c|c|c|c|c|c|c|c|c|c|}
\hline 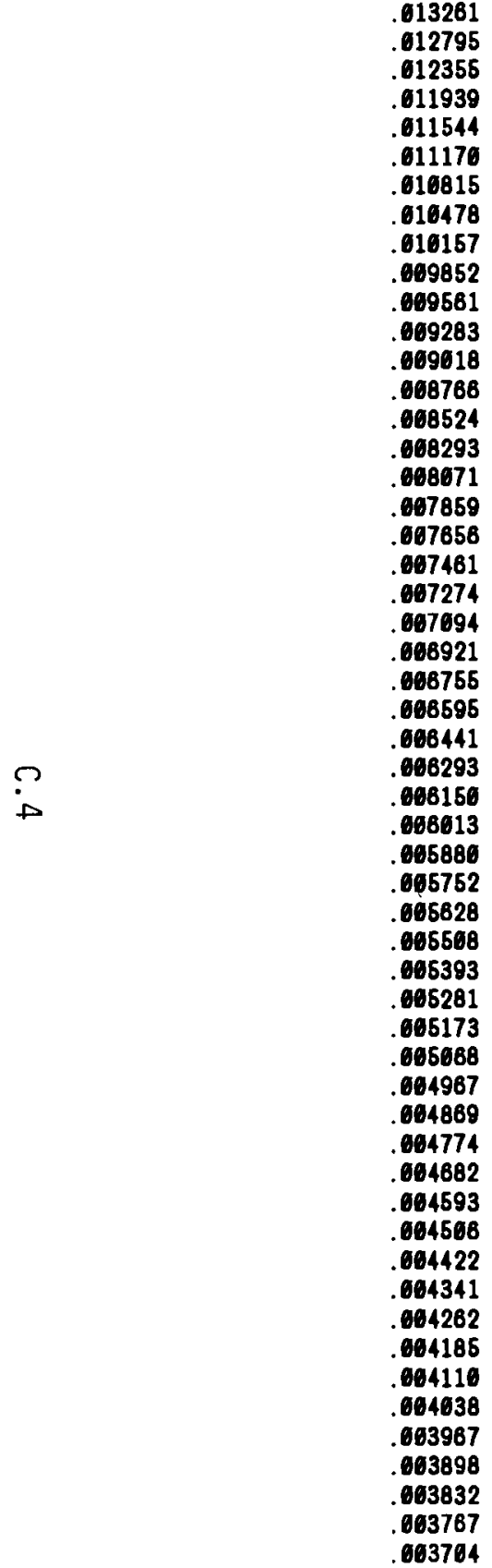 & 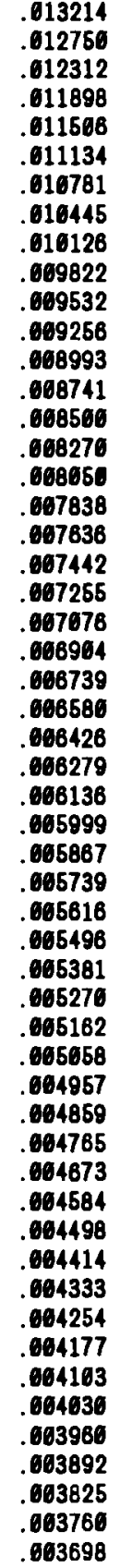 & 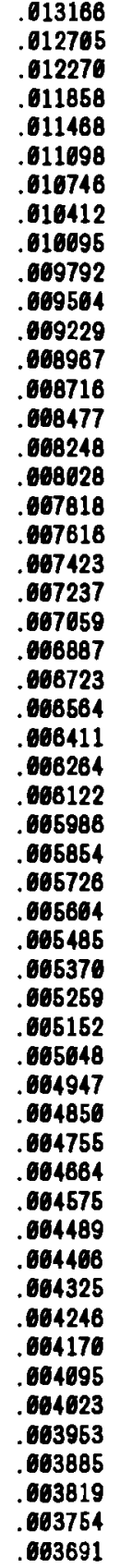 & 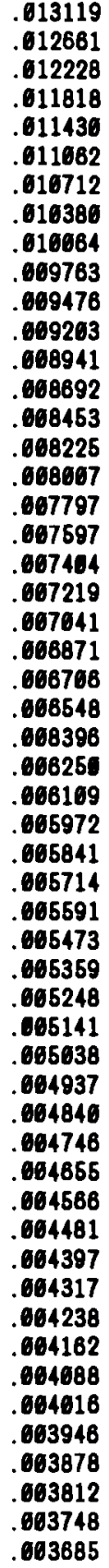 & 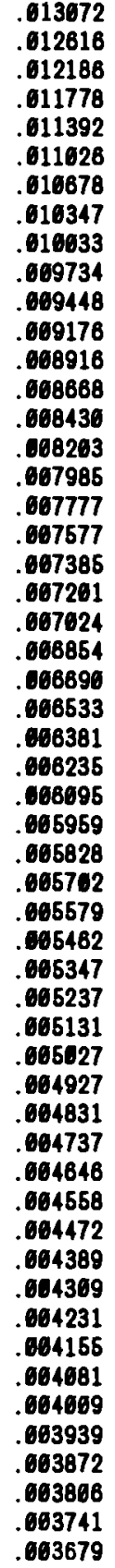 & 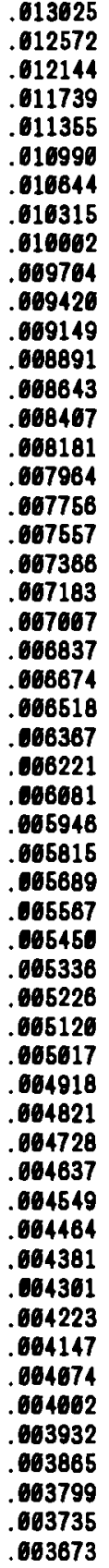 & 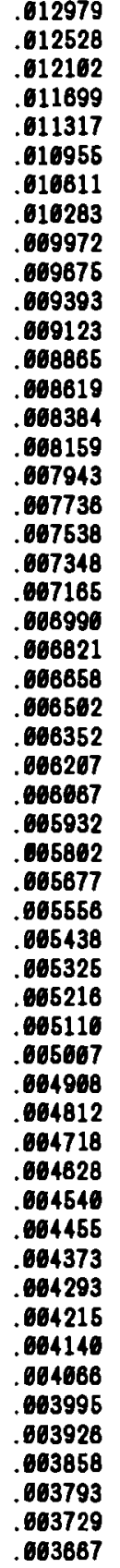 & 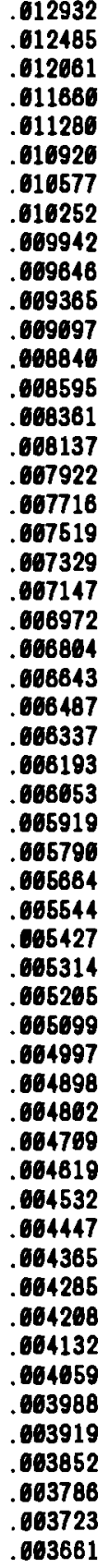 & 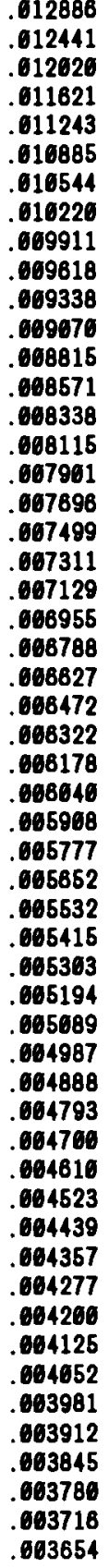 & 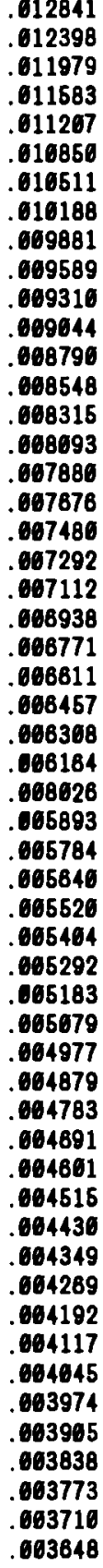 \\
\hline
\end{tabular}




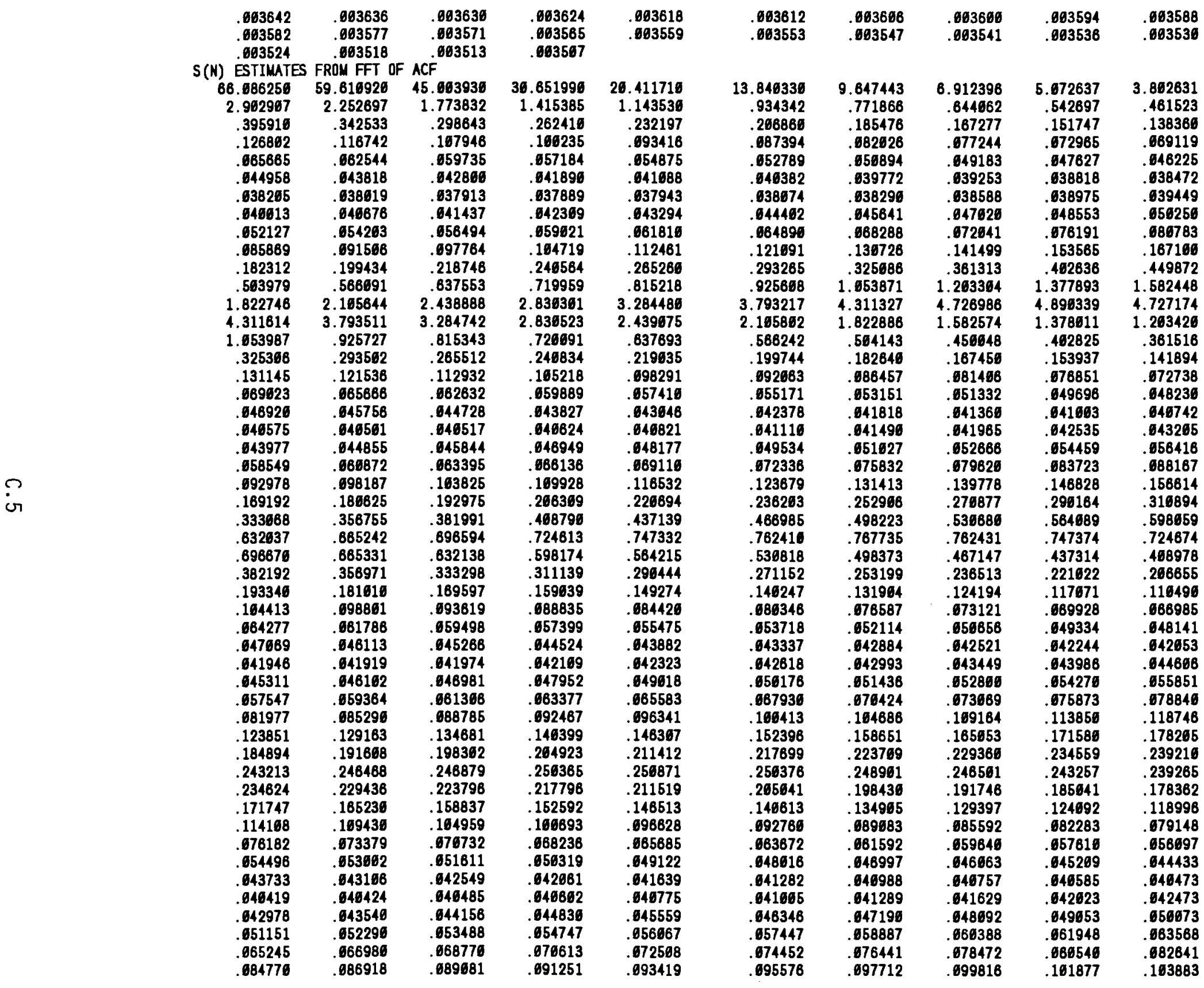




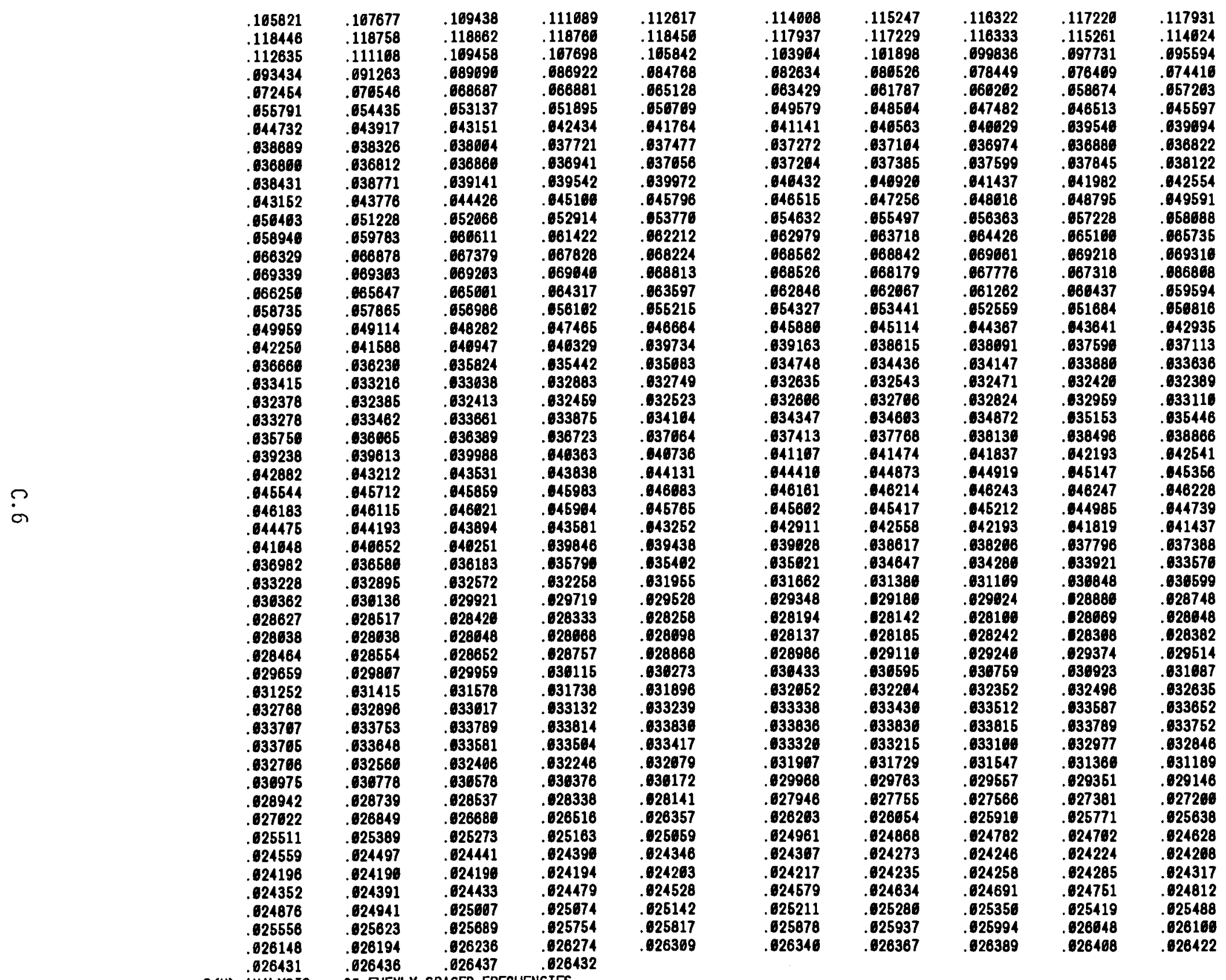




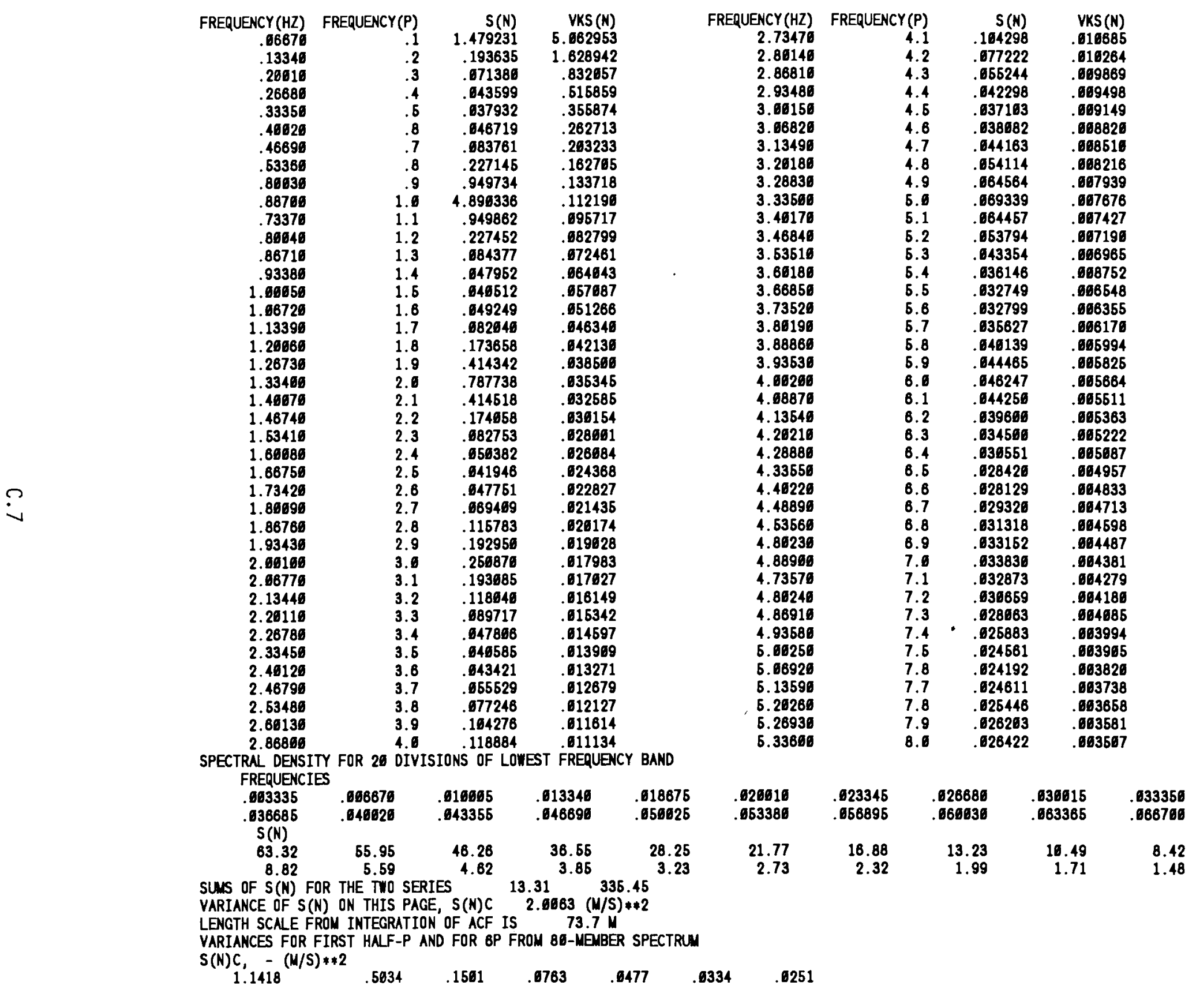


RUS

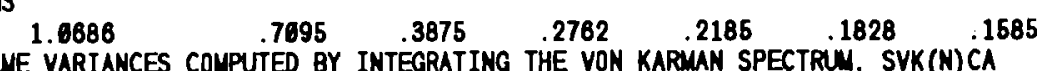

SANE VARIANCES COMPUTED BY INTEGRATING THE VON KARMAN SPECTRIN, SVK(N)CA

VARIANCES FOR FIRST HALF-P AND FOR GP FROM

SPECTRUY OF SIMUATED DATA S S(N)R

$\begin{array}{lllllll}1.1669 & .4441 & .1489 & .6763 & .6478 & .0336 & .0253\end{array}$

SPECTRA ESTIMATES FROM SIMULATED DATA

FIRST NUMBER IS SERIES MEAN

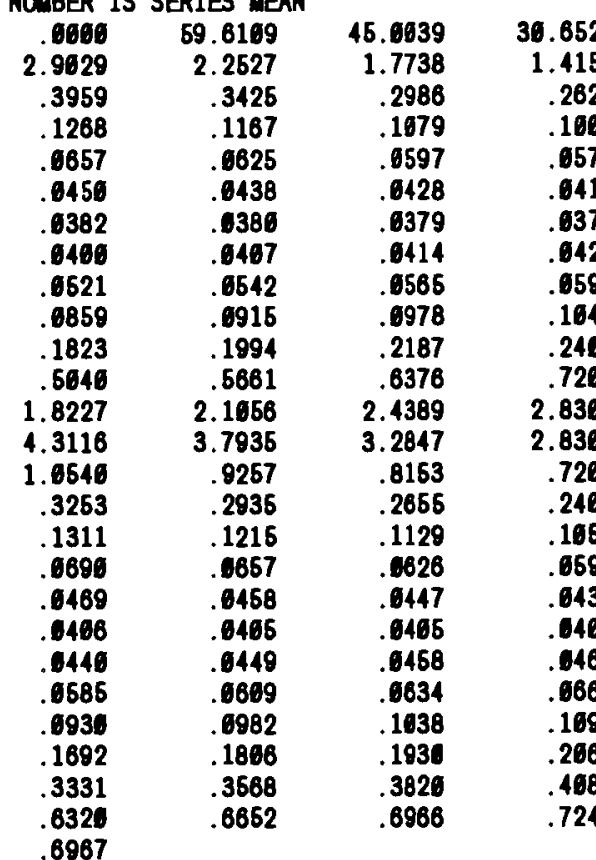

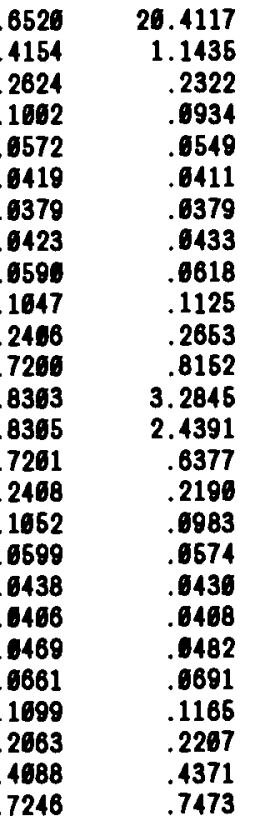

13.8463
.9343
.2669
.6874
.6528
.0464
.0381
.6444
.6649
.1211
.2933
.9256
3.7932
2.1658
.6662
.1997
.0921
.9552
.0424
.6411
.0495
.0723
.1237
.2362
.4670
.7624

9.6474
.7719
.1855
.6820
.6599
.6398
.6383
.6456
.6683
.1307
.3251
1.6539
4.3113
1.8229
.6841
.1826
.6865
.6532
.6418
.6415
.6516
.6758
.1314
.2629
.4982
.7877

6.9124
.6441
.1673
.6772
.6492
.6393
.6386
.6479
.6729
.1415
.3613
1.2633
4.7270
1.6826
.4689
.1676
.6814
.6513
.6414
.6420
.6527
.0796
.1398
.2769
.6397
.7624

6.0726
.6427
.1517
.0736
.0476
.0388
.6396
.0486
.0762
.1536
.4626
1.3779
4.8963
1.3786
.4628
.1539
.0769
.0497
.0416
.0426
.6546
.0837
.1488
.2962
.5641
.7474

3.8926

SMOM(1), SMOM (2) .0060 1.9163

SKEUNESS AND KURTOSIS $1856 \quad 2.8841$

HALF-RAMDOMIZING SIMUATION - PHASE RANDOMIZED

HALF-RANDOMIZING SIMUATION - PHASE RANDOMIZED
24 LOGARITHMICALLY SPACED BANDS AT 16 . PER SPECTRAL DECADE

BAND CENTER, HI, LOW (HZ), NS(N), HARMONIC COUNT PER BAND [NS(N):ORIO

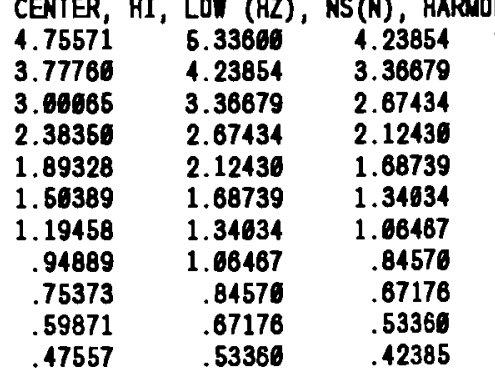

$\begin{array}{rrr}211 & 814 & 162 \\ 168 & 647 & 81 \\ 134 & 514 & 647 \\ 106 & 469 & 514 \\ 85 & 326 & 469 \\ 68 & 258 & 32 \\ 54 & 265 & 25 \\ 43 & 163 & 26 \\ 34 & 130 & 163 \\ 28 & 163 & 13 \\ 22 & 82 & 163\end{array}$

13568

$\begin{array}{cc}V K & V K A] \\ .01666 & .62617 \\ .01934 & .62349 \\ .02253 & .62737 \\ .02623 & .63186 \\ .63653 & .63768 \\ .03566 & .64325 \\ .04152 & .65644 \\ .04836 & .65876 \\ .05616 & .66821 \\ .06539 & .67942 \\ .07627 & .69263\end{array}$




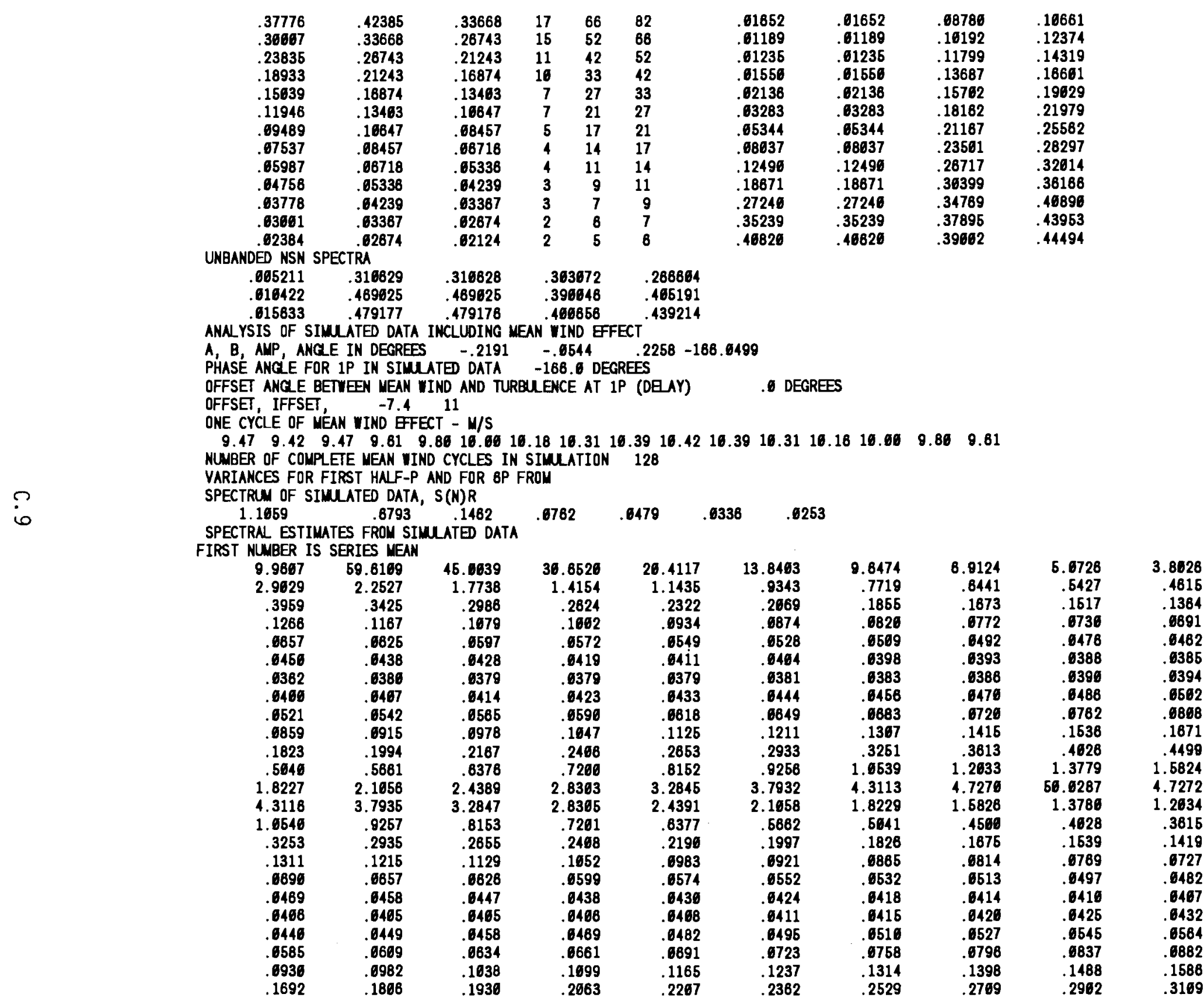




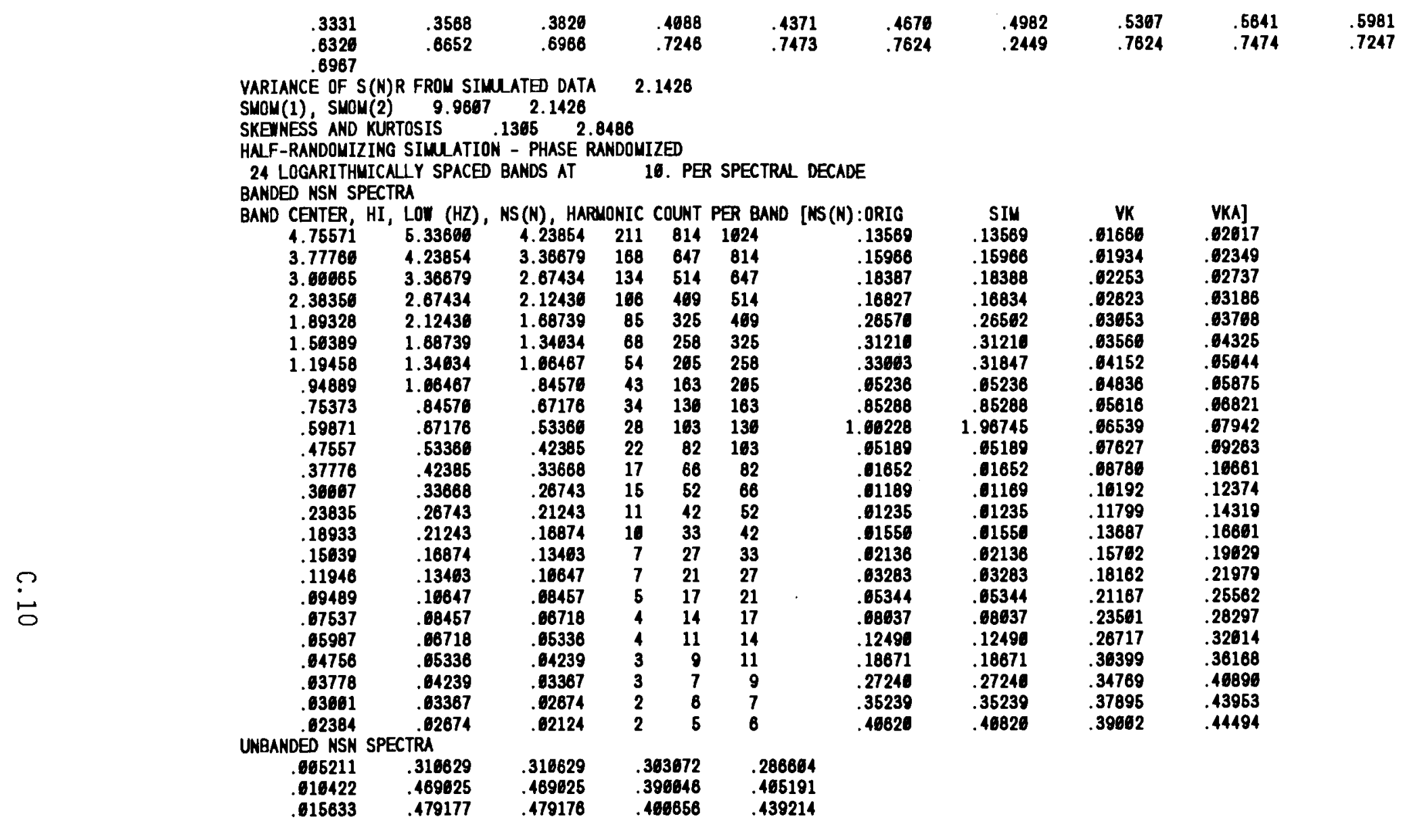




\section{APPENDIX D}

SAMPLE OUTPUT FROM THE FILE SERIES.DAT FOR THE HAWT CASE AT HALF-BLADE RADIUS 

APPENDIX D

SAMPLE OUTPUT FROM THE FILE SERIES.DAT FOR THE HAWT CASE AT HALF-BLADE RADIUS

D.1 SAMPLE FILE FOR TURBULENT PART OF THE WIND

\begin{tabular}{|c|c|c|c|}
\hline $\begin{array}{r}2048 \\
1.843446 \\
3.316686 \\
1.614217 \\
1.935520 \\
2.647616 \\
1.275372 \\
1.881323 \\
2.091939 \\
1.870421 \\
1.458670 \\
2.713935 \\
1.647073 \\
-1.094317 \\
1.099581 \\
1.112830 \\
6.748724 \mathrm{E}-01 \\
8.316345 \mathrm{E}-01\end{array}$ & $\begin{array}{r}2.076073 \\
1.021647 \\
1.613472 \\
9.914294 \mathrm{E}-01 \\
2.186547 \\
2.970832 \\
1.484519 \\
1.532165 \\
1.908166 \\
9.922648 \mathrm{E}-01 \\
5.219072 \mathrm{E}-01 \\
1.305969 \\
1.265098 \\
-7.755048 \mathrm{E}-01 \\
3.767361 \mathrm{E}-01 \\
9.644930 \mathrm{E}-01 \\
-2.477923 \mathrm{E}-01 \\
-1.086399 \\
4.849330 \mathrm{E}-02 \\
3.002124 \mathrm{E}-01 \\
-9.716650 \mathrm{E}-01 \\
-1.534747 \\
1.008137 \\
1.107034 \\
1.439541 \mathrm{E}-01 \\
-2.817943 \\
5.665348 \mathrm{E}-01 \\
9.821851 \mathrm{E}-01 \\
-1.171757 \\
-1.622636 \\
-4.204648 \mathrm{E}-01 \\
4.339325 \mathrm{E}-02 \\
-7.141615 \mathrm{E}-01 \\
-5.958565 \mathrm{E}-01 \\
1.250880 \mathrm{E}-01 \\
-8.368164 \mathrm{E}-01 \\
1.888407 \mathrm{E}-01 \\
7.312166 \mathrm{E}-01 \\
-4.228624 \mathrm{E}-01 \\
-7.432396 \mathrm{E}-01 \\
-7.120957 \mathrm{E}-01 \\
3.794590 \mathrm{E}-01 \\
2.434153 \mathrm{E}-01 \\
-2.013039\end{array}$ & $\begin{array}{r}400751 \mathrm{E}-01 \\
1.358754 \\
1.217244 \\
6.968585 \mathrm{E}-01 \\
1.074212 \\
1.559561 \\
5.747703 \mathrm{E}-01 \\
9.291232 \mathrm{E}-01 \\
9.984764 \mathrm{E}-01 \\
6.226134 \mathrm{E}-01 \\
8.686469 \mathrm{E}-01 \\
-1.167601 \mathrm{E}-01 \\
8.355237 \mathrm{E}-01 \\
8.751794 \mathrm{E}-01 \\
7.943738 \mathrm{E}-01 \\
-4.941007 \mathrm{E}-02 \\
5.105027 \mathrm{E}-01 \\
-1.216976 \\
1.339363 \\
5.216386 \mathrm{E}-01 \\
7.518607 \mathrm{E}-02 \\
-7.154712 \mathrm{E}-01 \\
1.480822 \\
-2.648050 \mathrm{E}-02 \\
4.306168 \mathrm{E}-01 \\
-2.212637 \\
-4.086412 \mathrm{E}-01 \\
7.135606 \mathrm{E}-01 \\
-6.695012 \mathrm{E}-01 \\
-1.818481 \\
3.056279 \mathrm{E}-01 \\
-2.247749 \mathrm{E}-01 \\
1.208970 \mathrm{E}-01 \\
-1.345321 \\
4.024305 \mathrm{E}-01 \\
-8.456659 \mathrm{E}-02 \\
1.147803 \\
-2.507349 \mathrm{E}-01 \\
-2.542650 \mathrm{E}-01 \\
-9.528984 \mathrm{E}-01 \\
-2.836452 \mathrm{E}-01 \\
1.079795 \\
-1.104215 \\
-1.139686\end{array}$ & $\begin{array}{r}1 \\
1 \\
7.182 \\
1 \\
6.344 \\
2.671 \\
1 \\
8.309 \\
1 \\
1.714 \\
-3.746 \\
1 \\
-8.856 \\
-2.097 \\
-6.738 \\
2.807 \\
-4.597 \\
-1 \\
-9.933 \\
-6.890 \\
-5.989 \\
-7.477 \\
-9.895 \\
7.699 \\
-2.478 \\
-8.139 \\
1.094 \\
1 \\
-1 \\
-4.316 \\
2.018 \\
-5.940 \\
-6.578 \\
3.919 \\
6.194 \\
-1 \\
1.952\end{array}$ \\
\hline
\end{tabular}

2.338139

D. 1 
2.389396E-01

4.654599E-01

4.228266E-01

$-8.789260 E-01$

5.132513E-01

2.893252E-01

$-8.879077 E-01$

$-1.324166$

$-9.390742 \mathrm{E}-02$

$-7.063335 \mathrm{E}-01$

3.891642E-01

$-7.367760 \mathrm{E}-01$

1.089556

$-3.865625 E-01$

$-8.947815 E-01$

$-2.281215$

1.222859

2.112708E-01

$-3.660117 E-01$ $-1.093969$

9.996289E-01

$-6.619879 E-01$

$-7.785997 \mathrm{E}-01$

$-3.961572 E-02$

$-3.618800 \mathrm{E}-01$

$-2.667359 E-01$

4. 522759E-02

$-3.092958 E-02$

$-2.057778 E-01$

$3.768280 \mathrm{E}-02$

8.304861E-01

$-2.237248 E-01$

$-5.074259 E-01$

9.252548E-01

8.714794E-01

$-8.664709 E-01$

$-7.595584 \mathrm{E}-01$

5.211271E-01

4.385185E-01

$1.790620 \mathrm{E}-01$

$-9.422884 \mathrm{E}-01$

$-6.517717 \mathrm{E}-01$

$-1.270611$

$5.643666 \mathrm{E}-01$

$-9.392869 \mathrm{E}-01$

$-1.581491$

$-1.207915$

$-6.220839 E-01$

$-1.063427$

$-1.834853$

$-1.806963$

8. 166504E-02
$2.586895 \mathrm{E}-01$

$3.748999 \mathrm{E}-01$ $-1.243848$

$-8.618394 \mathrm{E}-01$

$-6.676229 E-02$

8.658149E-01

$-1.590529$

$-6.970474 E-01$

$1.914034 \mathrm{E}-01$

$-6.770900 E-01$

$-1.422647$

$6.756864 \mathrm{E}-01$

1.448520

$-7.488615 E-01$

. -1.297430

$-1.799450$

1.012385

$1.752460 \mathrm{E}-01$

$-3.712884 \mathrm{E}-01$

$-1.733226$

1.067426

$-1.377589 \mathrm{E}-01$

$-1.547865$

1.286612E-01

4.329997E-01

8.061666E-01 $-1.943646$

1.291391E-01

$-1.037681$

$6.564618 \mathrm{E}-01$

$7.427335 \mathrm{E}-02$

$-3.141608 \mathrm{E}-01$ $-1.622937$

$7.660846 \mathrm{E}-01$

$6.146393 \mathrm{E}-01$ $-1.063849$

$-2.132871$

5.631825E-01

$-2.805782 E-01$

$-7.848344 \mathrm{E}-01$

$-1.527152$

$-1.004805 E-01$ $-1.542978$

$-1.699240 \mathrm{E}-01$

$-1.718435 \mathrm{E}-01$

$-6.798834 \mathrm{E}-02$ $-1.090602$

$-8.532871 E-01$

$-2.107415 E-01$ $-1.494505$

$-7.807907 \mathrm{E}-01$ $-1.105034$
$-4.403980 \mathrm{E}-01$

4.866753E-01

$-1.392797$

$-4.412740 \mathrm{E}-01$

$1.519745 \mathrm{E}-01$

1.251635

$-1.857567$

$-7.668741 \mathrm{E}-01$

1.058972

9.640802E-01

$-1.701642$

$-1.784716 E-01$

1.186957

$1.817799 \mathrm{E}-01$

$-1.233360$

$-1.081927 \mathrm{E}-01$

8.129695E-01

1.320962E-01

$-1.412306$

$1.461598 \mathrm{E}-01$

8.014847E-01

$-2.389369 E-01$

$-1.826867$

$-4.687365 E-01$

$-2.405456 E-01$

$-7.707934 \mathrm{E}-01$

$-1.046264$

4. $928303 \mathrm{E}-01$

$-1.187494$

4.523647E-01

$-1.088347$

9.848756E-02

$-2.445074$

4.336451E-01

$7.813359 \mathrm{E}-01$

$-1.151340$

$-1.071164$

4. $975958 \mathrm{E}-01$

$-8.766341 E-02$

$-9.576132 \mathrm{E}-01$

$-1.627165$

$-4.251462 E-01$

$-8.467219 E-01$

$-5.214103 E-01$

$-2.326468$

$-6.562498 E-01$

1.609885E-01

$-9.353518 E-01$

$-9.364847 \mathrm{E}-01$

$-3.634915 E-01$

1.264636

$-8.656137 E-02$
$-5.120499 E-01$

4.629282E-01

$-5.402253 E-01$

$6.633582 \mathrm{E}-01$

$-5.333039 E-01$

$3.742760 \mathrm{E}-01$

$-1.977337$

$7.605446 \mathrm{E}-01$

$-5.772703 E-01$

$7.786233 \mathrm{E}-01$

$-2.269276$

1.382987

$-1.266867 E-01$

2. $680401 \mathrm{E}-01$

$-2.578604$

1.173131

$-3.356437 \mathrm{E}-01$

4.122001E-01

$-1.506803$

$7.272745 \mathrm{E}-01$

$-9.882981 E-02$

$-2.438908 \mathrm{E}-01$

$-6.538156 \mathrm{E}-01$

$6.118602 \mathrm{E}-01$

$-1.148513$

$-3.945635 E-01$

$-3.632769 \mathrm{E}-01$

2.842263E-01

$-6.598514 E-01$

$-1.036177$

$-4.741601 E-01$

$-5.505564 \mathrm{E}-01$

$-9.582552 E-02$

$1.002876 \mathrm{E}-01$

$-3.054557 E-01$

$-8.370621 E-01$

$-5.379018 E-01$

7.969086E-01

$-1.470283 \mathrm{E}-01$

$-1.194698$

$-1.251946$

$-6.087676 \mathrm{E}-01$

$-1.741547 E-01$

$-9.946434 E-01$

$-7.609184 E-01$

$-1.165518$

4.218521E-01

$-1.617091$

$-1.209996$

$-1.007462$

1.787322

$-9.078007 E-01$

D.2 
D.2 FLUCTUATIONS CAUSED BY ROTATION THROUGH THE TOTAL WIND

\begin{tabular}{rr}
2048 & 11.546950 \\
11.645550 & 11.021650 \\
13.711030 & 12.036260 \\
11.789800 & 10.991430 \\
11.406400 & 11.604640 \\
12.449720 & 12.970830 \\
11.669710 & 11.907310 \\
12.056910 & 11.532170 \\
11.562820 & 11.326260 \\
11.672520 & 10.992260 \\
11.853010 & 10.944690 \\
12.889520 & 11.305970 \\
11.117950 & 10.683190 \\
8.707787 & 9.224495 \\
11.493920 & 10.799520 \\
11.288420 & 10.964490 \\
10.145750 & 9.170300 \\
8.970469 & 8.913601 \\
10.523090 & 10.471280 \\
10.149940 & 10.300210 \\
8.672288 & 8.446427 \\
8.188819 & 8.465253 \\
10.306720 & 11.430920 \\
10.823930 & 11.107030 \\
8.574611 & 9.562047 \\
8.653730 & 7.182057 \\
11.136510 & 10.989320 \\
10.564260 & 10.982190 \\
7.578473 & 8.246336 \\
8.929216 & 8.377364 \\
9.568401 & 10.002320 \\
10.685790 & 10.043390 \\
8.060882 & 8.703931 \\
9.417477 & 9.404143 \\
9.662163 & 10.547880 \\
10.470870 & 9.163183 \\
7.683899 & 9.606934 \\
10.542780 & 10.731220 \\
10.866200 & 9.999926 \\
9.822787 & 9.256761 \\
8.581502 & 8.705997 \\
9.986992 & 10.379460 \\
11.035730 & 10.666200 \\
8.748847 & 7.986961 \\
9.709820 & 9.676783 \\
10.267560 & 10.374900 \\
10.817170 & 9.178940 \\
9.296659 & 9.138161 \\
9.984132 & 9.351331 \\
10.091430 & 10.865820 \\
& \\
\hline
\end{tabular}

$\begin{array}{rr}10.358170 & 10.037310 \\ 11.534340 & 12.466440 \\ 11.611580 & 12.240600 \\ 10.498960 & 11.298150 \\ 10.545090 & 11.797710 \\ 11.735150 & 12.580220 \\ 10.969110 & 11.811960 \\ 10.731230 & 10.800050 \\ 10.469360 & 10.707360 \\ 10.798200 & 11.028570 \\ 11.262990 & 12.283620 \\ 9.685343 & 10.246590 \\ 10.306410 & 9.638812 \\ 11.050770 & 11.459310 \\ 11.188710 & 11.141300 \\ 9.752693 & 10.711670 \\ 9.981384 & 9.783581 \\ 8.958610 & 9.935760 \\ 11.733700 & 11.383110 \\ 10.323740 & 9.523540 \\ 9.546067 & 9.402339 \\ 9.460114 & 9.636478 \\ 11.875160 & 10.591150 \\ 9.775622 & 9.152394 \\ 9.901498 & 8.437181 \\ 7.962949 & 9.317041 \\ 9.985700 & 9.621320 \\ 10.515660 & 9.013162 \\ 8.801380 & 8.864312 \\ 8.357105 & 9.320825 \\ 10.699970 & 11.080360 \\ 9.577328 & 9.364282 \\ 9.591779 & 8.798141 \\ 8.830265 & 10.419840 \\ 10.796770 & 11.369450 \\ 9.717537 & 7.982899 \\ 10.618680 & 9.180435 \\ 9.924850 & 10.512260 \\ 10.140080 & 9.716326 \\ 8.849205 & 8.954207 \\ 9.187236 & 10.004000 \\ 11.255380 & 10.929860 \\ 9.290126 & 8.689289 \\ 8.662417 & 9.807380 \\ 9.030483 & 9.100052 \\ 10.662260 & 10.773300 \\ 9.001543 & 9.770143 \\ 9.360829 & 10.275460 \\ 9.622856 & 9.078797 \\ 11.427220 & \\ & 10.684640\end{array}$

11.950240

12.240600

11.298150

11.797710

12.580220

11.811960

10.800050

11.028570

12.283620

9.638812

11.459310

11.141300

10.711670

9.783581

9.935760

11.383110

9.523540

9.402339

9.636478

10.591150

9.152394

9.317041

9.621320

9.013162

9.320825

11.080360

9.364282

8.798141

10.419840

11.369450

7.982899

10.512260

9.716326

8.954207

10.004000

10.929860

8.689289

9.807380

9.100052

10.773300

9.770143

9.078797

D. 3 


\begin{tabular}{|c|c|c|c|}
\hline $\begin{array}{r}9.506433 \\
8.851419 \\
9.376973 \\
9.095770 \\
10.783500 \\
9.438809 \\
10.560440 \\
9.415541 \\
9.499559 \\
7.894371 \\
10.693740 \\
10.013370 \\
10.028330 \\
9.081616 \\
10.470510 \\
9.140115 \\
9.615741 \\
10.135970 \\
9.109000 \\
9.535367 \\
10.439570 \\
10.144660 \\
9.265102 \\
9.839786 \\
11.224830 \\
9.951861 \\
8.963454 \\
10.727360 \\
11.265820 \\
9.309114 \\
8.711322 \\
10.323230 \\
10.832860 \\
10.354650 \\
8.528592 \\
9.150331 \\
9.123730 \\
10.739950 \\
8.531593 \\
8.220612 \\
9.186425 \\
9.553502 \\
8.407454 \\
7.967250 \\
7.99173760 \\
9.464486 \\
9.733490 \\
8.722915 \\
8.382736\end{array}$ & $\begin{array}{r}8.832258 \\
9.302953 \\
9.609496 \\
9.322910 \\
9.000141 \\
10.675690 \\
10.866610 \\
9.251139 \\
9.125358 \\
8.200550 \\
10.430480 \\
10.175250 \\
10.051500 \\
8.266774 \\
10.485520 \\
9.862241 \\
8.874923 \\
10.128660 \\
9.851092 \\
10.806170 \\
8.479141 \\
10.129140 \\
8.380412 \\
10.656460 \\
10.497060 \\
9.685840 \\
7.795156 \\
10.766080 \\
11.037430 \\
8.936152 \\
7.285222 \\
10.563180 \\
10.142210 \\
9.215166 \\
7.890941 \\
9.899520 \\
8.879809 \\
9.830076 \\
9.246249 \\
9.932012 \\
9.332186 \\
9.146713 \\
9.207352 \\
8.505495 \\
9.641997 \\
8.894966 \\
9.298132 \\
7.637530 \\
9.319710 \\
9.204282\end{array}$ & $\begin{array}{r}8.536774 \\
9.035229 \\
10.529850 \\
11.139670 \\
8.692698 \\
9.623631 \\
10.657840 \\
10.357370 \\
9.160980 \\
9.693911 \\
10.283850 \\
10.307680 \\
8.982035 \\
9.948263 \\
10.272370 \\
9.936649 \\
8.567473 \\
9.333366 \\
9.230336 \\
9.404793 \\
9.348077 \\
10.294930 \\
8.283387 \\
10.627950 \\
9.305994 \\
9.900591 \\
7.025807 \\
10.609230 \\
11.175680 \\
8.650763 \\
8.399717 \\
10.673180 \\
10.306680 \\
8.844490 \\
7.843717 \\
9.750440 \\
9.547619 \\
9.280693 \\
7.144413 \\
9.519336 \\
10.555330 \\
8.866752 \\
8.534397 \\
9.812095 \\
11.658980 \\
9.715542 \\
9.142229 \\
9.185664 \\
11.646670 \\
8.931449 \\
9.294740 \\
10\end{array}$ & $\begin{array}{r}8.333031 \\
10.372650 \\
9.034831 \\
11.088990 \\
8.041092 \\
10.995090 \\
9.485415 \\
10.578410 \\
7.731764 \\
10.785230 \\
9.276458 \\
10.722570 \\
8.803564 \\
10.339380 \\
9.513271 \\
10.066480 \\
9.656552 \\
10.223960 \\
8.463589 \\
9.915804 \\
9.947091 \\
9.896328 \\
8.952250 \\
9.274191 \\
9.836207 \\
9.061545 \\
9.516276 \\
10.410660 \\
10.004910 \\
8.775040 \\
9.074200 \\
11.107280 \\
10.163340 \\
8.417403 \\
8.360155 \\
9.701600 \\
10.136210 \\
8.617458 \\
8.704351183 \\
9.932896 \\
9.144850 \\
10.732220 \\
7.995010 \\
8.402105 \\
9.302906 \\
8.1803840 \\
9.805149\end{array}$ \\
\hline
\end{tabular}

D. 4 


\section{APPENDIX E}

SAMPLE OUTPUT FROM ALL FILES FOR THE HAWT CASE AT FULL-BLADE RADIUS 



\section{E.1 SUMMARY.BRF FOR FULL-TIP RADIUS}

\section{HAIT SIMUATION}

SERIAL NUMBER HT16

RADIUS OF ROTATION $19.6 \mathrm{M}$

RATE OF ROTATION $.6670 \mathrm{HZ}$

HUB HEIGHT $30.5 \mathrm{M}$

SURFACE ROUGHNESS LENGTH .0506

MEAN WIND SPEFD $10.06 \mathrm{~m} / \mathrm{S}$

TURBULENCE RUS VALUES

$\begin{array}{ll}\text { U-COMPONENT } & 1.497 \mathrm{M} / \mathrm{S} \\ \text { V-COMPONENT } & 1.497 \mathrm{M} / \mathrm{S}\end{array}$

TURBULENCE VARIANCES

U-COMPONENT $2.241(\mathrm{M} / \mathrm{S}) * * 2$

$\checkmark$-COMPONENT $2.241(\mathrm{~N} / \mathrm{S}) * 2$

FRICTION VEOCITY . .624 $\mathrm{w} / \mathrm{s}$

TURBULENE INTEGRAL LENGTH SCALES

LONGITUDINAL $128.1 \mathrm{M}$

LATERAL 51.2

NUMBER DATA TO BE SIMULATED 2648

DISCRETIZATION INTERVAL .0937 SEC

ANCULAR DISCRETIZATION INTERVAL 22.6 DEGREES

NAMCLE WAS READ IN - DT WAS CALCULATED

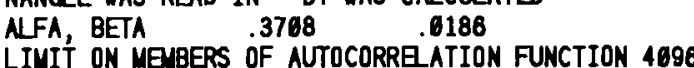

NUMBER OF HARMONICS IN SPECTRA

THIS IS ALSO A COMPARISON BETWEEN NUUBER OF HARMONICS IN ORIGINAL

SPECTRUM AND REDUCED VERSION.

FUNDAMENTAL FREQUENCY IS .665211 HZ

MAX FINAL VALUE OF CORREATION ACCEPTABLE WITHOUT WINDOWING . .00100

VARIANCE OF $S(N)$ ON THIS PAGE, $S(N) C 2.1012(M / S) \neq * 2$

VARIANCES FOR FIRST HALF -P AND FOR GP FROM 80-MEMER SPECTRU,

$S(N) C,-(M / S) * * 2$

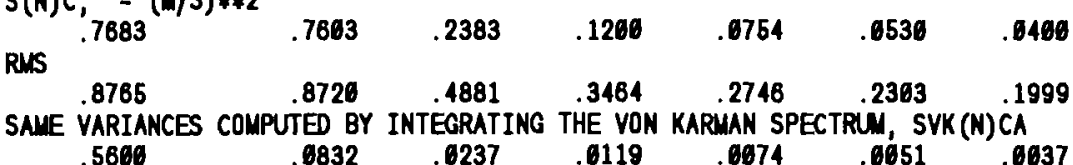
.5606 O832 .6237 .6119

VARIANCES FOR FIRST HALF-P AND FOR 6P FROM
SPECTRUM OF SIWULATED DATA, S(N)R

$$
\begin{array}{llll}
7363 & .5693 & .2244 & .1190
\end{array}
$$

VARIANCE OF S(N)R FROM SIMUATED DATA 1.8559

SKENNESS AND KURTOSIS $\quad-.6028 \quad 2.8684$

ANALYSIS OF SIMULATED DATA INCLUDING MEAN WIND EFFECT

VARIANCES FOR FIRST HALF-P AND FOR 6P FROM

SPECTRUM OF SIMULATED DATA, S(N)R

VARIANCE OF S(N)R FROM SIMULATED DATA 2.7808

$.0760 \quad .6531$

$.0531 \quad .0460$

SKEUNESS AND KURTOSIS.$- .6535 \quad 2.7323$ 


\section{E.2 SUMMARY.DAT FOR FULL-TIP RADIUS}

\section{HANT SIMLATION}

SERIAL NUMBER HT160

RADIUS OF ROTATION 19.

RATE OF ROTATION $\quad .6870 \mathrm{HZ}$

HUB HEIGHT $30.5 \mathrm{M}$

SURFACE ROUGHNESS LENGTH .

MEAN WIND SPEED $10.00 \mathrm{~m} / \mathrm{S}$

TURBULENCE RUS VALUES

U-COMPONENT $1.497 \mathrm{M} / \mathrm{S}$

$\checkmark$-COMPONENT $1.497 \mathrm{~m} / \mathrm{S}$

TURBULENCE VARIANCES

U-COUPONENT $2.241(\mathrm{M} / \mathrm{S}) * \approx 2$

V-COMPONEUT $2.241(\mathrm{M} / \mathrm{S}) * 2$

FRICTION VEOCITY .624 M/S

TURBULENCE INTEGRN LENGTH SCALES

LONGITUDINAL 128.1

LATERAL $51.2 \mathrm{M}$

MUBER DATA TO BE SIMULATED 2048

OISCRETIZATION INTERVAL

ALIAS FACTOR

.6937 SEC

ANCULAR DISCRETIZATION INTERVAL 22.5 DEGREES

MANELE WAS READ IN - DT WAS CALCULATED

NFA, BETA .3708

LIMIT ON MEMBERS OF AUTOCORREATION FUNCTION 4696

MUMBER OF HARYONICS IN SPECTRA 1024

THIS IS ALSO A COUPARISON BETUEEN NUMBER OF HARMONICS IN ORIGINAL

SPECTRY

FUECTRUM AND REDUCED VERSION.

MAX FINAL VALUE OF CORRE ATION ACCEPTABLE WITHOUT WINDOWING .00100 DIFFERENT FORUS OF VARIABLES:

- - INCLUDING EXTENSIONS ASSOCIATED WITH NLIAS REMOVN

- ND - DIMENSIONLESS VARIABLE

DISCRETIZATION INTERYAL - DT

DISCRETIZATIO

$$
.094 \text { SEC }
$$

- .023 SEC

-ND .196

NUMBER OF SIMULATED DATA - MTT

$$
2048
$$

2648
A
8192

FUNDARENTAL FREQUENCY - EN1

- $.06521 \mathrm{HI}$

IND $\quad .06249$

NYQUIST FREQUENCY - EN2

$-A \quad 21.34460 \mathrm{HZ}$ 


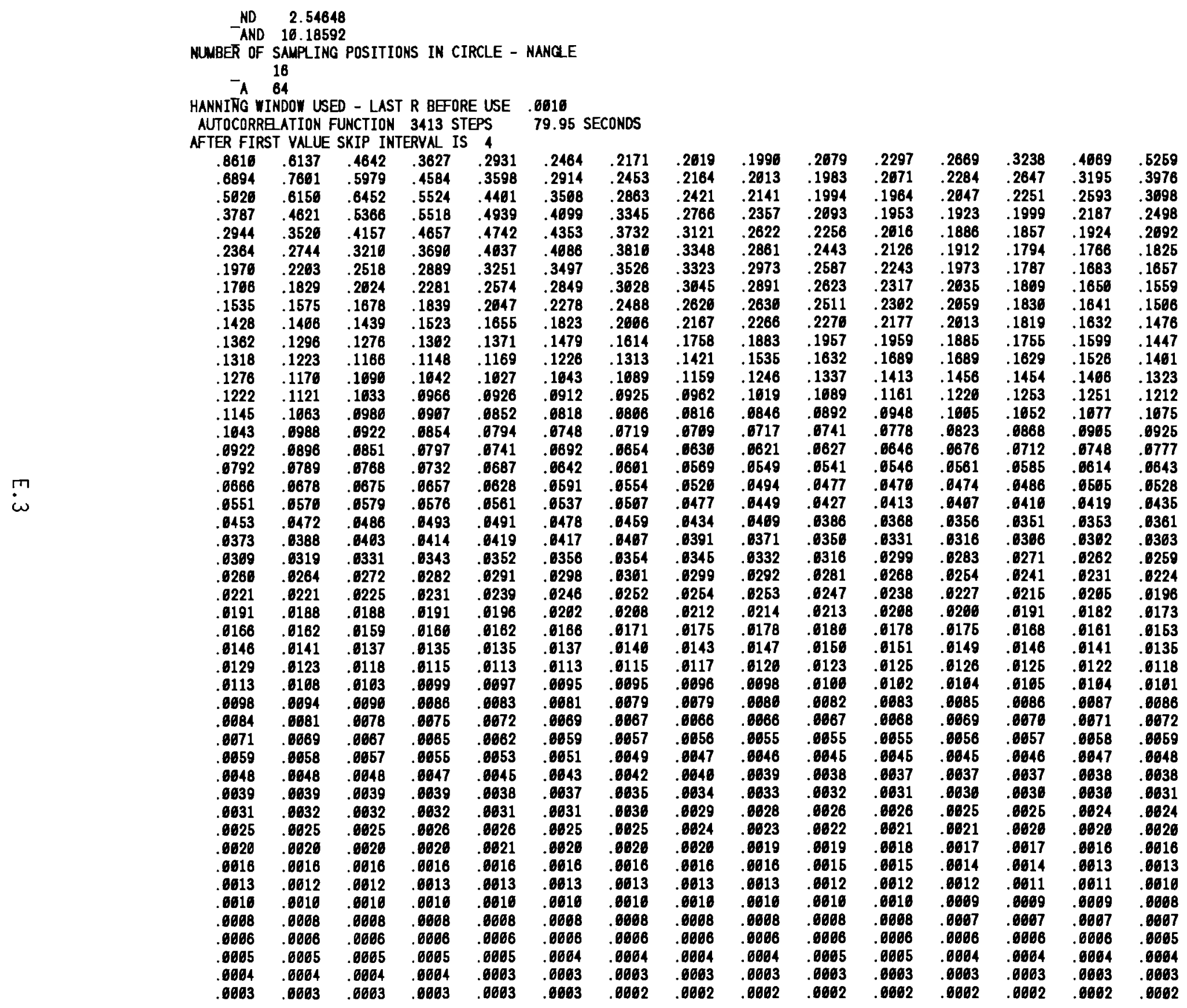




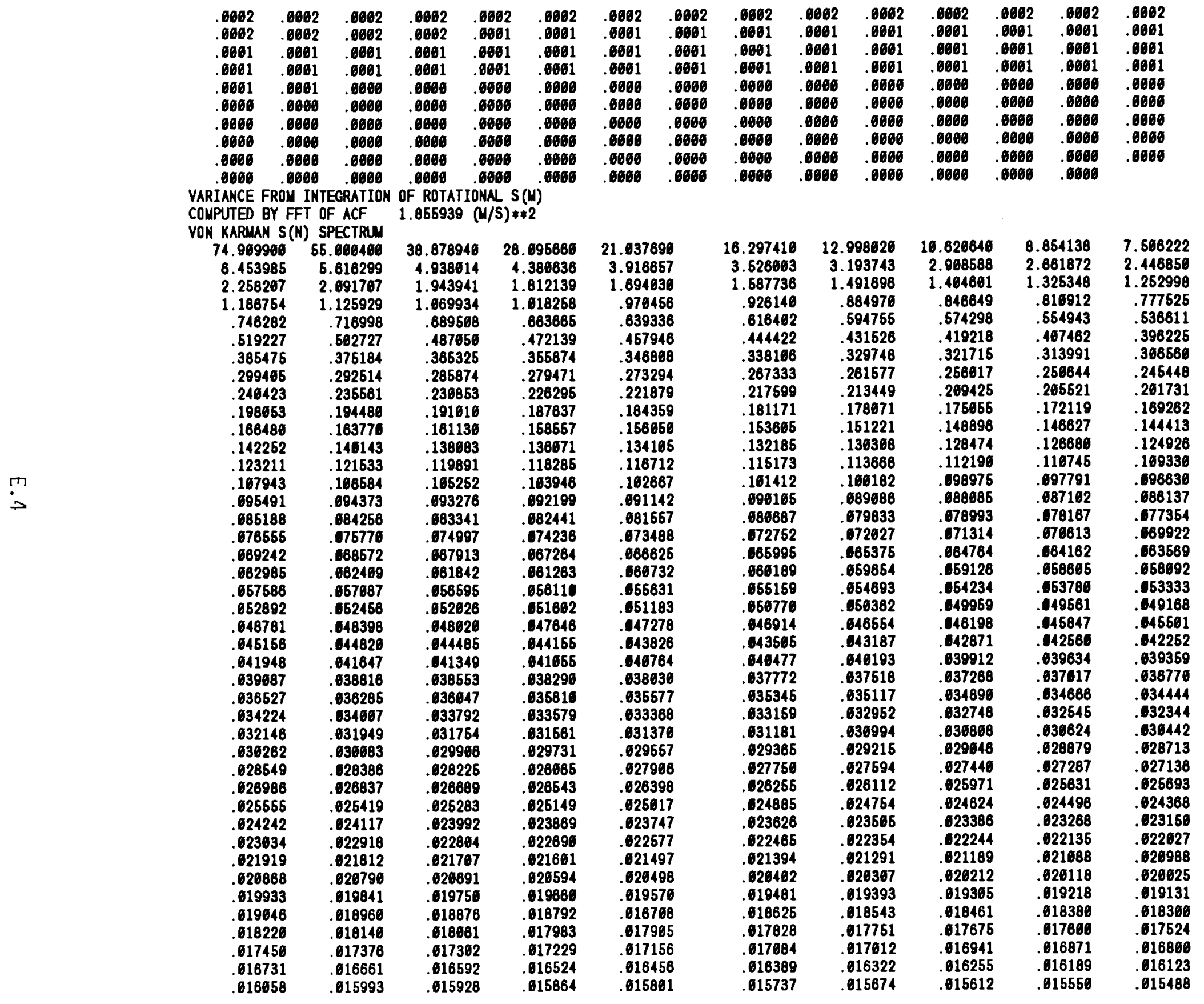




\begin{tabular}{|c|c|c|c|c|c|c|c|c|c|}
\hline 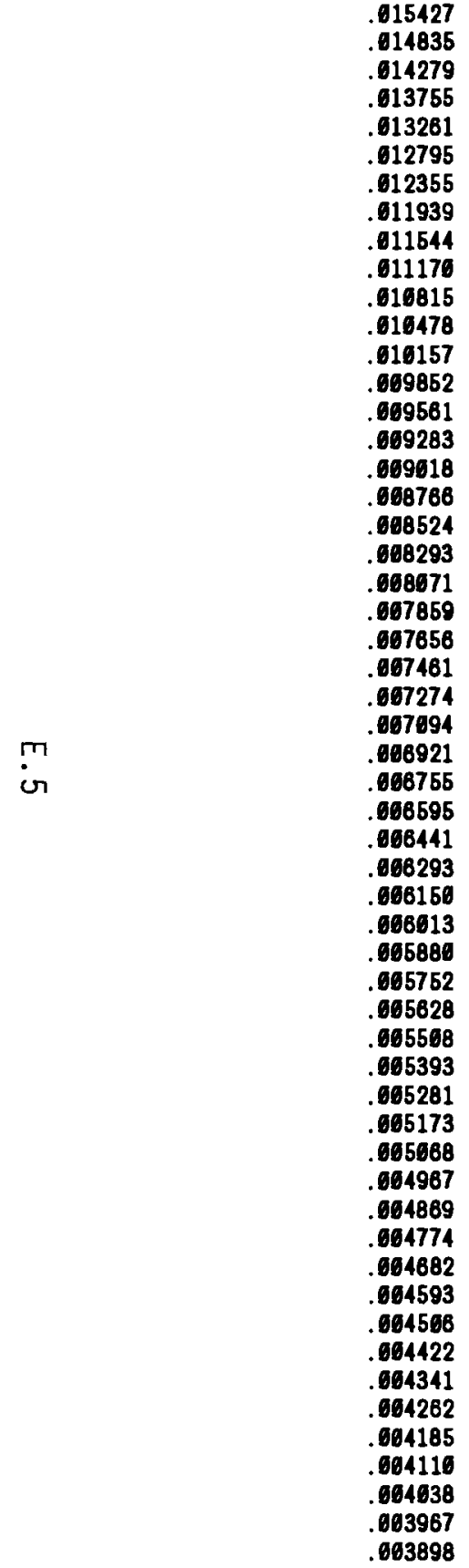 & 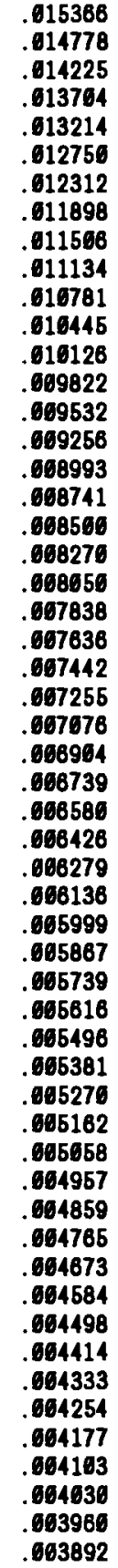 & 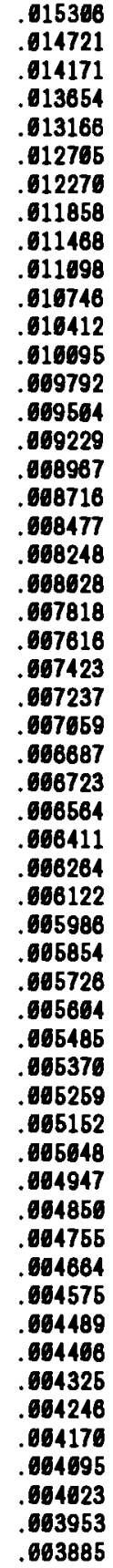 & 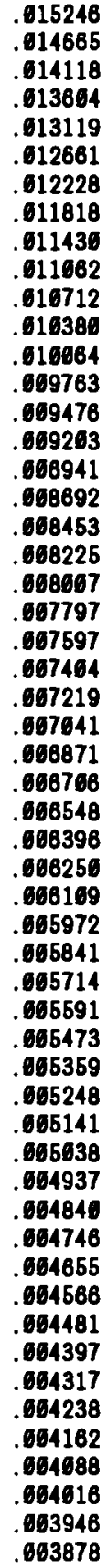 & 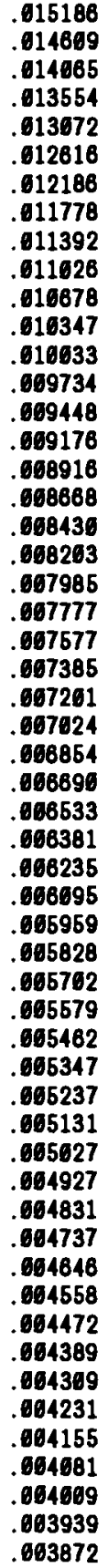 & 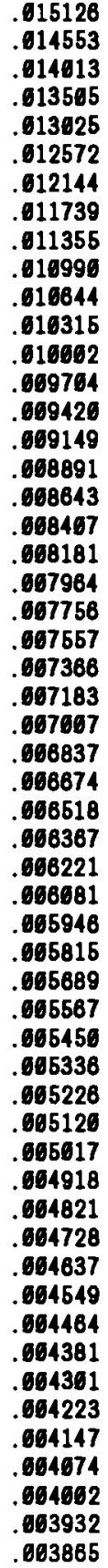 & 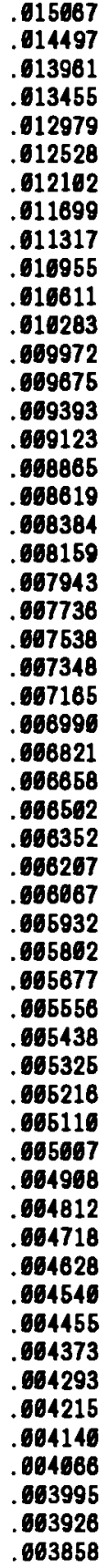 & 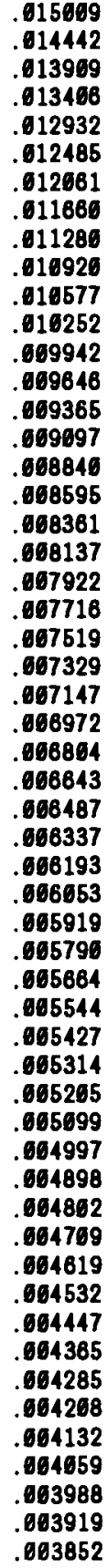 & 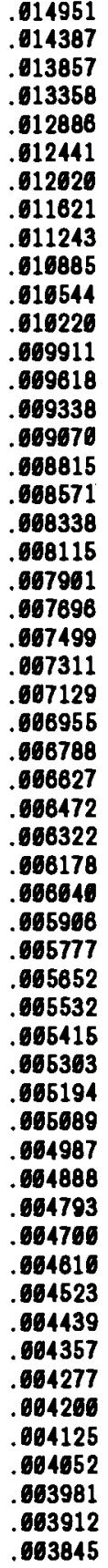 & 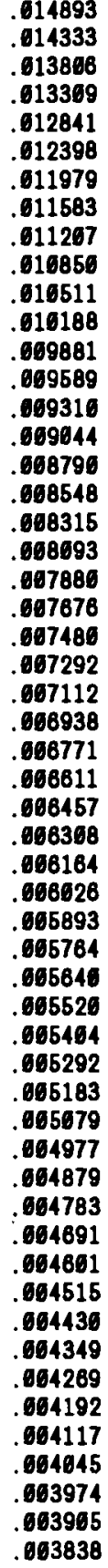 \\
\hline
\end{tabular}




\begin{tabular}{|c|c|c|c|c|c|c|c|c|c|}
\hline $\begin{array}{r}.663832 \\
.663767 \\
.663764 \\
.663642 \\
.603582 \\
. .603524 \\
\text { S(N) ESTIMATE }\end{array}$ & $\begin{array}{r}.063825 \\
.063768 \\
.063698 \\
.063638 \\
.063577 \\
.063518 \\
\text { S FROM FFT O }\end{array}$ & $\begin{array}{r}.003819 \\
.003754 \\
.003691 \\
.003630 \\
.003671 \\
.003613 \\
\text { ACF }\end{array}$ & $\begin{array}{r}.063812 \\
.063748 \\
.063685 \\
.063624 \\
.063656 \\
.063567\end{array}$ & $\begin{array}{r}.6038666 \\
.603741 \\
.603679 \\
.843618 \\
.803569\end{array}$ & $\begin{array}{r}.063799 \\
.663735 \\
.603673 \\
.603612 \\
.603653\end{array}$ & $\begin{array}{r}.063793 \\
. \quad 063729 \\
.093687 \\
.063686 \\
.083647\end{array}$ & $\begin{array}{r}.603786 \\
.603723 \\
.003661 \\
.003666 \\
.093511\end{array}$ & $\begin{array}{l}.683780 \\
.863716 \\
.683654 \\
.863594 \\
.683536\end{array}$ & $\begin{array}{l}.663773 \\
.693716 \\
.063648 \\
.063588 \\
.063536\end{array}$ \\
\hline $\begin{array}{l}\text { (N) ESTIMATE } \\
51.336460\end{array}$ & 45.663726 & 33.028760 & 26.965888 & 12.797396 & 7.921397 & 5.057817 & 3.348461 & 2.295381 & 1.628646 \\
\hline $\begin{array}{l}1.192480 \\
175135\end{array}$ & .899426 & .696931 & .553858 & .448625 & .376590 & .311318 & .265163 & .228606 & .199222 \\
\hline $\begin{array}{r}.176135 \\
867121\end{array}$ & . 155269 & 1.138665 & .124463 & .112427 & . 162860 & .093113 & 085282 & .678460 & .072435 \\
\hline .667121 & .682413 & .058268 & 654478 & 651115 & .048113 & .045467 & .042965 & .040769 & 638771 \\
\hline .636976 & .035331 & .033849 & 032562 & 031288 & .038167 & 029141 & 028223 & .027386 & 026627 \\
\hline .625944 & .025322 & .024768 & .024268 & .023824 & .023433 & 023888 & .022793 & .622539 & .622338 \\
\hline .622162 & .022633 & .021944 & .021894 & 21886 & .621913 & 621979 & 022686 & .622231 & .022428 \\
\hline .622849 & .022924 & .023243 & .623610 & 024630 & .024601 & 625832 & 025622 & .628279 & .627668 \\
\hline 627812 & 028782 & 629883 & 936785 & .031967 & .033274 & 634728 & 036332 & .638107 & .046072 \\
\hline 642254 & 044678 & 047380 & 666399 & 953779 & .057579 & 081861 & 068768 & .072213 & 078491 \\
\hline .685885 & 693986 & .103549 & .114695 & 127736 & .143880 & 161247 & 182897 & .288884 & 240223 \\
\hline .278348 & .325636 & 382591 & .454868 & .543433 & .655954 & .798602 & 988622 & 1.214380 & 1.616272 \\
\hline 1.968218 & 2.419629 & 3.086562 & 3.961738 & 6.069844 & 6.417074 & 7.964662 & 0.158943 & 9.663895 & 9.159512 \\
\hline 7.965496 & B. 417857 & 5. 060452 & 3.952183 & 3.085783 & 2.419202 & 1.968315 & 1.516316 & 1.214367 & .989686 \\
\hline .798570 & .655914 & .543388 & .454015 & .382546 & .324989 & .278310 & .246189 & .268836 & 182874 \\
\hline .161230 & .143068 & 127729 & .114695 & .163654 & 693977 & 085701 & 078513 & .672246 & 868741 \\
\hline 861960 & 657823 & 653829 & .050454 & 047442 & .044746 & 042327 & 046162 & 638193 & 036425 \\
\hline 634827 & 033381 & 632672 & .636888 & 029814 & .028842 & 027981 & .27168 & .026448 & 025862 \\
\hline .026222 & .024765 & 024246 & .623842 & .023489 & .023186 & .022930 & 022719 & .022551 & 022427 \\
\hline .622345 & 022364 & 622363 & .022344 & .022427 & .022652 & 022719 & 022931 & .023188 & .023493 \\
\hline .623847 & 024263 & O24715 & .026235 & 026818 & .026468 & 027191 & 027992 & .628879 & .029859 \\
\hline 636940 & $\$ 32133$ & .033451 & .634904 & 036589 & .038282 & 046243 & .042416 & .044825 & .47581 \\
\hline 060478 & 853796 & 057603 & .681651 & 066363 & .071535 & .77431 & 084692 & .01635 & 100201 \\
\hline 69951 & & 133808 & 148408 & 165193 & .184532 & 206861 & 232693 & 262626 & 297362 \\
\hline 337712 & .384614 & 439139 & .662492 & .576868 & .681122 & .759312 & 871989 & 1.009315 & 1.144879 \\
\hline 1.365182 & 1.478869 & 1.686112 & 1.838320 & 1.995439 & 2.168529 & 2.147118 & 2.106613 & 1.996581 & 1.838488 \\
\hline 1.868282 & 1.478985 & 1.365319 & 1.144994 & 1.006410 & .872967 & .759373 & .661171 & .678948 & .502524 \\
\hline .439166 & .384638 & .337734 & .297384 & .262850 & .232718 & .286889 & 184663 & .185229 & 148449 \\
\hline . 133853 & .121128 & .116866 & .168282 & .091702 & . 884185 & .077611 & 071622 & .086397 & .661751 \\
\hline 657610 & 053912 & .058601 & .047632 & .044965 & .642565 & 046402 & 038460 & .038687 & 035693 \\
\hline .033851 & 632347 & 631166 & .636097 & .629132 & .628269 & 027474 & 026788 & .628136 & .025572 \\
\hline .625872 & .024632 & 024248 & .623918 & .023840 & .023411 & 23229 & 023694 & .623604 & 022958 \\
\hline .622956 & 022999 & .023686 & .623218 & .023395 & .623620 & 23892 & 024215 & .624590 & 25019 \\
\hline 625587 & .026855 & .628869 & .627352 & .028109 & 628947 & 229872 & 38898 & .032010 & 893211 \\
\hline 634694 & .036079 & .037716 & .039502 & .041471 & .043635 & 046814 & 048632 & .861515 & . \\
\hline .658198 & .062667 & .066342 & .071070 & .076303 & .082099 & 088624 & 095651 & .1635686 & 112342 \\
\hline 122695 & .132929 & 144961 & .168320 & .173142 & .189571 & 207768 & 227865 & .250609 & 274359 \\
\hline 361022 & 338683 & 361578 & 395469 & .431617 & 469753 & 589432 & 549991 & & 629731 \\
\hline BBB196 & .697746 & 722658 & .738501 & .744617 & .738516 & 722589 & 697788 & $68 B 156$ & B2978B \\
\hline 598586 & .556840 & .569489 & 469809 & 431672 & .395523 & .361631 & 336136 & .381074 & .274411 \\
\hline .256082 & .227916 & 267816 & .189631 & .173205 & .168386 & .145632 & 133664 & .122175 & .112426 \\
\hline 163 & .096746 & 688625 & .682207 & .676417 & .671191 & 668471 & 062263 & .058341 & 854846 \\
\hline 651678 & 048861 & 946192 & 043 & & 63 & 637931 & 936311 & & 833496 \\
\hline 632279 & .631173 & 630169 & .029280 & .028438 & .627697 & 627631 & 26436 & .625966 & .025439 \\
\hline .625030 & .624678 & .024378 & .024129 & .623931 & .623780 & 623676 & 023617 & .623605 & .023638 \\
\hline .623716 & 623839 & .024669 & .624225 & .624491 & .6248068 & 025172 & 025592 & .626068 & 826603 \\
\hline .027200 & 027882 & 628594 & 629400 & 836284 & 631253 & 632313 & 033471 & 634732 & 636187 \\
\hline .037604 & .039234 & 041865 & 642932 & .645626 & 647302 & 649775 & 652462 & 655381 & 658551 \\
\hline
\end{tabular}




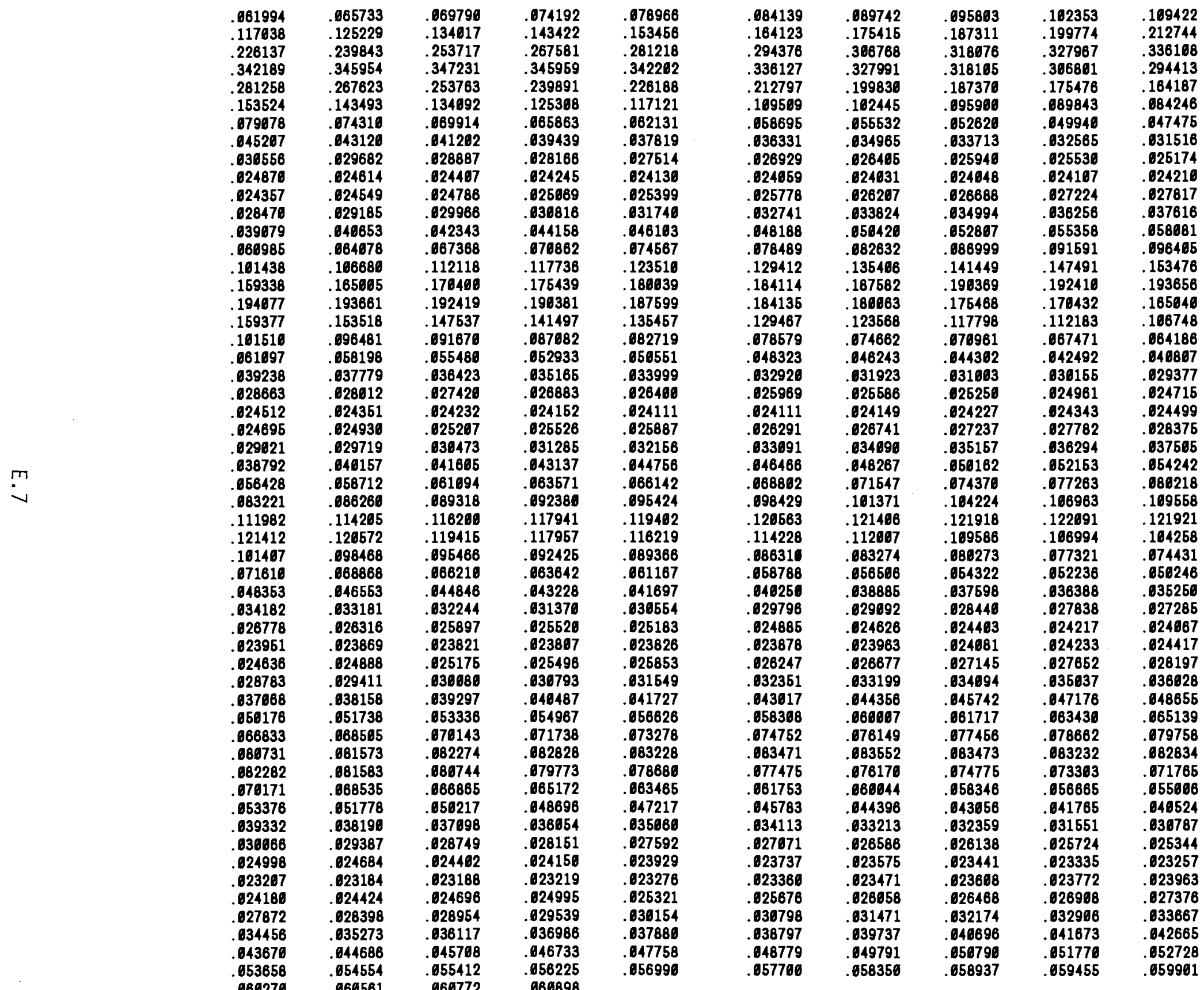


S(N) ANALYSIS - 80 EVENLY SPACED FREQUENCIES

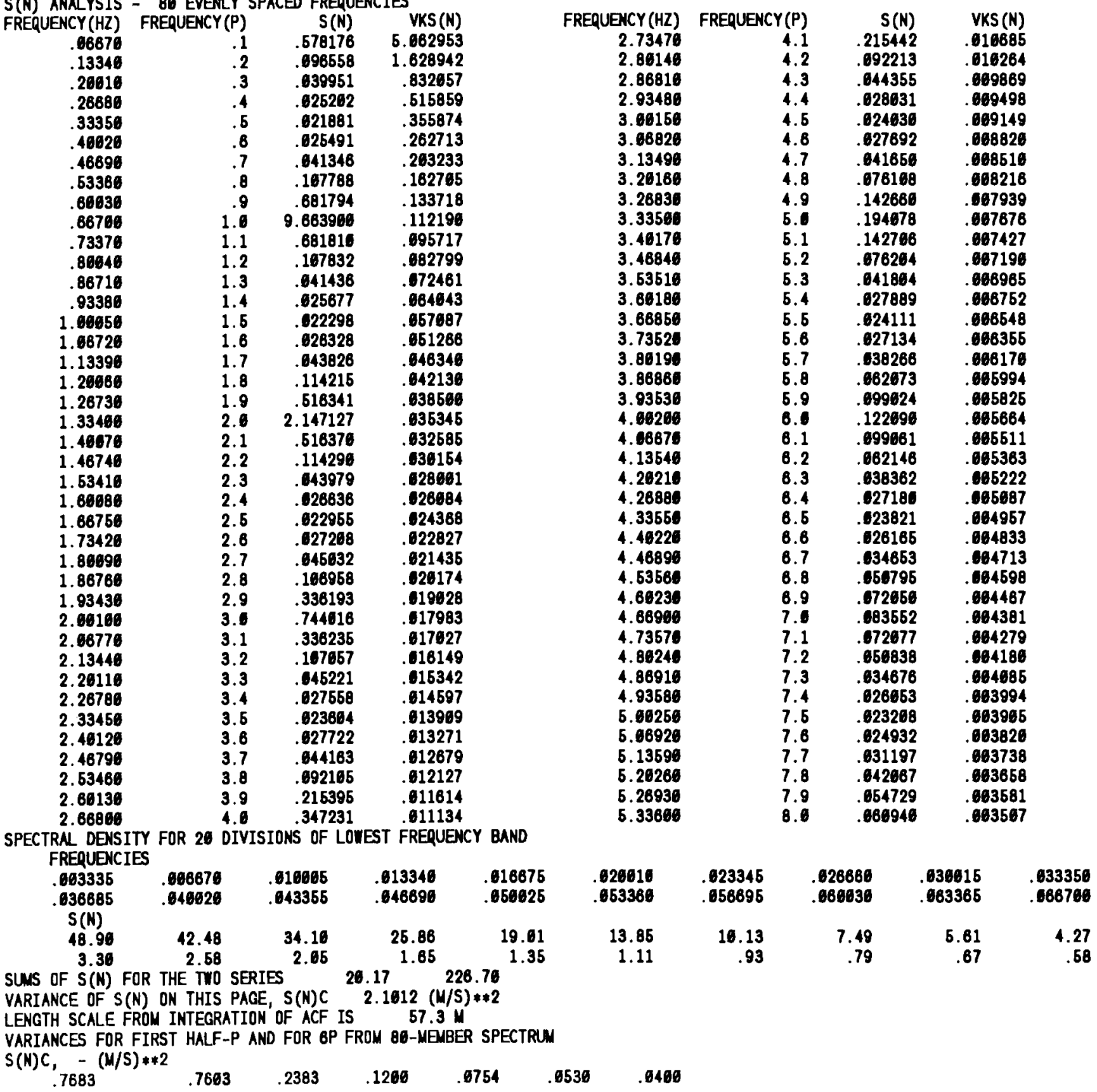


RUS

$\begin{array}{lllllll}.8765 & .8720 & .4881 & .3464 & .2746 & .2363 & .1999\end{array}$

SAME VARIANCES COMPUTED BY INTEGRATING THE VON KARMAN SPECTRU, SVK(N)CA

$\begin{array}{lllllll}5606 & .0832 & .0237 & .0119 & .0674 & .0651 & .0037\end{array}$

VARIANCES FOR FIRST HALF-P AND FOR GP FROM

SPECTRUI OF SIMULATED DATA, S(N)R

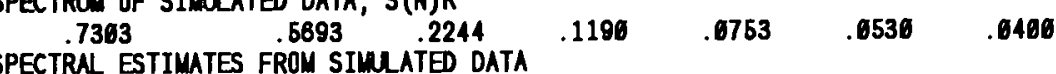

FIRST NUMBER IS SERIES MEAN

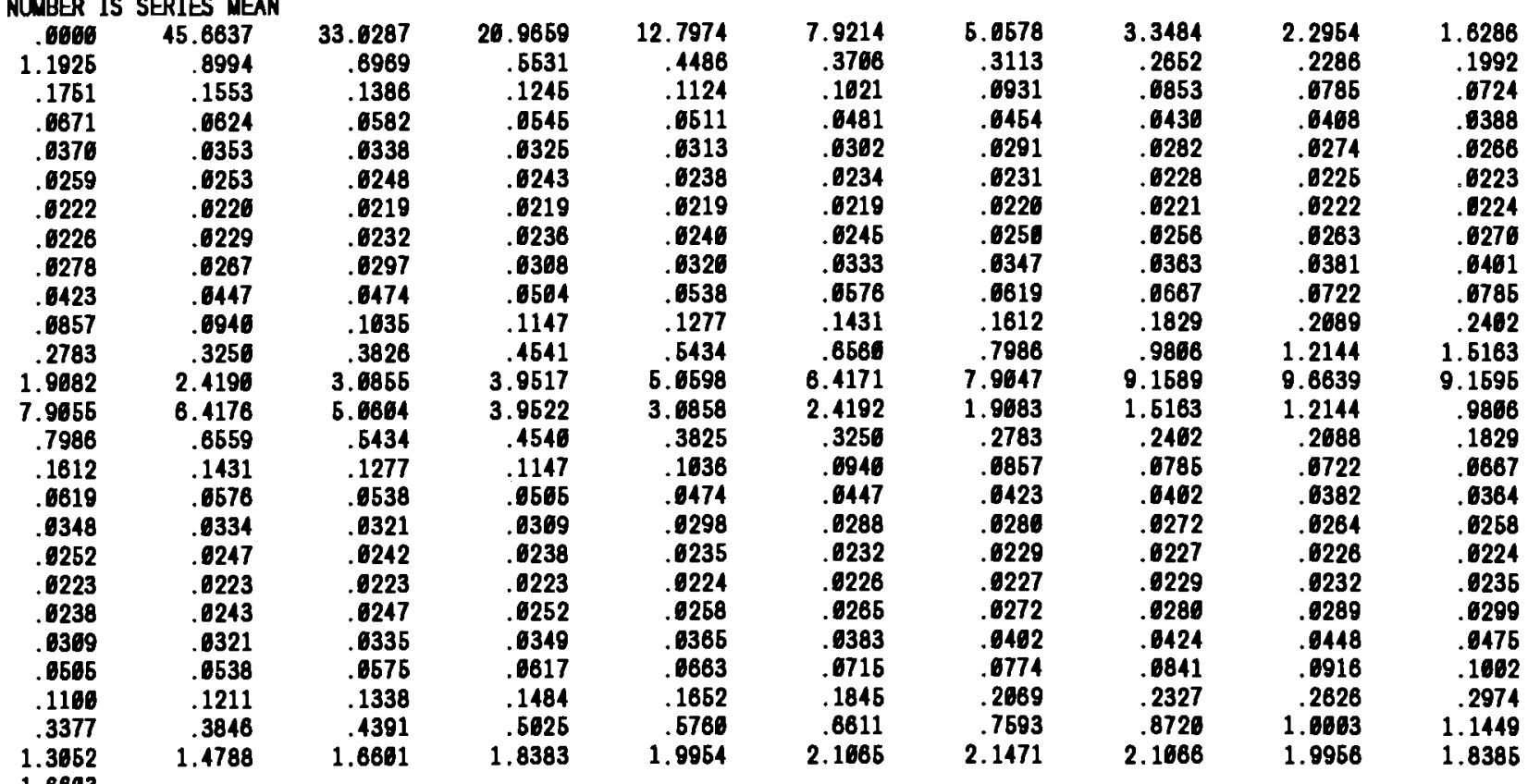

$$
1.6603
$$

1.8559

\section{VARIANCE OF S(N)R FROM SIMUATED DATA}

SMOM(1), SMOM(2) .

HALF-RANDOMIZING SIMULATION - PHASE RANDOMIZED

24 LOGARITHMICNLIY SPACED BANDS AT

16. PER SPECTRAL DECADE BANDED NSN SPECTRA

BAND CENTER, HI, LOW (HZ), NS(N), HARMONIC COUNT PER BAND [NS(N): ORIO

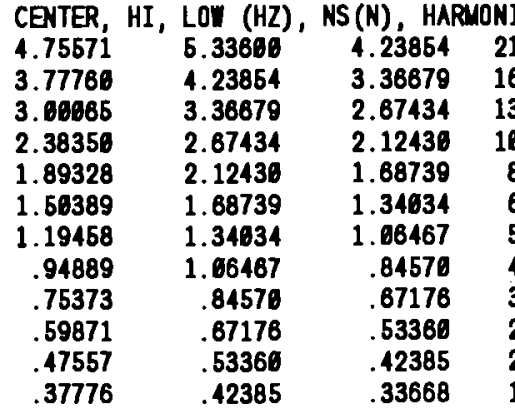

$\begin{array}{rrr}211 & 814 & 1624 \\ 168 & 647 & 814 \\ 134 & 514 & 647 \\ 166 & 469 & 614 \\ 85 & 325 & 469 \\ 68 & 258 & 325 \\ 54 & 265 & 258 \\ 43 & 163 & 265 \\ 34 & 130 & 163 \\ 28 & 163 & 130 \\ 22 & 82 & 163 \\ 17 & 86 & 82\end{array}$

$:$ ORIG
.20465
.25265
.29936
.21676
.46728
.45496
.54666
.02729
1.08427
1.43685
.02512
.09916




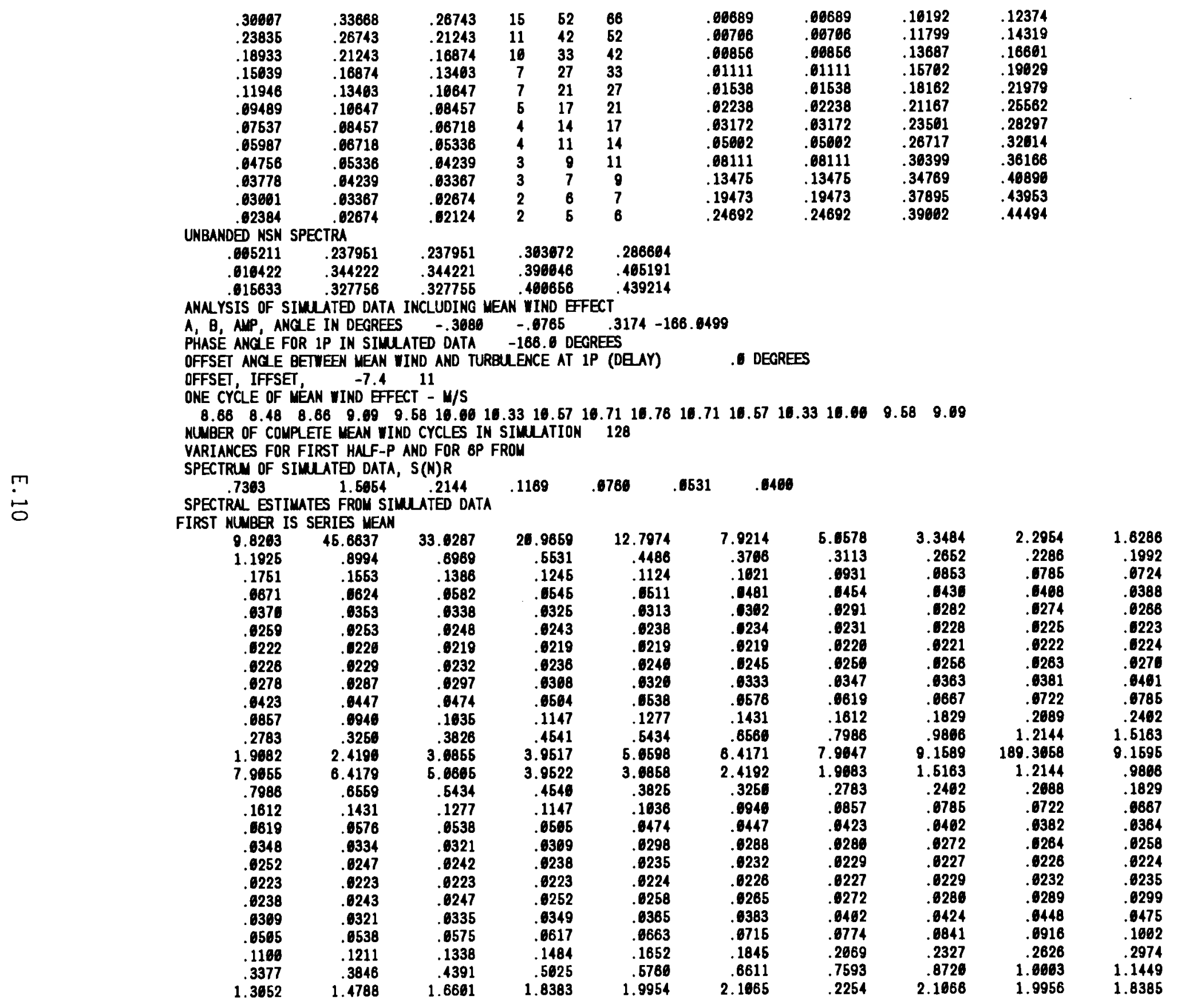


1.6603

VARIANCE OF S(N)R FROM SIMUATED DATA 2.7868

SMOM(1), SMOM(2) 9.82832 .7868
SKEWNESS AND KURTOSIS $2.0535 \quad 2.7323$

HALF-RANDOMIZING SIMUATION - PHASE RANDOMIZED

24 LOGARITHMICALY SPACED BAMDS AT 10. PER SPECTRAL DECADE

BANDED NSN SPECTRA

BAND CENTER, HI, LOW (HZ), NS(N), HARMONIC COUNT PER BAND [HS(N): ORIG

$\begin{array}{llccccc}\text { CENTER, HI, LOW (HZ), NS(N), HARMONIC COUNT PER BAND [NS(N) : ORIG } \\ 4.75571 & 5.33600 & 4.23854 & 211 & 814 & 1624 & .20405 \\ 3.77769 & 4.23854 & 3.36679 & 168 & 847 & 814 & .25255\end{array}$

$\begin{array}{lllllll}3.77780 & 4.23854 & 3.36679 & 168 & 847 & 814 & .25256\end{array}$

$\begin{array}{lllllll}3.06885 & 3.36679 & 2.67434 & 134 & 514 & 647 & .29936 \\ 2.38350 & 2.67434 & 2.12438 & 106 & 409 & 614 & .21678\end{array}$

$\begin{array}{llllll}2.38350 & 2.67434 & 2.12430 & 106 & 409 & 614\end{array}$

$\begin{array}{llllll}1.89328 & 2.12430 & 1.68739 & 85 & 325 & 409 \\ 1.56389 & 1.68739 & 1.34634 & 68 & 258 & 325\end{array}$

$\begin{array}{llllll}1.56389 & 1.68739 & 1.34634 & 68 & 258 & 325 \\ 1.19458 & 1.34634 & 1.06467 & 54 & 205 & 258\end{array}$

$\begin{array}{llllll}.94889 & 1.68467 & .84576 & 43 & 163 & 295\end{array}$

$\begin{array}{llllll}.75373 & .84570 & .67176 & 34 & 130 & 163\end{array}$

$\begin{array}{llllll}.59871 & .67176 & .53360 & 28 & 103 & 130\end{array}$

$\begin{array}{rrrrrr}.47557 & .63360 & .42385 & 22 & 82 & 103\end{array}$

$\begin{array}{rrrrrr}.47557 & .53360 & .42385 & 22 & 82 & 163 \\ .37776 & .42385 & .33668 & 17 & 66 & 82\end{array}$

$\begin{array}{llllll}.36067 & .43668 & .26743 & 15 & 52 & 66 \\ .23835 & .26743 & .21243 & 11 & 42 & 52\end{array}$

$\stackrel{m}{\risingdotseq}$

$\begin{array}{rrrrrr}.18933 & .21243 & .16874 & 16 & 33 & 42 \\ .15639 & .16874 & .13463 & 7 & 27 & 33\end{array}$

$\begin{array}{llllll}11946 & .13463 & .10647 & 7 & 21 & 27\end{array}$

$\begin{array}{llllll}.09489 & .16847 & .08457 & 5 & 17 & 21\end{array}$

$\begin{array}{llllll}.07537 & .08457 & .06718 & 4 & 14 & 17\end{array}$

98718

.01239

UNBANDED MSN SPECTRA

$\begin{array}{ll}.03367 & .02674 \\ .02674 & .02124\end{array}$

.21678

.46728
.45495

.54686

.02729

1.08427

.02512

.08918

.06918

.06689

.08858

.01111

.01538

.02238

.03172

.05662

.08111

.1347

.19473

.237951

.005211

237951

$\begin{array}{lllll}.018422 & .344222 & .344221 & .398646 & .465191 \\ .015633 & .327756 & .327755 & .468656 & .439214\end{array}$

$\begin{array}{lllll}.018422 & .344222 & .344221 & .398646 & .465191 \\ .015633 & .327756 & .327755 & .468656 & .439214\end{array}$

$\begin{array}{lllll}.018422 & .344222 & .344221 & .398646 & .465191 \\ .015633 & .327756 & .327755 & .468656 & .439214\end{array}$

.363972

SIM

.20461

.29965

.21972

.45852

.45496

.49816

.02729

1.68427

.02512

.06918

.06689

.0885

.01111

.01538

.02238

.03172

.05602

.08111

.1347

.19473
.24692

VK VKA]

$01034 \quad .02617$

02253

.02737

.03180

.03768

04162

95876

$05618 \quad .06821$

$06539 \quad 07942$

096263

19661

$10192 \quad .12374$

$11799 \quad .14319$

$13687 \quad .16681$

$15762 \quad .19629$

$18162 \quad .21979$

$21167 \quad .25562$

$26717 \quad 32914$

38168

.36168

$39802 \quad .44494$ 


\section{E.3 SERIES.DAT FOR FULL-RADIUS TURBULENCE}

2048

1.617282

3.387503

1.914813

1.643888

2.694727

1.485769

2.189775

1.916958

1.429579

1.682041

2.855364

1.576212

$-1.107286$

1.318149

1.466314

6.188316E-61

$-1.115180$

5.242541E-61

2.631396E- 01

$-7.833716 \mathrm{E}-61$

$-1.588337$

3. $875159 \mathrm{E}-61$

$-1.21923 \theta$

-8. 105719E-61

1.034462

6.254872E- 1

$-2.155171$

$-5.334645 \mathrm{E}-61$

6.049472E-61

$-1.817746$

$-1.297451 \mathrm{E}-61$

$-4.826513 \mathrm{E}-61$

$721474 E-61$
-1.961999

$-1.961999$

6. $919290 \mathrm{E}-61$

6.882237E- 1

$-8.867946 \mathrm{E}-01$

1. $592250 \mathrm{E}-61$

326847E- 61

$-1.119025$

2.838844E-61

4. $004532 \mathrm{E}-61$

6. 293469E-61

$-9.826756 \mathrm{E}-61$

$6.736292 \mathrm{E}-61$ $\begin{array}{llr}1.753488 & 2.465875 \mathrm{E}-01 & -2.620277 \mathrm{E}-01 \\ 7.430141 \mathrm{E}-01 & 1.621247 & 1.87\end{array}$ 1.371922 1.621247

$1.044866 \mathrm{E}-01$

$.937519 \mathrm{E}-02$

1.023962

$7.987343 \mathrm{E}-01$

2.426997E- 01

229862

1.513661E- 61

3. $809394 \mathrm{E}-61$

56247E-61

8. 838959E-61

1.162128

6. $838059 \mathrm{E}-61$

570135E- 01

$-6.752646 \mathrm{E}-61$

$-1.627640 \quad 6.256820 \mathrm{E}-61$

941341E- 01

1.690160

9.696435E-61

$-4.368353 \mathrm{E}-ø 1$
$8.467776 \mathrm{E}-61$

$192392 E-61$

$-1.113358$

$-1.343440$

1.634963

6. $926761 \mathrm{E}-61$

$4.575910 \mathrm{E}-91$

6. $966186 \mathrm{E}-61$

6. $968186 \mathrm{E}-61$

1.727259

$-1.795429$

1.265288

1.443889

$.926920 \mathrm{E}-61$

$898539 E-61$
1.040492

$-2.811404$

9.165386E-61

1.174983

$-7.347254 E-61$

$-1.642989$

-2.035655
$9.456291 E-62$

9. 450291E-62

1.552579E-61

$.552579 E-61$
-1.964534

$-1.964534$

4.551721E-61

1.584181E-61

-4. 102403E-61

8.718167E-62

$7.773871 \mathrm{E}-61$

$-1.576496$

3.101786E- 01

$2.721140 \mathrm{E}-01$

1.445096

2.137815E-61

$2.974114 \mathrm{E}-61$

6. $033488 \mathrm{E}-61$

. $594467 \mathrm{E}-61$

$-3.233668 \mathrm{E}-61$

1.871460

2. 170991

1.209229

1.694163

2.149475

37.123E-81

684526E-61

$8.692316 \mathrm{E}-61$

1.977336

4.154763E-61

8.611938E-62

1.088885

1.097689

9.365078E-61

3.741993E-61

$-6.429547 \mathrm{E}-62$

1.198434

1.914396E-02

(

$-4.386561 E-61$

3.338984E-61

$-4.658616 \mathrm{E}-61$

$-5.708797 \mathrm{E}-91$

4.

$-4.698346 E-01$

-

8.322967E-61

$-2.692068 \mathrm{E}-01$

7.583367E-61

1.

1.634484

$-1.351169$

$-6.523446 \mathrm{E}-61$

$-5.176416 E-61$

$-8.308401 \mathrm{E}-61 \quad-6.794658 \mathrm{E}-61 \quad-3.802976 \mathrm{E}-61$

$-3.893642 \mathrm{E}-01 \quad-2.272195 \mathrm{E}-62 \quad 1.723622 \mathrm{E}-01$

9.793259E-61 6.247334E-61

$\begin{array}{lll}-1.295225 & -1.486122\end{array}$

$-1.991425 \quad-9.874387 \mathrm{E}-61 \quad 5.427682 \mathrm{E}-01$

-2.808845E-61 -6.442695E- 61

3.674192E-61 7.882807E-61

$-1.360977 \quad-1.711572 \quad-8.618059 \mathrm{E}-01$

$\begin{array}{rrr}-9.916877 \mathrm{E}-61 & -5.573839 \mathrm{E}-61 & 1.094395 \\ 9.367424 \mathrm{E}-62 & 1.198298 \mathrm{E}-61 & -8.495193 \mathrm{E}-61\end{array}$

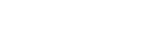




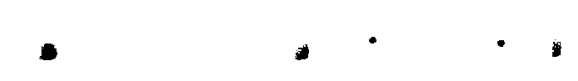

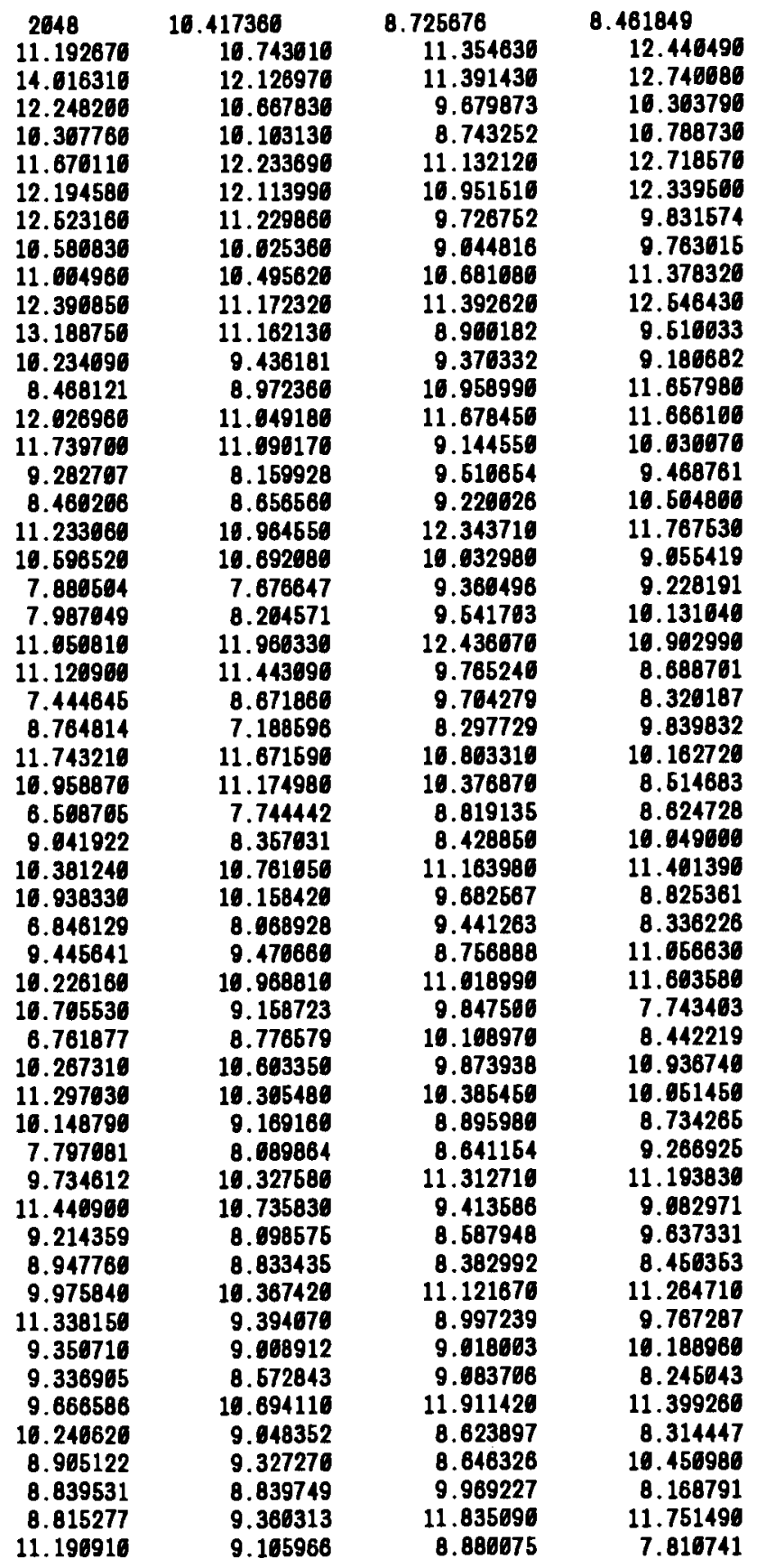




\begin{tabular}{|c|c|c|c|c|}
\hline$\stackrel{m}{\stackrel{m}{\oplus}}$ & 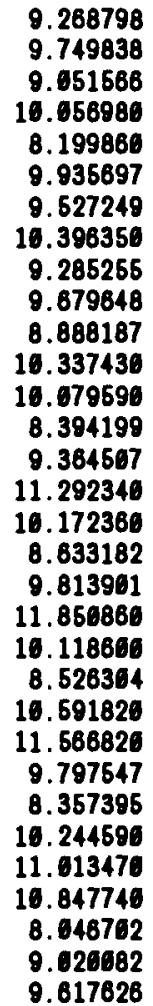 & 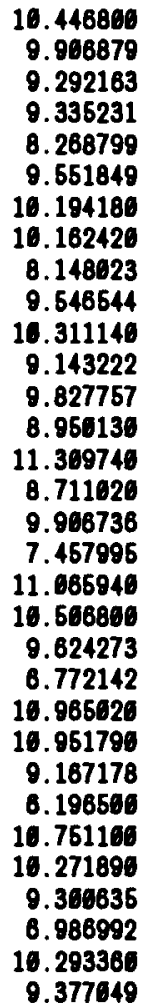 & $\begin{array}{r}9.134673 \\
9.967316 \\
11.651976 \\
9.257263 \\
9.652816 \\
9.646116 \\
16.767286 \\
8.932281 \\
9.865658 \\
9.321956 \\
10.324296 \\
8.574186 \\
9.137016 \\
8.278121 \\
9.781417 \\
9.318561 \\
16.694216 \\
7.188794 \\
10.877116 \\
9.373713 \\
9.862213 \\
5.968778 \\
16.796436 \\
11.171056 \\
8.729464 \\
7.145839 \\
16.777016 \\
10.794316 \\
8.773454 \\
6.713476 \\
16.168786 \\
16.478476\end{array}$ & 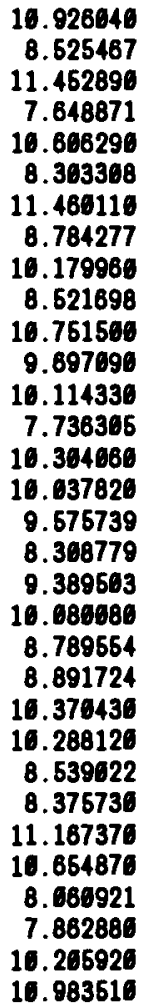 \\
\hline
\end{tabular}




\section{APPENDIX $F$}

SAMPLE OUTPUT FROM ALL FILES FOR THE 34-M VAWT CASE

FOR THE TANGENTIAL AND RADIAL WIND COMPONENTS

AT THE EQUATORIAL LOCATION OF A BLADE 
- 


\section{F.1 SUMMARY.BRF TANGENTIAL}

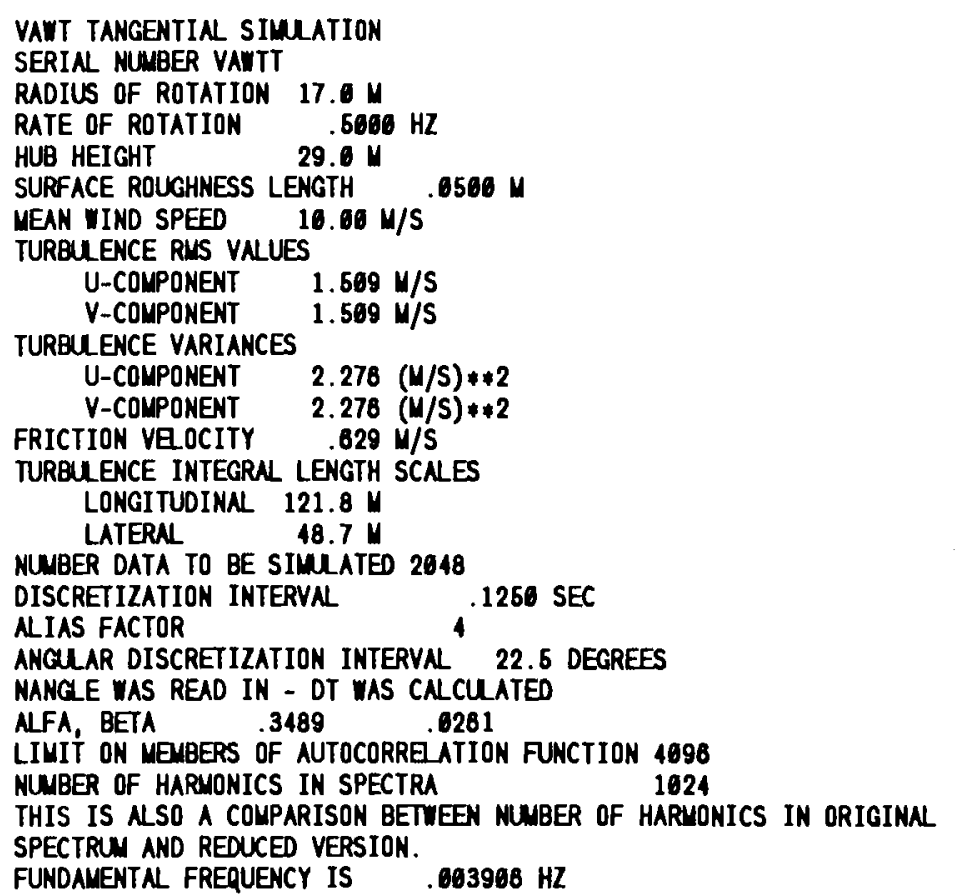

MAX FIMU VALUE OF CORRG ATION ACCEPTABE WITHOUT WINDOWING

VARIANCE OF $S(N)$ ON THIS PAGE, $S(N) C 2.0899$ (M/S) **2

VARIANCES FOR FIRST HALF-P AND FOR GP FROM BQ-MEMBER SPECTRU

$S(N) C_{1}-(N / S) * * 2$

$\begin{array}{llllll}.3393 & 1.0942 & .3985 & .1088 & .0657 & .6372\end{array}$

RUS

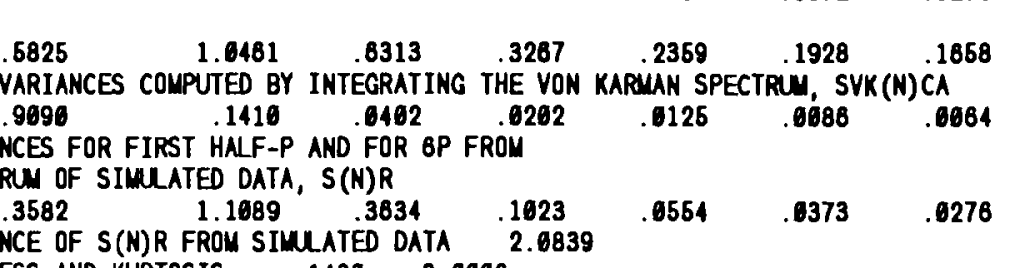

SPECTRUN OF SIMULATED DATA, S(N)R

VARIANCE OF S(N)R FROM SIMLATED DATA 2.6839

SKEWNESS AND KURTOSIS $-.1480 \quad 3.6606$

ANALYSIS OF SIMLLATED DATA INCLUDING MEAN WIND EFFECT

VARIANCES FOR FIRST HALF-P AND FOR 6P FROM

SPECTRUN OF SIMULATED DATA, S(N)R
3582
54.1260
1023
$.6554 \quad .6373$
.0276

VARIANCE OF S(N)R FROM SIMULATED DATA 55.1611

$\begin{array}{lll}\text { SKEWNESS AND KURTOSIS } & .0276 & 1.5932\end{array}$ 


\section{F.2 SUMMARY.DAT TANGENTIAL}

VAWT TANGENTIAL SIMLATION

SERIAL NLMBER VAITT

RADIUS OF ROTATION $17 . \mathrm{M}$

RATE OF ROTATION . $5060 \mathrm{HZ}$

29.0

MEAN UIND SPEED $10.00 \mathrm{~m} / \mathrm{S}$

TURBULENCE RUS VALUES

$$
\begin{array}{ll}
\text { U-COMPONENT } & 1.509 \mathrm{M} / \mathrm{S} \\
\text { Y-COMPONENT } & 1.599 \mathrm{~W} / \mathrm{S}
\end{array}
$$

TURBULENCE VARIANCES

U-COMPONENT $2.276(\mathrm{M} / \mathrm{S}) * 22$

V-COUPONENT $2.276(\mathrm{~N} / \mathrm{S}) * * 2$

FRICTION VEOCITY .629 $\mathrm{m} / \mathrm{S}$

TURBUEENCE INTECRLL LENGTH SCALES

LONGITUDINA $121.8 \mathrm{M}$

UBER DATA TO BE SIMUATED 2948

DISCRETIZATIOM INTERVN

NLIAS FACTOR
ANGUAR DISCRETIZATION INTERVNL
42.5 DECREES

ANGULAR DISCRETIZATION INTERVN 22.5
NAHGE WAS READ IN - DT WAS CNLCUATED

NFA, BETA .3489 .6281

LIMIT ON MEVERS OF AUTOCORREATION FUHCTION 4096

MUMBER OF HARQNONICS IN SPECTRA

THIS IS NSO A COMPARISON BETWEEN MUMBER OF HARYONICS IN ORIGINN

SPECTRUN AND REDUCED VERSION.

FUMDAYENTA FREQUENCY IS .083988 HZ

MAX FINAL VNUE OF CORREATION ACCEPTABLE WITHOUT WINDOWIMO .00100

DIFFERENT FORUS OF VARIABLES:

- ORIGIMM

A - INCLUDING EXTENSIONS ASSOCIATED NITH ALIAS REMOVA

- DIMENSIOMLESS VARIABLE

AND - BOTH OF THE ABOVE

DISCRETIZATION INTERVN - DT

-125 SEC
$-\quad .631$ SEC

AND .198

AND .049

MUMBER OF SIWLATED DATA - WT

- 2648

FUNDARENTNL FREQUENCY - EN1

-ND $.00391 \mathrm{HZ}$

ZND $\quad .06249$

NYQUIST FREQUENCY - EN2

A $16.06060 \mathrm{HZ}$ 
ND 2.54848

NLMBER OF SAMPLING POSITIONS IN CIRCLE - MANGLE

16
$-\quad 64$

ANGEET 1.5768

COSA, SIMA .006 1.000

DIRECTION COSINES FOR MOVING POINT

GHANING YINDOW USED - LAST R BEFORE USE - .0602

AUTOCORRE ATION FUNCTION 1453 STEPS

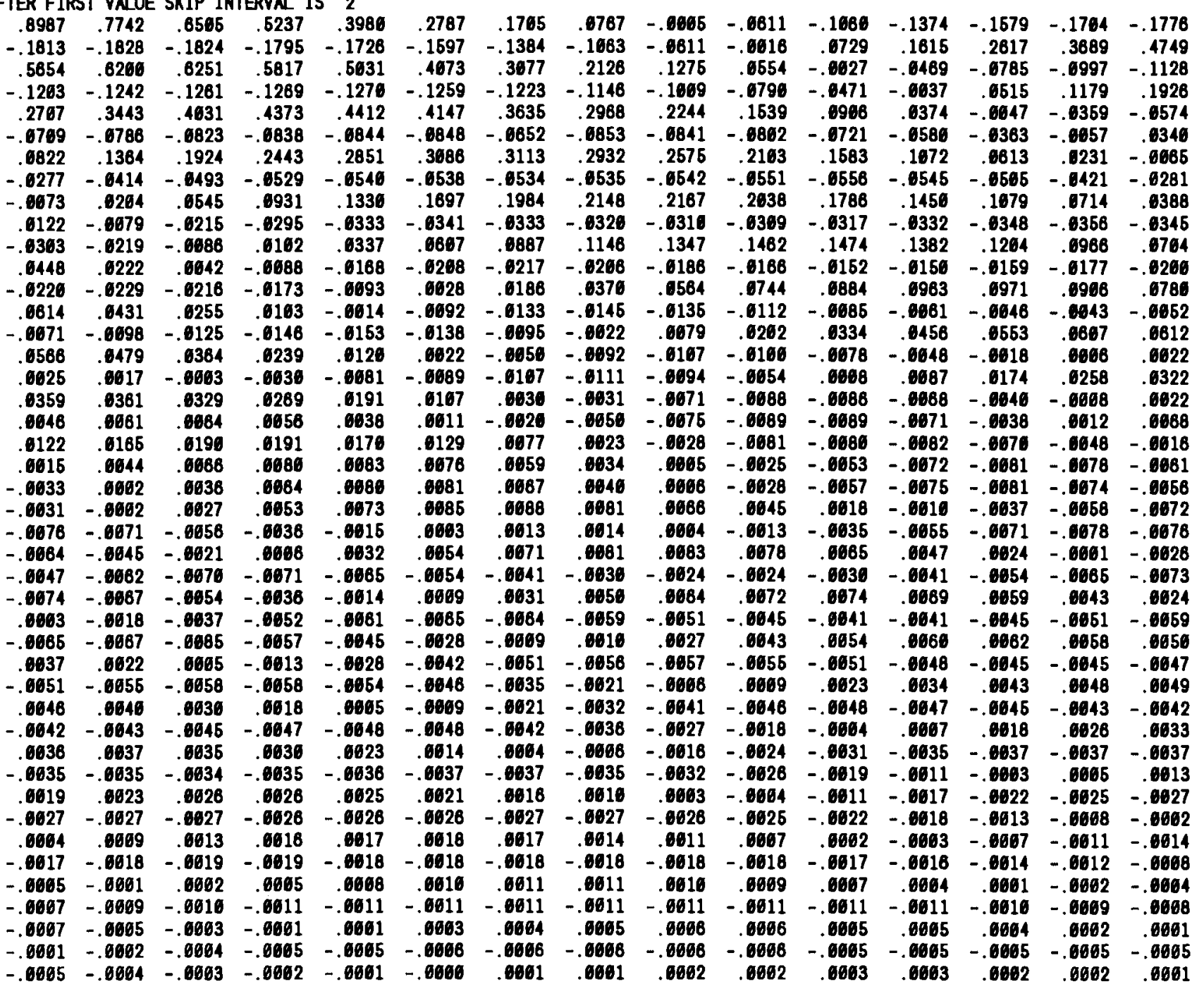




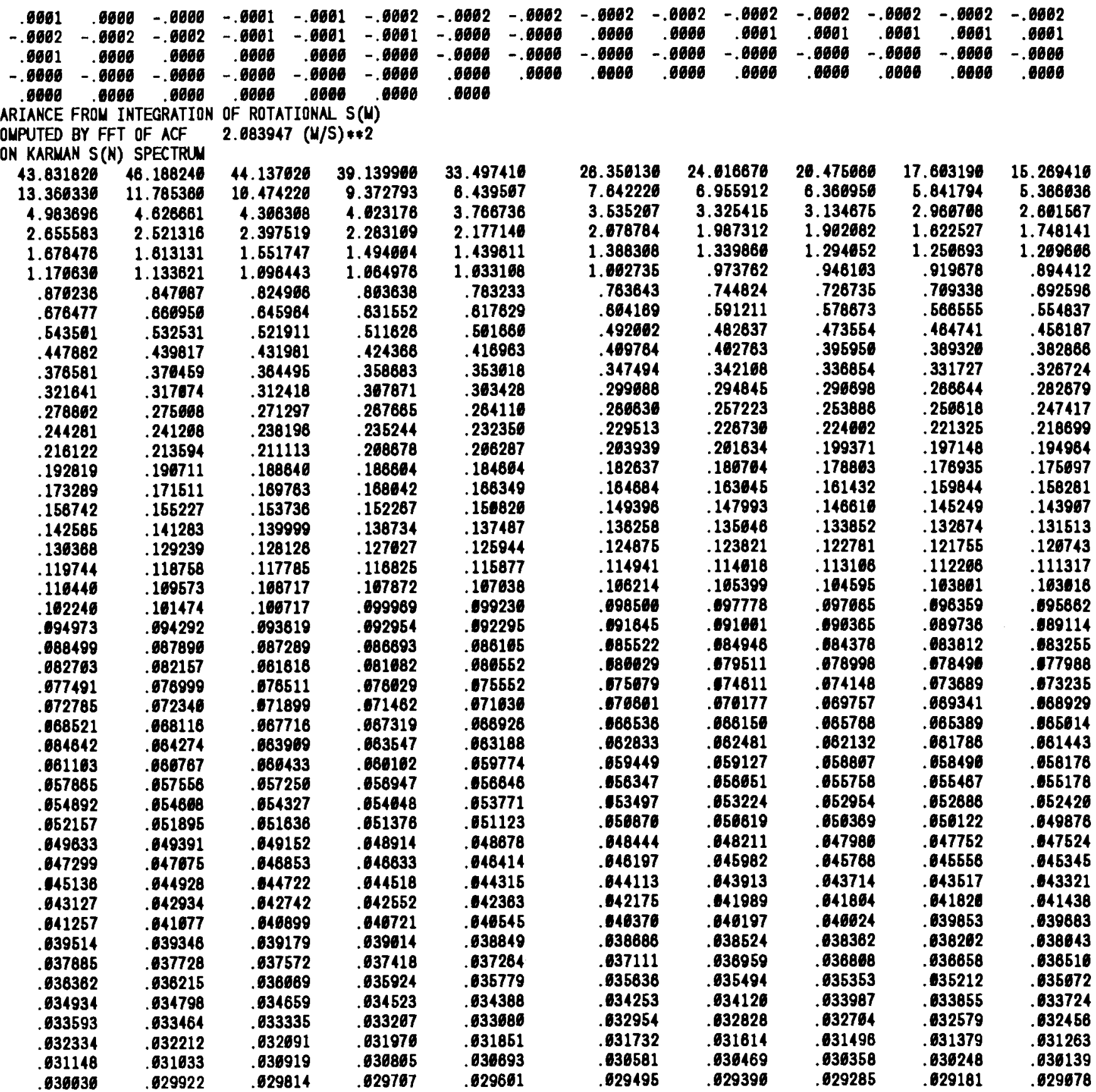




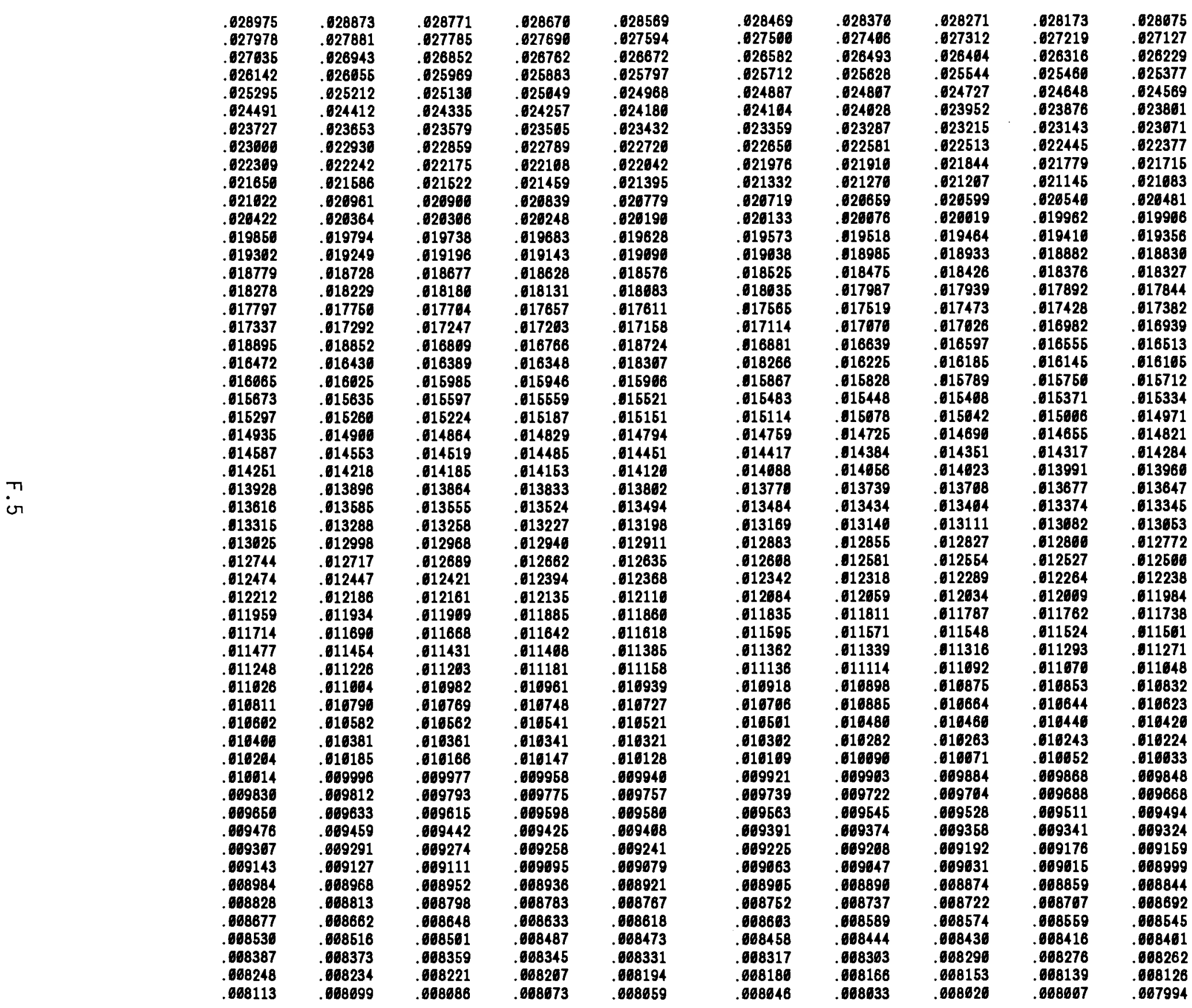




\begin{tabular}{|c|c|c|c|c|c|c|c|c|c|}
\hline$S(N)$ ESTIMATE & $\begin{array}{l}.607968 \\
\text { S FROM FFT or }\end{array}$ & ACF & .667942 & & & & & & \\
\hline 7.598779 & 7.566624 & 7.426835 & 7.163899 & 6.767264 & 6.693070 & 5.365778 & 1.616259 & 3.988969 & 3.313891 \\
\hline 2.837865 & 2.482243 & 2.161945 & 1.913813 & 1.765378 & 1.536836 & 1.386708 & 1.264282 & 1.186523 & 1.676051 \\
\hline $\begin{array}{r}.996786 \\
\end{array}$ & .921864 & .862284 & .816277 & .784107 & .722823 & .685463 & .652518 & .823393 & .597385 \\
\hline .573760 & .652223 & .632772 & .616390 & .499867 & .486799 & .472927 & .461165 & .460568 & .441131 \\
\hline .432765 & .425683 & 418139 & .411883 & .468368 & .461584 & .397423 & .393783 & . 396557 & .387841 \\
\hline .385661 & .384601 & .382782 & .381931 & .381439 & .381352 & .381711 & .382497 & .383651 & .385128 \\
\hline .386942 & .389149 & .391787 & .394838 & .398254 & .462010 & .468139 & .416710 & .416763 & .421280 \\
\hline .427219 & .433573 & .446467 & .447869 & .456823 & .464425 & .473579 & .483313 & .493733 & .564962 \\
\hline .517645 & .629953 & .543867 & .658276 & .573966 & .596901 & .669134 & .628631 & .649433 & .671752 \\
\hline .695967 & .722138 & .750508 & .781023 & .813884 & .849567 & .888849 & .031504 & .978266 & 1.029132 \\
\hline 1.684746 & 1.146218 & 1.214887 & 1.296891 & 1.376369 & 1.468884 & 1.573847 & 1.692477 & 1.828131 & 1.982849 \\
\hline 2.158194 & 2.358928 & 2.592176 & 2.867293 & 3.193257 & 3.577982 & 4.632137 & 4.575418 & 5. 238282 & 6.651627 \\
\hline 7.624127 & 8.118675 & 9.241292 & 10.267260 & 11.079640 & 11.614750 & 11.867210 & 11.963460 & 11.014960 & 11.768410 \\
\hline 11.488938 & 11.696810 & 16.285686 & 9.278114 & 6.118747 & 6.926146 & 5.863378 & 4.847329 & 4.073328 & 3.459382 \\
\hline $\begin{array}{r}11.486886 \\
2.968883\end{array}$ & 2.562595 & $\begin{array}{r}10.226223 \\
2.260\end{array}$ & $\begin{array}{l}9.270114 \\
1.948764\end{array}$ & $\begin{array}{l}0.716898 \\
1.71688\end{array}$ & $\begin{array}{l}0.028100 \\
1.523167\end{array}$ & 1.369972 & 1.219111 & 1.096912 & .991460 \\
\hline .986723 & .821954 & .752448 & .696468 & .635315 & .586814 & .543841 & .565360 & .470613 & .439162 \\
\hline 416877 & .385236 & .362463 & .341647 & .322683 & .365103 & .269244 & .274941 & 281957 & .256611 \\
\hline . 238958 & .228810 & .219867 & .211287 & .263887 & .188662 & .198173 & .184263 & .178952 & .174176 \\
\hline .169824 & .185832 & .162207 & .158991 & .156181 & .163721 & .161642 & .149824 & .147995 & .146882 \\
\hline .145676 & .144912 & .144373 & .144663 & .144010 & .144229 & .144699 & .146390 & .146293 & .147432 \\
\hline .148633 & .160498 & .152469 & .164556 & .168954 & .159635 & .162818 & .165899 & .189472 & .173352 \\
\hline .177575 & .182178 & .187174 & .192563 & .198365 & .264629 & .211415 & .218781 & .228685 & .236212 \\
\hline .244410 & .254381 & 265217 & .276971 & 289888 & .363465 & .318472 & .334969 & . 352934 & .372657 \\
\hline 394231 & .417947 & .444225 & .173501 & .566122 & .542432 & .582881 & .628889 & .680742 & .746328 \\
\hline .868551 & .886789 & .077327 & 1.683656 & 1.216052 & 1.360777 & 1.546838 & 1.753439 & 2.010139 & 2.323630 \\
\hline 2.764669 & 3.163873 & 3.858642 & 4.143364 & 4.657876 & 4.816588 & 4.859637 & 4.672941 & 4.298567 & 3.782085 \\
\hline 3. 230524 & 2.768578 & 2.252805 & 1.882084 & 1.586130 & 1.348812 & 1.156379 & .996023 & .864758 & .756942 \\
\hline .667942 & .693357 & .529795 & .475157 & .428186 & .387826 & .362894 & .322288 & .295181 & .271127 \\
\hline .249846 & .231019 & .214242 & .199136 & .185462 & .173113 & .162606 & .152608 & .142929 & .134628 \\
\hline .127027 & .126105 & .113825 & .168110 & .162869 & .098040 & .093803 & .089558 & .085879 & .682519 \\
\hline .079429 & .676564 & .673986 & .071634 & .069510 & .687581 & .065822 & .064228 & .082804 & .061649 \\
\hline . & .059479 & .858630 & . .657965 & . & .058840 & .068484 & .056231 & .056076 & .056625 \\
\hline .056083 & .658247 & .056586 & .658858 & .667380 & .057842 & .058487 & .059232 & .060073 & .061686 \\
\hline .062639 & .683177 & .664426 & .665785 & .667251 & .088827 & .676521 & .072343 & .074298 & .076388 \\
\hline .078615 & .686985 & .883511 & .686206 & .869680 & .692138 & .696388 & .098838 & .162513 & . 166435 \\
\hline .116619 & .115077 & .119822 & .124881 & .138291 & .136091 & .142311 & .148973 & .158113 & .163787 \\
\hline 172672 & 181043 & 199759 & 201275 & .212881 & .225122 & .238781 & .253836 & .270405 & .288684 \\
\hline . .3988663 & .331498 & .357019 & .385850 & .418216 & .454354 & .494984 & .541128 & .694435 & .655183 \\
\hline .726963 & .785615 & .839780 & . .8733800 & .878843 & .863780 & .863868 & .735664 & .882259 & .591736 \\
\hline .629163 & .475828 & .438522 & .391392 & .367808 & .328670 & .388684 & .276868 & .258554 & .236584 \\
\hline 222566 & .268952 & .195665 & .183394 & .172856 & .163287 & .154491 & .146449 & .139688 & 132349 \\
\hline .126153 & .128429 & .115125 & .116216 & .165678 & .161481 & .097585 & .093958 & .098579 & .087439 \\
\hline .084525 & .681818 & .079298 & .078948 & .674759 & .072727 & .076843 & .069697 & .687477 & . .865973 \\
\hline .064583 & .063303 & .862130 & .681054 & $.868 B 69$ & .059171 & .058380 & .057632 & .056986 & .056414 \\
\hline 655914 & .855485 & .855128 & .654835 & .654612 & .054452 & .054354 & .854317 & .654342 & .054429 \\
\hline .054576 & .654781 & .055045 & .655367 & .055750 & .856193 & .056894 & .057255 & .067876 & .858567 \\
\hline .059362 & .680111 & .066984 & .061921 & .662924 & .683997 & .065141 & .086358 & .067848 & .669815 \\
\hline 970461 & 071996 & .073665 & .075368 & .077163 & .078992 & .088981 & .083074 & .085277 & .087594 \\
\hline .090028 & .692587 & .695277 & .698106 & .161680 & .164266 & .167491 & .110945 & .114580 & .118467 \\
\hline .122435 & .126675 & .131138 & .135839 & .146800 & .146636 & .151558 & .157379 & .183513 & .169987 \\
\hline .176825 & .184031 & .191573 & 199998 & .267454 & .215716 & .224160 & 232678 & .246953 & .248465 \\
\hline .254223 & .257559 & .257860 & .254786 & .248886 & .246869 & .231647 & .222614 & .212488 & .203362 \\
\hline .194502 & .186076 & .178627 & .178388 & .163194 & .156450 & 156135 & .144268 & .138635 & . 133393 \\
\hline
\end{tabular}




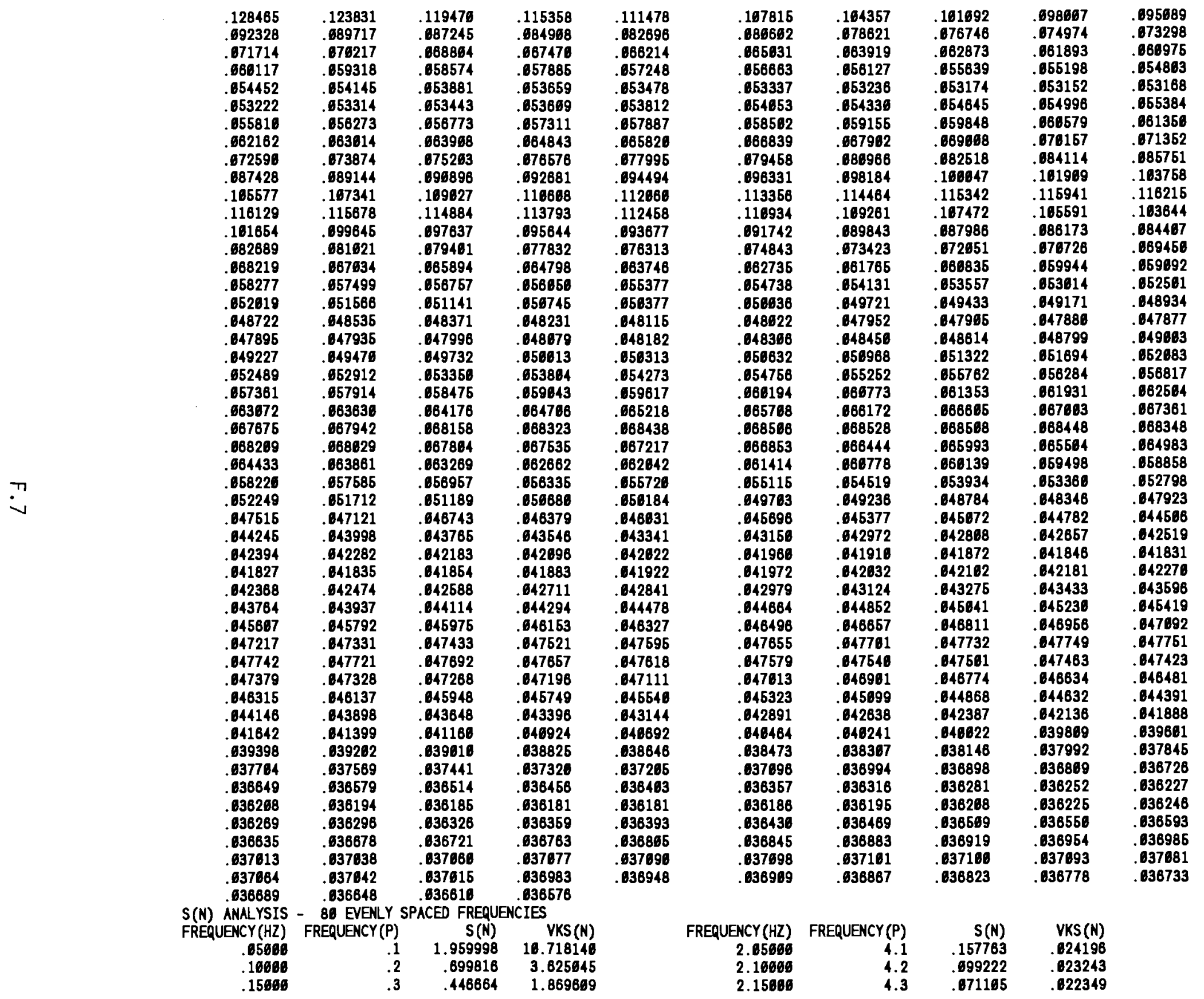




\begin{tabular}{|c|c|c|c|}
\hline 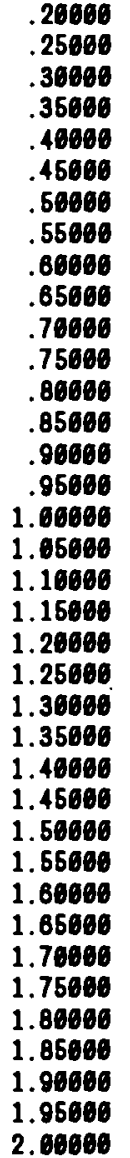 & $\begin{array}{l}.4 \\
.5 \\
.6 \\
.7 \\
.8 \\
.9 \\
1.6 \\
1.1 \\
1.2 \\
1.3 \\
1.4 \\
1.6 \\
1.6 \\
1.7 \\
1.8 \\
1.9 \\
2.6 \\
2.1 \\
2.2 \\
2.3 \\
2.4 \\
2.6 \\
2.6 \\
2.7 \\
2.8 \\
2.9 \\
3.8 \\
3.1 \\
3.2 \\
3.3 \\
3.4 \\
3.5 \\
3.6 \\
3.7 \\
3.8 \\
3.9 \\
4.6\end{array}$ & $\begin{array}{r}.383727 \\
.398256 \\
.481313 \\
.685993 \\
1.244187 \\
3.662816 \\
11.914956 \\
2.637568 \\
.656822 \\
.283361 \\
.173276 \\
.144362 \\
.159863 \\
.223432 \\
.463426 \\
1.107187 \\
4.859692 \\
.776876 \\
.226769 \\
.106897 \\
.063926 \\
.056676 \\
.065498 \\
.094659 \\
.159116 \\
.336358 \\
.078638 \\
.281253 \\
.128577 \\
.078346 \\
.059692 \\
.054341 \\
.059943 \\
.076373 \\
.168851 \\
.171326 \\
.257798\end{array}$ & $\begin{array}{r}1.163975 \\
.863638 \\
.693771 \\
.459578 \\
.368855 \\
.362552 \\
.253886 \\
.216634 \\
.187414 \\
.164625 \\
.144979 \\
.129239 \\
.116865 \\
.164916 \\
.095386 \\
.087169 \\
.086829 \\
.073786 \\
.068278 \\
.063463 \\
.659682 \\
.055178 \\
.051687 \\
.048537 \\
.045683 \\
.043688 \\
.046721 \\
.038556 \\
.036569 \\
.034741 \\
.033656 \\
.031496 \\
.036852 \\
.028716 \\
.027462 \\
.026299 \\
.025212\end{array}$ \\
\hline
\end{tabular}

SPECTRAL DENSITY FOR 20 DIVISIONS OF LOWEST FRERUENCY BAND

列

\begin{tabular}{|c|c|c|c|}
\hline 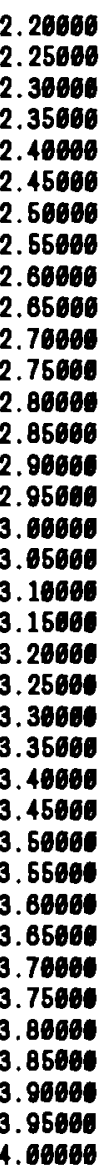 & $\begin{array}{l}4.4 \\
4.5 \\
4.6 \\
4.7 \\
4.8 \\
4.8 \\
5.0 \\
5.1 \\
5.2 \\
6.3 \\
5.4 \\
5.5 \\
5.6 \\
5.7 \\
5.8 \\
5.9 \\
6.6 \\
6.1 \\
6.2 \\
6.3 \\
6.4 \\
6.5 \\
6.6 \\
6.7 \\
6.8 \\
6.9 \\
7.0 \\
7.1 \\
7.2 \\
7.3 \\
7.4 \\
7.5 \\
7.6 \\
7.7 \\
7.8 \\
7.9 \\
8.0\end{array}$ & 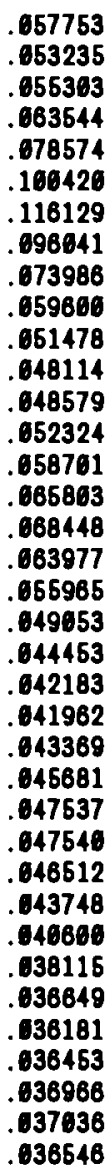 & 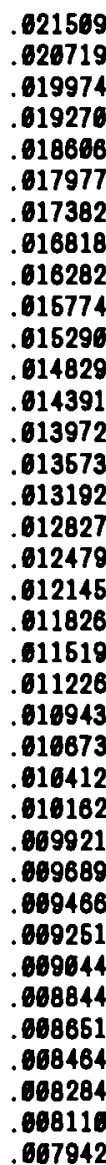 \\
\hline
\end{tabular}

FREQUENCIES

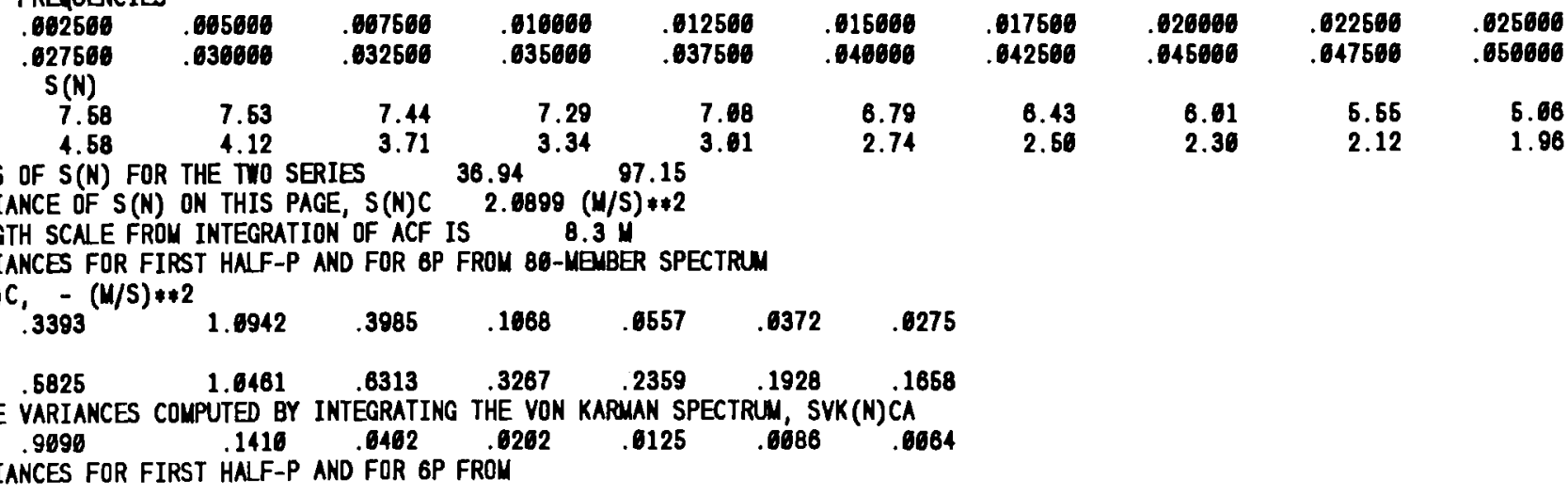


SPECTRUM OF SIMULATED DATA, S(N)R$$
3582
$$$$
1.1689 \quad .3634
$$

SPECTRAL ESTIMATES FROM SIMULATED DATA FIRST NUMBER IS SERIES MEAN

$\begin{array}{cccc}\text { NUMBER IS SERIES MEAN } & & \\ .6906 & 7.5668 & 7.4268 & 7.1538 \\ 2.8371 & 2.4622 & 2.1619 & 1.9138\end{array}$

$\begin{array}{lll}.0968 & .9219 & .8623 \\ .5737 & .5522 & .6328 \\ .4327 & .4251 & .4181 \\ .3857 & .3846 & .3828\end{array}$

$\begin{array}{rr}.4327 & .4251 \\ .3857 & .3840\end{array}$

.3828

1.8138

.8163

.5164

.4119

.3869

.3891

.3918

.3948

.4478

.6170

.6360

.5437

.7221
1.1462

.7565
1.2147

1.2147
2.5922

.5583

$\begin{array}{ll}1.0847 & 1.1462 \\ 2.1582 & 2.3589\end{array}$

2.5922

1.2969

2.8673

16.2673

$\begin{array}{rrr}7.0241 & 8.1101 & 9.2413 \\ 11.4889 & 11.0080 & 16.2867\end{array}$

2.9669

2.2262

9.2761

1.9468

.6965
.3416

.6965
.3416

.3416

.4107
.2396

.3852

.7524
.3624

.3624
.2198
.1622

.1622

.1457

1449

.1444

.1596

.1441
.1546

.1788

$.1665 \quad .1624$

.2444

.2544

.1872

.1926

.4736

1.6837
4.1434

.9773
3.6568

2.7946

3.1539

VARIANCE OF $S(N) R$ FROM SIMLATED DATA

$\operatorname{SMOM}(1), \operatorname{SMOM}(2)$

$.0660 \quad 2.6839$

SKEINESS AND KURTOSIS $-.1489 \quad 3.0606$

HALF-RANDOMIZING SIMUATION - PHASE RANDOMIZED

24 LOGARITHMICALLY SPACED BANDS AT 16. PER SPECTRAL DECADE

BANDED NSN SPECTRA
BAND CENTER, HI, LOW (HZ), NS(N), HARMONIC COUNT PER BAND [NS(N) : ORIG

\begin{tabular}{|c|c|c|c|c|c|}
\hline & & & & & \\
\hline .58600 & 4.60606 & 3.17731 & 211 & 814 & 1 \\
\hline .83178 & 3.17731 & 2.52383 & 168 & 647 & \\
\hline 2.24937 & 2.62383 & 2.06476 & 134 & 514 & \\
\hline 1.78673 & 2.69476 & 1.59243 & 106 & 469 & \\
\hline 1.41925 & 1.69243 & 1.26491 & 85 & 325 & \\
\hline 1.12735 & 1.26491 & 1.06476 & 68 & 258 & \\
\hline .89549 & 1.60475 & .79816 & 54 & 205 & \\
\hline .71131 & .79810 & & & 163 & \\
\hline .56502 & .633966 & .56357 & 34 & 136 & \\
\hline .44881 & .60357 & .46060 & 28 & 163 & \\
\hline .35650 & .460600 & .31773 & 22 & 2 & \\
\hline .28318 & .31773 & & 17 & 6 & \\
\hline .2249 & .25238 & .20647 & 15 & 52 & \\
\hline .17687 & .26047 & & 11 & 42 & \\
\hline .14 & .15924 & & 16 & 33 & \\
\hline & & & 7 & 27 & \\
\hline & .16648 & ת & 7 & 21 & \\
\hline
\end{tabular}

$08955 \quad .10048$
$.6554 \quad .6373$

.6276

$6.7073 \quad 6.6931$

0.7073

.4999

.4964

.3814

.4558

.6740

1.3753

3.1933

11.0796

1. 7156

.6353

.3226
.2937

.1662

.1440

.1579

.2897

1.6861

1.2101
4.6579

1. 5398

.7226
.4858

.4858

.3816

.4814

.4644

.5969

1.4889

3.6789

11.6147

6. 9201

1.6232

.6866

.3051

.1967
.1537

.1442

.1596

.2946

.3935

1.3698

1. 3867

$\begin{array}{rrrr}.3857 & 1.2643 & 1.1605 & 1.0761 \\ .6855 & .6525 & .6234 & .6974\end{array}$

3.3137

$\begin{array}{lll}.4612 & .4666 & .4411\end{array}$

$\begin{array}{llll}.3974 & .3938 & .3966 & .3878 \\ .3817 & .3825 & .3837 & .3851\end{array}$

$\begin{array}{llll}4681 & .4107 & .4168 & .4213\end{array}$

$\begin{array}{llll}.4601 & .4107 & .4168 & .4213 \\ 4736 & .4833 & .4937 & .5656\end{array}$

$\begin{array}{llll}.6091 & .6286 & .6494 & .6718\end{array}$

.8880

4.6321

.9315
1.6925

.9783

1.0291
1.9826

$\begin{array}{lll}4.5754 & 5.2383 & 6.0516\end{array}$

$11.9635 \quad 11.9160 \quad 11.7684$

$\begin{array}{llll}5.8634 & 4.8473 & 4.6733 & 3.4594\end{array}$

$\begin{array}{llll}1.3600 & 1.2191 & 1.6969 & .9916\end{array}$

$\begin{array}{llll}.5436 & .5653 & .4766 & .4391\end{array}$

$\begin{array}{llll}2892 & .2749 & .2620 & .2580\end{array}$

$\begin{array}{llll}.1962 & .1843 & .1796 & .1742 \\ .1615 & .1496 & .1486 & .1467\end{array}$

$\begin{array}{llll}.1447 & .1454 & .1463 & .1474\end{array}$

$.1628 \quad .1659$

$.2114 \quad .218$

$.3185 \quad .3349$

1.5460

.628

1.7534

.6807

2.0161

.2352

.3727

2.3230

2.3236
3.7821 


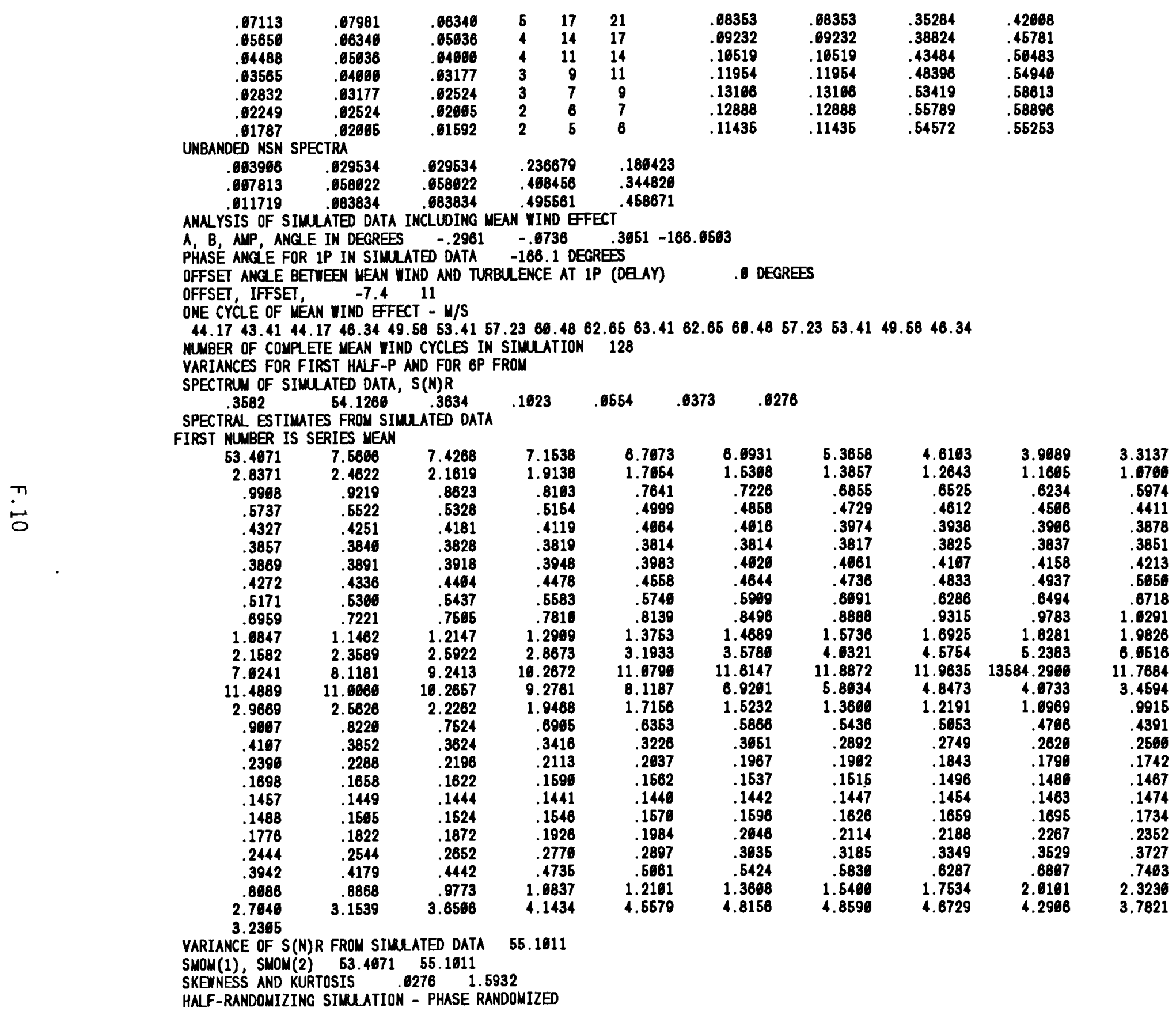


24 LOGARITHMICALLY SPACED BANDS AT 10. PER SPECTRAL DECADE

BANDED NSN SPECTRA

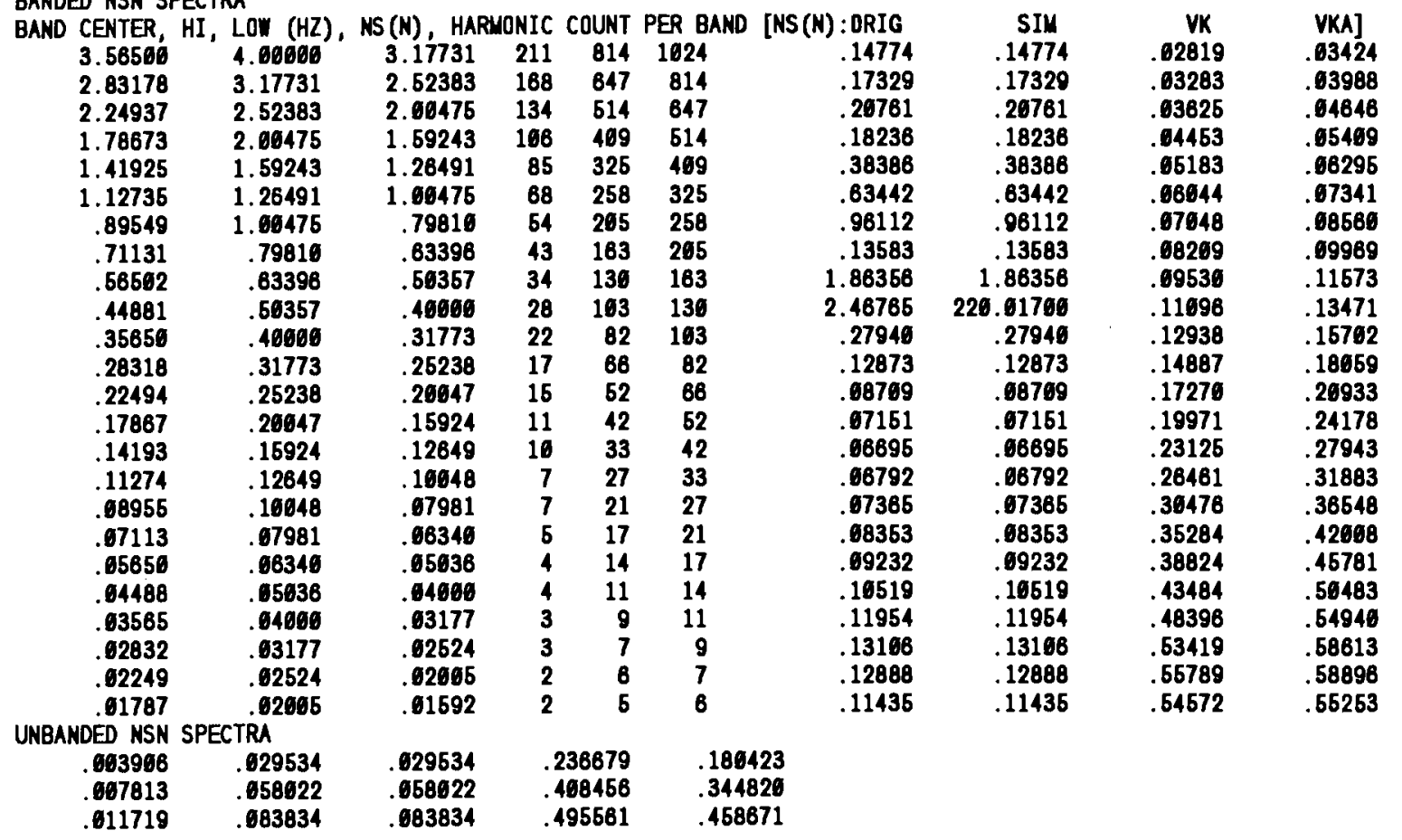




\section{F.3 SERIES.DAT TANGENTIAL}

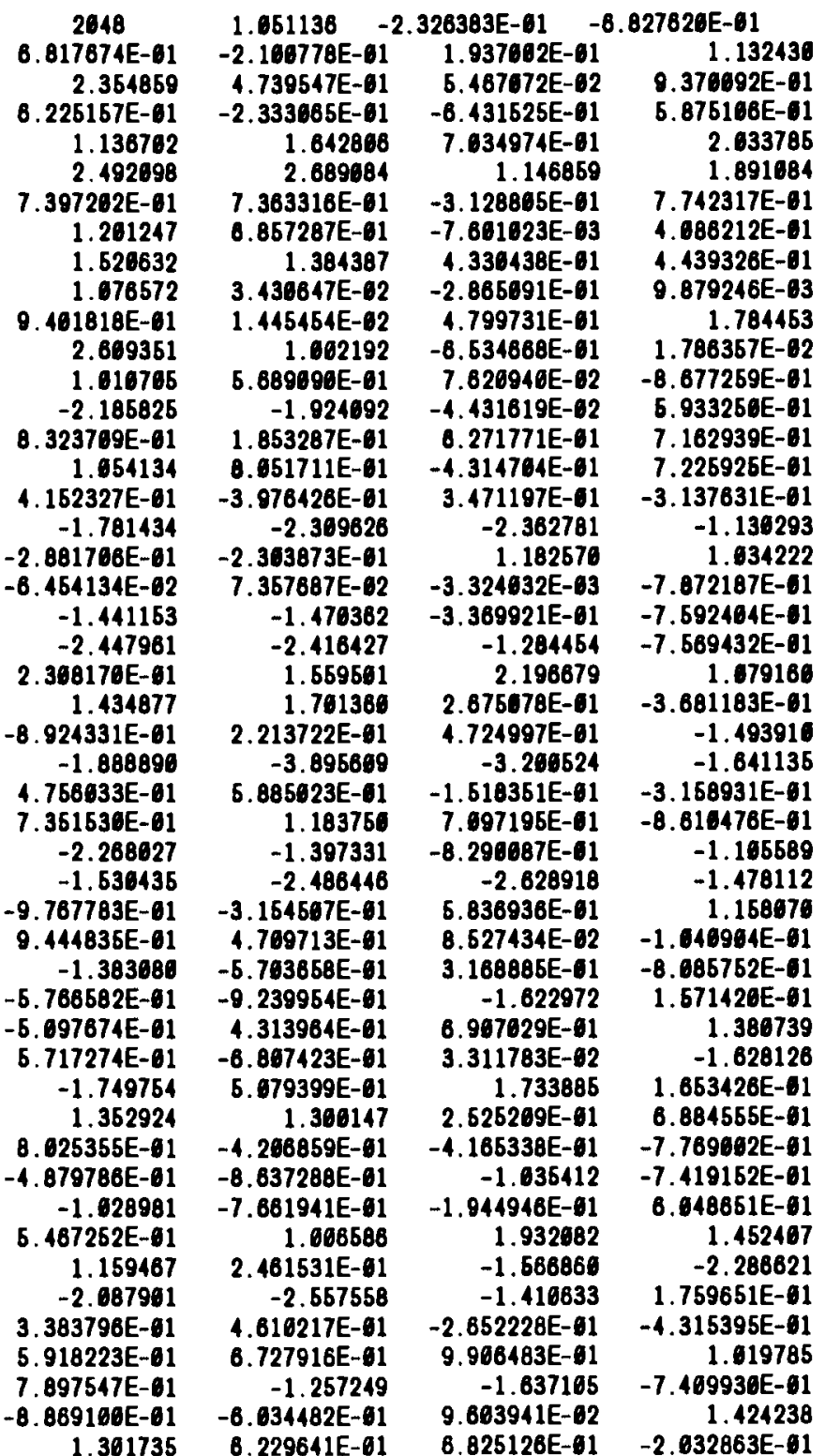

1.196113 


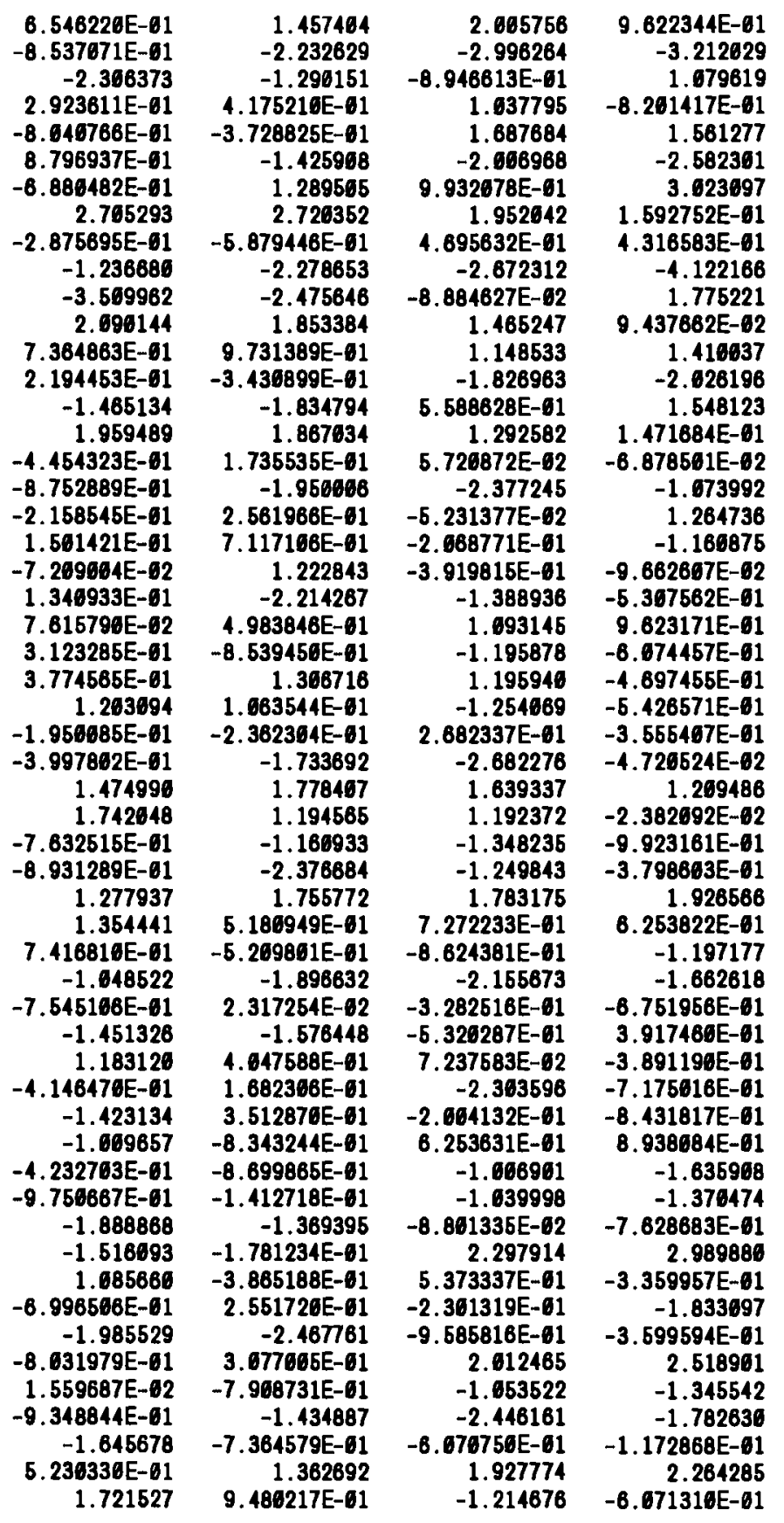




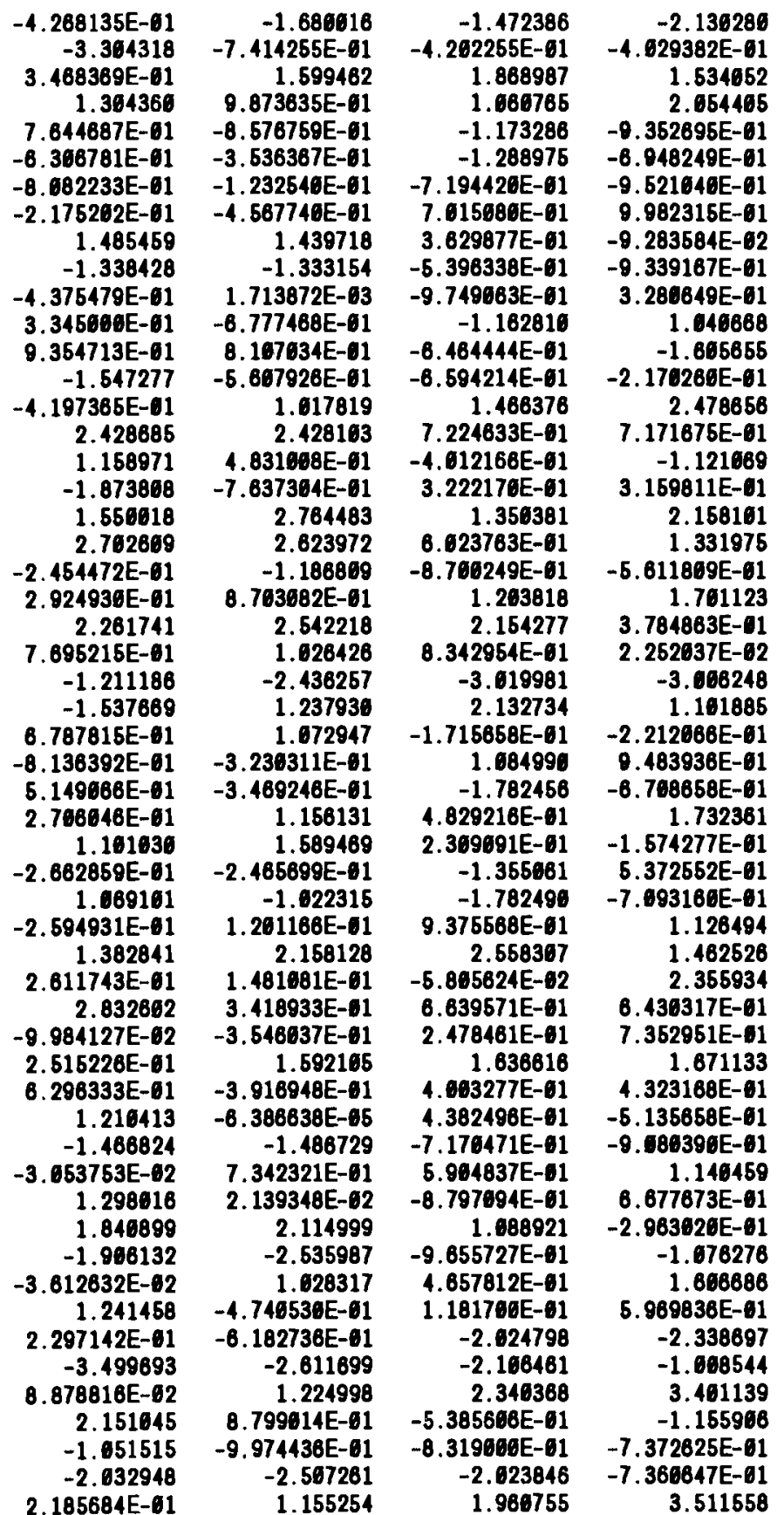




\begin{tabular}{|c|c|c|c|}
\hline 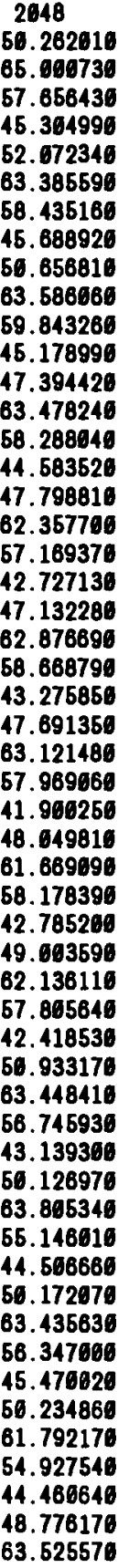 & 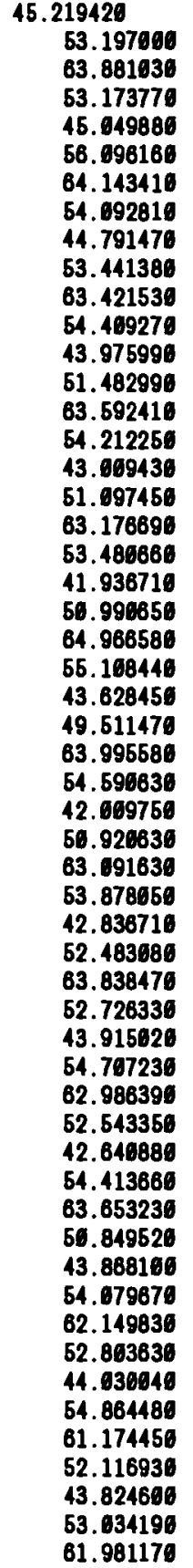 & 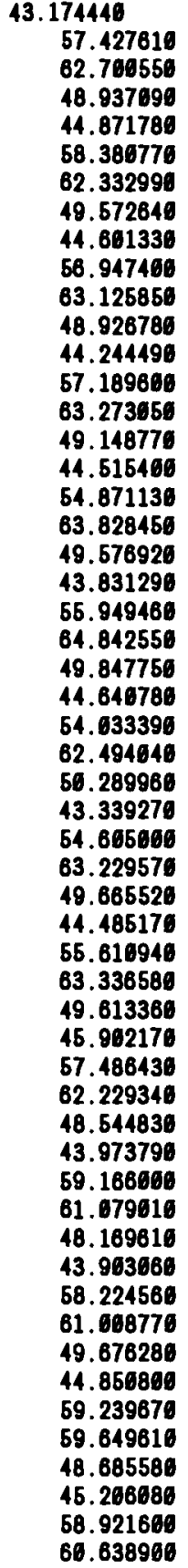 & 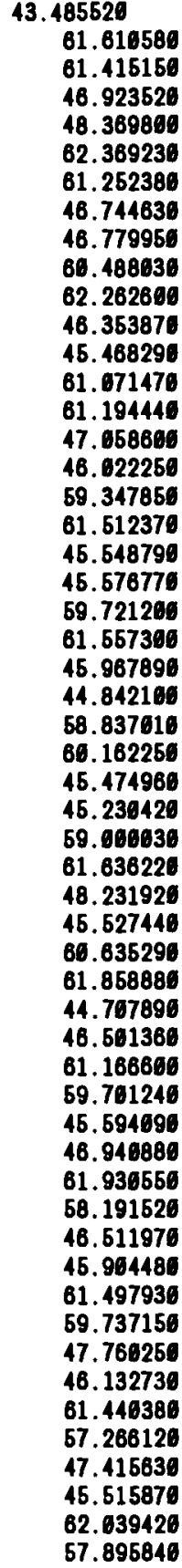 \\
\hline
\end{tabular}




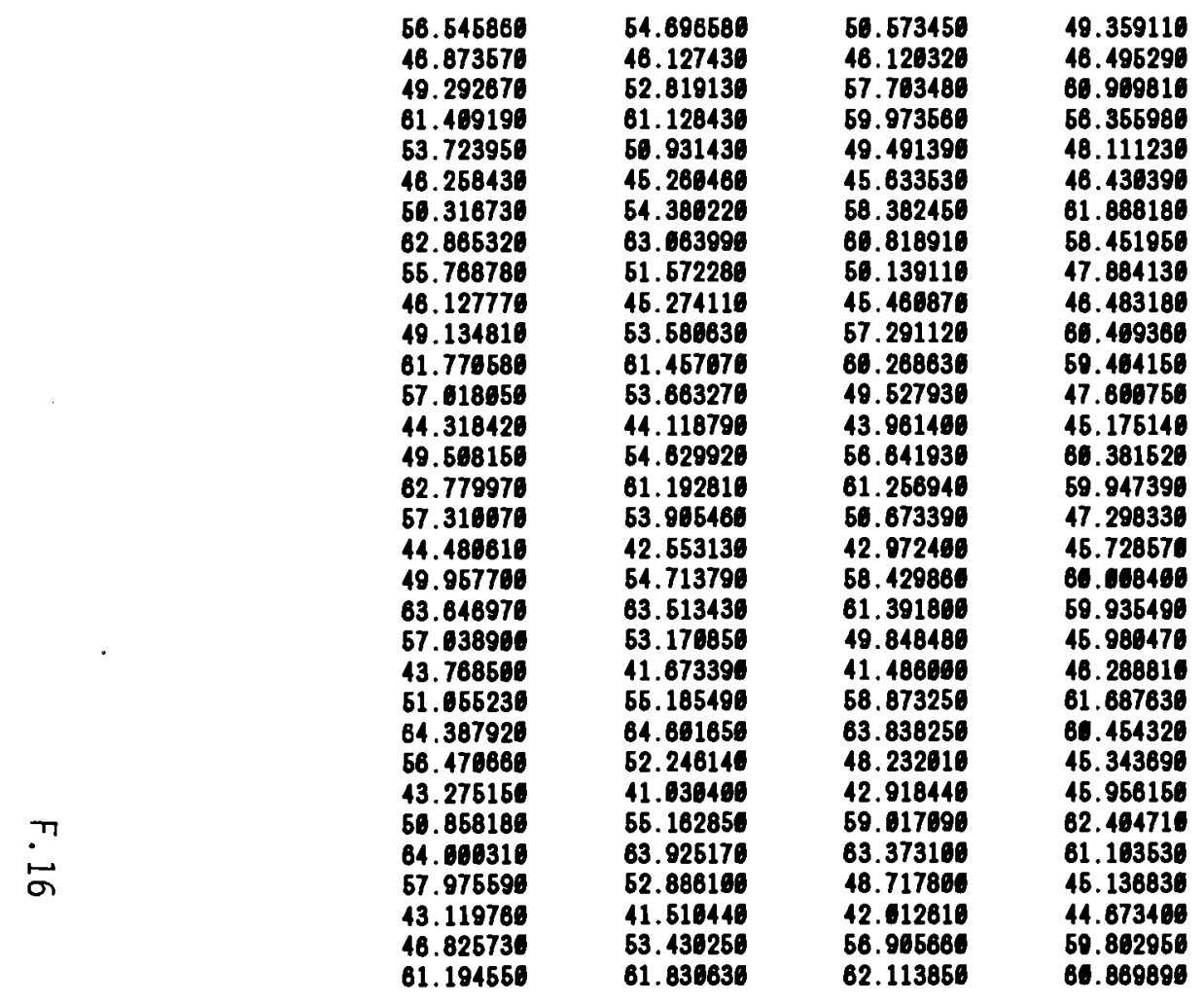




\section{F.4 SUMMARY.BRF NORMAL}

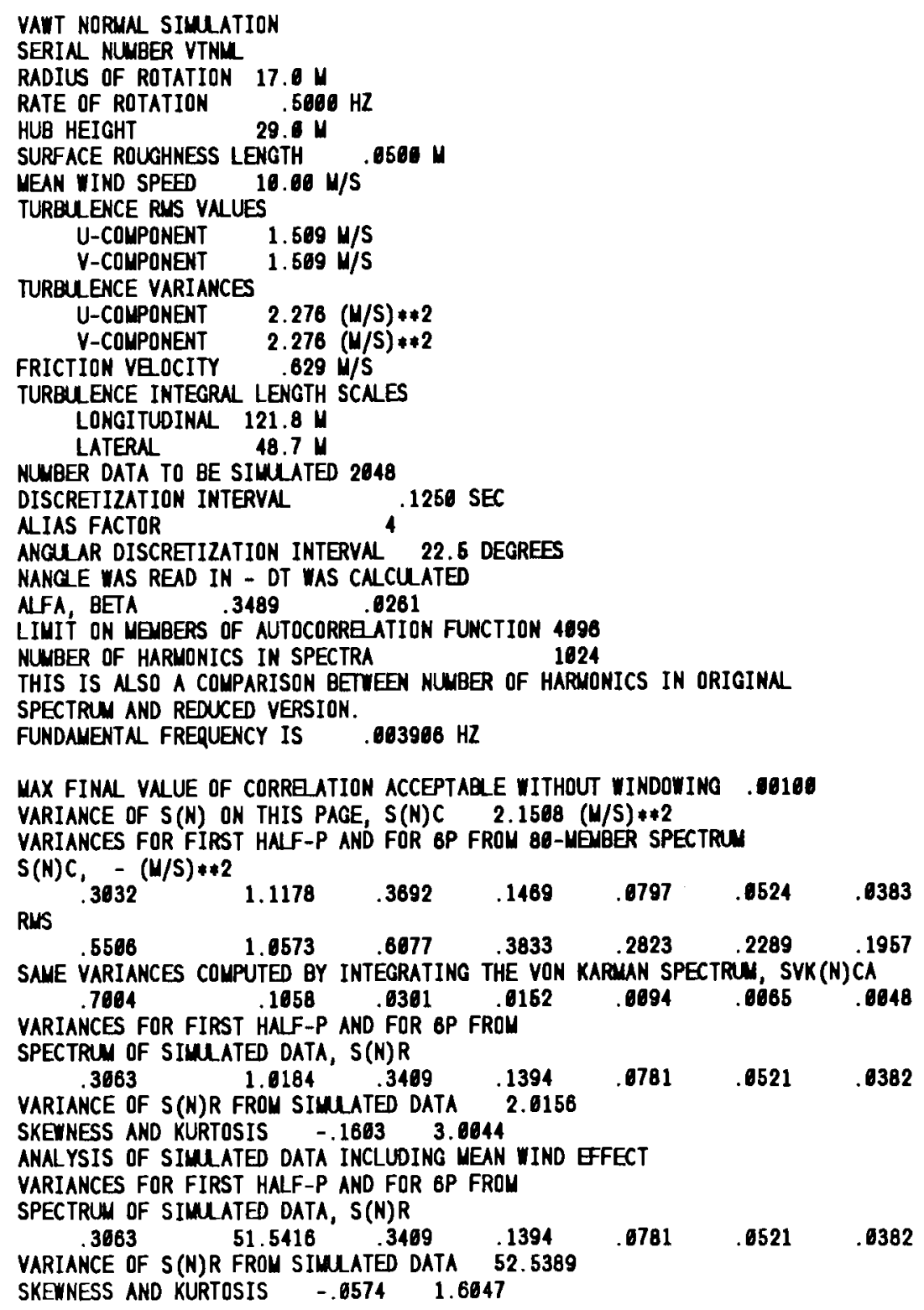




\section{F.5 SUMMARY.DAT NORMAL}

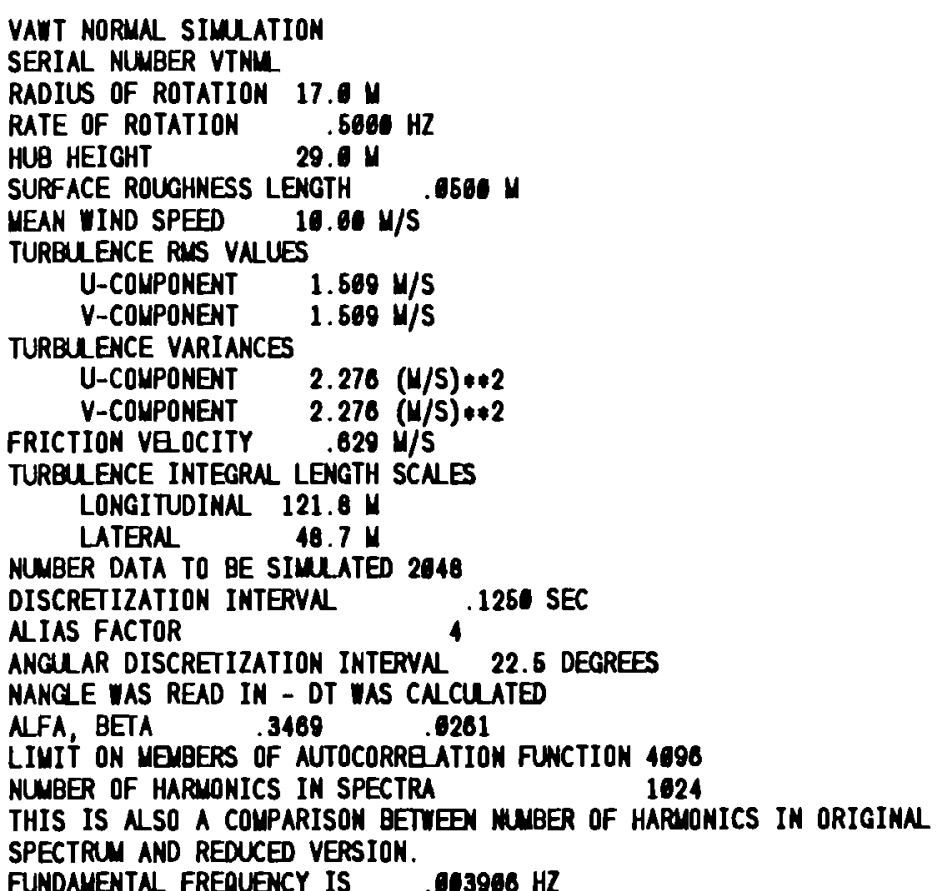

FUNDAMENTAL FREQUENCY IS .003986 HZ

MAX FINAL VNUE OF CORREATION ACCEPTABLE WITHOUT IIMDOWING ..00160 DIFFERENT FORUS OF VARIABLES:

- - INCLUDINO EXTENSIONS ASSOCIATED WITH ALIAS REMOVAL

ND - DIMENSIONLESS VARIAQLE

- AND - BOTH OF THE ABOVE

DISCRETIZATION INTERVAL - DT

- 125 SEC

-A .031 SEC

$\begin{array}{cc}\text { NDD } & .196 \\ \text { AND } & .049\end{array}$

NUMBER OF SIMLATED DATA - WT

2048

- $A 192$

FUNDARENTAL FREQUENCY - EN1

- $.06391 \mathrm{HL}$

NYQUIST FREQUENCY - EN2

$4.00000 \mathrm{HZ}$
$-\quad 16.00000 \mathrm{HZ}$ 
ND 2.54648

- 1 ND 18.18592

NUMBER OF SAMPLING POSITIONS IN CIRCLE - NANGE

18
$-\quad 64$

ANCEEA 3.1416

COSA, SINA -1.000

DIRECTION COSINES FOR MOYING POINT

OHAKNING WIMDOW USED - LAST R BEFORE USE . .6862

AUTOCORREATION FUNCTION 1648 STEPS 32.75 SECONDS

ATTER FIRST VALUE SKIP INTERYAL IS 2

$\begin{array}{llllllllllllllll}.8861 & .7122 & .5760 & .4498 & .3342 & .2310 & .1469 & .0843 & .0905 & -.0512 & -.6923 & -.1246 & -.1478 & -.1648 & -.1761\end{array}$

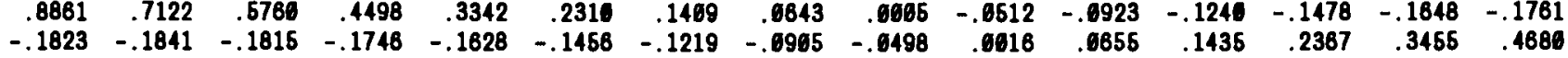

$\begin{array}{llllllllllllllll}.5953 & .6941 & .7622 & .6208 & .6071 & .3926 & .2877 & .1960 & .1183 & .0542 & .0627 & -.0379 & -.0691 & -.0925 & -.1697\end{array}$

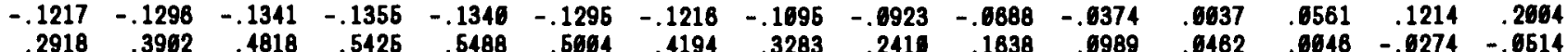

$\begin{array}{lllllllllllllll}-.0692 & -.0819 & -.6967 & -.6965 & -.0998 & -.1009 & -.1606 & -.0968 & -.0912 & -.0824 & -.0696 & -.0516 & -.0271 & .0055 & .0478\end{array}$

$\begin{array}{llllllllllllllll}.1010 & .1651 & .2381 & .3137 & .3863 & .4221 & .4288 & .3941 & .3354 & .2657 & .1965 & .1342 & .0817 & .0393 & .0682\end{array}$

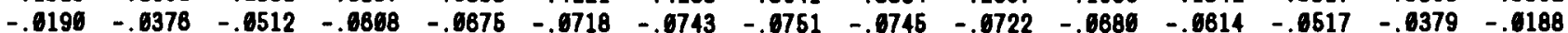

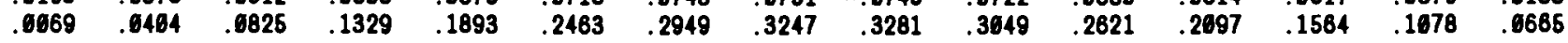

$\begin{array}{lllllllllllllll}.0331 & .0072 & -.0124 & -.0288 & -.0372 & -.0446 & -.0497 & -.0538 & -.0549 & -.0556 & -.0551 & -.0534 & -.0501 & -.0451 & -.0378\end{array}$

$\begin{array}{lllllllllllllll}-.0269 & -.0122 & .0677 & .0336 & .6661 & .1046 & .1472 & .1893 & .2246 & .2468 & .2482 & .2316 & .2065 & .1618 & .1217\end{array}$

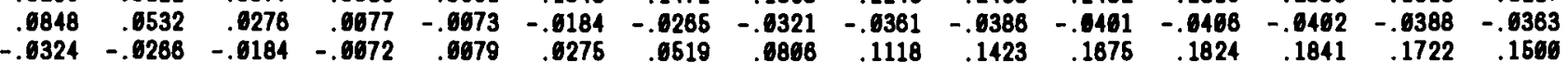

$\begin{array}{lllllllllllllll}.1219 & .0928 & .0652 & .0417 & .0225 & .0678 & -.0637 & -.0121 & -.0182 & -.0228 & -.0257 & -.0276 & -.0288 & -.0292 & -.0288\end{array}$

$\begin{array}{lllllllllllllll}-.0277 & -.0257 & -.0227 & -.0182 & -.0120 & -.0638 & .0678 & .0220 & .0398 & .0606 & .0829 & .1644 & .1220 & .1323 & .1333\end{array}$

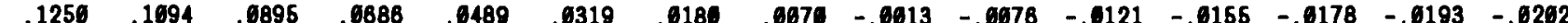

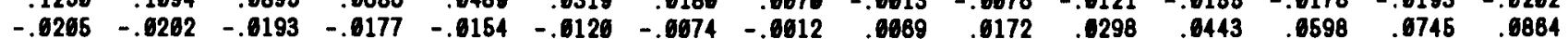

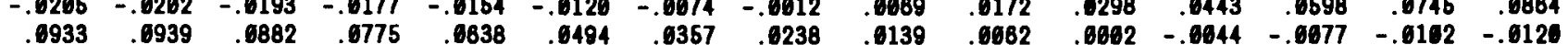

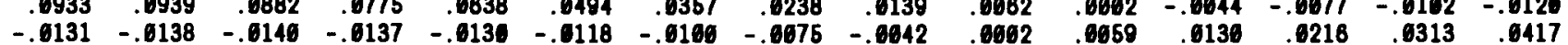

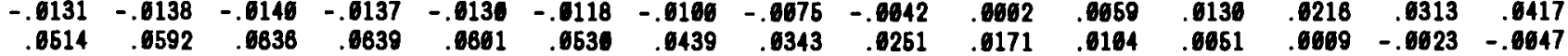

$\begin{array}{lllllllllllllll}-.0065 & -.0677 & -.0686 & -.0691 & -.0092 & -.0096 & -.0685 & -.0075 & -.0062 & -.0045 & -.0021 & .0009 & .0047 & .0094 & .0156\end{array}$

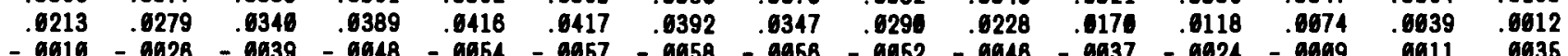

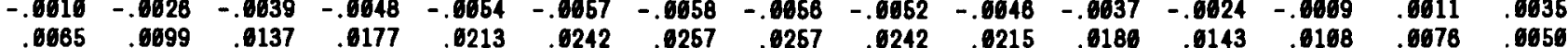

0928 - 011 - 093 - 013 - 0922 - 0928 - 0932 - 0934 - 0934 - 0933 -

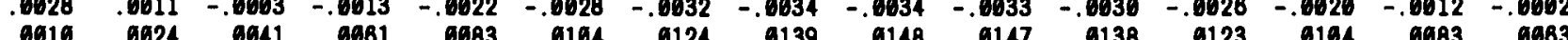

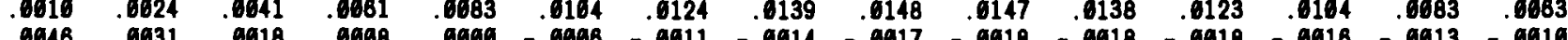

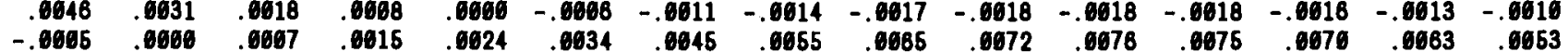

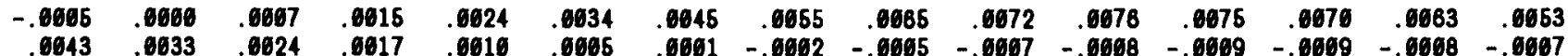

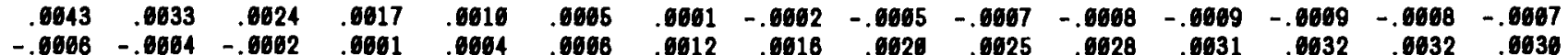

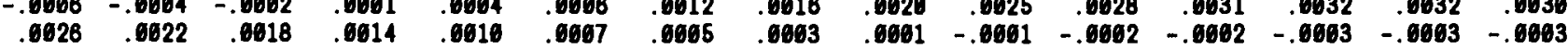

$\begin{array}{llllllllllllllll}-.0003 & -.0602 & -.0002 & -.0001 & -.0000 & .0001 & .0002 & .0063 & .0604 & .0005 & .0007 & .0008 & .0009 & .0009 & .0009\end{array}$

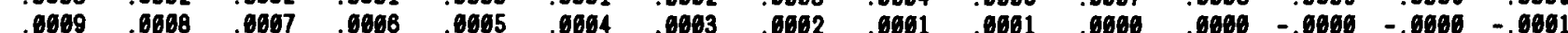

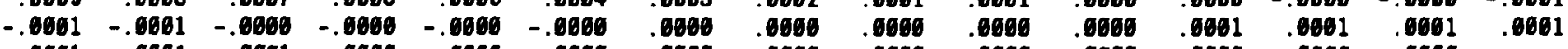

VARIANCE FROU INTEGRATION OF ROTATIOHAL $S(M)$

COMPUTED BY FFT OF ACF $2.016616(M / S) * 2$

VON KARMAN S(N) SPECTRUM

\begin{tabular}{|c|c|c|c|c|c|c|c|c|c|}
\hline $\begin{array}{r}7.119160 \\
6.579980 \\
3.796487 \\
2.966118 \\
1.264681 \\
.886329\end{array}$ & $\begin{array}{r}64.199360 \\
9.258147 \\
3.519763 \\
1.963849 \\
1.214633 \\
.852411\end{array}$ & $\begin{array}{r}50.645970 \\
8.172685 \\
3.273612 \\
1.899642 \\
1.168262 \\
.825881\end{array}$ & $\begin{array}{r}39.519820 \\
7.275158 \\
3.053752 \\
1.722653 \\
1.124542 \\
.866645\end{array}$ & $\begin{array}{r}31.146640 \\
6.522785 \\
2.856452 \\
1.642145 \\
1.683429 \\
.776620\end{array}$ & $\begin{array}{r}24.981916 \\
5.885717 \\
2.678666 \\
1.567474 \\
1.644666 \\
.753726\end{array}$ & $\begin{array}{r}20.380610 \\
5.341370 \\
2.517850 \\
1.498075 \\
1.608970 \\
.731892\end{array}$ & $\begin{array}{r}16.931689 \\
4.872370 \\
2.371866 \\
1.433451 \\
.973486 \\
.711651\end{array}$ & & $\begin{array}{r}12.226890 \\
4.169420 \\
2.117427\end{array}$ \\
\hline
\end{tabular}




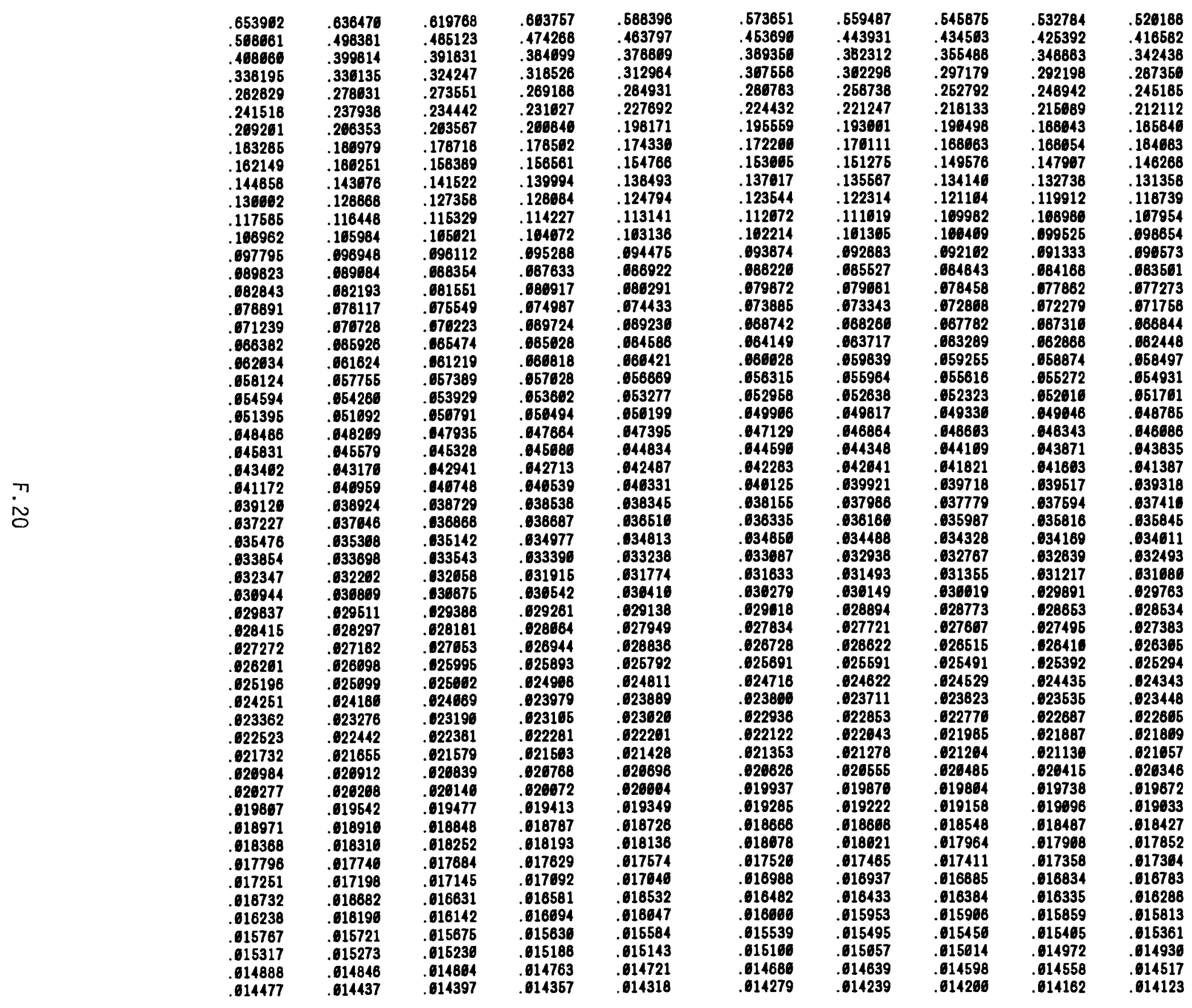




\begin{tabular}{|c|c|c|c|c|c|c|c|c|c|}
\hline 614684 & .614646 & .014008 & 013970 & .613932 & 013894 & 013857 & 013819 & .613782 & .613746 \\
\hline .613788 & .013672 & .013635 & .013599 & .613562 & .613526 & 013490 & .013455 & 613419 & 013384 \\
\hline .613348 & 013313 & .013278 & .013243 & .013268 & .613174 & 013139 & 013165 & .613671 & .013937 \\
\hline $\begin{array}{l}.013863 \\
.012872\end{array}$ & $\begin{array}{r}.612969 \\
912639\end{array}$ & $\begin{array}{l}.012936 \\
.612687\end{array}$ & $\begin{array}{l}.012982 \\
.612575\end{array}$ & $\begin{array}{l}.012869 \\
.612543\end{array}$ & .012836 & .012883 & $\begin{array}{l}.012778 \\
.012448\end{array}$ & $\begin{array}{l}.012737 \\
.012416\end{array}$ & $\begin{array}{l}.012784 \\
.012385\end{array}$ \\
\hline .012354 & .012323 & .612292 & .012281 & .012236 & .612260 & .012169 & .612139 & .012169 & 612079 \\
\hline .612649 & .012619 & .111989 & .611959 & .011938 & 011900 & 011871 & 011842 & 011813 & 611784 \\
\hline .611765 & 611726 & .611698 & .011669 & .011641 & .611613 & 011585 & 011667 & 011529 & 011561 \\
\hline .011473 & .011446 & 011418 & .611390 & .011363 & 611336 & .611369 & 011282 & .011255 & 011228 \\
\hline .611262 & .011175 & .011148 & .611122 & .011998 & .611070 & .011044 & 011818 & .610992 & 010968 \\
\hline .610946 & .016915 & .616889 & .616864 & 010838 & 616813 & 616788 & 016763 & 610738 & 610713 \\
\hline 010688 & .16864 & .16639 & .616815 & 010598 & .016566 & 016542 & 616518 & .016494 & .610476 \\
\hline .610448 & 016422 & .016398 & .616375 & 016351 & .616328 & 616365 & 616281 & .010258 & 610235 \\
\hline .016212 & .016189 & .010168 & .616143 & .010121 & .010098 & 616076 & 616053 & .616031 & 610869 \\
\hline .609986 & .069964 & .669942 & .669920 & .069898 & .669877 & .669855 & .069833 & .609812. & 669798 \\
\hline .669769 & .069747 & .699726 & .669705 & 009684 & .669683 & .669642 & .669821 & .069606 & $\begin{array}{l}.669579 \\
.699375\end{array}$ \\
\hline $\begin{array}{l}.699558 \\
.699355\end{array}$ & $\begin{array}{l}.609538 \\
.609335\end{array}$ & $\begin{array}{l}.699517 \\
.899316\end{array}$ & $\begin{array}{l}.669497 \\
.669296\end{array}$ & $\begin{array}{l}.069476 \\
.089278\end{array}$ & $\begin{array}{r}6699456 \\
669256\end{array}$ & .689237 & .669217 & $\begin{array}{l}.669395 \\
.699198\end{array}$ & $\begin{array}{l}.669375 \\
.669178\end{array}$ \\
\hline .689159 & .069140 & .069121 & .669101 & .009882 & .069063 & 069044 & 009628 & .009687 & .608988 \\
\hline . & .068951 & .688932 & .608914 & .068895 & .668877 & 668858 & 688840 & 688822 & 668884 \\
\hline $\begin{array}{l}688786 \\
988698\end{array}$ & .068788 & .688756 & .668732 & .688714 & .688696 & 668878 & 668661 & 688643 & 668628 \\
\hline $\begin{array}{l}688668 \\
688436\end{array}$ & $\begin{array}{l}.668591 \\
.96819\end{array}$ & $\begin{array}{r}689573 \\
.898462\end{array}$ & .688558 & $\begin{array}{l}06853939 \\
688389\end{array}$ & $\begin{array}{l}6888521 \\
.68352\end{array}$ & $\begin{array}{l}6858584 \\
8 B 9336\end{array}$ & $\begin{array}{l}6688487 \\
668319\end{array}$ & 098478 & $\begin{array}{l}.68453 \\
689288\end{array}$ \\
\hline .888276 & .088253 & .068237 & .688221 & 968284 & .688188 & 68B172 & 608158 & .008140 & 668124 \\
\hline 688168 & .088692 & .608077 & .608681 & .088645 & .608629 & 608014 & 607998 & .607983 & 667967 \\
\hline .667952 & 607937 & .687921 & .687966 & 087891 & .607876 & 687868 & 687845 & .607830 & 687815 \\
\hline .607860 & .667785 & .667771 & .667756 & .007741 & .687726 & 667712 & 667697 & .067682 & 607688 \\
\hline 697653 & 607639 & 687624 & .667610 & 607598 & .687582 & 687567 & 667553 & .067539 & 607525 \\
\hline .697511 & $\begin{array}{l}.607497 \\
.097359\end{array}$ & $\begin{array}{l}.607483 \\
.097345\end{array}$ & $\begin{array}{r}68776799 \\
.687332\end{array}$ & .867318 & 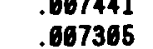 & 867291 & .667278 & .067264 & . 867251 \\
\hline .067238 & .067225 & .607212 & .667198 & .087185 & .607172 & 687159 & 667146 & 007133 & 667126 \\
\hline .687167 & 607695 & .007682 & 667669 & .0976568 & .607044 & 687831 & 667618 & .0076868 & .668993 \\
\hline .806981 & .086968 & . & .686943 & .886931 & .86919 & .8689968 & 868694 & .086882 & $\begin{array}{l}.668876 \\
.68756\end{array}$ \\
\hline .868738 & .806726 & $\begin{array}{l}.686833 \\
.686714\end{array}$ & $\begin{array}{l}.686821 \\
.688762\end{array}$ & .886691 & . & . & .868658 & .008644 & 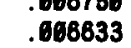 \\
\hline .606621 & .086810 & .6085988 & .6685887 & 068578 & 686564 & 686553 & 668542 & .606530 & .668519 \\
\hline 608568 & 068497 & .608486 & .668475 & 086464 & .608453 & 686442 & .668431 & .006420 & .686469 \\
\hline 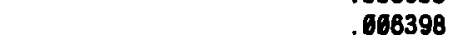 & 666387 & .606378 & .606365 & .068355 & 606344 & 668333 & 666322 & 696312 & .668361 \\
\hline 886291 & .666280 & .686269 & 666259 & 686248 & 606238 & 668228 & 668217 & 606267 & .668196 \\
\hline $60618 B$ & .006178 & .066166 & .688155 & .086146 & .668135 & 686125 & 686115 & .006185 & .668095 \\
\hline .606886 & .086675 & .666865 & .668655 & .086845 & .686035 & .688625 & .686815 & 806085 & 665995 \\
\hline \multirow{2}{*}{\multicolumn{10}{|c|}{ ESTIMATES FROM FFT OF ACF }} \\
\hline & & & & & & & & & \\
\hline 11.128880 & 16.865760 & 16.115426 & 8.986814 & .633777 & 6.222465 & 4.898858 & 3.764878 & 2.868726 & 2.269162 \\
\hline 1.748986 & 1.434786 & 1.214627 & 1.646836 & .968738 & .796445 & .690163 & .668714 & .545463 & .497202 \\
\hline .459164 & .426871 & . 397558 & .376512 & .346396 & . 326133 & .316802 & 297360 & .286967 & .277614 \\
\hline .268632 & .266636 & .252286 & .245859 & 240968 & .237159 & .234698 & .231240 & .228374 & .225695 \\
\hline .223222 & 221481 & .226442 & .219939 & 219692 & .219467 & .219260 & 219665 & 219875 & .219559 \\
\hline .220465 & .221689 & .222992 & .224312 & .225631 & .227866 & 228743 & .236769 & .233117 & .235877 \\
\hline .238325 & .246999 & .243742 & .246870 & .249965 & .253499 & .257466 & 261528 & .285746 & .276969 \\
\hline 274572 & 279392 & 284645 & .296356 & 296455 & .362826 & .369398 & 316208 & .323396 & .331153 \\
\hline .339663 & 348752 & 358490 & .368684 & 379295 & .390447 & 462405 & .415459 & 429781 & 445353 \\
\hline .462010 & 479606 & 498169 & .618047 & 539783 & .563925 & 598786 & 62 & 652361 & .686735 \\
\hline .723823 & .764664 & .810489 & .882856 & .922564 & .989886 & 1.064497 & 1.147151 & 1.2398965 & 1.346437 \\
\hline 1.472485 & 1.623582 & 1.864256 & 2.617752 & 2. 267967 & 2.563655 & 2.923757 & 3.381383 & 3.983482 & 4.783835 \\
\hline
\end{tabular}




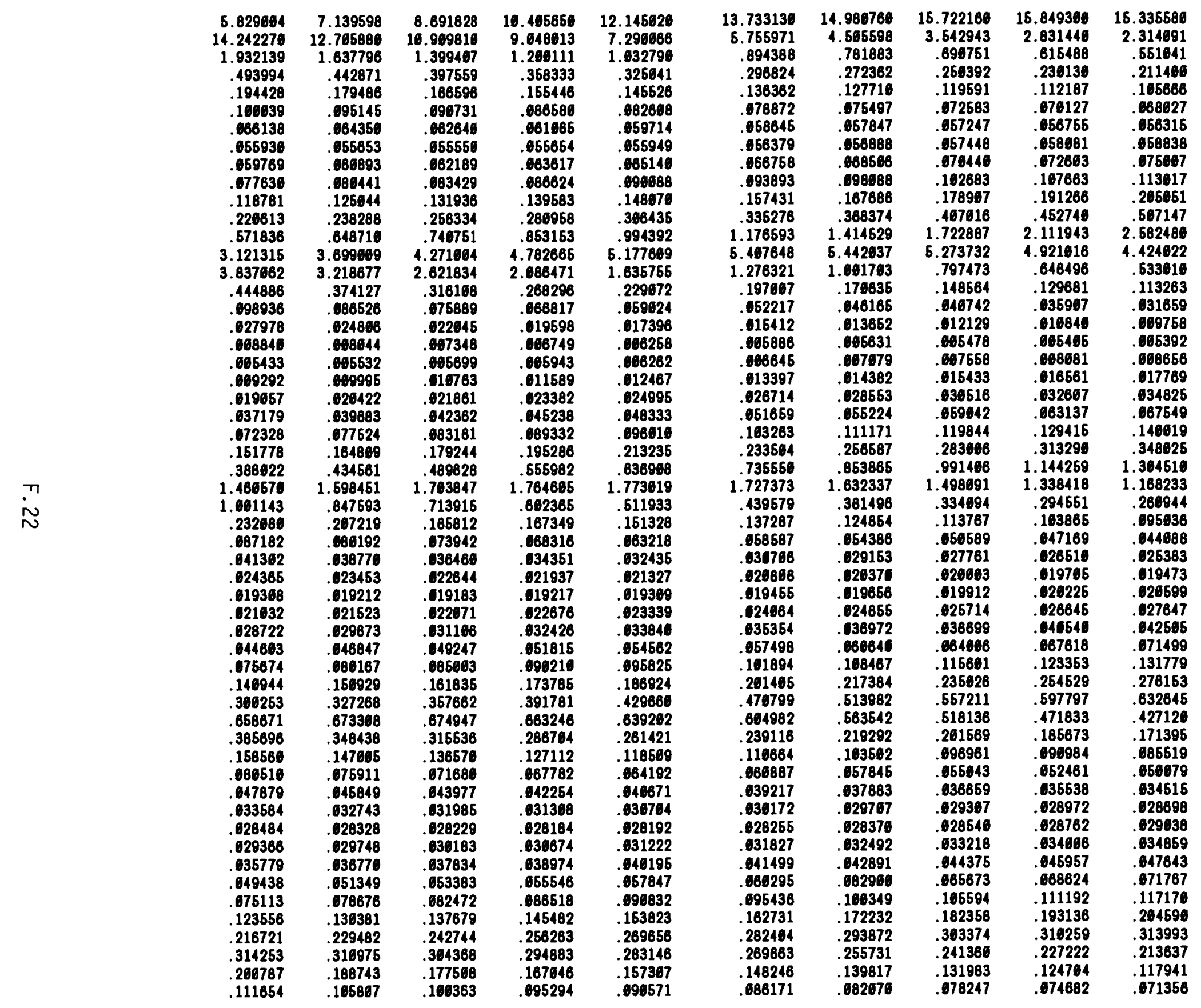




\begin{tabular}{|c|c|c|c|c|c|c|c|c|c|}
\hline 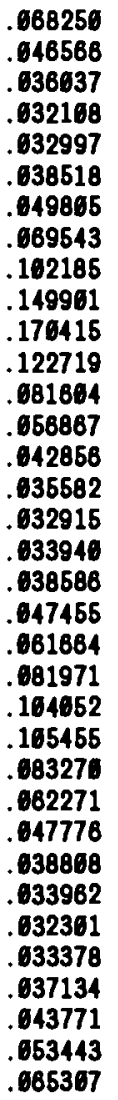 & 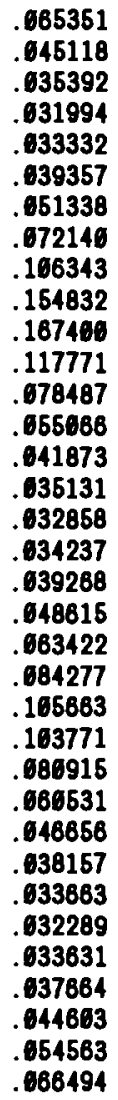 & 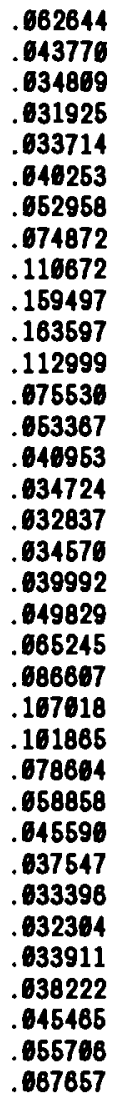 & $\begin{array}{l}.686116 \\
.642519 \\
.634285 \\
.631963 \\
.634141 \\
.641216 \\
.654669 \\
.677744 \\
.115168 \\
.163752 \\
.159176 \\
.168413 \\
.672726 \\
.651762 \\
.649693 \\
.634359 \\
.632852 \\
.634939 \\
.646760 \\
.651166 \\
.667132 \\
.688956 \\
.168676 \\
.699783 \\
.676343 \\
.657252 \\
.644576 \\
.636974 \\
.633158 \\
.632346 \\
.634217 \\
.638811 \\
.646359 \\
.656876 \\
.668787\end{array}$ & 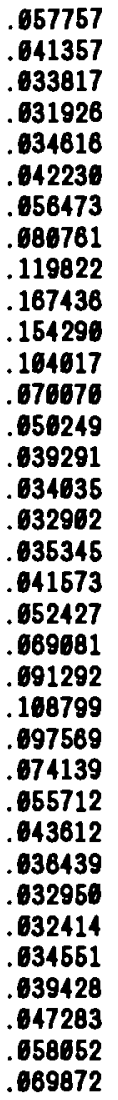 & 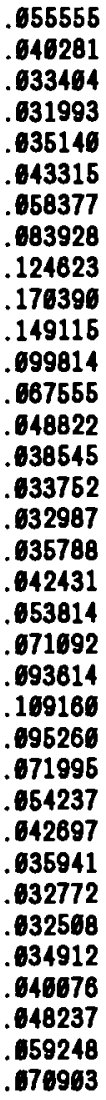 & $\begin{array}{l}.053499 \\
.039286 \\
.033944 \\
.032165 \\
.035712 \\
.044466 \\
.060384 \\
.087251 \\
.129553 \\
.172465 \\
.143784 \\
.095863 \\
.065173 \\
.047478 \\
.037863 \\
.033569 \\
.033168 \\
.036269 \\
.043337 \\
.055260 \\
.073163 \\
.095897 \\
.169143 \\
.092889 \\
.069916 \\
.052824 \\
.041839 \\
.035478 \\
.032622 \\
.032636 \\
.036361 \\
.046754 \\
.049221 \\
.060456 \\
.071867\end{array}$ & $\begin{array}{l}.651581 \\
.638367 \\
.632736 \\
.632261 \\
.636335 \\
.645688 \\
.682499 \\
.696734 \\
.134596 \\
.173546 \\
.138468 \\
.691981 \\
.662926 \\
.646213 \\
.637212 \\
.633364 \\
.633263 \\
.636789 \\
.644291 \\
.658767 \\
.675296 \\
.698115 \\
.168746 \\
.696484 \\
.687963 \\
.651474 \\
.641699 \\
.635649 \\
.632560 \\
.632777 \\
.635717 \\
.641462 \\
.650235 \\
.661671 \\
.672751\end{array}$ & $\begin{array}{l}.649791 \\
.637521 \\
.632478 \\
.632462 \\
.637669 \\
.646983 \\
.664727 \\
.694382 \\
.139697 \\
.173561 \\
.133669 \\
.688345 \\
.660788 \\
.645623 \\
.636621 \\
.633137 \\
.633454 \\
.637347 \\
.645294 \\
.658336 \\
.677471 \\
.169237 \\
.167982 \\
.688968 \\
.685957 \\
.656183 \\
.649232 \\
.634654 \\
.632466 \\
.632951 \\
.636161 \\
.642261 \\
.661277 \\
.662888 \\
.673541\end{array}$ & 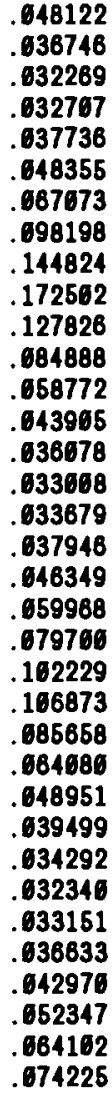 \\
\hline
\end{tabular}

\begin{tabular}{|c|c|c|c|c|c|c|c|c|c|}
\hline 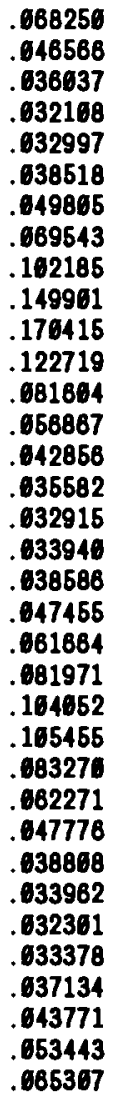 & $\begin{array}{l}.665351 \\
.645118 \\
.635392 \\
.631994 \\
.633332 \\
.639357 \\
.651338 \\
.672146 \\
.166343 \\
.154832 \\
.167406 \\
.117771 \\
.678487 \\
.655686 \\
.641873 \\
.635131 \\
.632858 \\
.634237 \\
.639268 \\
.648615 \\
.663422 \\
.684277 \\
.165663 \\
.163771 \\
.686915 \\
.668531 \\
.646856 \\
.638157 \\
.633663 \\
.632289 \\
.633631 \\
.637864 \\
.644603 \\
.654563 \\
.666494\end{array}$ & 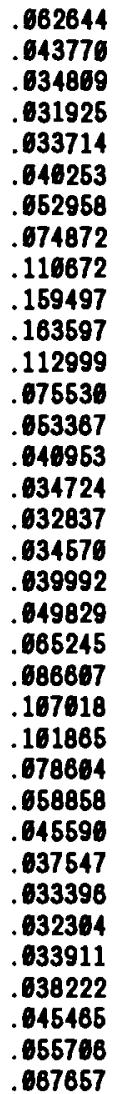 & 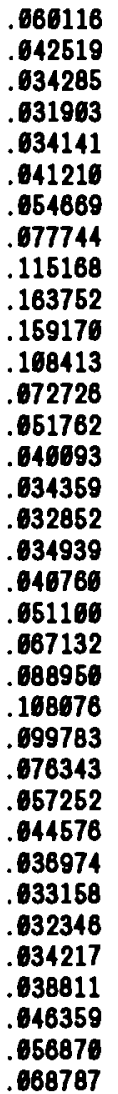 & 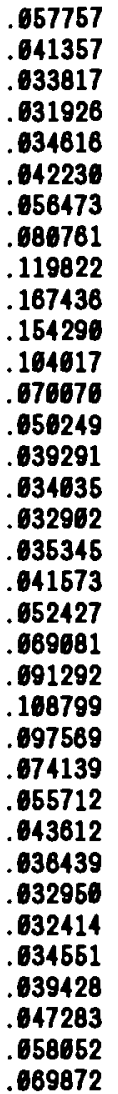 & 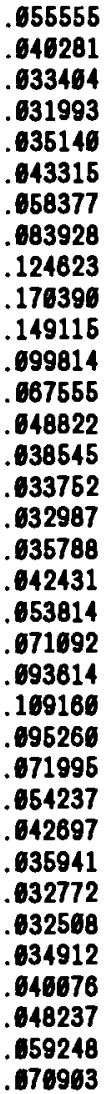 & 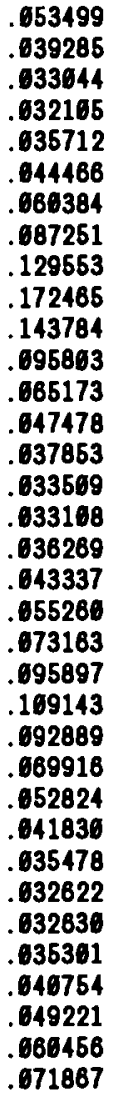 & $\begin{array}{l}.651581 \\
.638367 \\
.632736 \\
.632261 \\
.636335 \\
.645688 \\
.682499 \\
.698734 \\
.134596 \\
.173545 \\
.138468 \\
.691981 \\
.662926 \\
.646213 \\
.637212 \\
.633364 \\
.633263 \\
.636789 \\
.644291 \\
.658767 \\
.675296 \\
.698115 \\
.168746 \\
.696484 \\
.687963 \\
.651474 \\
.641069 \\
.635049 \\
.632560 \\
.632777 \\
.635717 \\
.641462 \\
.650235 \\
.681671 \\
.672751\end{array}$ & $\begin{array}{r}.649791 \\
.637521 \\
.632478 \\
.632462 \\
.637689 \\
.646983 \\
.664727 \\
.694382 \\
.139697 \\
.173561 \\
.133669 \\
.688345 \\
.660788 \\
.645623 \\
.636621 \\
.633137 \\
.633454 \\
.637347 \\
.645294 \\
.658336 \\
.677471 \\
.166237 \\
.167982 \\
.688968 \\
.685957 \\
.650183 \\
.646232 \\
.634654 \\
.632466 \\
.632951 \\
.636161 \\
.642261 \\
.651277 \\
.662888 \\
.673541\end{array}$ & 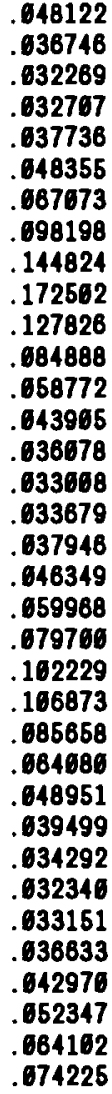 \\
\hline
\end{tabular}

$S(N)$ ANA YSIS - 80 EVENLY
FRERUENCY (HZ) FRERUENCY (P)

CED FREQUENCIES

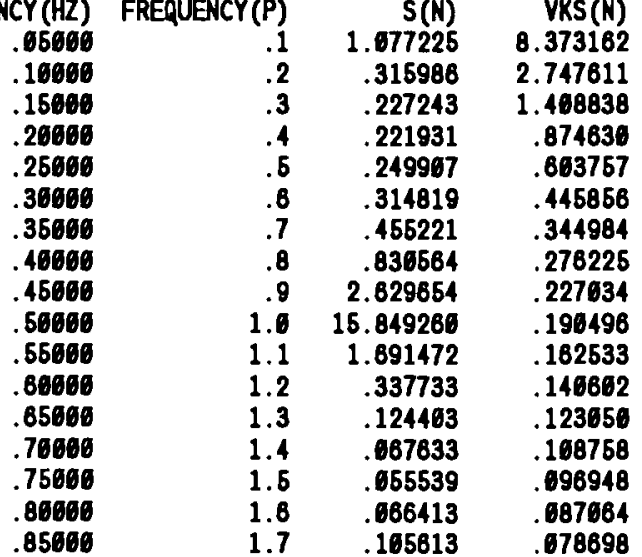

\begin{tabular}{|c|c|c|c|}
\hline 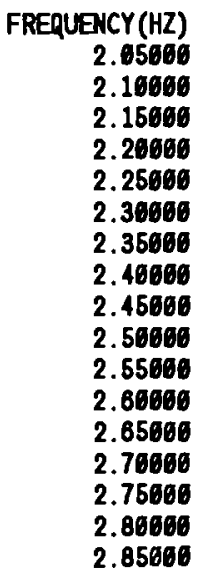 & $\begin{array}{r}\text { FREQUENCY }(P) \\
4.1 \\
4.2 \\
4.3 \\
4.4 \\
4.5 \\
4.6 \\
4.7 \\
4.8 \\
4.9 \\
5.6 \\
5.1 \\
5.2 \\
6.3 \\
5.4 \\
5.5 \\
6.8 \\
5.7\end{array}$ & $\begin{array}{r}S(N) \\
.243365 \\
.893318 \\
.047056 \\
.631181 \\
.628369 \\
.634681 \\
.052561 \\
.692634 \\
.184463 \\
.314252 \\
.169678 \\
.683686 \\
.649112 \\
.635271 \\
.631924 \\
.636294 \\
.649213\end{array}$ & $\begin{array}{l}\text { VKS (N) } \\
.618147 \\
.617433 \\
.616763 \\
.616132 \\
.615539 \\
.614986 \\
.614453 \\
.613955 \\
.613483 \\
.613637 \\
.612614 \\
.612212 \\
.611836 \\
.611467 \\
.611122 \\
.616793 \\
.616479\end{array}$ \\
\hline
\end{tabular}




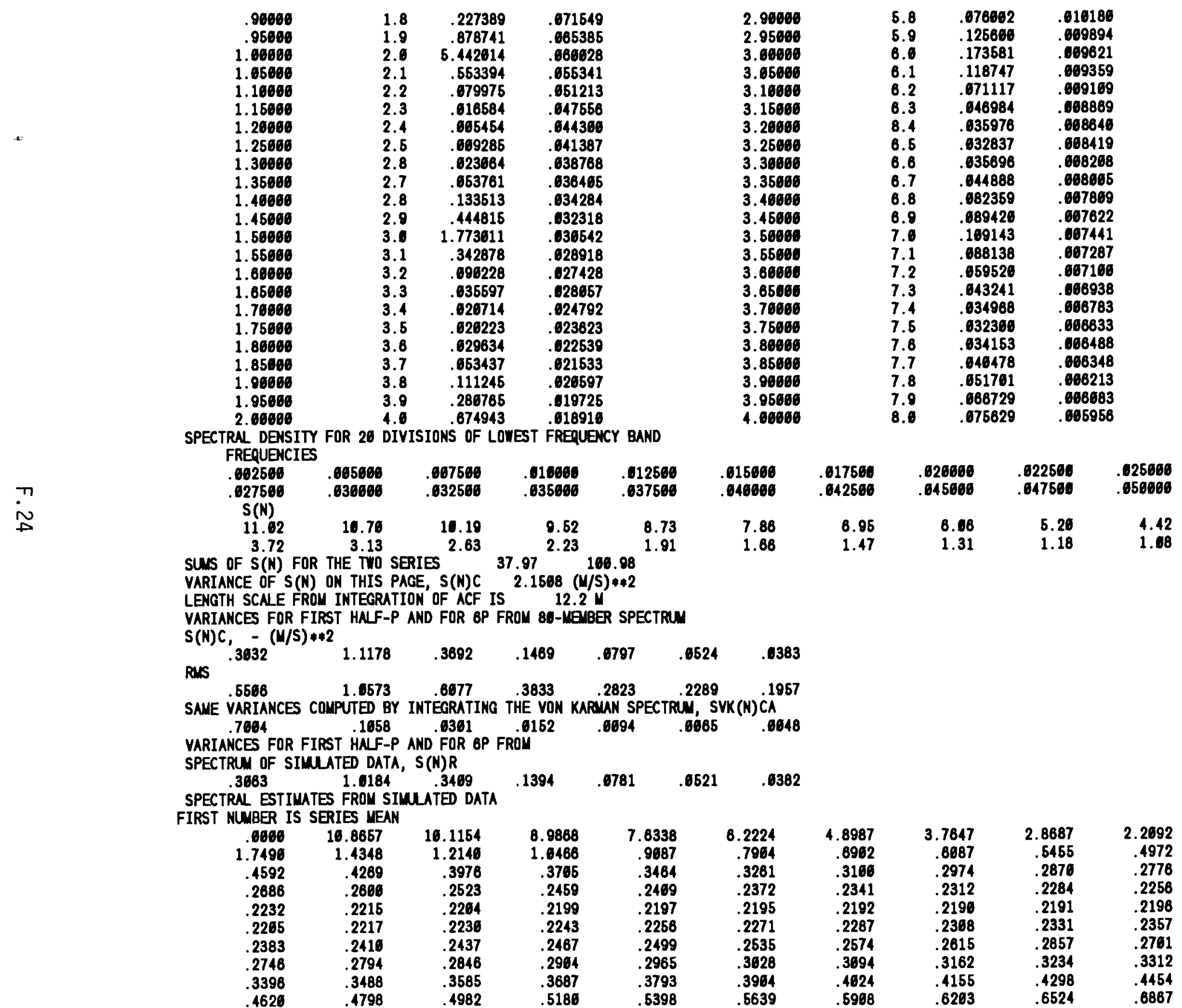




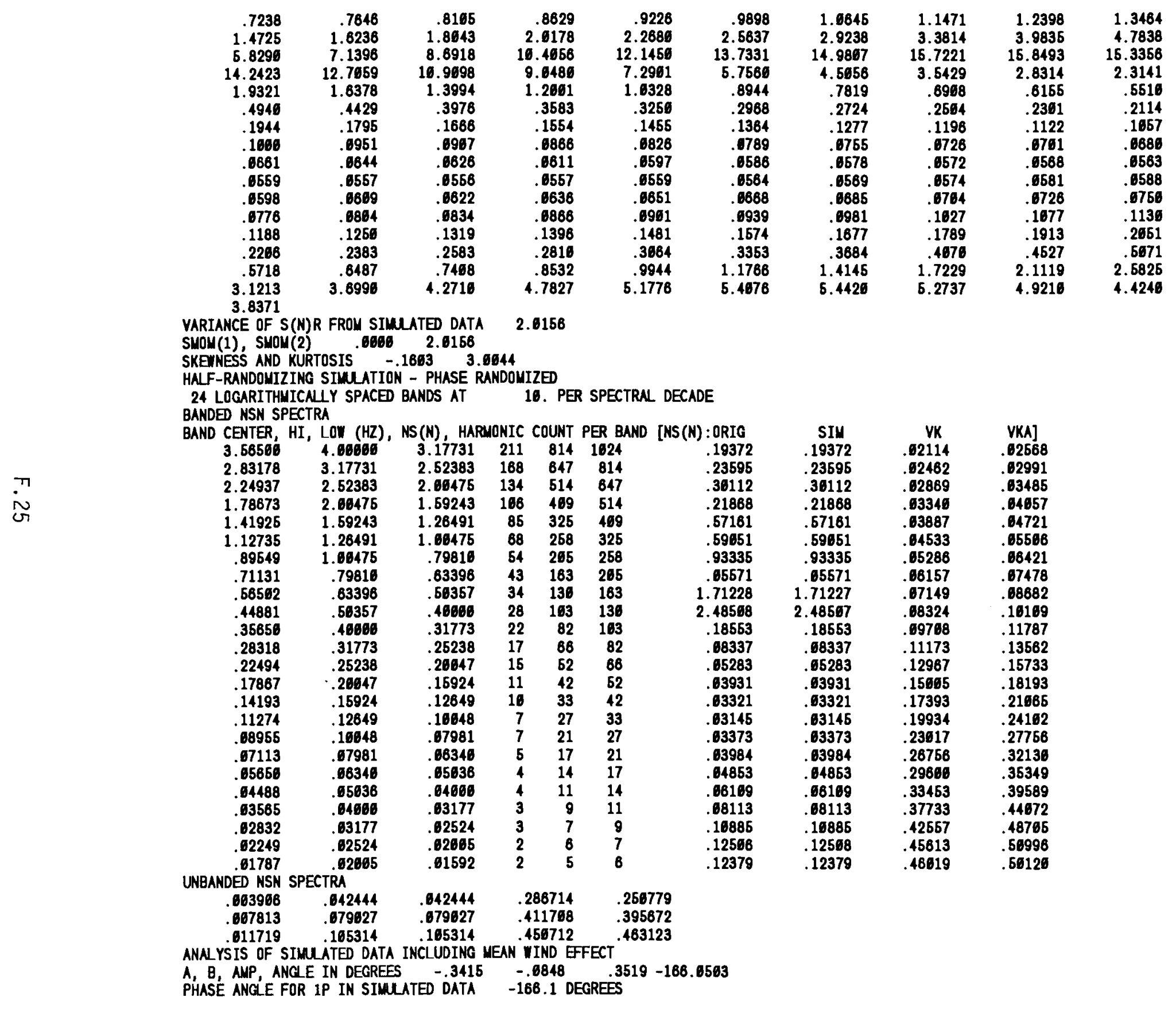


OFFSET ANGE BETWEEN MEAN WIMD AND TURBULENCE AT IP (DEAYY)

. DEGREES

OFFSET, IFFSET

$$
-7.411
$$

ONE CYCLE OF MÉAN WIND EFECT - M/S

$\begin{array}{llllllll}-3.83 & 3.83 & 7.67 & 9.24 & 16.00 & 9.24 & 7.07 & 3.83\end{array}$

MUMBER OF COMPLETE MEAN WIND CYCLES IN SIMULATION 128

VARIANCES FOR FIRST HALF-P AND FOR BP FROM

SPECTRUN OF SIMULATED DATA, S(N)R

$\begin{array}{llllllll}.3683 & 51.6418 & .3469 & .1394 & .0781 & .6521 & .0382\end{array}$

SPECTRAL ESTIMATES FROM SIMUATED DATA

FIRST NUMBER IS SERIES MEAN

$\begin{array}{cccc}.0606 & 10.8657 & 16.1154 & 8.9868 \\ 1.7499 & 1.4348 & 1.2140 & 1.0468\end{array}$

$\begin{array}{rr}1.7480 \quad 100 & 1.4348\end{array}$

$\begin{array}{rrrr}.7480 & 1.4348 & 1.2146 & 1.0466 \\ .4592 & .4268 & .3976 & .3706\end{array}$

$.2886 \quad .2660$

$2232 \quad .2215$

$2205 \quad .2217$

$\begin{array}{ll}.2383 & .2416 \\ .2746 & .2794\end{array}$

.2794

.3488
.4798

.7646

.3976

.3765

10

$.2204 \quad .2199$

.2230

.2189

.2437
.2846

.2848
.3586

.4620

1.4725

1.6236

.4982
.8165

1.8943

$6.8290 \quad 7.1398$

8.6918

$14.2423 \quad 12.7468$

10.9698

1.9321

1.6378

1.3994

.494

.4428
.1795

1.3994
.3976

1000

10081 .0951

$6559 \quad .0557$

$0588 \quad .0669$

9776

.1188

2290

.6718
.1213

.0804

.6968

.0628

.0658

.6834

.1319

.2583

6467

.7468
4.2716

.2487

.2964

.5180

.8180
.8629
2.0178

2.9178
10.4956

.9687
.3464

.3484
.2469

.2187

.2256

.2489

.2985

.3793
.6398

.8226

2.2880

9.0480

12.1460

7.2961

1.2001

.3583
.1564

1.6328

.3256
.1465

.0866

.0626

.0687

.6559

.6851

1308

.0801

6.2224

.7964
.3281

.3281
.2372

.2195

.2271

.2535

.3628

.3964

.9898

2. 6637

13.7331
6.7689

.7680

.8944
.2986

.2986
.1364

.1384
.0789
.0688

.6564

.6688

3.837

.2810

.3684

.6839

.3604
.9844

.3353

4.7627

5.1776

5.4676

4.8987

.6902
.3160

.2341

.2192

.2287

.2574

.3694
.4624

.5988

1.0646

2.9238

14.9867

4.5856

.7619

.2724

.1277
.0756

.0676

.0569

.0685

.0981

.1877

.3684
1.4145

5. 4420

2.2692

$\begin{array}{lll}.0087 & .5465 & .4972 \\ .2974 & .2876 & .2776\end{array}$

$.2312 \quad .2284 \quad .2256$

$.2190 \quad .2191 \quad .2196$

2368

.2816

.3162

.4166

.6203

.2331

.2857

.3234

.8624

3.3614

$15.7221 \quad 12949.7969$

$3.5429 \quad 2.8314$

2.8314
.6165

.6968

.2504

.1196

.0726

.6574

.0764

.1627

.1769

.4670

1.7229

6.2737

.6155
.6510

$.2361 \quad .2114$

$.1122 \quad .165$

$.0686 \quad .6683$

$.6581 \quad .658$

$.0728 \quad .675$

1077

.1913

0.1118

2.1119
4.9210

.1130

5671

2.5625

SMOM(1) SMOY(2) 62.5388

SKEUNESS AND KURTOSIS $-.0574 \quad 1.6047$

HALF-PAMDOYIZING SIYUUATOH - PHASE RANDOMIZED

24 LOGARITHMICA $\perp Y$ SPACED BANDS AT 10. PER SPECTRAL DECADE

PANDED NSH SPECTRA

BAND CEMTER HI, LOW (HZ), NS(N), HAPNONIC COUNT PER BAND [NS(N): ORIO

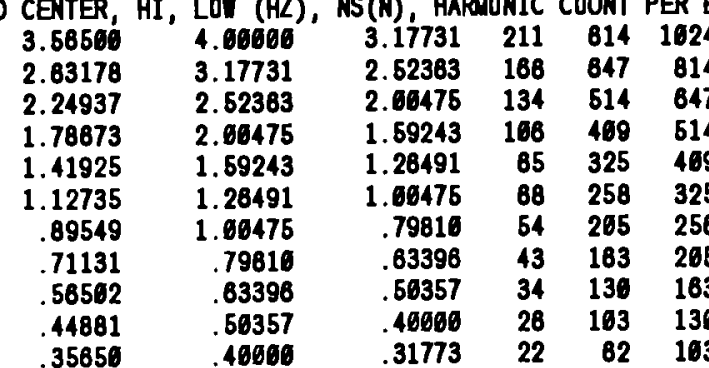

.35650

40060

.31773

\begin{tabular}{rrr}
163 & 130 \\
\hline & 62 & 193
\end{tabular}

.0810
.19372
.23596
.36112
.21688
.57161
.59651
.93335
.65571
1.71228
2.46568
.18553

SIM

.19372
.23595

.23595

21868

57161

.59951

.0557

1.71227

.60116
.16553

\begin{tabular}{|c|c|}
\hline $\begin{array}{c}V K \\
.62114 \\
.62482 \\
.62869 \\
.03340 \\
.63887 \\
.04533 \\
.05286 \\
.68167 \\
.67149 \\
.68324 \\
.69708\end{array}$ & $\begin{array}{l}\text { VKA] } \\
.02588 \\
.02891 \\
.03485 \\
.04657 \\
.04721 \\
.65586 \\
.06421 \\
.07478 \\
.68682 \\
.16109 \\
11787\end{array}$ \\
\hline
\end{tabular}

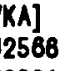

.

4657

4721

7478

11787 


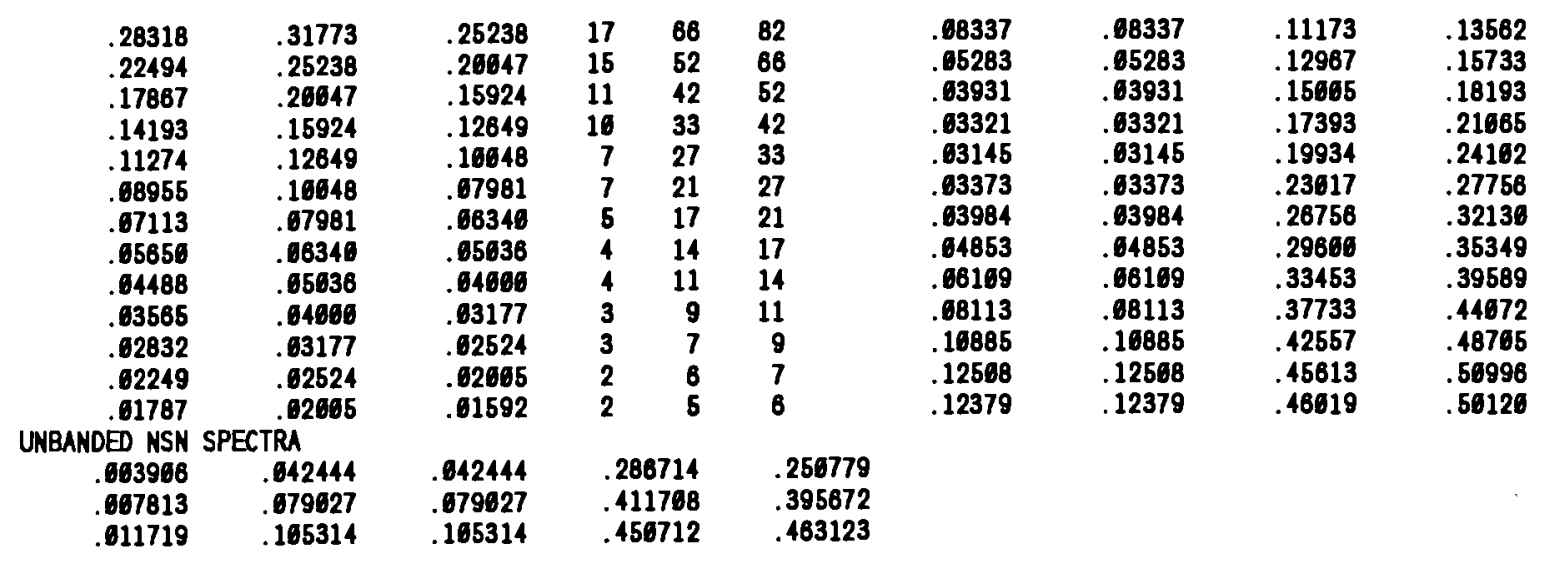




\begin{tabular}{|c|c|c|c|}
\hline 2048 & .188722 & $-4.168526 \mathrm{E}-61$ & \\
\hline 1786 & $1.111246 \mathrm{E}-62$ & $2.189247 \mathrm{E}-61$ & 1.11 \\
\hline & 01 & 1.887283E- 61 & 1.488686 \\
\hline & $121 \mathrm{E}-\theta$ & $-8.078672 E-61$ & $0986 E-61$ \\
\hline & 461 & $E-62$ & 1.835883 \\
\hline & & 4.9 & 33 \\
\hline & 8.90 & 1 & 14 \\
\hline & 01 & $.946847 \mathrm{E}-01$ & 1.741713 \\
\hline & .172362 & $.336316 \mathrm{E}-62$ & $.183839 \mathrm{E}-01$ \\
\hline 2918 & $-1.546351 \mathrm{E}-61$ & $.816853 \mathrm{E}-61$ & $4.632374 E-01$ \\
\hline & 4.01 & -61 & $\begin{array}{r}1.71 \\
08854 ?\end{array}$ \\
\hline 4283 & $2.981746 \mathrm{E}-61$ & & -1.883447 \\
\hline 7 & & .878 & 5.676288 \\
\hline & 1.22134 & 7.636987E-61 & 1.634115 \\
\hline 1.4 & $\begin{array}{l}1.6 \\
25538\end{array}$ & -81 & $\begin{array}{l}.84623 \\
.44866\end{array}$ \\
\hline 68 & 996 & & $\begin{array}{l}-4.4 \\
-5.8\end{array}$ \\
\hline & -8.346 & & 9.8517 \\
\hline & 3.72 & .2 & -6.9708 \\
\hline & $\begin{array}{l}-1.234424 \\
-2.605100\end{array}$ & $\begin{array}{l}-61 \\
1169\end{array}$ & $\begin{array}{l}-4.8640612 E-61 \\
-4.61366 \mathrm{E}-61\end{array}$ \\
\hline 14362 & 1308 & & \\
\hline & & 61 & -3.94 \\
\hline & $\begin{array}{c}-3.1408 \\
-3\end{array}$ & .61 & $\begin{array}{l}-1.16 \\
-1.3 t\end{array}$ \\
\hline -1.46, & B.1121 & & -1.69180 \\
\hline & & & -8.4104 \\
\hline & -8.922 & .5 & -8.8474 \\
\hline & & & -9.8 \\
\hline & $\begin{array}{r}-2.985 \\
3.768\end{array}$ & 1 & $\begin{array}{r}8.71437 \\
-1.08334\end{array}$ \\
\hline & $\begin{array}{r}3.76 \\
-3.43\end{array}$ & $\begin{array}{l}10-01 \\
53 E-61\end{array}$ & -8.78978 \\
\hline & -9.0 & & 4.07536 \\
\hline-4.29 & 1.91 & .34 & \\
\hline-1 & -7.731 & 3.0 & \\
\hline & $\begin{array}{l}4.47 \\
8.81\end{array}$ & 1.1 & $\begin{array}{c}-2.47756 \\
7.1638\end{array}$ \\
\hline$\because$ & -6.78 & -0.2 & -8.2743 \\
\hline & -1 & & -4.62158 \\
\hline & -4.7170 & 1.601 & 3.1828 \\
\hline & 7.59 & & 1.2 \\
\hline & & & \\
\hline Se & 3.584335 & $.819734 \mathrm{E}$ & -5.4 \\
\hline & 1994 & & 9.63273 \\
\hline & & & 851 \\
\hline-9.268. & -8.054780 & -01 & 1.5 \\
\hline & & & \\
\hline
\end{tabular}




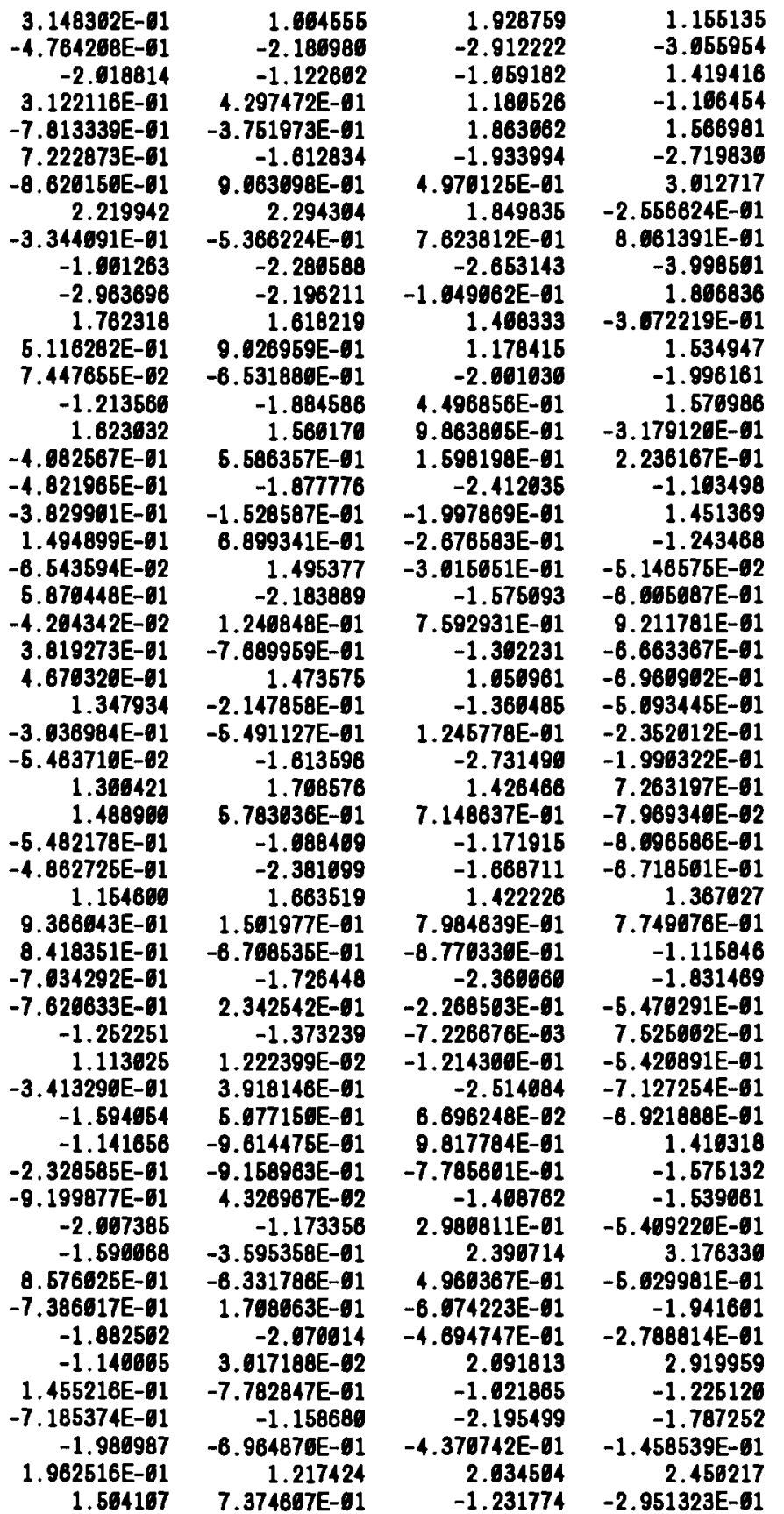




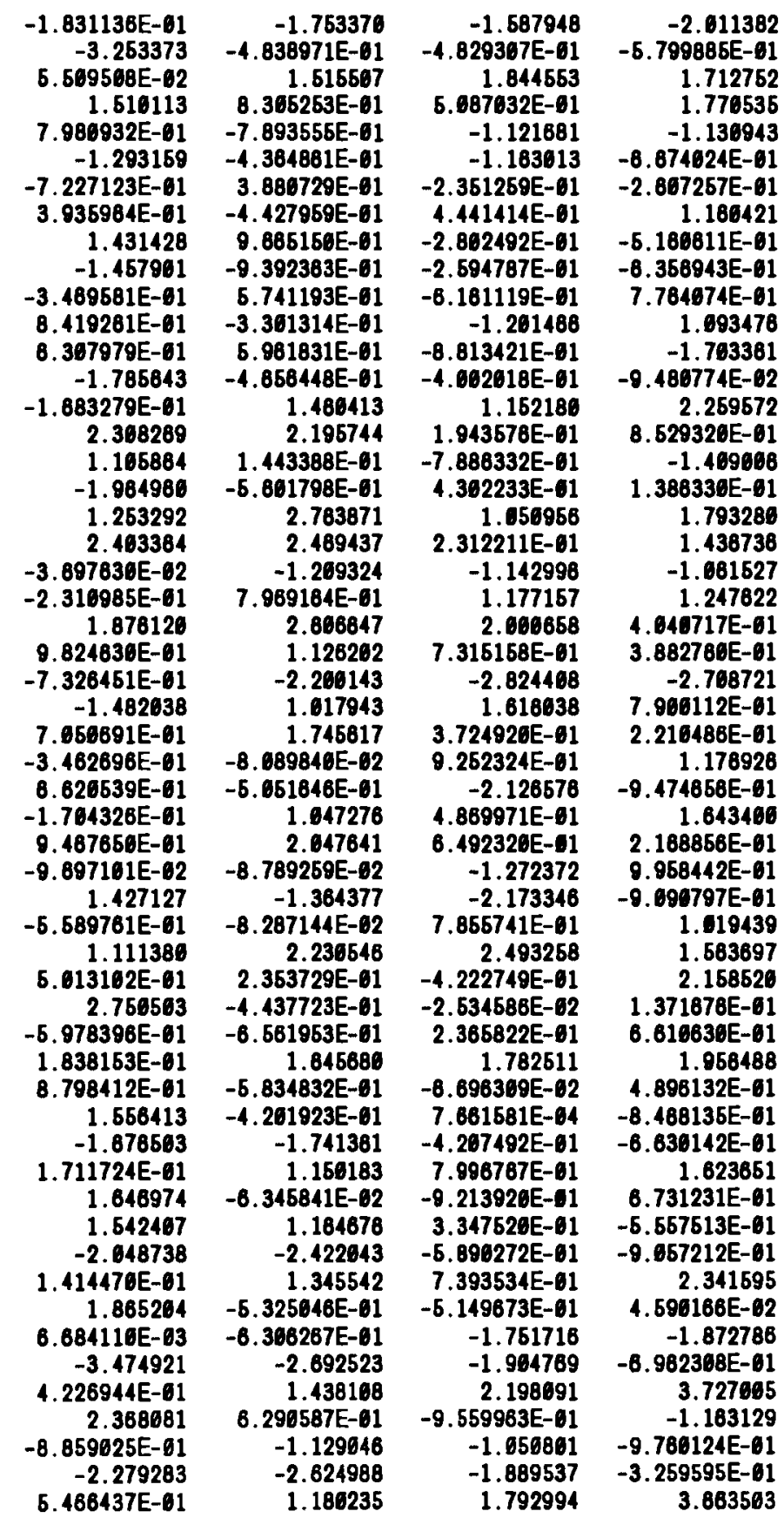




\begin{tabular}{|c|c|c|c|}
\hline $\begin{array}{c}2648 \\
16.680560\end{array}$ & $\begin{array}{r}-2.640111 \\
9.928887\end{array}$ & $\begin{array}{r}4.188512 \mathrm{E}-\theta 1 \\
9.45772 \theta\end{array}$ & $\begin{array}{r}2.982968 \\
8.199669\end{array}$ \\
\hline 6.319207 & 4.383993E- 61 & -4.613683 & -5.682382 \\
\hline .911636 & -10.114210 & -10.646850 & -6.891968 \\
\hline .898474 & 1.320462 & $3.92583 \theta$ & 8.986952 \\
\hline .336630 & 11.982916 & 9.733882 & 8.971931 \\
\hline 5. 655612 & $8.962578 \mathrm{E}-61$ & -4.158498 & -6.793464 \\
\hline-7.672824 & -9.495293 & -9.832860 & -6.896895 \\
\hline-2.331865 & 1.172363 & 3.888139 & 7.289453 \\
\hline 16.037966 & 9.845964 & 9.857110 & 7.5343965 \\
\hline 5.225876 & 4.619396E-62 & -3.638291 & -5.356454 \\
\hline-6.528328 & & -10.169376 & -7.096732 \\
\hline-2.884194 & $2.981753 E-61$ & 3.918680 & 6. 582724 \\
\hline 7.698746 & 8.195751 & 9.659985 & 7.828696 \\
\hline 4.879317 & $221341 \mathrm{E}-61$ & -3.683236 & -6.836953 \\
\hline-7.788238 & -8.998631 & -9.979948 & -6.587844 \\
\hline-3.544667 & $-4.255368 \mathrm{E}-61$ & 4.516918 & 7.926582 \\
\hline 7.417198 & 7.761365 & 7.244606 & 6. 482681 \\
\hline 4.073142 & $-8.345761 \mathrm{E}-62$ & -2.584776 & -6.885895 \\
\hline-9.684422 & -9.627168 & -9.368199 & -7.788147 \\
\hline-5.141742 & -1.234423 & 3.998279 & 6. 599688 \\
\hline 6.963378 & 7.494968 & 7.957626 & 6.699732 \\
\hline 4.371137 & 1.348767 & -1.985171 & -8.239618 \\
\hline-7.858984 & -8.166663 & -8.868989 & -7.4658665 \\
\hline$-0.1+2+3$ & 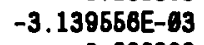 & 4.839209 & \\
\hline 7.790988 & 189 & 6.409336 & 5.712207 \\
\hline 4.350362 & $6.112116 E-61$ & -3.682369 & -7.186229 \\
\hline-8.426243 & -8.883826 & -8.646179 & -7.912715 \\
\hline-6.197325 & $-8.922379 \mathrm{E}-61$ & 3.868977 & B. 186327 \\
\hline 7.989814 & 7.499136 & 6.589238 & 6.105280 \\
\hline 3.355687 & -2.88537 & -3.363928 & -6.199631 \\
\hline-8.514 & & -8.94676 & -7.17 \\
\hline-5.552489 & $-3.438972 \mathrm{E}-61$ & 4.615021 & B.192898 \\
\hline 8.798781 & 9.690484 & 7.424252 & 7.478684 \\
\hline 3.397592 & $1.916874 \mathrm{E}-61$ & -3.592252 & -6.067168 \\
\hline-8.867949 & -10.773150 & -8.934417 & -8.334486 \\
\hline-5.661172 & 4. 476869E-61 & 5.607057 & 6.823312 \\
\hline & 10.891720 & 9.127738 & 7781451 \\
\hline 4.800292 & $-5.768653 \mathrm{E}-61$ & -4.449975 & -7.898508 \\
\hline-9.676841 & -11.686960 & -10.031620 & -7.533228 \\
\hline-4.989434 & $-4.717607 \mathrm{E}-61$ & 3.926978 & 7.387354 \\
\hline 9.644896 & 10.769160 & 10.768760 & 8. 273322 \\
\hline 4.633578 & $-1.439216 \mathrm{E}-61$ & -5.601156 & -9.012287 \\
\hline-16.776216 & -12.224396 & -10.446228 & -6.701881 \\
\hline-3.736960 & 3. $584348 E-61$ & 3.728638 & B. 523596 \\
\hline 9.718486 & 10.519958 & 10.242796 & 8.934341 \\
\hline 4.616467 & -1.320588 & -5.692984 & -7.956236 \\
\hline-16.165650 & -10.685470 & -9.435485 & -5.516788 \\
\hline-2.85 & $6.943556 E-61$ & 4.786859 & 6. 633597 \\
\hline & 11.60455 & 11.187650 & B. 22620: \\
\hline 3.350413 & & -6.739957 & -16.1 \\
\hline-11.257616 & -11.122600 & -10.297980 & -6.651651 \\
\hline-3.514621 & 4.297485E-61 & 5.667361 & 5.964615 \\
\hline 8.457462 & 9.624863 & 11.161860 & 6.638049 \\
\hline 4912 & -1.612834 & -5.768829 & -9.796898 \\
\hline
\end{tabular}

\section{351156}




\begin{tabular}{|c|c|c|c|}
\hline 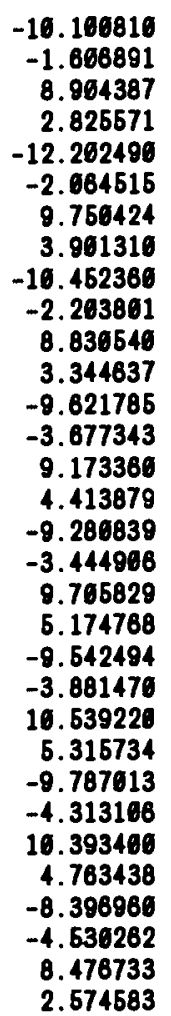 & 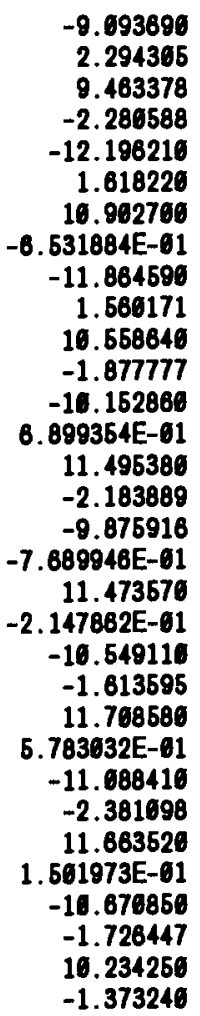 & $\begin{array}{r}-8.741783 \\
5.678671 \\
16.661180 \\
-6.479978 \\
-9.343701 \\
5.235168 \\
16.417210 \\
-5.827865 \\
-8.789109 \\
4.613216 \\
9.398615 \\
-6.238870 \\
-9.438582 \\
3.659177 \\
8.937296 \\
-5.461928 \\
-8.479562 \\
2.624605 \\
10.289769 \\
-5.187320 \\
-9.114218 \\
1.695346 \\
10.685260 \\
-3.111971 \\
-16.416716 \\
2.158125 \\
10.661026 \\
-3.628371 \\
-16.11583 \theta \\
1.466776 \\
9.611945 \\
-3.834062\end{array}$ & 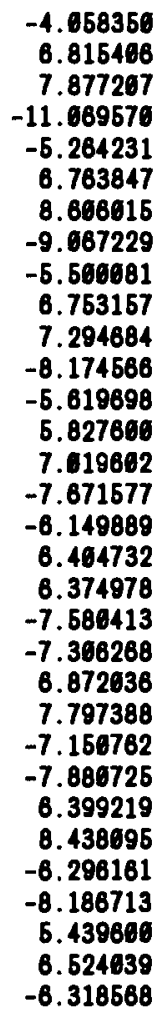 \\
\hline
\end{tabular}


APPENDIX G

SUPPLEMENTARY BIBLIOGRAPHY 

APPENDIX G

SUPPLEMENTARY BIBLIOGRAPHY

Anderson, M. B. 1982. "The Interaction of Turbulence with a Horizontal Axis Wind Turbine." In Proceedings of the 4th BWEA Wind Energy Conference, Cranfield, United Kingdom, pp. 104-118.

Anderson, M. B. 1985. "Turbulence--A Frequency Domain Analysis for Vertical Axis Wind Turbines." In Proceedings of the 7th British Wind Energy Association Conference, Oxford University, March 27-29, 1985.

Anderson, M. B., A. D. Garrad, and U. Hassan. 1984. "Teeter Excursions of a Two-Bladed Horizontal-Axis Wind Turbine Rotor in a Turbulent Velocity Field." Journal of Wind Engineering and Industrial Aerodynamics 17:71-88.

Anderson, M. B., S. J. R. Powles, and E. A. Bossanyi. 1985. "The Response of a Vertical-Axis Wind Turbine to Fluctuating Aerodynamic Loads." In Proceedings of the 7th British Wind Energy Association Conference, Oxford University, March 27-29, 1985.

Connell, J. R. 1981. The Spectrum of Wind Speed Fluctuations Encountered by a Rotating Blade of a Wind Energy Conversion System: Observations and Theory. PNL-4093, Pacific Northwest Laboratory, Richland, Washington.

Connel1, J. R. 1981. "The Effect of Space-Time Variation of Turbulent Wind and Cyclical Sampling Around a Circle on the Observed Spectrum of Turbulence." In Proceedings of the 3rd AMS Conference on Turbulence and Diffusion, American Meteorological Society, Boston, Massachusetts.

Connel1, J. R. 1985. "Research on Turbulent Wind in the U.S. Wind Energy Technology Program." Paper presented at the 14th IEA Experts Meeting on Turbulent Wind, Stockholm, Sweden, December 4, 1985.

Conne11, J. R. 1985. "A Primer of Turbulence at the Wind Turbine Rotor." In Proceedings of the AWEA/DOE Wind Energy Workshop (Windpower 185), pp. 57-66. American Wind Energy Association, Alexandria Virginia; also SERI/CP-217-2902, Solar Energy Research Institute, Golden, Colorado.

Connel1, J. R., and R. L. George. 1983. "A New Look at Turbulence Experienced by a Rotating Wind Turbine." In Proceedings of the Second ASME Wind Energy Symposium, pp. 455-480. American Society of Mechanical Engineers, New York, New York.

Connell, J. R., and R. L. George. 1983. "Scaling Wind Characteristics for Designing Small and Large Wind Turbines." In Proceedings of the American Solar Energy Society Annual Meeting (Wind Workshop VI), pp. 513-524. American Solar Energy Society, Newark, Delaware. 
Connel1, J. R., and R. L. George. 1987. Using a New Characterization of Turbulent Wind for Accurate Correlation of Wind Turbine Response with Wind Speed. PNL-6283, Pacific Northwest Laboratory, Richland, Washington.

Connel1, J. R., and R. L. George. 1987. "Accurate Correlation of Wind Turbine Response with Wind Speed Using a New Characterization of Turbulent Wind." Journal of Solar Energy Engineering 109:321-329.

Conne11, J. R., and R. L. George. 1988. "Accurate Correlation of Wind Turbine Response with Wind Speed." Solar Energy 109:321-329.

Connell, J. R., R. L. George, V. R. Morris and V. A. Sandborn. 1985. Rotationally Sampled Wind and MOD-2 Wind Turbine Response. EPRI AP-4335, ETectric Power Research Institute, Palo Alto, California.

Connell, J. R., V. R. Morris and M. E. Hinchee. 1987. "Input Turbulence Features at a Megawatt-Size Wind Turbine-Medicine Bow, Wyoming." In Proceedings of the Sixth ASME Wind Energy Symposium, pp. 201-213, American Society of Mechanical Engineers, New York, New York.

Connel1, J. R., and D. C. Powel1. 1989. "Comparison of Measured and Modeled Turbulence Spectra for a Point Rotating as on a Horizontal-Axis Wind Turbine." Journal of Solar Energy Engineering. In press.

Dragt, J. B. 1985. "Load Fluctuations and Response of Rotor Systems in Turbulent Wind Fields." Netherlands Energy Research Foundation Report ECN-72, The Netherlands.

Ficht1, G. 1983. Covariance Statistics of Turbulence Velocity Components for Wind Energy Conversion System Design - Homogeneous, Isotropic Case.

PNL-3499, Pacific Northwest Laboratory, Richland, Washington.

Fordham, E. J., and M. B. Anderson. 1982. "An Analysis of Results from an Atmospheric Experiment to Examine the Structure of the Turbulent Wind Seen by a Rotating Observer." In Proceedings of the 4th BWEA Workshop, Cranfield, United Kingdom.

George, R. L. 1984. Simulation of Winds As Seen by a Rotating Vertical Axis Wind Turbine Blade. PNL-4914, Pacific Northwest Laboratory, Richland, Washington.

George, R. L., and J. R. Connell. 1984. Rotationally Sampled Wind Characteristics and Correlations with MOD-OA Wind Turbine Response. PNL-5238, Pacific Northwest Laboratory, Richland, Washington.

Hardesty, R. M., and B. F. Weber. 1984. "Lidar Measurement of Turbulence Encountered by Horizontal Axis Wind Turbines." Journal of Atmospheric and Oceanic Technology 4(1):191-203.

Hardesty, R. M., R. J. Keeler, M. J. Post, and R. A. Richter. 1981b. "Characteristics of Coherent Lidar Returns from Calibration Targets and Aerosols." J. of Applied Optics 20:3763-3769. 
Hardesty, R. M., J. A. Korre11, and F. F. Hall. 1981. Lidar Measurement of Wind Velocity Turbulence Encountered by a Rotating Wind Turbine. DOE/RL/10236-81-1, U.S. Department of Energy, Available at NTIS, Springfield, Virginia.

Hardesty, R. M., J. A. Korrell, and F. F. Hall. 1982. Lidar Measurement of Wind Velocity Turbulence Spectra Encountered by a Rotating Turbine Blade. DOE/ET/10236-81/1, National Oceanic and Atmospheric Administration, Wave Propagation Laboratory, Boulder, Colorado.

Homicz, G. F. 1988. VAWT Stochastic Loads Produced by Atmospheric Turbulence. SAND87-1256C, Sandia National Laboratories, Albuquerque, New Mexico.

Kristensen, L., and S. Frandsen. 1982. "Model for Power Spectra of the Blade of a Wind Turbine Measured from the Moving Frame of Reference." Journal of Wind Engineering and Industrial Aerodynamics 10:249-262.

Powel1, D. C., and J. R. Connell. 1986. "A Model for Simulation of Turbulence at a Point Rotating as on a HAWT or VAWT Blade." In Proceedings of the Fifth ASME Wind Energy Symposium. American Society of Mechanical Engineers, New York, New York.

Powell, D. C., and J. R. Connell. 1986. Review of Wind Simulation Methods for Horizontal-Axis Wind Turbine Analysis. PNL-5903, Pacific Northwest Laboratory, Richland, Washington.

Powe11, D. C., and J. R. Connel1. 1987. "Verification of Theoretically Computed Spectra for a Point Rotating in a Vertical Plane." Solar Energy $39(1): 53-63$.

Powell, D. C., J. R. Connell, and R. L. George. 1985. Verification of Theoretically Computed Spectra for a Point Rotating in a Vertical Plane. PNL-5440, Pacific Northwest Laboratory, Richland, Washington.

Sandborn, V. A., and J. R. Conne11. 1984. Measurement of Turbulent Wind Velocities Using a Rotating Boom Apparatus. PNL-4888, Pacific Northwest Laboratory, Richland, Washington.

Vermeulen, P. E. J. 1981. "Definition of the Turbulence Concept in Relation to Wind Turbine Design." Netherlands Organization for Applied Scientific Research Report 81-09061/nvu, The Netherlands. 



\section{DISTRIBUTION}

No. of

Copies

OFFSITE

10 DOE/Office of Scientific and Technical Information

J. Cadogan

U.S. Department of Energy Wind/Ocean Technologies Division 1000 Independence Avenue Forrestal Building, Room 5F064 Washington, DC 20585

C. I. Aspliden 1925 N. Harvard Street Arlington, VA 22201

5 J. R. Connell

Colorado State University Engineering Research Center Foothills Campus

Fort Collins, CO 80523

K. Cousineau

Zond Systems Incorporated 13000 Jameson Road

Tehachapi, CA 93561

H. Dodd

Sandia National Laboratories

Division 6225

Albuquerque, NM 87185

W. Holley

U.S. Windpower, Inc.

400 West Cummings Park

Suite 3050

Woburn, MA 01801

R. H. Kirchhoff

University of Massachusetts

Department of Mechanical Engineering

Amherst, MA 01003
No. of

Copies
A. H. Miller
10013 Tepopa Drive
Oakdale, CA 95361
D. C. Powell
2110 Hudson Avenue
Richland, WA 99352
L. Schienbein
Flowind Corporation
1183 Quarry Lane
Pleasanton, CA 94566

R. B. Schlueter

Michigan State University

Department of Electrical Engineering

East Lansing, MI 48824

J. P. Sullivan

Purdue University

Aeronautics \& Astronautics

Grissom Hall

W. Lafayette, IN 47907

R. M. Sundar

Embry-Riddle Aeronautical University

3200 N. Willow Creek Road

Prescott, AZ 86301

R. W. Thresher

Solar Energy Research Institute 1617 Cole Boulevard

Golden, CO 80401

V. A. Vachon

P.0. Box 149

Manchester, MA 01944

P. Veers

Sandia National Laboratories

Division 6225

Albuquerque, NM 87185 
No. of

Copies

S. N. Walker

Oregon State University

Department of Mechanical

Engineering

Corvallis, OR 97331

A. D. Wright

Solar Energy Research Institute 1617 Cole Boulevard

Golden, CO 80401

\section{ONSITE}

DOE Richland Operations office

D. R. Segna
No. of

Copies

28 Pacific Northwest Laboratory

J. C. Barnard

C. E. Elderkin

D. L. Elliott

J. W. Falco

G. L. Gower

J. M. Hales

P. C. Hays

V. R. Morris

E. L. Owczarski

R. L. Skaggs

J. A. Stottlemyre

L. L. Wende 11 (10)

R. E. Wildung

Publishing Coordination

Technical Report Files (5) 